\title{
THE IMPACT OF CORE \\ TEMPERATURE CORRECTIONS ON EXERCISE-INDUCED HYPOXEMIA
}

Nicholas Jon Shipp B.Sc. (Hons)

Department of Medicine, University of Adelaide 


\section{DECLARATION}

I declare that this thesis contains no material which has been accepted for the award of any other degree or diploma in any University or tertiary institution and, to the best of my knowledge and belief, contains no material previously published or written by another person except where due reference has been made in the text.

I give consent to this copy of my thesis, when deposited in the University library, being available for loan and photocopying

Nicholas Jon Shipp

Date 


\section{DEDICATION}

This thesis is dedicated to my family and friends and, especially, to my future wife Belinda. Your support throughout its making has been invaluable and I look forward to our life ahead. 


\section{ACKNOWLEDGEMENTS}

I take this opportunity to gratefully acknowledge my supervisors and the assistance they have given me in making this thesis possible. To Dr. Andrew Thornton, Dr. Christopher Gore and Dr. Mark Holmes in the early stages of formulating and starting this thesis and, specifically, to Professor Garry Scroop for all of the hours spent in the laboratory testing and in the editing process. I would also like to thank the entire staff of the Department of Thoracic Medicine, Royal Adelaide Hospital, and in particular the staff of the Lung Function Laboratory. Finally, thank you to all of the subjects who participated in the experiments and the pilot studies. 


\section{PUBLICATIONS AND PRESENTATIONS}

\section{Publications-}

Shipp, N.J., G.C. Scroop, S.C. Jackson, M.D. Holmes, A.T. Thornton, C.J. Gore. Rectal temperature correction overestimates the frequency of exerciseinduced hypoxemia. Medicine and Science in Sports and Exercise. 36(7): 11111116, 2004.

\section{Presentations-}

2003 American College of Sports Medicine Annual Meeting. The impact of core temperature corrections on exercise-induced hypoxemia. Shipp NJ, Scroop GC, Gore CJ, Holmes MD, and Thornton, AT. 


\section{TABLE OF CONTENTS}

DISCLOSURE AND CONSENT

DEDICATION

ACKNOWLEDGEMENTS iv

PUBLICATIONS AND PRESENTATIONS v

TABLE OF CONTENTS vi

LIST OF TABLES $\quad$ xii

LIST OF FIGURES Xiv

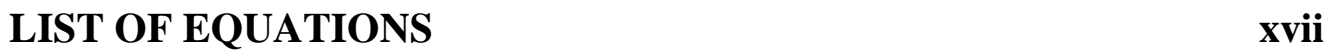

$\begin{array}{ll}\text { ABSTRACT } & \text { xviii }\end{array}$

$\begin{array}{llr}\text { CHAPTER } 1 & \text { Introduction } & 1\end{array}$

1.1 Exercise-Induced Hypoxaemia 1

1.2 Defining Exercise-Induced Hypoxemia 4

1.3 Possible Causes of Exercise-Induced Hypoxemia 7

1.3.1 Ventilation / Perfusion ( $\left.\dot{\mathrm{V}}_{\mathrm{A}} / \dot{\mathrm{Q}}\right)$ Inequality 7

1.3.2 Inadequate Hyperventilatory Response. 12

$\begin{array}{lll}\text { 1.3.3 Veno-arterial Shunt } 23 & 23\end{array}$

1.3.4 Diffusion Limitation 25

1.4 Prevalence of Exercise-Induced Hypoxemia 38

$\begin{array}{lll}\text { 1.4.1 Gender } & 46\end{array}$

$\begin{array}{lll}\text { 1.4.2 Age } & 49\end{array}$ 
1.4.3 Exercise Modality

1.5 Effect of Exercise-Induced Hypoxemia on Performance

1.6 Measurement of Oxygen Levels in Blood 56

1.6.1 Reproducibility of Blood Gases during Exercise 57

1.7 Body Temperature at Rest and During Exercise 59

1.7.1 Body Temperature Regulation at Rest 59

1.7.2 Body Temperature During Exercise 63

$1.8 \quad$ Temperature Correction of Arterial Blood Gases 71

1.9 Oxygen - Haemoglobin Dissociation, Temperature and Oxygen Content

1.9.1 The Oxygen-Haemoglobin Dissociation Curve and Temperature

$\begin{array}{lll}\text { 1.9.2 Oxygen Content } & 78\end{array}$

1.10 Summary and Aims of Thesis 80

$\begin{array}{llr}\text { CHAPTER } 2 & \text { General Methods }\end{array}$

$2.1 \quad$ Laboratory Environment 82

2.2 Subjects 83

2.2.1 General 83

2.2.2 Measurement of Resting Pulmonary Function 83

$\begin{array}{ll}\text { 2.2.2.1 Spirometry Measurement } & 84\end{array}$

2.2.2.2 Diffusing Capacity for Carbon Monoxide Measurement (DLCO) $\quad 84$

$\begin{array}{lll}2.3 & \text { Body Temperature } & 86\end{array}$ 
2.3.1 General 86

2.3.2 Rectal Temperature $\quad 86$

2.3.3 Oesophageal Temperature $\quad 89$

2.3.4 Arterial Blood Temperature 90

$\begin{array}{lll}\text { 2.3.5 } & \text { Muscle Temperature } & 92\end{array}$

2.3.6 Calibration of Temperature Probes and Thermistors 95

2.4 Arterial Catheterisation and Blood Sampling 97

$\begin{array}{lll}\text { 2.4.1 Arterial Catheterisation } & 97\end{array}$

$\begin{array}{ll}\text { 2.4.2 Blood Sampling } & 100\end{array}$

$\begin{array}{lll}2.4 .3 & \text { Blood Gas Analysis } & 101\end{array}$

2.4.4 Temperature Correction of Blood Gas Values 101

2.4.5 Measurement of Hematocrit 103

2.5 Oxygen Consumption and Carbon Dioxide Production 103

2.5.1 Measurement Procedures 103

2.5.2 Pre-test Calibration Procedures 104

2.5.3 Validation of Metabolic System 105

2.5.4 Technical Error of Measurement of $\dot{\mathrm{VO}}_{2} \max \quad 105$

2.6 Treadmill Protocol for Incremental Exercise 108

2.7 Heart Rate and ECG measurement 108

$\begin{array}{lll}2.8 & \text { Data analysis } & 109\end{array}$

CHAPTER 3 Thermal Status During Incremental Exercise

$\begin{array}{lll}3.1 & \text { Introduction } & 110\end{array}$ 
3.2.1 Subjects and Experimental Protocol

3.2.2 Temperature Probe Placement and Exercise Test Protocol

3.2.3 Data Analysis

3.3.1 General Anthropometric and Metabolic Data

3.3.2 Incremental Exercise Test

3.3.3 Body Temperature Responses During and Immediately Following Incremental Exercise Test

3.3.3.1 Temperature Responses during Incremental Exercise Test

3.3.3.3 Correlation and Prediction of Temperature Responses

3.3.3.4 Temperature Responses Following Cessation of the Incremental Exercise Test

\section{CHAPTER 4 Oxygen Status during Incremental Exercise}

4.2 Methods 
4.2.3 Blood Gas Temperature Correction and Arterial Content Equations

4.2.4 Data Analysis 146

4.3 Results

4.3.1 Uncorrected Oxygen Partial Pressures During Incremental Exercise

4.3.2 $\mathrm{PaO}_{2}$ Corrected for Rectal Temperature During Incremental Exercise

4.3.3 $\mathrm{PaO}_{2}$ Corrected for Arterial Blood Temperature During Incremental Exercise

4.3.4 $\mathrm{PaO}_{2}$ Corrected for Oesophageal Temperature During Incremental Exercise

4.3.5 $\mathrm{PaO}_{2}$ Corrected for Active Muscle Temperature During Incremental Exercise

4.3.6 $\quad \mathrm{PaO}_{2}$ values Relative to Workload Intensity

4.3.7 $\mathrm{PaO}_{2}$ Following Cessation of an Incremental Exercise Test

4.3.9 Arterial Oxygen Content during Exercise.

CHAPTER 5 Reproducibility of $\mathrm{PaO}_{2}$ changes during incremental exercise 
5.2.1 Subjects

5.2.2 Experimental Control

5.2.3 Temperature Probe Placement

5.2.4 Arterial Catheter Insertion

5.2.5 Temperature Measurement and Arterial Blood Sampling

5.2.6 Exercise Test Protocol

5.2.7 Data Analysis

5.3 Results

5.3.1 Metabolic Variables

5.3.2 Reproducibility of Resting and End-exercise Temperatures

5.3.3 Resting $\mathrm{PaO}_{2}$ values

5.3.4 Exercise $\mathrm{PaO}_{2}$ values

5.3.5 Prevalence of EIH in Repeat Tests

CHAPTER 6

6.1 Summary of the Problem

CHAPTER 7

Appendices

7.1 Subject Information, Consent Forms and Medical Questionnaire

7.2 Metabolic System Calibration Data 


\section{LIST OF TABLES}

Table1.1 Current status of research into exercise induced hypoxaemia in humans.

Table 2.1 Mean values $( \pm S D)$ for the physical characteristics and pulmonary function of all subject sets.

Table 2.2. Test-retest results for $\dot{\mathrm{VO}}_{2}$ max reproducibility.

Table 2.3 ANOVA result for $\dot{\mathrm{VO}}_{2}$ max reproducibility.

Table 3.1 Anthropometric, metabolic and respiratory function data of 23 trained subjects.

Table 3.2 Metabolic data at the cessation of an incremental treadmill test to exhaustion.

Table 3.3 Resting, end-exercise and temperature changes at each measurement site during the incremental exercise test.

Table 3.4 Pearson Product Moment Correlation analysis of temperatures at relative workloads (\% $\dot{\mathrm{VO}}_{2}$ peak).

Table 3.5 Temperature difference $\left({ }^{\circ} \mathrm{C}\right)$ between measured and calculated values from regression equations at relative $\% \dot{\mathrm{VO}}_{2}$ peak. 128

Table 4.1 Temperature correction site, definition and prevalence of EIH.

Table 4.2 $\quad \mathrm{CaO}_{2}$ resting and end-exercise values.

Table 5.1 Mean values $( \pm \mathrm{SD})$ for metabolic variables and time to exhaustion in Tests 1 and 2. 
Table 5.2 Reproducibility of resting and end-exercise temperatures $( \pm \mathrm{SD})$.

Table 5.3 Reproducibility of uncorrected $\left(37^{\circ} \mathrm{C}\right)$ resting $\mathrm{PaO}_{2}$ values $(n=10)$.

Table 5.4 Uncorrected $\left(37^{\circ} \mathrm{C}\right)$ individual and mean $( \pm \mathrm{SD})$ values for $\Delta \mathrm{PaO}_{2}$ and minimum $\mathrm{PaO}_{2}$ for Tests 1 and 2 . 176

Table 5.5 Reproducibility analysis of uncorrected $\left(37^{\circ} \mathrm{C}\right)$ values $( \pm \mathrm{SD})$ for $\Delta \mathrm{PaO}_{2}$ and minimum $\mathrm{PaO}_{2}$.

Table 5.6 Prevalence of EIH in Tests 1 and 2. 178 


\section{LIST OF FIGURES}

Figure 1.1 Distribution of ventilation and perfusion ratios in the upright lung.

Figure 1.2 The ventilatory response to changes in $\mathrm{PaCO}_{2}$.

Figure 1.3. $\mathrm{O}_{2}$ dissociation curve showing how the effective slope of the curve varies with mixed venous $\mathrm{PO}_{2}$ (points V1, V2) when alveolar $\mathrm{PO}_{2}$ (point A) remains constant

Figure 1.4 Control mechanisms for body temperature regulation.

Figure 1.5 The Oxygen-Haemoglobin Dissociation curve.

Figure 2.1 The Exercise laboratory.

Figure 2.3 ESO-1 temperature probe.

Figure $2.4 \quad$ IT-21 temperature probe.

Figure 2.5 The J-loop, Y-adaptor, extension tubing and three-way tap assembly with thermistor in situ.

Figure 2.7 Muscle temperature probe in situ.

Figure 2.8 An example of temperature thermistor calibration against a spiritfilled, NATA certified, thermometer. 
Figure 2.10 Arterial blood sampling configuration with blood temperature thermistor.

Figure 3.1 Individual temperature responses during incremental treadmill exercise.

Figure 3.2 Rectal temperature during incremental exercise test relative to percent of peak oxygen uptake $\left(\% \dot{\mathrm{VO}}{ }_{2}\right.$ peak).

Figure 3.3 Arterial temperature during incremental exercise test relative to percent of peak oxygen uptake (\% $\dot{\mathrm{VO}}_{2}$ peak).

Figure 3.4 Oesophageal temperature during incremental exercise test relative to percent of peak oxygen uptake (\% $\dot{\mathrm{V}} \mathrm{O}_{2}$ peak).

Figure 3.5 Muscle temperature during incremental exercise test relative to percent of peak oxygen uptake (\% $\dot{\mathrm{VO}}_{2}$ peak).

Figure 3.6 Linear regression results for temperature responses during incremental exercise.

Figure 3.7 Temperature responses at each measurement site in the $10 \mathrm{~min}$ following cessation of the incremental exercise test (Time $=0$ ).

Figure 4.1 Individual uncorrected $\mathrm{PO}_{2}$ values $(\mathrm{n}=23)$ for arterial blood during the incremental exercise test. 
Figure 4.2 Individual $\mathrm{PO}_{2}$ values $(\mathrm{n}=20)$ for arterial blood corrected for rectal temperature during the incremental exercise test.

Figure 4.3 Individual $\mathrm{PO}_{2}$ values $(\mathrm{n}=20)$ for arterial blood corrected for arterial blood temperature during the incremental exercise test.

Figure 4.4 Individual $\mathrm{PO}_{2}$ values $(\mathrm{n}=23)$ for arterial blood corrected for oesophageal temperature during the incremental exercise test.

Figure 4.5 Individual $\mathrm{PO}_{2}$ values $(\mathrm{n}=10)$ for arterial blood corrected for active muscle temperature during the incremental exercise test.

Figure 4.6 Mean $\mathrm{PaO}_{2}$ (for all subjects) relative to peak aerobic power ( $\mathrm{V}_{2}$ peak)

Figure 4.7 Mean $\mathrm{PaO}_{2}( \pm \mathrm{SEM})$ following cessation of the incremental exercise test.

Figure 6.1 $\mathrm{PaO}_{2}$ from Rest $\left(\mathrm{T}_{0}\right)$ to the end of the 10 min post exercise period.

Figure 6.2 Relationship between $\dot{\mathrm{VO}}_{2}$ max and minimum $\mathrm{PaO}_{2}$ 193

Figure 6.3 Relationship between $\dot{\mathrm{VO}}{ }_{2}$ max and maximum $\Delta \mathrm{PaO}_{2}$. 


\section{LIST OF EQUATIONS}

Equation 1.1 The Fick Diffusion Equation.

Equation 1.2 Correction of blood gas values $(\mathrm{PaO} 2)$ to measured core temperature values.

Equation 1.3 Correction of blood gas values (PaCO2) to measured core temperature values.

Equation 1.4 Correction of blood gas values $(\mathrm{pH})$ to measured core temperature values.

Equation 1.5 Arterial Oxygen content equation.

Equation 2.1 Calculation for normal $\mathrm{FEV}_{1}$ values.

Equation 2.2 Calculation for normal FVC values.

Equation 2.3 Diffusing capacity for Carbon Monoxide equation.

Equation 2.4 Calculation for normal diffusing capacity values.

Equation 2.5 Correction of $\mathrm{PaO}_{2}$ for temperature.

Equation 2.6 Temperature correction of $\mathrm{SaO}_{2}$. 


\section{ABSTRACT}

The primary purpose of this doctoral dissertation was to investigate the effect of body temperature responses at physiologically relevant sites during an incremental exercise test on the phenomenon of exercise-induced hypoxemia (EIH). This phenomenon has been considered as an important limitation to physical performance with a prevalence of $\sim 50 \%$ in trained male athletes, but described in both sexes, across the range of both age and physical fitness in more recent literature. Previously this phenomenon has been described as a decrement in both arterial oxygen partial pressure $\left(\mathrm{PaO}_{2}\right)$ and oxy-haemoglobin saturation $\left(\mathrm{SaO}_{2}\right.$ or $\left.\mathrm{SpO}_{2}\right)$ with, particularly important for $\mathrm{PaO}_{2}$, a lack of or inappropriate correction made for the change in body temperature during intense exercise.

The initial study of this thesis determined the thermal response within the body at physiologically relevant sites measured simultaneously during an incremental exercise test. The results demonstrated the inadequacy of rectal temperature as an indicator of the acute temperature changes occurring during an incremental exercise test due to its slow response rate and relative thermal inertia. Radial arterial blood and oesophageal temperatures were shown to behave almost identically during the exercise test, albeit with an offset of approximately $1.3^{\circ} \mathrm{C}$, and were considered much more appropriate and relevant indicators of thermal changes during exercise. As an extension of the initial work active muscle temperature (vastus lateralis) was measured during the 
exercise test, demonstrating a significantly lower resting temperature than the oft-reported "core" temperatures (rectal and oesophageal) as well as a significantly greater increase in temperature in comparison to all other measurement sites. Overall, the results of this first study indicated that the physiologically relevant temperatures measured at the oesophageal and muscle sites differed markedly to the outdated rectal temperature measurement site and should be used as measures of thermal response when evaluating oxygen loading (oesophageal) or unloading (active muscle).

Utilising the definition of EIH as a decrease in $\mathrm{PaO}_{2}$ of $\geq 10 \mathrm{mmHg}$, the effect of temperature correcting $\mathrm{PaO}_{2}$ was evaluated in the second study. Arterial blood gases measured simultaneously to the temperature measurements during the incremental exercise test were adjusted for the temperature changes at each site (every $1^{\circ} \mathrm{C}$ increase in temperature will increase a $\mathrm{PaO}_{2}$ value by $\sim 5 \mathrm{mmHg}$ ). Whilst uncorrected $\mathrm{PaO}_{2}$ values indicated an almost $100 \%$ prevalence of EIH in this group, oesophageal temperature corrected $\mathrm{PaO}_{2}$ values decreased this prevalence to $\sim 50 \%$ while muscle temperature corrections resolved all cases of EIH and demonstrated an HYPEROXAEMIA (i.e. the reverse of the wellestablished phenomenon) in the majority of subjects. Further investigation of arterial oxygen content during the exercise test indicates that there is no disruption in the delivery of oxygen to the active muscles and therefore any performance decrement should be attributed to another mechanism.

Whilst the phenomenon of EIH is determined by the definition applied and the use of temperature corrections in the case of $\mathrm{PaO}_{2}$, its reproducibility in a test-retest situation had not previously been determined. Utilising a subset of 
previously tested subjects, the reproducibility of both temperature and $\mathrm{PaO}_{2}$ were determined with results indicating that the blood gas response was highly reproducible, especially the minimum $\mathrm{PaO}_{2}$ value noted during each exercise test. However, comparing a more statistically relevant definition of a change in $\mathrm{PaO}_{2}$ of \pm 2 standard deviations from the mean resting $\mathrm{PaO}_{2}$ to the previous delimiter of $10 \mathrm{mmHg}$ indicated a lesser reproducibility of the prevalence of EIH.

In summary, this thesis exposes the inadequacies of previous research into EIH with regard to the expected reproducibility of the phenomenon and the need to correctly adjust $\mathrm{PaO}_{2}$ values for exercise-induce hyperthermia as well as demonstrating the difference in thermal responses to acute exercise in physiologically significant areas of the body. Furthermore, previously described correlations between the change in $\mathrm{PaO}_{2}$ and $\dot{\mathrm{VO}}_{2}$ max were not evident in the subjects tested within this thesis, nor was there any indication of a diffusion limitation based on reduced pulmonary capillary transit time (by association with $\dot{\mathrm{V}}{ }_{2}$ max) or pulmonary oedema (rebuked by a rapid return of $\mathrm{PaO}_{2}$ to above resting levels following exercise cessation). 


\section{CHAPTER 1}

\section{Introduction}

\subsection{EXERCISE-INDUCED HYPOXEMIA}

An arterial oxy-haemoglobin saturation $\left(\mathrm{SaO}_{2}\right)$ of $98-99 \%$ and arterial oxygen partial pressure $\left(\mathrm{PaO}_{2}\right)$ of $\sim 95 \mathrm{mmHg}$ are considered usual values in healthy, young individuals at rest. It is also expected, assuming a normal response of the respiratory and cardiovascular control systems, that neither changes significantly, even during heavy exercise (Wasserman, Hansen et al, 1994).

Until a study by Lillienthal and colleagues (1946), it was general medical opinion that only in disease states would $\mathrm{PaO}_{2}$ or $\mathrm{SaO}_{2}$ vary markedly from resting levels. These authors observed a significant decrease in $\mathrm{PaO}_{2}$ during a bout of severe exercise, and a range of reduced end-exercise $\mathrm{PaO}_{2}$ values in individuals undertaking a moderate exercise protocol. In this study 6 male subjects completed multiple experimental exercise bouts with the average $\mathrm{PaO}_{2}$ dropping from $94.2 \mathrm{mmHg}$ at rest to $88.9 \mathrm{mmHg}$ at the point of end-exercise. The alveolar-arterial gradient or the alveolar-arterial difference [(A-a) $\left.\mathrm{DO}_{2}\right]$ increased correspondingly from $8.9 \mathrm{mmHg}$ at rest to $16.6 \mathrm{mmHg}$ after exercise. Whilst not included in the averaged results, one subject (R.L.R.) completed a higher intensity exercise protocol when compared with other subjects and this 
resulted in a widening of the (A-a) $\mathrm{DO}_{2}$ of up to $38 \mathrm{mmHg}$. This was due to a significantly lower end-exercise $\mathrm{PaO}_{2}$ ( 73 compared with $\left.\sim 93, \mathrm{mmHg}\right)$ as alveolar $\mathrm{PO}_{2}\left(\mathrm{PAO}_{2}\right)$ did not differ from the average reported for all other tests. Following this research Holmgren and Linderholm (1958) undertook a study of 14 junior endurance athletes (mean age $=17.8 \mathrm{yr}$ ), looking specifically at the changes in $\mathrm{PaO}_{2}$ under exercise conditions. The average $\mathrm{PaO}_{2}$ in these subjects at the end of maximal exercise was $78.8 \mathrm{mmHg}$, a significant decrease in $\mathrm{PaO}_{2}$ from the resting average of $100.9 \mathrm{mmHg}$. One subject's $\mathrm{PaO}_{2}$ decreased to 57 mmHg, a $25 \mathrm{mmHg}$ drop from their pre-exercise value, with the exhaustive workload eliciting a $40 \mathrm{mmHg}$ drop $(120 \mathrm{mmHg}$ to $80 \mathrm{mmHg}$ ) in a further subject. The elevated pre-exercise $\mathrm{PaO}_{2}$ of this subject was attributed to the short time between arterial catheterisation and arterial blood sampling and the relative hyperventilation this would have caused, a factor which would exaggerate the drop in end-exercise arterial oxygen partial pressure.

With this previous research in mind, Rowell and colleagues (1964) performed maximal exercise tests on a small group of sedentary males both prior to and following an intensive training programme. Arterial blood was taken in the last 15 seconds of a 3 minute run set at a speed to achieve the subject's maximal rate of oxygen consumption ( $\dot{\mathrm{VO}}_{2}$ max). A small decrease $(2.4 \%)$ in average $\mathrm{SaO}_{2}$ was noted from rest to end-exercise in the subjects before the training regime, which became $4 \%$ following training. The same maximal test was performed by 4 well-trained athletes and while their resting $\mathrm{SaO}_{2}$ was slightly higher than the sedentary subjects (97.5\% compared with 95.8\%), at the end of the exercise test the athletes' $\mathrm{SaO}_{2}$ had decreased significantly by $12.3 \%$. 
The authors concluded there may exist three mechanisms by which the athletes were unable to maintain resting $\mathrm{SaO}_{2}$ levels: that the flow of red blood cells through the pulmonary capillaries is too rapid to allow adequate time for complete oxygen uptake, that pulmonary shunts exist or there is a change in the shape of the oxygen-dissociation curve that is greater than previously reported.

In 1984, Dempsey and associates performed a relatively thorough investigation into the effect of short-term, exhaustive exercise on $\mathrm{PaO}_{2}$. Sixteen (16) highly trained runners undertook a progressive exercise test with brachial artery blood samples taken throughout and blood gas values corrected for simultaneous measurements of rectal temperature. All but 4 subjects showed marked decreases in $\mathrm{PaO}_{2}$, with 2 subjects recording an end-exercise value of $<$ $60 \mathrm{mmHg}$. This research led to the conception of the term Exercise-Induced Arterial Hypoxaemia, or EIAH. With regard to explaining the decrease in $\mathrm{PaO}_{2}$ in these subjects, the authors dismissed the effect of both ventilation / perfusion ( $\dot{\mathrm{V}}_{\mathrm{A}} / \dot{\mathrm{Q}}$ ) inequality and veno-arterial shunt, suggesting overly short red blood cell transit times through the pulmonary circulation and a diffusion limitation as probable causes. An absent or minimal level of compensatory hyperventilation (a ventilatory rate capable of maintaining $\mathrm{P}_{\mathrm{A}} \mathrm{O}_{2}$ and $\mathrm{PaO}_{2}$ ) was also suggested as being a contributory factor in these athletes.

It is these initial few investigations that spawned a concerted effort over the past 20 years to define the causes and effects of exercise-induced hypoxaemia $(\mathrm{EIH})$ in athletes. Furthermore, the finding that a significant proportion of well-trained athletes undergo considerable oxyhaemoglobin 
desaturation and/or arterial hypoxaemia during exercise (Brown, Knowlton et al, 1993; Powers, Dodd et al 1988), which in turn has been suggested to influence performance (Powers, Lawler et al, 1989; Martin and O’Kroy, 1993), has created great interest in defining the mechanism/s by which EIH occurs.

However, a review of the literature identified serious concerns about the manner in which oxygen status during exercise was characterised by a majority of authors. In particular, the exclusive focus seemed to be on changes in either $\mathrm{PaO}_{2}$ or haemoglobin oxygen saturation rather than the critical dependent, namely oxygen content, which not only has a sigmoid relationship with these 2 variables but also dictates any consequences of the phenomenon to oxygen uptake and therefore performance. Furthermore, more than half of the published studies either failed to correct oxygen status for exercise-induced hyperthermia or, without any apparent logic, used changes in rectal temperature for their corrections. These seemed to be inexplicable oversights and, given the potential significance of the phenomenon to some $50 \%$ of endurance athletes, a more complete investigation of these aspects of oxygen status during exercise was needed and this formed the major focus of this thesis.

\subsection{DEFINING EXERCISE-INDUCED HYPOXEMIA}

Normative values for $\mathrm{PaO}_{2}$ are regularly used in assessing an individual's health status and a range of "normal” values exist for any age group. For example, Landgraf and Ehrly (1980) compared a group of 18-30 year old males and females with a group of 50-60 year olds and reported a significant decrease 
in resting $\mathrm{PaO}_{2}$ (93.7mmHg compared with $76.9 \mathrm{mmHg}$, respectively) with increasing age. Such is the consistency of the reduction of $\mathrm{PaO}_{2}$ with age that it has been possible to produce equations which calculate the expected value of an individual at any age (Andrews, Copeland et al, 1981; Crapo, Jensen et al, 1999). With regard to clinical exercise testing, a reduction from resting values in $\mathrm{SaO}_{2}$ of $\geq 4 \%$, a $\mathrm{SaO}_{2} \leq 88 \%$ or a $\mathrm{PaO}_{2} \leq 55 \mathrm{mmHg}$ are considered to be of significance (American Association for Respiratory Care, 2005; American Thoracic Society, 2003), and indicate an inadequacy of or the presence of disease within the cardiac, respiratory or vascular systems. Of importance is that these reference values differentiate between oxyhaemoglobin saturation obtained by arterial blood sampling and that obtained using pulse oximetry, the publications recommending the latter should only be used to show trending phenomenon rather than to determine absolute change.

In a review of the history, aetiology and effect of EIH, Dempsey and Wagner (1999) attempted to divide the degree of desaturation during exercise into three levels of EIH. Mild EIH was defined as a reduction in absolute $\mathrm{SaO}_{2}$ levels from resting values to between 95\% and 93\%, moderate EIH between 93\% and $91 \%$, with any subject recording a $\mathrm{SaO}_{2}$ of less than $91 \%$ being classed as having severe hypoxaemia. When looking to define EIH with regard to changes in $\mathrm{PaO}_{2}$, Dempsey and Wagner (1999) indicated that for a reduction of $3 \%$ in $\mathrm{SaO}_{2}$ (to elicit a "mild” EIH episode) $\mathrm{PaO}_{2}$ would be required to drop by $10 \mathrm{mmHg}$, which would indicate a "failure of lung function to maintain arterial oxygenation”. 
Prefaut, Durand et al (2000) suggested a minimum, persistent decrease of $10 \mathrm{mmHg}$ in $\mathrm{PaO}_{2}$ was sufficient to define arterial hypoxaemia during exercise. This figure was arrived at by combining a $5 \mathrm{mmHg}$ variability in the measurement of $\mathrm{PaO}_{2}$ with a $3 \mathrm{mmHg}$ exercise hyperthermia correction factor. An additional $2 \mathrm{mmHg}$ was included to provide a "rigorous definition". The temperature correction factor of $3 \mathrm{mmHg}$ was based on 3 separate studies (Caillaud, Anselme et al, 1996; Whipp and Wasserman, 1970; ChwalbinskaMoneta and Hänninen, 1989) which noted only a slight change (less than $0.6^{\circ} \mathrm{C}$ ) in body temperature during 12-minute incremental exercise tests. This defining $10 \mathrm{mmHg}$ drop in $\mathrm{PaO}_{2}$ also corresponds to the level of desaturation (96\% and below) which has been reported to have a reducing effect on exercise performance (O’Kroy and Martin, 1989; Powers, Lawler et al, 1989) and is therefore considered as being significant with various authors.

With regard to this thesis, a reduction in $\mathrm{PaO}_{2}$ of $10 \mathrm{mmHg}$ or more from rest to end exercise (as defined by means of an arterial blood gas measurement) was considered as the point differentiating between athletes who exhibit EIH and those considered "normal", such that their $\mathrm{PaO}_{2}$ levels were maintained during exercise. No performance impairment or disease was suggested due to this reduction in $\mathrm{PaO}_{2}$ and the cut-off point was defined only to be consistent with previous published work in producing separate groups for comparison. 


\subsection{POSSIBLE CAUSES OF EXERCISE-INDUCED HYPOXEMIA}

Whilst the existence of the phenomenon of EIH has been unquestioned over the last few decades, the mechanisms by which it occurs have been more controversial and the focus of a great deal of research. There have been several recent reviews of EIH; its history, mechanisms and its effects (Powers, Martin et al, 1993; Dempsey and Wagner, 1999; Prefaut, Durand et al, 2000; Nielsen, 2003); however, one of the earliest reviews by Powers and Williams (1987) outlined the main mechanisms which have been the focus of most research for the last few decades. These mechanisms were identified as; 1) a ventilation / perfusion ( $\left.\dot{\mathrm{V}}_{\mathrm{A}} / \dot{\mathrm{Q}}\right)$ inequality, 2) an inadequate hyperventilatory response to exercise, 3) a diffusion limitation and 4) veno-arterial shunt. Furthermore, recent research (Connes, Bouix et al, 2004; Galy, Hue et al, 2005) has shown changes in blood viscosity during moderate intensity exercise may play a role in reducing the re-oxygenation of blood as it passes through the lungs; however, this may be included as a possible limitation to diffusion rather than a separate cause.

\subsubsection{Ventilation / Perfusion $\left(\dot{V}_{\mathrm{A}} / \dot{\mathrm{Q}}\right)$ Inequality}

The uptake of $\mathrm{O}_{2}$ and the release of $\mathrm{CO}_{2}$ in the lung are related to the ratio of alveolar ventilation $\left(\dot{\mathrm{V}}_{\mathrm{A}}\right)$ and the rate of blood flow through the pulmonary alveolar capillaries ( $\dot{\mathrm{Q}})$, commonly known as the ventilation-perfusion $\left(\dot{\mathrm{V}}_{\mathrm{A}} / \dot{\mathrm{Q}}\right.$ ) ratio. In the standing position at rest both perfusion and ventilation in the apex 
of the lung are less than that observed at the base of the lung; however, the reduction in ventilation is considerably less than that of perfusion which results in a $\mathrm{V}_{\mathrm{A}} / \mathrm{Q}$ ratio as much as thrice the ideal value for efficient gas exchange. This, in essence, leads to the creation of a physiological dead space. Conversely, at the base of the lung there is significantly more capillary blood flow as compared with ventilation. This leads to a reduced $\mathrm{V}_{\mathrm{A}} / \mathrm{Q}$ ratio (to as low as $60 \%$ of the ideal ratio), and is responsible for a decreased re-oxygenation of the transient blood, creating a type of physiological shunt. Figure 1.1 is a graphic representation of this distribution of $\mathrm{V}_{\mathrm{A}} / \mathrm{Q}$.

NOTE: This figure is included on page 8 of the print copy of the thesis held in the University of Adelaide Library.

Figure 1.1 Distribution of ventilation and perfusion ratios in the upright lung. (McArdle et al, 2006) 
At rest, the effect of these extremities in the $\dot{\mathrm{V}}_{\mathrm{A}} / \dot{\mathrm{Q}}$ ratio almost cancel each other out with respect to the oxygenation levels of systemic arterial blood; however a residual effect of combining these two phenomenon is such that arterial $\mathrm{PO}_{2}$ is always lower than alveolar $\mathrm{PO}_{2}$ ( $\sim 95 \mathrm{mmHg}$ compared to 104 mmHg at rest). This difference in the alveolar and arterial $\mathrm{PO}_{2}$ is called the alveolar-arterial gradient or the alveolar-arterial difference [(A-a) $\left.\mathrm{DO}_{2}\right]$.

The development of the ability to measure continuous distributions using the multiple inert gas elimination technique (MIGET) allowed changes in the $\dot{\mathrm{V}}_{\mathrm{A}} / \dot{\mathrm{Q}}$ ratio to be determined in humans during exercise (Wagner, Naumann et al, 1974; Wagner, Saltzman et al, 1974). In 1977, Gledhill et al investigated the distribution of $\dot{\mathrm{V}}_{\mathrm{A}}$ and $\dot{\mathrm{Q}}$ both at rest and during graded cycle ergometry. Their data showed an increasing non-uniformity of $\dot{\mathrm{V}}_{\mathrm{A}} / \dot{\mathrm{Q}}$ ratios (due to an increased intraregional inhomogeneity of ventilation distribution) during increasing exercise severity coupled with a progressively increasing mean $\dot{\mathrm{V}}_{\mathrm{A}} / \dot{\mathrm{Q}}$ ratio. The researchers concluded that this increasing non-uniformity was responsible for over $50 \%$ of the $(\mathrm{A}-\mathrm{a}) \mathrm{DO}_{2}$ at the modest levels of exercise $\left(\dot{\mathrm{VO}}_{2} \leq 2.2 \mathrm{~L} \cdot \mathrm{min}^{-}\right.$ ${ }^{1}$ ) completed by their subjects This finding was supported by Gale, Torre-Bueno et al (1985) and Wagner, Gale et al (1986). It was suggested by the former authors that, whilst there may be an improvement of topographical $\dot{\mathrm{V}}_{\mathrm{A}} / \dot{\mathrm{Q}}$ relationships, the MIGET technique revealed a worsening of intraregional $\dot{\mathrm{V}}_{\mathrm{A}} / \dot{\mathrm{Q}}$ mismatch responsible for the increased $(\mathrm{A}-\mathrm{a}) \mathrm{DO}_{2}$. 
Whilst the research performed by Wagner, Gale et al (1986) also supported the effect of exercise on the $\dot{\mathrm{V}}_{\mathrm{A}} / \dot{\mathrm{Q}}$ ratio, the mismatch, and its effect on $\mathrm{PaO}_{2}$, was considered to be of little importance as a factor limiting gas exchange during intense exercise. These authors suggested that whilst the (Aa) $\mathrm{DO}_{2}$ rises sharply at higher levels of exercise $\left(\dot{\mathrm{VO}}_{2} \sim 55 \mathrm{ml} \cdot \mathrm{min}^{-1} \cdot \mathrm{kg}^{-1}\right)$, the component attributable to the $\dot{\mathrm{V}}_{\mathrm{A}} / \dot{\mathrm{Q}}$ mismatch remains constant at approximately one-third, the other two-thirds attributable to a diffusion limitation, a finding consistent with research performed by Hammond, Gale et al (1986). In contrast, Hopkins, McKenzie et al (1994) attributed $>60 \%$ of the (Aa) $\mathrm{DO}_{2}$ to the $\dot{\mathrm{V}}_{\mathrm{A}} / \dot{\mathrm{Q}}$ mismatch. The authors suggested that whilst their highlytrained athletes did develop a diffusion limitation during maximal exercise, $\dot{\mathrm{V}}_{\mathrm{A}} / \dot{\mathrm{Q}}$ heterogeneity had the greatest effect on pulmonary gas exchange, a characteristic which may have reflected the uniqueness of the subject population.

Numerous authors (Gale, Torre-Bueno et al, 1985; Torre-Bueno, Wagner et al, 1985; Hammond, Gale et al, 1986 (a and b); Wagner, Gale et al, 1986; Manier, Moinard et al, 1991; Schaffartzik, Poole et al, 1992; Wagner, 1992; Podolsky, Eldridge et al, 1996; Hopkins, Gavin et al, 1998; Rice, Thornton et al, 1999; Rice, Scroop et al, 2000; Olfert, Balouch et al, 2004; Verges, Flore et al, 2005) have investigated and postulated as to the possible cause of $\dot{\mathrm{V}}_{\mathrm{A}} / \dot{\mathrm{Q}}$ inequality during exercise. Wagner (1992) put forward various possible causes, concluding that there exists "much intersubject variation and no clear-cut mechanism has been demonstrated to date”. Of these causes, being 1) minor structural differences in airways and/or blood vessels which, only on exercise, 
cause variations in normal airways or vascular resistance, 2) insufficient time for the mixing of inspired and alveolar gas, a so-called gas phase diffusive limitation, 3) a temporary accumulation of interstitial fluid due to increased hydrostatic vascular pressures, it was concluded the latter was the most "attractive"; however, at the time, no method was available to detect small increases in extravascular fluid content caused by exercise.

In their review of EIH in 1999, Dempsey and Wagner concluded, again, that whilst there are multiple possible causes of increased $\dot{\mathrm{V}}_{\mathrm{A}} / \dot{\mathrm{Q}}$ inequality and, hence, EIH in trained athletes, it was a transient interstitial edema that was the best supported, even if by largely indirect evidence (Rasmussen, Hanel et al, 1986; Caillaud, Anselme et al, 1993; Caillaud, Serre-Cousine et al, 1995; Prefaut, Anselme-Poujol and Caillaud, 1997; Anholm, Milne et al, 1999). At simulated altitude it has been shown (Gale, Torre-Bueno et al, 1985) that there is an increase in the $\dot{\mathrm{V}}_{\mathrm{A}} / \dot{\mathrm{Q}}$ inequality of unacclimatised athletes which returned to normal levels when the subjects began breathing 100\% oxygen. This resulted from a decrease in cardiac output $(19.2$ to $13.9 \mathrm{~L} / \mathrm{min})$ and an assumed reduction of hypoxic vasoconstriction which would reduce pulmonary artery pressure and hence the driving pressure for fluid flux into the alveoli. Schaffartzik and colleagues (1992) hypothesised that if a $\dot{\mathrm{V}}_{\mathrm{A}} / \dot{\mathrm{Q}}$ mismatch persisted after exercise, beyond a time which cardiac output and ventilation had returned to normal, this would be consistent with the presence of pulmonary oedema. Their subjects were divided into those with increasing $\dot{\mathrm{V}}_{\mathrm{A}} / \dot{\mathrm{Q}}$ inequality during exercise (G1) and those whose mismatch remained stable (G2). Exercise was 
performed at an inspiratory $\mathrm{PO}_{2}$ of $91 \mathrm{mmHg}$, given that exercise under hypoxic conditions is known to accentuate $\dot{\mathrm{V}}_{\mathrm{A}} / \dot{\mathrm{Q}}$ mismatch (Torre-Bueno, Wagner et al, 1986). From their results, the authors concluded that the difference between groups could not be attributed to small inequalities in airways resistance, nor inhomogenous pulmonary vasconstriction as proposed by Hultgren (1982). Pulmonary oedema was supported by the measurement of a lower $\mathrm{pH}$ in $\mathrm{G} 1$ accompanied by a higher cardiac index which, the authors proposed, suggested a higher pulmonary arterial pressure and thus transvascular fluid flux.

In summary, whilst $\dot{\mathrm{V}}_{\mathrm{A}} / \dot{\mathrm{Q}}$ inequality has been shown to have a significant effect on the size of the A-a $\mathrm{DO}_{2}$ in humans during exercise, the cause of this effect is highly variable between subjects and groups and its exact contribution to EIH during intense exercise uncertain.

\subsubsection{Inadequate Hyperventilatory Response.}

\subsubsection{Ventilation at Rest}

At rest, the rate of ventilation (the movement of air between the atmosphere and the alveoli) is monitored and controlled at multiple points to ensure sufficient uptake of oxygen and elimination of carbon dioxide as required by the body. The involuntary control of ventilation is co-ordinated by the brain's "respiratory centres", located in the medulla oblongata and the pons (pneumotaxic area), which regulate the rhythmic cycling of inspiration and expiration (Guyton, 1981). A cyclic pattern of graded action potentials is discharged from the medulla by the dorsal and ventral respiratory groups of 
neurons which act in inspiration and expiration, respectively, are mutually inhibitory and cross communicate to act in symmetry. The pneumotaxic area emits impulses to the inspiratory centre, and acts to control the tidal volume. When the pneumotaxic signals are strong inspiration is limited, with weak signals resulting in longer inspiration times and hence larger tidal volumes.

During quiet respiration the ventral respiratory area remains dormant, with expiration resulting from passive recoil of the inspiratory muscles and elastic structures of the lung and surrounding rib cage. During increased pulmonary ventilation, excitation signals from the inspiratory area spill over into the expiratory area and cause the expiratory muscles to contribute to forceful exhalation.

As well as the central respiratory centres, breathing is controlled by the central and peripheral chemoreceptors and mechanoreceptors. The central chemoreceptors are located on the ventrolateral side of the medullary surface and are sensitive to the concentration of hydrogen ions $\left[\mathrm{H}^{+}\right]$. The cerebral spinal fluid $\mathrm{pH}$ is closely related to the $\mathrm{pH}$ of blood plasma due to carbon dioxide diffusing easily across the blood / brain barrier. An increase in blood $\mathrm{PCO}_{2}$ causes an increase in the $\mathrm{pH}$ of the cerebral spinal fluid which, when detected by the central chemoreceptors, causes a rapid increase in respiration. This shortterm regulatory mechanism uses a negative feedback system whereby any change beyond the "set" level of $\mathrm{pH}$ causes a response via changes in respiration rate. 
The peripheral chemoreceptors are located in the arch of the aorta and in the bifurcation of the carotid artery and are known as the aortic and carotid bodies, respectively. The peripheral chemoreceptors act most importantly to detect variations in the $\mathrm{PaO}_{2}$ of the blood, as well as detecting $\left[\mathrm{H}^{+}\right]$and $\mathrm{PaCO}_{2}$ levels and changes in temperature and blood pressure. These receptors send a continuous signal to the respiratory centre with a decrease in the $\mathrm{PaO}_{2}$ causing an intensification of the signal creating, in response, an increase in minute ventilation. The peripheral chemoreceptors are not highly sensitive to small changes in $\mathrm{PaO}_{2}$. Increased signal emission usually occurs only when there has been a significant drop in $\mathrm{PaO}_{2}$ to below $60 \mathrm{mmHg}$ (Von Euler, 1938), a partial pressure that corresponds to the beginning of the steep component of the dissociation curve. At this point any further decrease in $\mathrm{PaO}_{2}$ causes a large decrease in oxygen saturation of haemoglobin whereas above this point oxyhaemoglobin $\left(\mathrm{HbO}_{2}\right)$ levels change very little with $\mathrm{PaO}_{2}$ and no respiratory response is necessary.

Whilst it may take significant changes in $\mathrm{PaO}_{2}$ to increase the activation of the peripheral chemoreceptors they are, however, highly sensitive to changes in $\mathrm{PaCO}_{2}$. An increase in $\mathrm{PaCO}_{2}$ of only $5 \mathrm{mmHg}$ can cause a ventilatory response such that minute ventilation is more than doubled (Figure 1.2), whilst a decrease in $\mathrm{PaCO}_{2}$ removes the stimulus to breathe, depressing ventilation and causing an accumulation of metabolic $\mathrm{CO}_{2}$ until $\mathrm{PaCO}_{2}$ returns to its normal set point. 
NOTE: This figure is included on page 15 of the print copy of the thesis held in the University of Adelaide Library.

Figure 1.2 The ventilatory response to changes in PaCO2. (McArdle et al, 2006)

As with the central chemoreceptor response to changes in $\mathrm{PaCO}_{2}$, the peripheral receptor response is mainly due to the effect of $\mathrm{CO}_{2}$ on $\left[\mathrm{H}^{+}\right]$. Of the two types of receptors, the central chemoreceptors play the more important role in maintaining homeostasis, with only $\sim 20 \%$ of the ventilatory response being due to stimulation by the peripheral chemoreceptors. The rapid response rate of the peripheral chemoreceptors, however, makes them extremely important in matching ventilation to abrupt changes in $\mathrm{PaCO}_{2}$ (Wasserman, Whipp et al, 1979).

\subsubsection{Ventilation during Exercise 22}

During exercise minute ventilation can increase up to 20 times its resting value whilst arterial $\mathrm{PO}_{2}$ and $\mathrm{PCO}_{2}$ are maintained in normal, healthy individuals 
at or near resting values. The increase in pulmonary ventilation and metabolic requirements are closely matched whilst there are no significant changes in the stimulatory factors of the arterial chemoreceptors (Grodins, 1950; Dejours, 1963; Wasserman, Van Kessel et al, 1967; Comroe, 1974). However, in some cases, during strenuous exercise, $\mathrm{PaCO}_{2}$ can fall as low as $25 \mathrm{mmHg}$; a level that would, with respect to decreased stimulation of chemoreceptors, lead to a reduction in the ventilatory drive (Mitchell, 1990).

A decrease in $\mathrm{pH}$ due to the production of lactic acid in the muscle is the most consistent change to occur in individuals during exercise. In particular, strenuous exercise and its resulting decrease in $\mathrm{pH}$ (increased $\left[\mathrm{H}^{+}\right]$) has been shown to be an influencing factor in increasing ventilation above the respiratory compensation point (Wasserman, Whipp et al, 1979; Meyer, Faude et al, 2004). It is thought that this hyperventilation acts as a compensatory mechanism to cope with the excess $\mathrm{CO}_{2}$ and $\left[\mathrm{H}^{+}\right]$which is unable to be buffered by the bicarbonate system (Beaver, Wasserman et al, 1986). Muscular exercise also causes an increase in the release of potassium ions $\left(\mathrm{K}^{+}\right)$(Newstead, Donaldson et al, 1990) with the rate of release shown to be directly related to the intensity of exercise (Paterson, 1992). Hyperkalemia has been shown to increase the excitation of arterial chemoreceptors, muscle chemoreflex and slow adapting pulmonary stretch receptors and the effects of $\mathrm{K}^{+}$are increased by lactic acid and an increased noradrenaline concentration (O’Neill, Dorrington et al, 1993; Paterson, Rogers et al, 1993). Changes in $\left[\mathrm{K}^{+}\right]$are not proportional to the ventilatory response during exercise which has lead to the theory that $\left[\mathrm{K}^{+}\right]$may only play a supporting role in the control of exercise hyperpnoea, predominantly 
through modulation of the arterial chemoreflex. Therefore, whilst chemical stimuli play a dominant role maintaining blood gas and $\mathrm{pH}$ status at rest through their gross effect on ventilation, during exercise these stimuli are most important for the finer adjustments of ventilation, especially during steady state exercise (Paterson, 1997).

The rapid rate in the change of ventilation at both the start and cessation of exercise is too abrupt to be attributed to an alteration of the chemical constituents of the blood. It has therefore been postulated that there are two main stimuli that influence this rapid response; 1) a humoral response such that the transition from rest to work causes a change in some blood-borne agent (catecholamines; Bannister and Griffiths, 1972 or $\mathrm{CO}_{2}$; Wasserman, Whipp et al, 1981) and 2) a neural response which either originates in the brain (Eldridge, Millhorn et al, 1985, Krogh and Lindhard, 1913) or in the exercising muscles (Bennett, 1984; Mitchell, Reardon et al, 1977; Kao, 1963; Dejours, 1965) and is transmitted to the medullary neurons via descending or ascending neural pathways. It has also been suggested that the increase in heat production [which has a known stimulatory effect on ventilation (Cunningham and O’Riordan, 1957) and responds rapidly to exercise (Gonzalez-Alonso, Quistorff et al, 2000)] contributes to exercise hyperpnoea, and that the rapid increase in ventilation at the onset of exercise may be a "learned" response to maintain stable blood gas levels (Helbling, Boutellier et al, 1997; Wood, Fatemian et al, 2003).

Yamamoto et al (1987) postulated that the ventilatory response to exercise may be, in fact, controlled by a number of mechanisms and eliminating a single neural or humoral mechanism may not affect hyperpnoea. It is due to this 
multiple control, the authors hypothesised, that experimental research has found seemingly contradictory evidence for the mechanism of ventilatory control. Other authors have also suggested control is influenced by a combination of all mechanisms mentioned previously which interact depending on the mode, intensity and duration of exercise (Whipp and Davis, 1979; Mateika and Duffin, 1995).

Whilst during mild to moderate exercise there is a proportional increase in ventilation to meet metabolic demands, intense and severe exercise causes a disproportionate increase in ventilation known as hyperventilation. This hyperventilation coincides with an increased dependency on anaerobic metabolism for energy production and provides the means by which a high diffusion gradient is maintained in the alveoli, sustaining uptake and elimination of oxygen and carbon dioxide, respectively.

Whipp (1994) stated that "the appropriateness of the ventilatory response to exercise ..... depends not on the level of ventilation achieved but on the extent to which it achieves its pulmonary gas-exchange and acid-base regulatory requirements. Alveolar, and hence arterial, blood gas partial pressures can only be regulated at or close to resting values if ventilation increases in proportion to metabolic rate.”. It has been suggested, however, that during high intensity exercise in well-trained athletes, there is a relative hypoventilation which is insufficient to meet the demands of the respiratory system in maintaining alveolar and hence arterial, oxygen partial pressure. This relative hypoventilation, or inadequate hyperventilation as it is referred to in the current literature, has been postulated both as having relatively little effect (Hopkins and 
McKenzie, 1989; Powers, Martin et al, 1992; Hopkins, McKenzie et al, 1994; Norton, Squires et al, 1995; Buono and Maly, 1996) as well as being a major contributor to the development of EIH (Dempsey, Hanson et al, 1984; Miyachi and Tabata, 1992; Caillaud, Anselme et al, 1993; Harms and Stager, 1995; Gavin, Derchak et al, 1998; Rice, Scroop et al, 1999; Rice, Thornton et al, 1999; Durand, Mucci et al, 2000).

\subsubsection{Inadequate hyperventilation during exercise}

In theory, an inadequate hyperventilatory response to exercise has the capacity to cause arterial hypoxaemia by reducing alveolar $\mathrm{PO}_{2}$ and, consequently, inhibiting diffusion of oxygen through the lung into pulmonary blood. Whilst this theory is supported (Dempsey, Hanson et al, 1984; Powers, Martin et al, 1993; Harms and Stager, 1995; Rice, Scroop et al, 1999; Durand, Mucci et al, 2000), the occurrence and effect of hyperventilation is a disputed area of research. A number of authors (Caillaud, Anselme et al, 1993; Dempsey, Hanson et al, 1984; Durand, Mucci et al, 2000; Gavin, Derchak et al, 1998; Harms, McClaren et al, 1998; Harms and Stager, 1995; Miyachi and Shibayama, 1992; Miyachi and Tabata, 1992; Prefaut, Anselme et al, 1994; Rice, Scroop et al, 1999; Rice, Thornton et al, 1999) have assigned at least a proportion of the cause of EIH to inadequate hyperventilation, while others have indicated that inadequate hyperventilation plays no role in the development of the phenomenon (Buono and Maly, 1996; Chapman, Emery et al, 1998; Hopkins and McKenzie, 1989; Mota, Casan et al, 1999; Norton, Squires et al, 1995, Powers, Martin et al 1992). 
Where it has been assigned as a cause of EIH, there have been various mechanisms hypothesised for the cause of inadequate hyperventilation itself. These include reduced chemosensitivity (Byrne-Quinn, Weil et al, 1971), flow limitation (Hesser, Linnarson et al, 1981) and respiratory muscle fatigue (Bye, Farkas et al, 1983) due to the increased cost of breathing during intense exercise.

Harms and Stager (1995) investigated the theory of low chemoresponsiveness as a cause of EIH. The authors observed the hypercapnic and hypoxic ventilatory responsiveness (HCVR and HVR, respectively) and found that both were reduced in individuals who underwent EIH. A positive correlation $(\mathrm{p}<0.05)$ was observed between the ventilatory equivalents for oxygen $\left(\dot{\mathrm{V}}_{\mathrm{E}} / \dot{\mathrm{V}} \mathrm{O}_{2}\right)$ and carbon dioxide $\left(\dot{\mathrm{V}}_{\mathrm{E}} / \dot{\mathrm{V} C O} \mathrm{O}_{2}\right)$ and $\mathrm{SaO}_{2}$, results also observed by Norton, Squires and colleagues (1995) and Miyachi and Tabata (1992). It must be noted, however, that changes in the oxygenation of the blood were evaluated by pulse oximetry with only the Norton group (1995) using arterial blood gas measurements which remained uncorrected for temperature changes during the exercise test.

Rice et al (1999a and b) observed that almost 50\% of the hypoxemia observed during both cycling and running exercises was attributable to inadequate hyperventilation. These authors suggested the existence of EIH to be a multifactorial phenomenon which was influenced by the trained athletes' reduced sensitivity to changes in $\mathrm{PaCO}_{2}$ during submaximal exercise, as well as the physical limitations of breathing at exercise intensities at, or approaching, 
$\dot{\mathrm{VO}}_{2}$ max. The authors also observed the previously described relationship between $\mathrm{PaO}_{2}$ and $\dot{\mathrm{V}}_{\mathrm{E}} / \dot{\mathrm{V}} \mathrm{O}_{2}$ and $\dot{\mathrm{V}}_{\mathrm{E}} / \dot{\mathrm{V}} \mathrm{CO}_{2}$ at $\dot{\mathrm{VO}}_{2} \max$.

During maximal exercise the trained athlete may attain rates of minute ventilation 40 to $60 \%$ greater than that of an untrained individual in an attempt to maintain homeostasis of blood gas values (Dempsey, 1986; Dempsey, Hanson et al, 1982). In doing so the athlete may reach the mechanical limit of airflow (Johnson, Saupe et al, 1992). These authors comprehensively assessed the relationship between mechanical constraints on breathing during exercise and the development of hypoxaemia and observed that a true mechanical limit to $\dot{\mathrm{V}}_{\mathrm{E}}$ was reached during at least a portion of inspiration, with most of expiration flow limited. This flow limitation leads to a reduced alveolar ventilation and hence the inability of the arterial blood to maintain a normal level of oxygenation, increasing the $(\mathrm{A}-\mathrm{a}) \mathrm{DO}_{2}$. The authors concluded that whilst there may have been the opportunity to marginally increase $\dot{\mathrm{V}}_{\mathrm{E}}$ during maximal exercise via a volitional effort, this response did not occur due to the marked increase in mechanical work required (Hesser, Linnarsson et al, 1981; Klas and Dempsey, 1989).

As highly trained athletes are reported to reach their mechanical limitations for respiration it is hypothesised that during such maximal exercise the respiratory muscles are utilised to such an extent that they may become fatigued (Johnson, Aaron et al, 1996; Mota, Casan et al, 1999). In 1991, Mancini and co-authors observed a decrease in the oxygenation levels of the respiratory muscles in patients with a reduced stroke volume during exercise, a 
finding reproduced in measuring the oxygenation of the intercostal muscles of healthy subjects during maximal exercise (Nielsen, Boesen et al, 2001). Nielsen et al (2001) demonstrated a level of oxygen extraction in the respiratory muscles during maximal exercise which indicated the performance of maximal work in these muscles, further supporting the theory of fatigue. Furthermore, it has been reported that the capacity to perform work is improved with respiratory muscle training (RMT) (Inbar, Weiner et al, 2000; Spengler and Boutellier, 2000; Voliantis, McConnell et al, 2001). In one such study (Inbar, Weiner et al, 2000), 10 well-trained subjects underwent a training program to improve the strength and endurance of their inspiratory muscles, with a further 10 subjects undertaking a sham training program. Whilst both strength and endurance were significantly improved in the trained group, these improvements did not result in improvements in $\dot{\mathrm{VO}}_{2}$, breathing reserve or $\mathrm{SaO}_{2}$ either during or at peak exercise. Similarly, Stuessi and co-authors (2001) compared the breathing and cycling endurance time and blood gas concentrations of 13 subjects after RMT with 15 control subjects. Whilst both breathing and cycling endurance time were significantly improved, no changes in $\mathrm{PaO}_{2}$ and $\mathrm{SaO}_{2}$ were reported. The authors concluded that whilst the changes in endurance were substantial, they could not be attributed to an increased oxygen supply. In theory, the improved efficiency of the working respiratory muscles may, however, allow greater blood flow to the active muscles during exercise (Harms, Wetter et al, 1998). The work of Stuessi et al (2001) is consistent with that of Inbar and colleagues in as much as the 13 subjects who underwent the RMT were sedentary. This is a 
cohort which in normal circumstances does not undergo EIH, and may not respond as would a group consisting of well-trained athletes undergoing RMT.

In summary, whilst an early review of research on EIH suggested it may not be a product of inadequate hyperventilation during exercise, more recent and current work from our own laboratory (Rice, Scroop et al, 1999; Rice, Thornton et al, 1999) indicate it may be important in the development of this phenomenon. This only furthers the need for more research to be performed in ascertaining the role of respiratory mechanics and limitations in the development of EIH.

\subsubsection{Veno-arterial shunt}

Veno-arterial shunt with respect to pulmonary function can be divided into two separate types; intra- and extra-pulmonary shunt. Extrapulmonary shunt occurs due to anatomical disturbances or anomalies in which venous blood passes directly between the atria or the ventricles in a right to left shunt (e.g. the Tetralogy of Fallot). This also occurs when venous blood drains from the bronchi or thebesian veins directly into the left ventricle. When intra-pulmonary shunt occurs in the lungs it may be due to atelectasis or hemangioma, and results in blood passing through areas of low or no ventilation, preventing the exchange of oxygen and carbon dioxide. When these shunts occur, the blood which has not undergone any re-oxygenation mixes with oxygenated blood and leaves the heart bound for the peripheral circulation and organs at a $\mathrm{PaO}_{2}$ which is lower than normal.

In normal, healthy individuals at rest, $0.5-1.5 \%$ of cardiac output does not undergo normal gas exchange in the lungs (Bachofen, Hobi et al, 1973; 
Hammond, Gale et al, 1986). Veno-arterial shunt accounts for approximately $50 \%$ of the observed (A-a) $\mathrm{DO}_{2}(4-5 \mathrm{mmHg})$ at rest (Gledhill, Froese et al. 1977; Whipp and Wasserman, 1969), with Asmussen and Neilsen (1960) proposing this shunt could explain a similar level during exercise of moderate intensity.

Previous detection of pulmonary shunt has been performed utilising two principal techniques: MIGET (multiple inert gas exchange technique) and 100\% $\mathrm{O}_{2}$ breathing (Wagner, Gale et al, 1986). The MIGET enables detection of intrapulmonary shunt by measuring the retention of the highly insoluble gas sulphur hexafluoride $\left(\mathrm{SF}_{6}\right)$, whilst $100 \% \mathrm{O}_{2}$ breathing is utilised to detect any reduction in expected $\mathrm{PaO}_{2}$ due to deoxygenated blood mixing with oxygenated blood. These techniques may, however, underestimate the extent of actual shunt due to methodological inadequacies (Eldridge, Dempsey et al, 2004).

Whilst the body of work regarding intrapulmonary shunts in humans has concurred that it has negligible effect on the increased $(\mathrm{A}-\mathrm{a}) \mathrm{DO}_{2}$ during intense exercise recent research by Eldridge and co-workers (2004) questions the previous techniques utilised in assessing the extent of right to left shunt, indicating they may have lead to a significant underestimation of the existence and contribution. These authors utilised agitated saline contrast echocardiography (ASC Echo) to assess the existence of intrapulmonary shunts in a group of 23 healthy volunteers with no observed intrapulmonary or intracardiac shunts on normal contrast echocardiogram. Under exercise conditions ( $\sim 59 \% \dot{\mathrm{VO}}_{2}$ max and above) $91 \%$ of subjects exhibited ASC Echo results which indicated the passage of contrast bubbles through the pulmonary circulation via intrapulmonary shunts. The shunts were proposed due to the 
bubble size being greater than that of the pulmonary capillaries, preventing their passage through these vessels. The authors concluded that there exists dormant arteriovenous intrapulmonary shunts which are recruited during moderate to high intensity exercise. This limits the rise in regional pulmonary vascular pressure, preserving cardiac output but with the effect of widening the $(\mathrm{A}-\mathrm{a}) \mathrm{DO}_{2}$

Whilst current research into the existence and effect of pulmonary shunt on the (A-a) $\mathrm{DO}_{2}$ re-opens the debate on its place as a possible cause of $\mathrm{EIH}$, the small number of data suggest that it is negligible during high intensity exercise, and may be assumed to be as such until further research is able to clarify its possible impact.

\subsubsection{Diffusion Limitation}

The rate of transfer of oxygen and carbon dioxide across the alveolar surface into or from the blood stream is dependent upon factors which include the distance the oxygen has to travel to be taken up by the red blood cells, the diffusion gradient across the diffusion barrier, and chemical and physiological conditions which affect the uptake of oxygen by the haemoglobin. Piiper and Scheid (1980) explained the degree of any expected diffusion limitation in terms of their compound variable $\mathrm{D} /(\beta \dot{\mathrm{Q}})$; where $\mathrm{D}$ is the diffusing capacity of the lung $\left(\mathrm{mL} \cdot \mathrm{min}^{-1} \cdot \mathrm{mmHg}^{-1}\right), \beta$ is the mean slope of the (conceptually) linear dissociation curve in the physiological range $\left(\mathrm{mLO}_{2} \cdot \mathrm{L} \operatorname{blood}^{-1} \cdot \mathrm{mmHg}^{-1}\right)$ and $\dot{\mathrm{Q}}$ is cardiac output $\left(\mathrm{L} \cdot \mathrm{min}^{-1}\right)$. The authors noted that whilst all three variables increased during exercise, the value for the compound variable falls. This fall 
can be accentuated by limited increases in $\mathrm{D}$ or by greater than usual increases in $\beta$ or $\dot{\mathrm{Q}}$, as commonly seen in athletes.

As would be expected, any factor which limits the rate of diffusion of oxygen into the pulmonary blood has the possible effect of reducing arterial $\mathrm{PO}_{2}$. During exercise, diffusion may be limited by transient changes to the structure of the alveolar-blood diffusion barrier and/or conditions which have a physiological effect in reducing the rate of oxygen transfer. Current research into diffusion limitation suggests that it is responsible for up to $60 \%$ of the (A-a)DO (MIGET $^{2}$ analysis), the remaining amount due to $\dot{\mathrm{V}}_{\mathrm{A}} / \dot{\mathrm{Q}}$ mismatch in trained athletes capable of a high $\dot{\mathrm{V}} \mathrm{O}_{2}$ max and cardiac output (Hammond, Gale et al, 1986; Hopkins, McKenzie et al, 1994).

A reduced rate of diffusion will occur in persons suffering such chronic illnesses as silicosis, active tuberculosis or any condition which may cause interstitial fibrosis due to a thickening of the respiratory membrane, and acute conditions such as left heart failure and pneumonia which may cause an increase in the diffusion barrier and, hence, a reduced diffusion rate, due to pulmonary oedema. Whilst these conditions are not expected in healthy, trained athletes, it has been proposed pulmonary oedema may occur during high intensity exercise (Wagner, Gale et al, 1986; Wagner, Sutton et al, 1987; Rasmussen, Elkjaer et al, 1988; West, Colice et al, 1995; Podolsky, Eldridge et al, 1996; Hopkins, Gavin et al, 1998; Anholm, Milne et al, 1999; Sosa Leon, Hodgson et al, 2002). Wagner et al (1986) theorised the very high cardiac output during intense exercise elevates vascular pressure to such a degree that leakage of fluid across 
the capillary endothelium occurs causing the accumulation of fluid in the interstitial spaces, increasing the diffusion distance for oxygen exchange and causing a diffusion limitation.

\subsubsection{Pulmonary Capillary Transit Time}

At rest, the transit time for red blood cells through the pulmonary capillaries (PCTT) has been estimated at $~ 0.75$ seconds (Roughton, 1945; Johnson, Spicer et al, 1960; Wagner, 1977). With a mixed venous $\mathrm{PaO}_{2}$ of 40 mmHg the equilibration time for oxygen exchange is approximately 0.25 seconds; therefore, in healthy individuals the PCTT is not responsible for any (A-a) $\mathrm{DO}_{2}$. In a normal, untrained subject whose $\dot{\mathrm{VO}}_{2}$ max may approach 3.0 L.min ${ }^{-1}$ and cardiac output may reach 20 L. $\mathrm{min}^{-1}$, the rate of deoxygenated blood flow through the pulmonary system is sufficiently slow to allow adequate exchange of blood gases within the minimum time required for complete equilibration (0.25-0.4 seconds: Dempsey, Hanson et al, 1982; Wagner, 1982; Gledhill, Froese et al, 1977; Wagner, 1977; Staub, Bishop et al, 1962). Dempsey and Fregosi (1985) postulated that athletes capable of exercising at intensities requiring an $\dot{\mathrm{VO}}_{2}>4.5 \mathrm{~L} \cdot \mathrm{min}^{-1}$ may create an alveolar - end-capillary oxygen disequilibrium due to red blood cell pulmonary capillary transit times (PCTT) which are less than those required for complete gas transfer. This decrease in PCTT is due to the pulmonary blood volume reaching its upper limit at approximately $25 \mathrm{~L} \cdot \mathrm{min}^{-1}$ whilst pulmonary blood flow continues to increase beyond this level. 
In a study designed to measure the pulmonary transit time of blood through the lungs, Hopkins, Belzberg et al (1996) produced some of the most direct evidence of the possibility of a diffusion limitation based on red blood cell transit time through the pulmonary capillaries. Using isotope labelled erythrocytes, pulmonary blood volume and PTT were measured in 10 highly trained athletes ( $\dot{\mathrm{VO}}_{2} \max \sim 5.2 \mathrm{~L} \cdot \mathrm{min}^{-1}$ ). From the results obtained, and using a maximal pulmonary capillary volume of $225 \mathrm{~mL}$, it was estimated approximately $40 \%$ of erythrocytes had a PCTT of less than 0.3 seconds and that as well as this, $15 \%$ had PCTT of less than 0.14 seconds. Whilst, on average, the PCTT may have been $\sim 0.4$ seconds (which, again, has been estimated as sufficient for oxygen equilibrium to occur in the lungs) it is the distribution of these PCTT which may cause a diffusion limitation.

This decrease in PCTT was also investigated by Warren and colleagues (1991) five years prior to the Hopkins et al research. These authors also discovered that there was a decrease in PCTT during exercise of increasing intensity; however, they concluded that the increase was offset by a capillary blood volume which increased with each workload, maintaining PCTT to within a time of 0.4-0.5 seconds.

Though these two studies give similar results regarding a decreasing PCTT during increasing intensities of exercise, with different conclusions it is important to view the shortcomings of both papers. Of the 16 highly trained subjects utilised by Warren et al (1991), only one exhibited significant EIH during the testing protocol. This was demonstrated by an observed (A-a) $\mathrm{DO}_{2}$ which did not exceed 25mmHg, even at an exercise intensity approaching $90 \%$ 
$\dot{\mathrm{VO}}_{2}$ max, making it difficult to compare the subjects to those used in previous research investigating the mechanism of EIH. To assess changes in blood gas levels arterial blood gas samples were corrected for sublingual temperature after the cessation of exercise, not during exercise. This method is rarely used to measure core temperature responses to exercise and without its exact correlation to other core temperatures will result in erroneous data correction due to the influence of temperature on $\mathrm{PaO}_{2}$.

Hopkins, Belzberg and associates (1996) did not measure changes in $\mathrm{PaO}_{2}$ for their subjects which prevents them from making any assumptions regarding their subjects and the causality of EIH. PCTT was also estimated, not calculated as, as the authors state, "the relationship(s) between whole lung transit time and blood volume and pulmonary capillary transit time and blood volume are not well established”. This in itself implies that their conclusions may be somewhat erroneous due to the possibility of both over and underestimating PCTT to such a degree as to alter its influence.

To further cloud the issue regarding PCTT and diffusion equilibrium, the PCTT estimated as satisfying the minimum time required for complete gas exchange are based on alveolar and mixed venous $\mathrm{PaO}_{2}$ of $40 \mathrm{mmHg}$ and 100 mmHg, respectively. However, during exercise mixed venous $\mathrm{PO}_{2}$ may drop as low as $15-20 \mathrm{mmHg}$ in trained athletes whilst $\mathrm{PAO}_{2}$ remains fairly constant (Åstrand and Rodahl, 1986). This is important as the time required to ascertain any degree of equilibrium at a fixed alveolar $\mathrm{PO}_{2}$ is dependent on the value of the mixed venous $\mathrm{PO}_{2}$ such that a lower venous $\mathrm{PO}_{2}$ will significantly increase the time required to reach a $\mathrm{PO}_{2}$ approaching $\mathrm{PAO}_{2}$. Wagner (1982) states that it 
is not simply $\mathrm{PAO}_{2}$ or the driving gradient between alveolar and mixed venous $\mathrm{PO}_{2}$ which is responsible for the rate of equilibrium. He states it is the slope of the dissociation curve between the two points (see Figure 1.3) that is most important. Whilst the diffusion gradient between A and V2 is obviously greater than that between A and V1, the point V1 lies more closely to the actual alveolar $\mathrm{PO}_{2}$ on the dissociation curve and will equilibrate in less time than the mixed venous blood at V2.

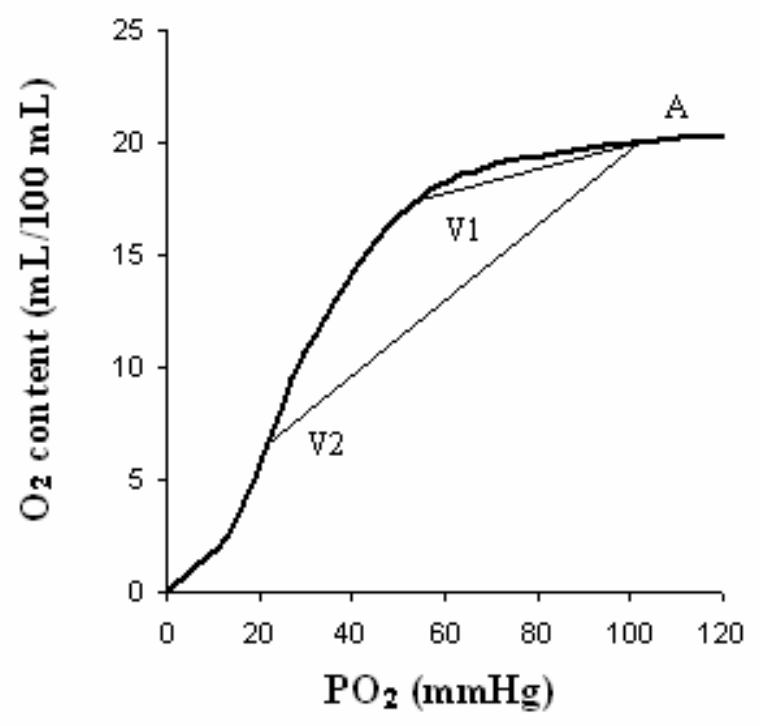

Figure 1.3. $\quad \mathrm{O}_{2}$ dissociation curve showing how the effective slope of the curve varies with mixed venous $\mathrm{PO}_{2}$ (points $\mathrm{V} 1, \mathrm{~V} 2$ ) when alveolar $\mathrm{PO}_{2}$ (point A) remains constant (from Wagner, 1982).

The current data on PCTT is somewhat inconclusive as to the direct effect it has on the appearance of EIH in highly trained individuals. The data does suggest, however, the possibility of a diffusion limitation caused by a wide range of PCCT's during high intensity exercise which may lead to incomplete transfer 
of oxygen into the red blood cells during their passage through the pulmonary capillaries.

\subsubsection{Blood Rheological Responses to Exercise}

In some of the most recent research into the mechanism of EIH, Connes, Bouix et al (2004) and Galy, Hue et al (2005) demonstrated changes in blood

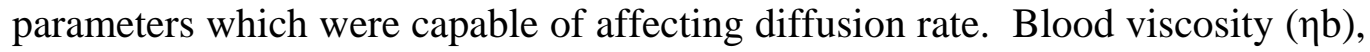
plasma viscosity ( $\eta$ ), erythrocyte rigidity (Tk) and Hematocrit (Hct) were measured during an incremental test to exhaustion by Connes and co-workers (2004) with their subjects divided into two groups depending on their $\mathrm{SpO}_{2}$ response to exercise (Low $=\mathrm{a}$ decrease in $\mathrm{SpO}_{2} \geq 4 \%$, High $=$ no significant reduction in $\mathrm{SpO}_{2}$ ). The Low group exhibited a higher Hct, $\eta \mathrm{b}$ and plasma viscosity than the High group. Whilst Tk decreased during increasing intensity of exercise in the High group there was no change in this parameter in the Low group. The authors suggested a complex interaction between red blood cell rigidity, Hct and plasma viscosity exists and is responsible for the increased $\eta \mathrm{b}$ in the Low group. They agreed with previous research which suggested the increased blood viscosity leads to a decrease in gas exchange due to an increase in vascular shear stress (the tangential force per unit area exerted on the vessel wall) (Julien, Hakim et al , 1985; Nihill, McNamara et al, 1976).

Galy and colleagues (2005) further researched the link between blood rheological responses and EIH in highly trained athletes. The authors also found an increasing $\mathrm{Tk}$ in runners during exercise at or approaching the ventilatory threshold of the subjects. The increased red blood cell rigidity was attributed to 
an increase in the transport capacity of lactic acid in trained runners as demonstrated by a relatively lower blood lactate concentration when compared to the cycling group. Again this increased rigidity was implicated in a decrease in $\mathrm{SpO}_{2}$ and $\mathrm{PaO}_{2}$ which, during high or maximal intensity exercise, may lead to the appearance of EIH. Further to the theories arrived at by this research, studies performed in 1995 and 1998 by Aguilaniu and co-workers observed the effect on $\mathrm{PaO}_{2}$ of a diet supplemented with polyunsaturated fatty acids (PUFA). This diet is known to decrease blood viscosity by increasing the cell membrane fluidity and deformability (reduced Tk) of red blood cells and hence increases the diffusing capacity for oxygen. Following 6 weeks of this diet the subjects completed an incremental cycling test with $\mathrm{PO}_{2}$ measured from arterial samples taken throughout the test. When compared to a pre-diet exercise test the athletes showed a significantly smaller drop in $\mathrm{PaO}_{2}$ (17.2mmHg compared with 12.9 mmHg) from rest to end-exercise (Aguilaniu, Flore et al, 1995) which could not be attributed to a confounding prostaglandin effect produced by the supplementation (Aguilaniu, Flore et al, 1998). Whilst the effect of PUFA on masters athletes is evident, the mechanism by which the changes are effected and the applicability of the response to the general athletic population are unknown.

\subsubsection{Pulmonary Oedema and Stress Failure}

The diffusion distance of oxygen across the respiratory membrane averages approximately $0.5 \mu \mathrm{m}$, with areas as low as $0.2 \mu \mathrm{m}$. This extremely small distance is ideal for the rapid passive diffusion of oxygen and carbon 
dioxide, a process that is directly affected by any increase in this distance as described by Fick's Law which states that the rate of transfer of a gas through a sheet of tissue is proportional to the tissue area and the difference in gas partial pressures between the two sides and inversely proportional to the tissue thickness. In addition, the rate of transfer is also proportional to the diffusion constant of the gas and the properties of the tissue which it is passing through (Equation 1.1).

$$
\begin{aligned}
& \text { Rate of gas transfer } \quad \propto \frac{\mathrm{A}}{\mathrm{T}} \cdot \mathrm{D} \cdot\left(\mathrm{P}_{\mathrm{A}}-\mathrm{P}_{\mathrm{a}}\right) \\
& \text { Where } \quad \mathrm{D} \quad \propto \frac{\text { Sol }}{\sqrt{\mathrm{MW}}}
\end{aligned}
$$

And ; $\quad$ A $\quad=$ Tissue area

$$
\begin{array}{ll}
\mathrm{T} & =\text { Tissue Thickness } \\
\mathrm{D} & =\text { Diffusion Constant } \\
\text { Sol } & =\text { Gas Solubility } \\
\mathrm{MW} & =\text { Molecular Weight }
\end{array}
$$

Equation 1.1 The Fick Diffusion Equation.

Obviously, most variables in this equation do not change significantly during exercise, with the possible exception of tissue thickness and the partial pressure gradient between alveolar and arterial $\mathrm{PO}_{2}\left(\mathrm{P}_{\mathrm{A}}-\mathrm{P}_{\mathrm{a}}\right)$. These equations 
also describe why $\mathrm{CO}_{2}$ diffuses at a rate up to 20 times that of $\mathrm{O}_{2}$, as it has a much greater solubility but a similar molecular weight.

The effect of exercise on cardiac output can result in increases in mean pulmonary artery pressures to over $40 \mathrm{mmHg}$ (Wagner, Gale et al, 1986) and capillary wedge pressures can rise from the normal range of $5-15 \mathrm{mmHg}$ to above 20mmHg (Goresky, Warnica et al, 1972; Wagner, Gale et al, 1986). Increased wedge pressures translate to an increased pulmonary venous pressure and elevated microvascular pressure which leads to a transudation of fluid (Starling's Forces). If this fluid is not reabsorbed as normal, the accumulation can cause pulmonary oedema which increases the diffusion distance for oxygen across the alveolar membrane and, hence, reduces the rate of diffusion (a diffusion limitation).

The evidence for the existence of exercise induced pulmonary oedema has been largely controversial. Studies have shown in the perfused lung of dogs that a four fold increase in blood flow results in an accumulation of extravascular fluid (Younes, Bshouty et al, 1987) with a study into normoxic and hypoxic exercise responses in sheep and goats (Coates, O’Brodovich et al, 1984) revealing a significant increase in lymph flow (nearly triple) which is relevant to possible pulmonary oedema. By hyperhydrating horses with amounts of fluid equal to approximately $6 \%$ of their body weight during a three day trial, Sosa Leon and colleagues (2002) were able to induce a $15 \mathrm{mmHg}$ decrease in $\mathrm{PaO}_{2}$ during moderate intensity exercise. This exercise induced hypoxemia occurred without any corresponding $\mathrm{PaCO}_{2}$ differences, leading the authors to conclude 
that the hyperhydration may cause pulmonary oedema due to extravasation of the administered fluid.

In human subjects there are few studies which show direct evidence of pulmonary oedema during exercise (Anholm, Milne et al, 1999; Caillaud, SerreCousine et al, 1995). Computer tomography was used by Caillaud and colleagues (1995) to show increases in lung density in athletes competing in a triathlon. The authors measured a decreased transfer coefficient which corresponded to an increase in the number of opacities noted on the tomography scans. The cyclists participating in the research by Anholm and co-workers (1999) underwent chest radiographs both before and following the exercise bouts of differing length and intensities with the radiographs analysed by three different radiographers for signs of pulmonary oedema. The overall oedema score was increased in $70 \%$ of the subjects post-exercise, the other $30 \%$ either unchanged or showing a decreased overall oedema score. The authors were unable to estimate the effect of this oedema on exercise performance but concurred with previous suggestions that it was due to the inability of the lymphatic system to completely clear the extravascular lung water which was created by the high pressure of the precapillary vessels. The authors concluded that prolonged exercise of high-intensity at moderate altitude results in pulmonary oedema in some subjects.

Whilst there is a small amount of evidence for the existence of exerciseinduced pulmonary oedema, there is also a body of work that disputes this fact. Two studies by the author Miles and colleagues (Miles, Doerr et al, 1983; Miles, Enoch et al, 1986) suggest the changes seen in diffusing capacity following 
exercise are consistent with those of cardiac output. Similarly, Hanel, Clifford et al (1994) and Hanel, Teunissen et al (1997) observed changes in diffusing capacity which the authors attributed to changes in central blood volume and not pulmonary oedema, a suggestion supported by McKenzie, Lama et al (1999) who found no significant change in the $\mathrm{SaO}_{2}$ in subjects performing two consecutive (within 1 hour of each other) $\dot{\mathrm{VO}}_{2}$ max tests. In a study using dogs which were euthanized either at rest or following maximal exercise, Marshall, Soma and colleagues (1975) observed no significant differences in lung water volume leading the authors to conclude that pulmonary oedema does not occur during exercise.

Besides the high pulmonary capillary pressure causing a transudation of fluid into the alveolar spaces which is unable to be removed by the lymphatic system, it has been suggested that pulmonary oedema may be caused by various other mechanisms. A series of experiments in the early 1990's by West and associates (West, Tsukimoto et al, 1991; West, Mathieu-Costello, 1992a; West, Mathieu-Costello, 1992b; West, Mathieu-Costello et al, 1995), led to the introduction of the term "stress failure" with regard to pulmonary capillaries. The authors suggested the thin membrane over which gas exchange occurs could undergo mechanical failure, a situation which may lead to a pulmonary injuryevoked airway inflammatory response resulting in the release of histamine and/or other chemical mediators from inflammatory and mast cells (Mucci, Durand et al, 2001; Prefaut, Anselme-Poujol et al, 1997; Prefaut, Durand et al 2000) Whilst this stress failure was also reported to have led to pulmonary haemorrhage in both racehorses and humans (Birks, Mathieu-Costello et al, 
1997, Hopkins, Schoene et al, 1997), more recent research disputes the correlation between high intensity exercise and the role of histamine and inflammation in the development of a gas exchange disturbance (Edwards, Hunte et al, 2000; Hopkins, Schoene et al, 1998, Manohar, Goetz et al, 2002; Wetter, Xiang et al, 2002). In particular, Wetter and associates (2002) observed the effect of a pharmacological blockade of the inflammatory response in young athletes, noting that administration of anti-inflammatory drugs did not assuage EIH during maximal exercise. The researchers stated that airway inflammation is insufficient to impair gas exchange even though there is an increase in plasma histamine following maximal exercise, and conclude that, in young athletes, lung inflammation does not significantly contribute to the widened (A-a) $\mathrm{DO}_{2}$ during exercise. An analysis of the response to repeat bouts of exercise in women previously shown to undergo EIH (St. Croix, Harms et al, 1998) also led the authors to the conclusion that, whilst they had previously been inclined to accept the theory that intense exercise led to diminished gas exchange due to stress failure of the capillary endothelium, the decreased hypoxaemic response to a second exercise bout made it impossible to attribute EIH to a mechanism or mechanisms that persisted long after exercise cessation or was aggravated by subsequent bouts of exercise.

The role of nitric oxide (NO), an important mediator with regard to lung inflammation (Teeter and Bleecker, 1996), has also been investigated in subjects with EIH, non-EIH athletes and inactive subjects (Kippelen, Caillaud et al, 2002). The authors found no association between NO and athletes with or without EIH and concluded that whilst their results do not support a link 
between pulmonary inflammation and $\mathrm{EIH}$, there may exist a potential down regulation of NO leading to a gas exchange disturbance.

Overall, the possible effect of pulmonary oedema in disturbing normal gas transfer is indisputable; however, the mechanism by which it occurs and, more so, its prevalence in healthy, exercising individuals still needs to be researched more fully.

\subsection{PREVALENCE OF EXERCISE-INDUCED HYPOXEMIA}

In the most recent reviews of exercise-induced hypoxemia (Dempsey and Wagner, 1999; Prefaut, Durand et al, 2000; Nielsen, 2003), the prevalence of this phenomenon has been estimated at approximately $50 \%$. This is an extremely simplistic assessment of the occurrence of EIH and does not take into account such parameters as methodology, age, sex or relative fitness of the subjects utilised in the individual studies. Table 1.1 contains a summary of studies which have attempted to assess the existence or mechanism of EIH in various types of athletes and using different methodologies, noting the important differences between each study and the relative findings. 


\begin{tabular}{|c|c|c|c|c|c|c|}
\hline Author & $\begin{array}{l}\text { Subject } \\
\text { Information }\end{array}$ & $\begin{array}{l}\text { Test Type and } \\
\text { Exercise Mode }\end{array}$ & $\begin{array}{l}\dot{\mathbf{V O}}{ }_{2} \max \\
(\text { L.min } \\
\text { (1) }\end{array}$ & $\begin{array}{l}\mathrm{PaO}_{2}(\mathrm{mmHg}) \text { or } \mathrm{SaO}_{2} \\
(\%) \text { at } \dot{\mathrm{VO}} \mathrm{O}_{2} \mathrm{max} \\
\text { (changes from pre- } \\
\text { exercise) }\end{array}$ & $\begin{array}{l}\text { Temperature } \\
\text { Correction site }\end{array}$ & Incidence of EIH \\
\hline Aguilaniu et al, 1995 & 8 Masters athletes, & $\begin{array}{l}\text { Incremental cycling } \\
\text { test to exhaustion }\end{array}$ & 3.4 & $\mathrm{PaO}_{2}=76(17)$ & & \\
\hline Aguilaniu et al, 2002 & $\begin{array}{l}38 \text { male professional } \\
\text { mountain rescue workers }\end{array}$ & $\begin{array}{l}\text { Incremental cycling } \\
\text { test to exhaustion }\end{array}$ & 3.6 & $\begin{array}{l}\text { GED } \mathrm{PaO}_{2}=80 \\
\mathrm{~N} \mathrm{PaO}_{2}=92\end{array}$ & $\begin{array}{l}\text { Mean oesophageal } \\
\text { temperature from previous } \\
\text { test applied to all results }\end{array}$ & $\begin{array}{l}14 \text { subjects }(37 \%) \Delta \mathrm{PaO}_{2}>10 \\
\mathrm{mmHg}(\mathrm{GED}), 14 \text { subjects } \\
\Delta \mathrm{PaO}_{2} \leq 10(\mathrm{~N})\end{array}$ \\
\hline Anselme et al, 1994 & $\begin{array}{l}28 \text { males, } 14 \text { trained (7 } \\
\text { young (YA), } 7 \text { masters } \\
\text { athletes (MA)), } 14 \\
\text { control (YC, MC). }\end{array}$ & $\begin{array}{l}\text { Incremental cycling } \\
\text { test to exhaustion }\end{array}$ & $\begin{array}{l}\mathrm{YC}=2.9 \\
\mathrm{MC}=2.0 \\
\mathrm{YA}=4.8 \\
\mathrm{MA}=3.2\end{array}$ & $\begin{array}{l}\mathrm{PaO}_{2} \mathrm{YC}=101(+2) \\
\mathrm{PaO}_{2} \mathrm{MC}=101(+7) \\
\mathrm{PaO}_{2} \mathrm{YA}=83(19) \\
\mathrm{PaO}_{2} \mathrm{MA}=81(13)\end{array}$ & $\begin{array}{l}\text { Not used. Definition of } \\
\text { EIH increased to 8mmHg. }\end{array}$ & $\begin{array}{l}4 \text { athletes }(29 \%) \\
\Delta \mathrm{PaO}_{2}<10 \mathrm{mmHg} \\
8 \text { athletes }(58 \%) \Delta \mathrm{PaO}_{2}=10- \\
20 \mathrm{mmHg} \\
2 \text { subjects } \Delta \mathrm{PaO}_{2}>20 \mathrm{mmHg}\end{array}$ \\
\hline Brown et al , 1993 & $\begin{array}{l}11 \text { trained male(?) } \\
\text { cyclists }\end{array}$ & $\begin{array}{l}\text { Incremental cycling } \\
\text { test to exhaustion }\end{array}$ & 5.1 & $\begin{array}{l}\mathrm{SpO}_{2}=90 \% \\
\mathrm{SaO}_{2}=95 \%\end{array}$ & $\begin{array}{l}\text { Not used. } \Delta \mathrm{T} \text { considered } \\
\text { insignificant for this type of } \\
\text { test. }\end{array}$ & $\begin{array}{l}7 \text { subjects (64\%) using pulse } \\
\text { oximetry, No (0\%) subjects } \\
\text { using arterial blood gas }\end{array}$ \\
\hline Caillaud et al , 1993 & $\begin{array}{l}8 \text { highly trained athletes } \\
\text { (HT) and } 8 \text { untrained } \\
\text { subjects }\end{array}$ & $\begin{array}{l}\text { Incremental cycling } \\
\text { test to exhaustion }\end{array}$ & $\begin{array}{l}\mathrm{HT}=4.7 \\
\mathrm{UT}=3.3\end{array}$ & $\begin{array}{l}\mathrm{HT} \mathrm{PaO}_{2}=83(21) \\
\text { UT } \mathrm{PaO}_{2}=101(0)\end{array}$ & Not used. & $100 \%$ of $\mathrm{HT}, 0 \%$ for UT \\
\hline Chapman et al , 1999 & 19 highly trained males & $\begin{array}{l}\text { Incremental treadmill } \\
\text { test to exhaustion }\end{array}$ & $\begin{array}{l}\mathrm{EIH}=4.8 \\
\text { Non-EIH }=4.5\end{array}$ & $\begin{array}{l}\text { EIH SpO } \mathrm{Sp}_{2}=88 \\
\text { Non-EIH SpO }{ }_{2}=94\end{array}$ & Not used. & $\begin{array}{l}8 \text { subjects }(42 \%) \text { with } \mathrm{SpO}_{2} \\
<90 \%, 6 \text { subjects }(32 \%) \text { Non- } \\
\text { EIH }\left(\mathrm{SpO}_{2}>92 \%\right)\end{array}$ \\
\hline Connes et al, 2004 & 20 highly trained athletes & $\begin{array}{l}\text { Incremental cycling } \\
\text { test to exhaustion }\end{array}$ & 4.6 & $\begin{array}{l}\Delta \mathrm{SpO} 2 \text { for High group }=2.3 \% \\
\Delta \mathrm{SpO} 2 \text { for Low group }=4.8 \%\end{array}$ & Not used & $\begin{array}{l}9 \text { subjects ( } 45 \% \text { ) with a } \Delta \mathrm{SpO} 2 \\
\text { of } \geq 4 \%\end{array}$ \\
\hline Dempsey et al, 1984 & $\begin{array}{l}16 \text { highly trained male } \\
\text { endurance athletes }\end{array}$ & $\begin{array}{l}\text { Incremental treadmill } \\
\text { test to exhaustion }\end{array}$ & 4.8 & $\begin{array}{l}\text { Mean } \mathrm{PaO}_{2}=75 \text { at maximal } \\
\text { exercise (16) }\end{array}$ & Rectal Temperature & $\begin{array}{l}4 \text { subjects }(25 \%) \Delta \mathrm{PaO}_{2}<10 \\
4(25 \%) \Delta \mathrm{PaO}_{2}=10-15 \\
8(50 \%) \Delta \mathrm{PaO}_{2}>15\end{array}$ \\
\hline Durand et al, 2004 & $\begin{array}{l}20 \text { highly trained male } \\
\text { athletes (EIH and Non- } \\
\text { EIH) } \\
9 \text { untrained males (UT) }\end{array}$ & $\begin{array}{l}\text { Incremental cycling } \\
\text { test to exhaustion }\end{array}$ & $\begin{array}{l}\mathrm{EIH}=4.5 \\
\text { Non-EIH }=4.4 \\
\mathrm{UT}=3.1\end{array}$ & $\begin{array}{l}\text { EIH } \mathrm{PaO}_{2}=86(20) \\
\text { Non-EIH } \mathrm{PaO}_{2}=99(0) \\
\text { UT } \mathrm{PaO}_{2}=110(+8)\end{array}$ & $\begin{array}{l}\text { Not used. Definition of EIH } \\
\text { increased to } \Delta \mathrm{PaO}_{2}> \\
10 \mathrm{mmHg} \text { to account for } \Delta \mathrm{T}\end{array}$ & $\begin{array}{l}50 \% \text { of trained athletes } \Delta \mathrm{PaO}_{2} \\
>10 \text {. } \\
\text { No ( } 0 \% \text { ) UT subjects. }\end{array}$ \\
\hline
\end{tabular}




\begin{tabular}{|c|c|c|c|c|c|c|}
\hline Author & $\begin{array}{l}\text { Subject } \\
\text { Information }\end{array}$ & $\begin{array}{l}\text { Test Type and } \\
\text { Exercise Mode }\end{array}$ & $\begin{array}{l}\dot{\mathbf{V O}}{ }_{2} \text { max } \\
(\text { L.min }\end{array}$ & $\begin{array}{l}\mathrm{PaO}_{2}(\mathrm{mmHg}) \text { or } \mathrm{SaO}_{2} \\
(\%) \text { at } \mathrm{VO}_{2} \text { max } \\
\text { (changes from pre- } \\
\text { exercise) }\end{array}$ & $\begin{array}{l}\text { Temperature } \\
\text { Correction site }\end{array}$ & Incidence of EIH \\
\hline Durand et al, 2000 & $\begin{array}{l}22 \text { male endurance } \\
\text { trained athletes }\end{array}$ & $\begin{array}{l}\text { Incremental cycling } \\
\text { test to exhaustion }\end{array}$ & $\begin{array}{l}\mathrm{EIH}=4.7 \\
\text { Non-EIH }=4.5\end{array}$ & $\begin{array}{l}\text { EIH } \mathrm{PaO}_{2}=86(16) \\
\text { Non-EIH PaO } \\
2=96(2)\end{array}$ & $\begin{array}{l}\text { Not used. Definition of EIH } \\
\text { increased to } \Delta \mathrm{PaO}_{2}> \\
10 \mathrm{mmHg} \text { to account for } \Delta \mathrm{T}\end{array}$ & $\begin{array}{l}12 \text { subjects with } \Delta \mathrm{PaO}_{2}> \\
10 \mathrm{mmHg}\end{array}$ \\
\hline Durand et al 1999 & $\begin{array}{l}9 \text { male endurance trained } \\
\text { athletes }\end{array}$ & $\begin{array}{l}\text { Incremental cycling } \\
\text { test to exhaustion }\end{array}$ & 4.7 & $\begin{array}{l}\mathrm{PaO}_{2}=85(13) \text { arterialised } \\
\text { blood samples from earlobe }\end{array}$ & $\begin{array}{l}\text { Not used. Definition of EIH } \\
\text { increased to } \Delta \mathrm{PaO}_{2}> \\
10 \mathrm{mmHg} \text { to account for } \Delta \mathrm{T}\end{array}$ & $100 \%$ in preliminary test \\
\hline Edwards et al, 2000 & $\begin{array}{l}10 \text { male competitive } \\
\text { cyclists }\end{array}$ & $\begin{array}{l}\text { Incremental cycling } \\
\text { test to exhaustion }\end{array}$ & 5.3 & $\mathrm{PaO}_{2}=87(27)$ & Arterial Blood temperature & $\begin{array}{l}3 \text { subjects } \mathrm{PaO}_{2} 100-90 \\
3 \text { subjects } \mathrm{PaO}_{2} 80-90 \\
5 \text { subjects } \mathrm{PaO}_{2}<80\end{array}$ \\
\hline Galy et al, 2005 & $\begin{array}{l}10 \text { male triathletes, } \\
\text { duathletes }\end{array}$ & $\begin{array}{l}20 \text { min of Running } \\
\text { (R)and cycling(C) at } \\
\text { ventilatory threshold }\end{array}$ & 4.7 & $\begin{array}{l}\mathrm{R} \mathrm{PaO}_{2}=85(14), \mathrm{SpO} 2= \\
93(6) \\
\mathrm{C} \mathrm{PaO}_{2}=89(11), \mathrm{SpO} 2= \\
95(4)\end{array}$ & Not used & - \\
\hline Gavin and Stager, 1999 & $\begin{array}{l}13 \text { actively training } \\
\text { males }\end{array}$ & $\begin{array}{l}\text { Incremental cycle } \\
\text { ergometer and } \\
\text { treadmill tests to } \\
\text { exhaustion. }\end{array}$ & $\begin{array}{l}\text { Running }(R)=4.8 \\
\text { Cycling }(C)=4.6\end{array}$ & $\begin{array}{l}\text { (R) } \mathrm{SpO} 2=89(7) \\
\text { (C) } \mathrm{SpO} 2=93(3)\end{array}$ & Not used & $\begin{array}{l}\text { (R) } 10 \text { subjects (100) } \mathrm{SpO}_{2}< \\
92 \% \\
\text { (C) } 5 \text { subjects }(50 \%) \mathrm{SpO}_{2}< \\
\text { 92\% }\end{array}$ \\
\hline Gore et al, 1996 & $\begin{array}{l}9 \text { Trained, } 11 \text { Untrained } \\
\text { males }\end{array}$ & $\begin{array}{l}\text { Incremental cycling } \\
\text { test to exhaustion }\end{array}$ & $\begin{array}{l}\text { Trained }(\mathrm{T})=5.5 \\
\text { Untrained }(\mathrm{U})=3.9\end{array}$ & $\begin{array}{l}\mathrm{TPaO} \mathrm{P}_{2}=68(30), \mathrm{SpO}_{2}= \\
90(8) \\
\mathrm{U} \mathrm{PaO}_{2}=89(2), \mathrm{SpO}_{2}=95(2)\end{array}$ & Not used & - \\
\hline Hanel et al, 1994 & 7 trained male rowers & $\begin{array}{l}\text { 6-min of "all-out" } \\
\text { rowing }\end{array}$ & 4.4 & $\mathrm{PaO}_{2}=91(14), \mathrm{SpO}_{2}=95(3)$ & Not used. & - \\
\hline Harms and Stager, 1995 & $\begin{array}{l}36 \text { physically active } \\
\text { males }\end{array}$ & $\begin{array}{l}\text { Incremental treadmill } \\
\text { test to exhaustion }\end{array}$ & $\begin{array}{l}\text { Normal }(\mathrm{N})=4.5 \\
\text { Hypoxemic }(\mathrm{H})=4.8\end{array}$ & $\begin{array}{l}\text { (N) } \mathrm{SpO}_{2}=94(3) \\
(\mathrm{H}) \mathrm{SpO}_{2}=88(9)\end{array}$ & Not used & $\begin{array}{l}13 \text { subjects (36\%) } \mathrm{SpO}_{2} \leq 90 \% \text {, } \\
15 \text { subjects (42\%) } \mathrm{SpO}_{2}>92 \%\end{array}$ \\
\hline Harms et al, 1998 & 29 healthy young women & $\begin{array}{l}\text { Incremental treadmill } \\
\text { test to exhaustion }\end{array}$ & 3.4 & $\begin{array}{l}\text { Normal } \mathrm{PaO}_{2}=93, \mathrm{SpO} 2=95 \\
\mathrm{EIH}^{\mathrm{PaO}_{2}}=77, \mathrm{SpO} 2=91\end{array}$ & Oesophageal Temperature & $\begin{array}{l}22 \text { subjects }(76 \%) \Delta \mathrm{PaO}_{2} \\
>10 \mathrm{mmHg}\end{array}$ \\
\hline
\end{tabular}




\begin{tabular}{|c|c|c|c|c|c|c|}
\hline Author & $\begin{array}{l}\text { Subject } \\
\text { Information }\end{array}$ & $\begin{array}{l}\text { Test Type and } \\
\text { Exercise Mode }\end{array}$ & $\begin{array}{l}\dot{\mathrm{VO}} \mathrm{O}_{2} \max \\
\left(\mathrm{L}_{\mathrm{min}}{ }^{-1}\right)\end{array}$ & $\begin{array}{l}\mathrm{PaO}_{2}(\mathrm{mmHg}) \text { or } \mathrm{SaO}_{2} \\
(\%) \text { at } \dot{\mathrm{VO}}_{2} \text { max } \\
\text { (changes from pre- } \\
\text { exercise) }\end{array}$ & $\begin{array}{l}\text { Temperature } \\
\text { Correction site }\end{array}$ & Incidence of EIH \\
\hline Harms et al, 2000 & 25 healthy women & $\begin{array}{l}\text { Incremental treadmill } \\
\text { test to exhaustion }\end{array}$ & 3.3 & $\begin{array}{l}\text { Normal SpO2 = } 94(2) \\
\text { EIH SpO2 = } 90(6) \\
\text { Combined PaO2 = } 82(16)\end{array}$ & Oesophageal Temperature & $\begin{array}{l}15 \text { subjects }(60 \%) \Delta \mathrm{PaO}_{2} \\
>10 \mathrm{mmHg}\end{array}$ \\
\hline $\begin{array}{l}\text { Holmgren and Linderholm, } \\
1958\end{array}$ & 14 male junior cyclists & $\begin{array}{l}\text { Incremental cycling } \\
\text { test to exhaustion }\end{array}$ & $\sim 4.6$ & $\mathrm{PaO}_{2}=79(22)$ & Not used & - \\
\hline Hodges et al, 2005 & 9 healthy males & $\begin{array}{l}\text { Incremental cycle } \\
\text { test to exhaustion }\end{array}$ & 4.9 & $\mathrm{SpO}_{2}=93(5)$ & Not used & $\begin{array}{l}\text { Subjects selected on basis of } \\
\Delta \mathrm{SpO}_{2}>4 \%\end{array}$ \\
\hline $\begin{array}{l}\text { Hopkins and McKenzie, } \\
1989\end{array}$ & $\begin{array}{l}12 \text { competitive male } \\
\text { athletes }\end{array}$ & $\begin{array}{l}5 \text { min treadmill test } \\
\text { at } \dot{\mathrm{VO}}{ }_{2} \max \end{array}$ & 4.6 & $\mathrm{PaO}_{2}=78(29), \mathrm{SpO}_{2}=92(6)$ & Not used & - \\
\hline Hopkins et al, 1994 & $\begin{array}{l}10 \text { high aerobic capacity } \\
\text { athletes }\end{array}$ & $\begin{array}{l}\text { Incremental cycling } \\
\text { test to exhaustion }\end{array}$ & 5.2 & $\mathrm{PaO}_{2}=94(4)$ & Arterial blood temperature & - \\
\hline Hopkins et al, 2000 & 17 active women & $\begin{array}{l}\text { Running and cycling } \\
\text { incremental tests to } \\
\text { exhaustion }\end{array}$ & $\begin{array}{l}\text { Running }(\mathrm{R})=3.0 \\
\text { Cycling }(\mathrm{C})=2.9\end{array}$ & $\begin{array}{l}\mathrm{R} \mathrm{PaO}_{2}=92(18) \\
\mathrm{CPaO}_{2}=104(9)\end{array}$ & Arterial blood temperature & $\begin{array}{l}6 \text { subjects }(35 \%) \mathrm{PaO}_{2}=81- \\
89 \mathrm{mmHg} \\
4 \text { subjects (24\%) } \mathrm{PaO}_{2} \\
\leq 80 \mathrm{mmHg}\end{array}$ \\
\hline $\begin{array}{l}\text { Koskolou and McKenzie, } \\
1994\end{array}$ & $\begin{array}{l}7 \text { competitive male } \\
\text { cyclists }\end{array}$ & $\begin{array}{l}5 \text { min cycle test at } \\
\dot{\mathrm{VO}}_{2} \max \end{array}$ & 4.9 & $\mathrm{SpO}_{2}=96$ & Not used & - \\
\hline Laursen et al, 2005 & 13 male triathletes & $\begin{array}{l}\text { Incremental cycle } \\
\text { and treadmill tests to } \\
\text { exhaustion }\end{array}$ & $\begin{array}{l}\text { Running }(\mathrm{R})=4.6 \\
\text { Cycling }(\mathrm{C})=4.4\end{array}$ & $\begin{array}{l}\mathrm{R} \mathrm{SpO}_{2}=93(4) \\
\mathrm{C} \mathrm{SpO}_{2}=93(4)\end{array}$ & Not used & - \\
\hline Lawler et al, 1988 & $\begin{array}{l}7 \text { Trained, } 6 \text { untrained } \\
\text { males }\end{array}$ & $\begin{array}{l}\text { Incremental cycle } \\
\text { test to exhaustion }\end{array}$ & $\begin{array}{l}\text { Trained }(\mathrm{T})=4.5 \\
\text { Untrained }(\mathrm{U})=3.5\end{array}$ & $\begin{array}{l}\mathrm{T} \mathrm{SpO}_{2}=90(7) \\
\mathrm{USpO}_{2}=96(1)\end{array}$ & Not used & - \\
\hline Legrand et al, 2005 & $\begin{array}{l}19 \text { endurance trained } \\
\text { males }\end{array}$ & $\begin{array}{l}\text { Incremental cycle } \\
\text { test to exhaustion }\end{array}$ & 4.1 & $\begin{array}{l}\text { Normal } \mathrm{SpO}_{2}=95(2) \\
\text { EIH SpO }_{2}=91(6)\end{array}$ & Not used & 10 subjects (53\%) $\mathrm{SpO}_{2}<93 \%$ \\
\hline Lillienthal et al, 1946 & 6 healthy males & $\begin{array}{l}\text { Constant workload } \\
\text { treadmill exercise }\end{array}$ & - & $\mathrm{PaO}_{2}=89(5)$ & Not used & - \\
\hline
\end{tabular}




\begin{tabular}{|c|c|c|c|c|c|c|}
\hline Author & $\begin{array}{l}\text { Subject } \\
\text { Information }\end{array}$ & $\begin{array}{l}\text { Test Type and } \\
\text { Exercise Mode }\end{array}$ & $\begin{array}{l}\dot{\mathrm{VO}} \mathrm{O}_{2} \max \\
\left(\mathrm{L}_{\mathrm{min}}{ }^{-1}\right)\end{array}$ & $\begin{array}{l}\mathrm{PaO}_{2}(\mathrm{mmHg}) \text { or } \mathrm{SaO}_{2} \\
(\%) \text { at } \mathrm{VO}_{2} \text { max } \\
\text { (changes from pre- } \\
\text { exercise) }\end{array}$ & $\begin{array}{l}\text { Temperature } \\
\text { Correction site }\end{array}$ & Incidence of EIH \\
\hline McKenzie et al, 1999 & $\begin{array}{l}13 \text { endurance trained } \\
\text { males }\end{array}$ & $\begin{array}{l}\text { Incremental cycle } \\
\text { tests to exhaustion }\end{array}$ & 4.8 & $\begin{array}{l}\text { Test } 1 \mathrm{SpO}_{2}=91(5) \\
\text { Test } 2 \mathrm{SpO}_{2}=92(4)\end{array}$ & Not used & - \\
\hline Miyachi and Tabata, 1992 & $\begin{array}{l}9 \text { untrained males } \\
22 \text { endurance trained } \\
\text { males }\end{array}$ & $\begin{array}{l}\text { Incremental cycle } \\
\text { test to exhaustion }\end{array}$ & 3.6 & $\mathrm{SpO}_{2}=95(5)$ & Not used & - \\
\hline Mucci et al, 2004 & $\begin{array}{l}12 \text { sportsmen, } 10 \\
\text { sportswomen }\end{array}$ & $\begin{array}{l}\text { Incremental treadmill } \\
\text { test to exhaustion }\end{array}$ & $\begin{array}{l}\text { Males }-3.3 \text { before, } \\
3.6 \text { after training } \\
\text { Females }-2.6 \text { before, } \\
2.8 \text { after training }\end{array}$ & $\begin{array}{l}\text { Normal } \mathrm{SpO}_{2}=96 \text { (3) before, } \\
96 \text { (2) after training } \\
\text { EIH SpO2 = 95 (4) before, } 91 \\
\text { (6) after training }\end{array}$ & Not used & $\begin{array}{l}9 \text { subjects ( } 41 \% \text { ) after training } \\
\Delta \mathrm{SpO}_{2}>4 \%\end{array}$ \\
\hline Mucci et al, 2001 & $\begin{array}{l}18 \text { endurance trained } \\
\text { male athletes and } 10 \\
\text { untrained men }\end{array}$ & $\begin{array}{l}\text { Incremental cycle } \\
\text { test to exhaustion }\end{array}$ & $\begin{array}{l}\text { Trained }=4.8 \\
\text { Untrained }=3.3\end{array}$ & $\begin{array}{l}\text { Normal } \mathrm{PaO}_{2}=103(+5) \\
\text { EIH } \mathrm{PaO}_{2}=89(10) \\
\text { Untrained } \mathrm{PaO}_{2}=113(+13)\end{array}$ & Tympanic Temperature & $\begin{array}{l}9 \text { trained subjects }(50 \%) \Delta \mathrm{PaO}_{2} \\
>8 \mathrm{mmHg}\end{array}$ \\
\hline Nielsen at al, 1998 & 11 competitive rowers & 6 min all-out rowing & 5.0 & $\begin{array}{l}\mathrm{SpO}_{2}=93(5) \\
\mathrm{PaO}_{2}=15.5(+1.5)\end{array}$ & Not used & - \\
\hline Nielsen et al, 2002 & 9 healthy males & Rhythmic handgrip & 5.4 & $\mathrm{SpO}_{2}=98(0)$ & Not used & - \\
\hline Nourry et al, 2004 & 24 prepubertal children & $\begin{array}{l}\text { Incremental cycle } \\
\text { test to exhaustion }\end{array}$ & $\begin{array}{l}\text { Girls }=1.3 \\
\text { Boys }=1.8\end{array}$ & $\begin{array}{l}\text { Normal } \mathrm{SpO}_{2}=96(1) \\
\mathrm{EIH} \mathrm{SpO}_{2}=91(6)\end{array}$ & Not used & $\begin{array}{l}7 \text { subjects ( } 29 \% \text { ), consisting of } \\
5 \text { boys and } 2 \text { girls } \Delta \mathrm{SpO}_{2} \geq 4 \%\end{array}$ \\
\hline Olfert et al, 2004 & $\begin{array}{l}8 \text { female and } 7 \text { male } \\
\text { matched subjects }\end{array}$ & $\begin{array}{l}\text { Incremental cycle } \\
\text { test to exhaustion }\end{array}$ & $\begin{array}{l}3.4 \text { males } \\
3.1 \text { females }\end{array}$ & $\begin{array}{l}\text { Males } \mathrm{SpO}_{2}=98(0), \mathrm{PaO}_{2}= \\
108(+3) \\
\text { Females } \mathrm{SpO}_{2}=98(0), \mathrm{PaO}_{2} \\
=109(+1)\end{array}$ & $\begin{array}{l}\text { Arterial blood temperature } \\
+0.5^{\circ} \mathrm{C}\end{array}$ & - \\
\hline Pedersen et al, 1996 & 8 elite level cyclists & $\begin{array}{l}\text { Incremental cycling } \\
\text { test to exhaustion }\end{array}$ & 5.4 & $\begin{array}{l}\mathrm{PaO}_{2}=82(17) \\
\mathrm{SpO}_{2}=95(3)\end{array}$ & Not used & - \\
\hline Powers et al, 1984 & $\begin{array}{l}7 \text { male and } 2 \text { female } \\
\text { trained, healthy subjects }\end{array}$ & $\begin{array}{l}\text { Incremental arm } \\
\text { cranking and cycle } \\
\text { tests to exhaustion }\end{array}$ & $\begin{array}{l}\text { Males }=3.9 \\
\text { Females = } 2.5\end{array}$ & $\begin{array}{l}\text { Cycle } \mathrm{SpO}_{2}=90(7) \\
\text { Arm Cranking } \mathrm{SpO}_{2}=91(6)\end{array}$ & None used & - \\
\hline
\end{tabular}




\begin{tabular}{|c|c|c|c|c|c|c|}
\hline Author & $\begin{array}{l}\text { Subject } \\
\text { Information }\end{array}$ & $\begin{array}{l}\text { Test Type and } \\
\text { Exercise Mode }\end{array}$ & $\begin{array}{c}\dot{\mathrm{VO}} \mathrm{O}_{2} \max \\
\left(\mathrm{L}_{\mathrm{min}}{ }^{-1}\right)\end{array}$ & $\begin{array}{l}\mathrm{PaO}_{2}(\mathrm{mmHg}) \text { or } \mathrm{SaO}_{2} \\
(\%) \text { at } \dot{\mathrm{VO}}_{2} \text { max } \\
\text { (changes from pre- } \\
\text { exercise) }\end{array}$ & $\begin{array}{l}\text { Temperature } \\
\text { Correction site }\end{array}$ & Incidence of EIH \\
\hline Powers et al, 1988 & $\begin{array}{l}16 \text { Untrained males } \\
27 \text { Moderately trained } \\
\text { males } \\
25 \text { Highly trained males }\end{array}$ & $\begin{array}{l}\text { Incremental cycle } \\
\text { test to exhaustion }\end{array}$ & $\begin{array}{l}\text { Untrained }=3.5 \\
\text { Trained }=4.5\end{array}$ & - & Not used & $\begin{array}{l}14 \text { Highly trained males (52\%) } \\
\text { with } \mathrm{SpO}_{2} \leq 91 \% \\
\text { No }(0 \%) \text { untrained or } \\
\text { moderately trained males }\end{array}$ \\
\hline Powers et al, 1989 & $\begin{array}{l}13 \text { Trained and } 7 \text { Highly } \\
\text { Trained males }\end{array}$ & $\begin{array}{l}\text { Incremental cycle } \\
\text { test to exhaustion }\end{array}$ & $\begin{array}{l}\text { Trained }=3.5 \\
\text { Highly Trained }=5.0\end{array}$ & - & Not used & - \\
\hline Powers et al, 1991 & 6 untrained males & $\begin{array}{l}\text { Incremental cycle } \\
\text { test to exhaustion }\end{array}$ & 3.1 & $\mathrm{PaO}_{2}=92(5)$ & Rectal Temperature & - \\
\hline Powers et al, 1992 & $\begin{array}{l}12 \text { Highly trained } \\
\text { endurance cyclists }\end{array}$ & $\begin{array}{l}\text { Incremental cycle } \\
\text { test to exhaustion }\end{array}$ & 5.5 & $\begin{array}{l}\text { Normal } \mathrm{PaO}_{2}=90(7) \\
\text { Moderate } \mathrm{EIH} \mathrm{PaO}_{2}=84(14) \\
\text { Severe EIH } \mathrm{PaO}_{2}=80(19)\end{array}$ & Arterial temperature & $\begin{array}{l}3 \text { subjects }(25 \%) \Delta \mathrm{PaO}_{2}=13- \\
15 \mathrm{mmHg} \\
5 \text { subjects }(42 \%) \Delta \mathrm{PaO}_{2}>18 \\
\text { mmHg }\end{array}$ \\
\hline Prefaut et al, 1994 & $\begin{array}{l}10 \text { Young athletes (YA) } \\
10 \text { Master controls (MC) } \\
10 \text { Master athletes (MA) }\end{array}$ & $\begin{array}{l}\text { Incremental cycle } \\
\text { test to exhaustion }\end{array}$ & $\begin{array}{l}\mathrm{YA}=4.6 \\
\mathrm{MA}=2.6 \\
\mathrm{MC}=2.1\end{array}$ & $\begin{array}{l}\mathrm{PaO}_{2} \mathrm{YA}=89(14) \\
\mathrm{PaO}_{2} \mathrm{MA}=71(18) \\
\mathrm{PaO}_{2} \mathrm{MC}=93(3)\end{array}$ & Not used & $\begin{array}{l}10 \mathrm{MC}(100 \%), 2 \mathrm{YA}(20 \%) \\
\Delta \mathrm{PaO}_{2}<10 \mathrm{mmHg} \\
4 \mathrm{YA}(40 \%), 6 \mathrm{MA}(60 \%) \\
\Delta \mathrm{PaO}_{2}=10-15 \mathrm{mmHg} \\
4 \mathrm{YA}, 4 \mathrm{MA}(40 \%) \Delta \mathrm{PaO}_{2}>16 \\
\mathrm{mmHg}\end{array}$ \\
\hline Prefaut et al, 1997 & 7 Masters athletes & $\begin{array}{l}\text { Incremental cycle } \\
\text { test to exhaustion }\end{array}$ & 3.6 & $\mathrm{PaO}_{2}=71$ (19) & Not used & $\begin{array}{l}100 \% \text { (from previous } \\
\text { experiment) }\end{array}$ \\
\hline Rasmussen et al, 1991 & $\begin{array}{l}2 \text { female and } 8 \text { male } \\
\text { novice rowers }\end{array}$ & $\begin{array}{l}\text { 6-min all out arm } \\
\text { cranking (AC), } \\
\text { running (R) or } \\
\text { rowing(Ro) }\end{array}$ & 4.5 & $\begin{array}{l}\mathrm{AC} \mathrm{PaO}_{2}=110(+10), \mathrm{SpO}_{2}= \\
\text { 97(1) } \\
\mathrm{R} \mathrm{PaO}_{2}=108(+8), \mathrm{SpO}_{2}= \\
\text { 96(2) } \\
\mathrm{Ro} \mathrm{PaO}_{2}=113(+13), \mathrm{SpO}_{2}= \\
\text { 95(3) }\end{array}$ & Not used & 1 subject $(10 \%) \mathrm{SpO}_{2} \leq 92 \%$ \\
\hline Rice et al, 1999 & $\begin{array}{l}15 \text { competitive male } \\
\text { cyclists }\end{array}$ & $\begin{array}{l}\text { Incremental cycle } \\
\text { test to exhaustion }\end{array}$ & 4.8 & $\begin{array}{l}\mathrm{PaO}_{2}=88(13) \\
\mathrm{SaO}_{2}=95(3) \\
\mathrm{SpO}_{2}=96(3)\end{array}$ & Rectal temperature & $\begin{array}{l}8 \text { subjects (53\%) with } \mathrm{PaO}_{2}< \\
90 \mathrm{mmHg}\end{array}$ \\
\hline
\end{tabular}




\begin{tabular}{|c|c|c|c|c|c|c|}
\hline Author & $\begin{array}{l}\text { Subject } \\
\text { Information }\end{array}$ & $\begin{array}{l}\text { Test Type and } \\
\text { Exercise Mode }\end{array}$ & $\begin{array}{l}\dot{\mathrm{V}} \mathrm{O}_{2} \text { max } \\
\left(\mathrm{L} \cdot \mathrm{min}^{-1}\right)\end{array}$ & $\begin{array}{l}\mathrm{PaO}_{2}(\mathrm{mmHg}) \text { or } \mathrm{SaO}_{2} \\
(\%) \text { at } \mathrm{VO}_{2} \text { max } \\
\text { (changes from pre- } \\
\text { exercise) }\end{array}$ & $\begin{array}{l}\text { Temperature } \\
\text { Correction site }\end{array}$ & Incidence of EIH \\
\hline Rice et al 1999b & 12 highly trained cyclists & $\begin{array}{l}\text { Incremental cycle } \\
\text { test to exhaustion }\end{array}$ & 5.1 & 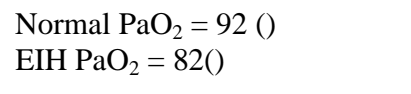 & Arterial Temperature & $\begin{array}{l}7 \text { subjects }(58 \%) \Delta \mathrm{PaO}_{2}> \\
10 \mathrm{mmHg}\end{array}$ \\
\hline Rowell et al, 1964 & 4 sedentary males & $\begin{array}{l}3 \text { min treadmill run at } \\
\dot{\mathrm{V}} \mathrm{O}_{2} \max \end{array}$ & $\begin{array}{l}\text { Untrained }=3.5 \\
\text { Trained }=4.8\end{array}$ & $\begin{array}{l}\text { Before training } \mathrm{SpO}_{2}=93(2) \\
\text { After training } \mathrm{SpO}_{2}=91(4) \\
\text { Varsity Athletes } \mathrm{SpO}_{2}= \\
\text { 85(12) }\end{array}$ & None used & - \\
\hline Sheel et al, 2000 & $\begin{array}{l}18 \text { Highly trained male } \\
\text { cyclists }\end{array}$ & $\begin{array}{l}\text { Incremental cycle } \\
\text { test to exhaustion }\end{array}$ & 4.9 & $\begin{array}{l}\text { Normal } \mathrm{SpO}_{2}=94(3) \\
\mathrm{EIH} \mathrm{SpO}_{2}=90(8)\end{array}$ & - & - \\
\hline St. Croix et al, 1998 & 28 Healthy women & $\begin{array}{l}\text { Incremental and } \\
\text { constant-load tests to } \\
\text { exhaustion }\end{array}$ & 3.4 & $\begin{array}{l}\text { Normal } \mathrm{SpO}_{2}=95(1), \mathrm{PaO}_{2}= \\
95(5) \\
\text { EIH SpO } \\
(22)\end{array}$ & Oesophageal temperature & $\begin{array}{l}22 \text { subjects }(79 \%) \Delta \mathrm{PaO}_{2}> \\
10 \mathrm{mmHg}\end{array}$ \\
\hline Stuessi et al, 2001 & $\begin{array}{l}28 \text { healthy subjects, } 15 \\
\text { control, } 13 \text { respiratory } \\
\text { muscle training (RMT) }\end{array}$ & $\begin{array}{l}\text { Constant load test } \\
\left(70 \% \dot{\mathrm{VO}}_{2} \max \right) \text { to } \\
\text { exhaustion }\end{array}$ & 2.4 & $\begin{array}{l}\text { RMT } \mathrm{PaO}_{2}=86(4) \\
\text { Control } \mathrm{PaO}_{2}=89(2)\end{array}$ & Not used & - \\
\hline Todaro et al, 1995 & 6 highly trained cyclists & $\begin{array}{l}\text { Incremental cycle } \\
\text { test to exhaustion }\end{array}$ & 4.9 & $\begin{array}{l}\text { Normal } \mathrm{PaO}_{2}=93(0) \\
\text { EIH } \mathrm{PaO}_{2}=72(19)\end{array}$ & Not used & 5 subjects (83\%) \\
\hline Turcotte et al, 1997 & $\begin{array}{l}24 \text { male endurance } \\
\text { athletes }\end{array}$ & $\begin{array}{l}\text { Incremental cycle } \\
\text { test to exhaustion }\end{array}$ & 4.2 & $\begin{array}{l}\text { Normal } \mathrm{SpO}_{2}=93 \\
\mathrm{EIH} \mathrm{SpO}_{2}=88\end{array}$ & Not used & 13 subjects $(54 \%) \mathrm{SpO}_{2}<91 \%$ \\
\hline Warren et al, 1991 & 16 males & $\begin{array}{l}\text { Incremental cycle } \\
\text { test to exhaustion }\end{array}$ & 4.9 & $\begin{array}{l}\mathrm{PaO}_{2} \text { at } 80 \% \dot{\mathrm{VO}}{ }_{2} \max =85 \\
(15)\end{array}$ & Sublingual temperature & 9 subjects (56\%) $\mathrm{SpO}_{2} \leq 90 \%$ \\
\hline Wetter et al, 2001 & 17 trained females & $\begin{array}{l}\text { Constant load tests } \\
\left(90 \% \dot{\mathrm{VO}}_{2} \max \right) \text { to } \\
\text { exhaustion }\end{array}$ & 2.9 & $\begin{array}{l}\text { High } \mathrm{PaO}_{2}=93(1) \\
\text { Low } \mathrm{PaO}_{2}=79(26)\end{array}$ & Oesophageal Temperature & $\begin{array}{l}7 \text { subjects }(41 \%) \Delta \mathrm{PaO}_{2}> \\
10 \mathrm{mmHg}\end{array}$ \\
\hline
\end{tabular}




\begin{tabular}{|c|c|c|c|c|c|c|}
\hline Author & $\begin{array}{l}\text { Subject } \\
\text { Information }\end{array}$ & $\begin{array}{l}\text { Test Type and } \\
\text { Exercise Mode }\end{array}$ & $\begin{array}{l}\dot{\mathbf{V}} \mathbf{O}_{2} \max \\
\left(\text { L. } \text { min }^{-1}\right)\end{array}$ & $\begin{array}{l}\mathrm{PaO}_{2}(\mathrm{mmHg}) \text { or } \mathrm{SaO}_{2} \\
(\%) \text { at } \dot{\mathrm{VO}}_{2} \text { max } \\
\text { (changes from pre- } \\
\text { exercise) }\end{array}$ & $\begin{array}{l}\text { Temperature } \\
\text { Correction site }\end{array}$ & Incidence of EIH \\
\hline Wetter et al, 2002 & $\begin{array}{l}9 \text { male, } 8 \text { female } \\
\text { endurance trained } \\
\text { athletes }\end{array}$ & $\begin{array}{l}\text { Incremental treadmill } \\
\text { test to exhaustion }\end{array}$ & $\begin{array}{l}\text { Males }=4.7 \\
\text { Females }=3.0\end{array}$ & $\begin{array}{l}\mathrm{SpO}_{2}=92(6) \\
\mathrm{PaO}_{2} \text { Male }=78, \text { Female }=82\end{array}$ & Oesophageal temperature & - \\
\hline $\begin{array}{l}\text { Whipp and Wasserman, } \\
1969\end{array}$ & 5 normal males & $\begin{array}{l}\text { Incremental cycle } \\
\text { test to exhaustion }\end{array}$ & 3.3 & $\mathrm{PaO}_{2}=97(0)$ & Rectal temperature & - \\
\hline Williams et al, 1986 & $\begin{array}{l}10 \text { Highly trained male } \\
\text { runners } \\
7 \text { untrained males }\end{array}$ & $\begin{array}{l}\text { Incremental } \\
\text { exhaustive and } \\
\text { constant load ( } 95 \% \\
\dot{\mathrm{VO}}_{2} \text { max) treadmill } \\
\text { tests }\end{array}$ & $\begin{array}{l}\text { Runners }(\mathrm{R})=4.6 \\
\text { Untrained }(\mathrm{U})=3.4\end{array}$ & $\begin{array}{l}\text { Maximal exercise } \\
\mathrm{R} \mathrm{SpO2}=86(11) \\
\mathrm{U} \text { SpO2 }=94(3) \\
\text { Constant load } \\
\text { R SpO2 = } 87(9) \\
\text { U SpO2 = 93 (4)) }\end{array}$ & Not used & - \\
\hline
\end{tabular}

Table1.1 Current status of research into exercise induced hypoxaemia in humans. 


\subsubsection{Gender}

While the majority of studies in EIH have concentrated on the incidence and mechanism of this phenomenon in young male athletes, a small body of work regarding EIH in women does exist. Harms, McClaran et al (1998) performed a thorough investigation into the aetiology and incidence of EIH in 29 healthy women. The women had a $\dot{\mathrm{VO}}_{2}$ max range from $93-188 \%$ of their predicted value and performed a maximal exercise test to exhaustion during which blood gas samples were regularly withdrawn and subsequently corrected for oesophageal temperature changes during exercise. The authors demonstrated 22 of the 29 subjects (76\%) developed significant hypoxaemia, using a drop in $\mathrm{PaO}_{2}$ of $>10 \mathrm{mmHg}$ as the difference between normal subjects and EIH sufferers. While the relatively high incidence of EIH in this group was significant, even more so was the discovery that half of these 22 subjects had a $\dot{\mathrm{V}} \mathrm{O}_{2}$ max within $15 \%$ of their predicted normal value, a finding not supported in studies utilising male subjects. The authors suggested that as women have a smaller vital capacity, diffusion surface, reduced airway diameter and lower total haemoglobin, even for height, mass and age matched males (Mead, 1980; Schwartz, Katz et al, 1988; Thurlbeck, 1982), they may be especially vulnerable to pulmonary limitations during exercise. In a further study, utilising a cohort of these same subjects (28 of the 29), St Croix, Harms and colleagues (1998) assessed the effect of prior exercise on EIH in these women, and reported a decreased hypoxaemic response (improved $\mathrm{PaO}_{2}$ ) to a constant load exercise test following a maximal test. As mentioned previously, the authors concluded that 
the existence of EIH in these subjects could not be attributed to a mechanism or mechanisms that persisted long after the cessation of exercise or which is aggravated by subsequent exercise bouts, a theory which opposes a suggested stress failure of the capillary endothelium as a proposed mechanism. Additionally, the authors theorised EIH in these subjects must be due to a functionally based mechanism which is only present during the actual exercise bout.

Whilst the initial research by Harms et al (1998) was extremely thorough in its methodology, research since this publication has not reproduced the relatively high incidence of EIH in female subjects. In attempting to evaluate the effect of EIH on $\dot{\mathrm{VO}}_{2}$ max in women, Harms, McClaren and co-workers (2000) tested 25 competitive runners in duplicate incremental exercise tests, one at $\mathrm{F}_{\mathrm{I}} \mathrm{O}_{2}=21 \%$ and one at $\mathrm{F}_{\mathrm{I}} \mathrm{O}_{2}=26 \%$. Of these subjects, 10 maintained a $\mathrm{PaO}_{2}$ within $10 \mathrm{mmHg}$ of resting values at maximal exercise intensity, whilst the remaining 15 reduced their $\mathrm{PaO}_{2}$ to $67-88 \mathrm{mmHg}$. This is a significantly lower percentage of EIH sufferers than noted in their initial cohort (60\% compared to 76\%) yet the methodologies employed by the authors in their determination of results and the subject fitness levels were almost identical.

Further studies regarding the existence and / or effect of EIH in females have provided a varied range of levels of incidence. In comparison to the $76 \%$ found by Harms, McClaran et al (1998), Mucci, Blondel and colleagues (2004) found no incidence of EIH in the 10 female subjects they tested. This number was increased to two, however, following an intense 8-week high-intensity training period, again linking the effect of training, $\dot{\mathrm{VO}}_{2}$ max and the occurrence 
of EIH, but failing to reproduce the high incidence seen previously. The fact that the sportswomen tested by Mucci and co-workers (2004) had a significantly lower $\dot{\mathrm{VO}}_{2}$ max, and that their EIH status was designated by a drop in oximeter readings of $>4 \% \mathrm{SpO}_{2}$, however, makes direct comparison more difficult.

Two separate research articles have cited the hyperventilation of subjects during the preparation phase as reason not to utilise any resting $\mathrm{PaO}_{2}$ measurements obtained in calculating EIH (Hopkins, Barker et al, 2000; Wetter, St Croix et al, 2001). Instead the authors chose to set a threshold for $\mathrm{PaO}_{2}$ to group their subjects as normal or as exercise-induced hypoxaemic. Wetter and co-authors (2001) obtained arterial blood samples and corrected them for oesophageal temperature in 17 female runners. Following an incremental $\dot{\mathrm{VO}}_{2}$ max test the subjects were separated into 2 groups; those whose $\mathrm{PaO}_{2}$ exceeded $80 \mathrm{mmHg}$ at the highest workload (HIGH, $\mathrm{n}=9$ ), and those whose values were $\leq 80 \mathrm{mmHg}$ (LOW, $\mathrm{n}=8$ ). Of the LOW group, 7 of the 8 subjects had a reduction in $\mathrm{PaO}_{2}$ of $>10 \mathrm{mmHg}$, showing that whilst a general cut-off point to define EIH may be somewhat practical it does not distinguish between those that have undergone significant changes in $\mathrm{PaO}_{2}$ and those who have not. Again this incidence is somewhat lower than that shown by Harms and co-workers ( 45\%).

In defining those with and those without EIH, Hopkins, Barker and colleagues (2000) utilised three cut-off points and assumed resting $\mathrm{PaO}_{2}$ to be $\sim 100 \mathrm{mmHg}$. Those with no EIH said to have a $\mathrm{PaO}_{2} \geq 90 \mathrm{mmHg}$, those with mild $\mathrm{EIH}$ a $\mathrm{PaO}_{2}$ between 81 and $89 \mathrm{mmHg}$, and those with severe $\mathrm{EIH} \mathrm{a} \mathrm{PaO}_{2}$ less than or equal to $80 \mathrm{mmHg}$. This resulted in no fewer than 10 of the 17 subjects (59\%) tested being designated to one of the EIH groups. Again, this 
cut-off, not unlike that used by Wetter et al (2001), is problematic in that resting $\mathrm{PaO}_{2}$ is an extremely individual variable and normal resting values have been seen in the high nineties and low eighties, allowing significant error to be introduced in the calculation of the rate of incidence of EIH in females.

Whilst the actual incidence of the existence and prevalence of EIH in females is of some debate, all previously cited research with females is unanimous as to the belief that EIH occurs at a generally lower $\dot{\mathrm{VO}}_{2}$ compared with males, and it is likely that the lower lung size of females (Olfbert, Balouch et al, 2004), a diffusion limitation due to a lower haemoglobin (Hopkins and Harms, 2004), and flow limitation (leading to reduced minute ventilation) are more important in determining whether an impairment of gas exchange occurs during exercise than sex, per se.

\subsubsection{Age}

Exercise-induced hypoxaemia has been shown to occur in cohorts outside of the predominantly young, highly-trained athletic population. Whilst there is little research regarding its existence in the very young (Laursen, Tsang et al, 2002; Nourry, Fabre et al, 2004), it has been shown to exist in master athletes (Masse-Biron, Mercier et al , 1990; Anselme, Caillaud et al, 1994; Prefaut, Anselme et al, 1994; Aguilaniu, Flore et al , 1995; Prefaut, Anselme-Poujol, et al, 1997; Aguilaniu, Flore et al , 1998; Mucci, Prioux et al, 1998).

Current research into EIH in children is inconclusive as to its prevalence. Laursen, Tsang and co-workers (2002) sampled 19 active prepubescent females with a maximal aerobic power similar to that of adult women exhibiting EIH 
( $\dot{\mathrm{VO}}_{2} \max \sim 43 \mathrm{~mL} \cdot \mathrm{kg}^{-1} \cdot \mathrm{min}^{-1}$; Harms, McClaran et al, 1998). The authors were unable to elicit a hypoxemic response (as measured by $\mathrm{SaO}_{2}$ ) in any of the subjects despite all completing a maximal-effort incremental cycling test. More recent research (Nourry, Fabre et al, 2004) has, however, discovered evidence of EIH in both prepubescent males and females undertaking regular sportive training and/or competition. Twenty six children (age $=10.2 \pm 0.2 \mathrm{y}$ ) performed an incremental cycling test to exhaustion with a drop of at least $4 \%$ or greater of $\mathrm{SaO}_{2}$ (as measured by pulse ear oximetry) satisfying the criteria for EIH. Of the 26 subjects, 7 (30\%) were classed as exhibiting EIH, with 5 boys and 2 girls making up this hypoxaemic group. Whilst all other pulmonary parameters were the same between the EIH and non-EIH subjects, the EIH boys and girls showed statistically smaller FVC and breathing reserve (BR). The authors suggested the appearance of EIH characteristics in this cohort was due to the higher level of training the subjects were involved in compared with the "active" subjects utilised in the study by Laursen and colleagues (2002). The authors suggested no cohort-relative cause/s of the hypoxaemia, above those usually associated with EIH in adults, including the effect of smaller lung size.

It is well known that as we age we reduce our maximal aerobic power due to a reduction in such parameters as maximal heart rate, pulmonary ventilation and muscle strength (Åstrand and Rodahl, 1986). It has been shown that as we age we also decrease the normal resting level of $\mathrm{PaO}_{2}$ (Crapo, Jensen et al, 1999), such that a normal $\mathrm{PaO}_{2}$ of $100 \pm 5 \mathrm{mmHg}$ for $19-24$ year olds decreases to an average value under $89 \mathrm{mmHg}$ for subjects over 64 years of age. It is therefore imperative that this age-related drop in resting $\mathrm{PaO}_{2}$ is taken into 
account when classifying older test subjects for EIH, such that an excessive incidence is not reported.

Studies have revealed that the older master athletes undergo a similar or increased incidence of EIH when compared with less active, similarly aged people and younger athletes (Masse-Biron, Mercier et al, 1990; Prefaut, Anselme et al, 1994). It has been hypothesised that these older athletes are more susceptible to the phenomenon due to a number of factors including a relative hypoventilation (Prefaut, Anselme at al, 1994), an increased $\mathrm{PCO}_{2}$ threshold (Mucci, Prioux et al, 1998), mild transient pulmonary oedema (Prefaut, Anselme-Poujol et al, 1997) and / or a reduced pulmonary capillary transit time due to a decreased lung size (Masse-Biron, Mercier et al, 1990). Whilst there is a paucity of data on master athletes / older subjects and the prevalence of EIH, Masse-Biron and co-workers (1990) investigated the existence of haemoglobin desaturation and reported a $67 \%$ incidence of desaturation (a decrease in $\mathrm{SaO}_{2}$ of $>4 \%$ ) in both incremental and constant load exercise tests. Four years later, Prefaut and colleagues (1994) examined 10 master athletes and compared them with 10 young athletes and 10 inactive, older subjects. Every master athlete exhibited EIH in comparison to 8 of the 10 young athletes and none of the agematched, inactive individuals. Furthermore, the magnitude of the EIH was larger, elicited at a lower percentage of $\dot{\mathrm{VO}}_{2}$ max and regardless of the lower training regimen compared to the young athletes.

Mucci, Anselme-Poujol et al (1999) also found a significant decrease in $\mathrm{PaO}_{2}$ in older athletes whilst examining the connection between histamine and $\mathrm{EIH}$, an interconnection postulated from previous work by this group of authors 
(Anselme, Caillaud et al, 1994; Prefaut, Anselme-Poujol et al, 1997). The previous research (Anselme et al, 1994) had shown that histamine release was increased in both young and masters-aged athletes demonstrating a hypoxemic response to exercise. Whilst not assessed for master athletes, this finding was disputed in young EIH athletes by Wetter, Xiang et al in 2002. Further research (Prefaut, Anselme-Poujol et al, 1997) with older athletes, however, supported the increased release of histamine during intense exercise in this cohort and, furthermore, demonstrated increased $\mathrm{PaO}_{2}$ levels during exercise following administration of a histamine-release inhibitor.

The effect of age on the physiology of man is well documented and understood, however evidence of an abnormal incidence of EIH in prepubescent and older athletes is difficult to substantiate given the low numbers of such athletes that have currently been tested. The mechanisms by which EIH occurs in older athletes remains somewhat elusive, as with those of younger athletes; however, the possibility of a multifactorial cause is not to be discounted. It must also be remembered that, with changes in the body due to ageing, an applicable level of resting $\mathrm{PaO}_{2}$ and $\mathrm{SaO}_{2}$ must always be used as a baseline in older athletes.

\subsubsection{Exercise Modality}

The two most utilised modes of exercise within the laboratory setting are the cycle ergometer and the treadmill. Studies into the differences in maximal oxygen consumption rates have shown that this variable does not differ with exercise modality (Medelli, Maingourd et al, 1993; Laursen, Rhodes et al, 2005, 
Caputo and Denadai, 2006) or is higher in running than cycling (Thys, Dreezen et al, 1979; Pannier, Vrijens et al, 1980; Kohrt, Morgan et al, 1987; Schneider, Lacroix et al, 1990; Schneider and Pollack, 1991; Gavin and Stager, 1999; Basset and Boulay, 2000). Studies that have utilised triathletes as subjects (Kohrt, Morgan et al, 1987; Medelli, Maingourd et al, 1993; Basset and Boulay, 2000; Laursen, Rhodes et al, 2005; Caputo and Denadai, 2006) and hence eliminated the specificity of training effect and efficiency are still unable to agree on the effect of mode of exercise and those authors looking specifically at the effect of exercise mode on the occurrence and severity of EIH are also divided (Gavin and Stager, 1999; Rice, Scroop et al, 2000; Galy, Le Gallais et al. 2005; Laursen, Rhodes et al, 2005). Given this evidence it would seem prudent to utilise treadmill running as the exercise modality when testing EIH levels in athletes as they are expected to be at least as prone, if not more so, to experiencing this phenomenon.

\subsection{EFFECT OF EXERCISE - INDUCED HYPOXEMIA ON PERFORMANCE}

The main interest in EIH during exercise is a result of its possible effect on the performance of athletes during exercise. It has been supposed that the reported decreases in $\mathrm{SaO}_{2}$ and $\mathrm{PaO}_{2}$ during exercise in athletes will lead to compromised provision of oxygen to the working muscles (Dempsey and Wagner, 1999) which may in turn cause an increased level of anaerobic energy 
production, increased metabolic acidosis (Koskolou and McKenzie, 1994) and a resultant reduced time to exhaustion or reduced power production.

Koskolou and McKenzie (1994) artificially induced hypoxemia in 7 highly trained cyclists, reducing their normal $\mathrm{SaO}_{2}$ of $94 \%$ to $90 \%$ and $87 \%$ under mild and moderate hypoxemic conditions, respectively. Only the moderately hypoxemic conditions produced a significant reduction in total work output, with $\dot{\mathrm{VO}}_{2}$ remaining the same irrespective of the conditions. Whilst the authors propose that at or beyond the level of desaturation produced under moderate hypoxemic conditions the athletes' performance is compromised, the artificial conditions and the methodology of testing for EIH makes it impracticable to predict the natural effect of EIH on a subjects' performance. A more relevant project by Harms and colleagues (2000) prevented the exercise-induced desaturation of haemoglobin in a group of 25 healthy young women. By increasing inspired $\mathrm{PO}_{2}$ to $198 \mathrm{mmHg}\left(\mathrm{FIO}_{2}=26 \%\right)$ the average end $\mathrm{SaO}_{2}$ was increased from $\sim 92 \%$ to $\sim 97 \%$, with a concurrent increase in $\dot{\mathrm{VO}}_{2}$ max and increased maximal work rate. The authors distinguished between those who underwent a significant level of desaturation $\left(\mathrm{SaO}_{2} \leq 92 \%, \mathrm{n}=15\right)$ and those whose $\mathrm{SaO}_{2}$ remained at normal levels $\left(\mathrm{SaO}_{2} \geq 93 \%, \mathrm{n}=10\right)$, and observed an increased $\dot{\mathrm{VO}}_{2}$ max in 22 of the 25 subjects and a corresponding increase in maximal work rate. In conclusion, Harms and co-workers postulated that EIH (a reduction of $\mathrm{SaO}_{2}$ of $>3 \%$ below rest) causes a decrease in $\mathrm{VO}_{2}$ max of $2 \%$ for every $1 \%$ drop in arterial haemoglobin saturation; however, it seems this conclusion stems from a somewhat erroneous analysis of changes on $\dot{\mathrm{VO}}_{2}$ max whereby the authors regarded any change in $\dot{\mathrm{VO}}_{2}$ max above zero to be 
undeniable proof of improvement without consideration to inherent methodological or scientific error.

In a similar experiment in 1989, Powers, Lawler et al (1989) observed the effect of desaturation on the $\dot{\mathrm{VO}}_{2}$ max of 20 trained athletes. As with Harms et al (2000), the athletes were divided into 2 groups, the cut-off $\mathrm{SaO}_{2}$ being 92\%, and the effect of an $\mathrm{FIO}_{2}$ of $26 \%$ on $\dot{\mathrm{VO}} 2$ max investigated. An increased $\dot{\mathrm{VO}}_{2}$ max was observed in the EIH group breathing 26\% oxygen, the authors calculating that a decline of $1 \%$ of $\dot{\mathrm{VO}}_{2}$ max per $1 \%$ decrease in haemoglobin saturation below 92\% would occur in the EIH athletes.

More recently, Grataloup, Prieur and co-workers (2005) investigated the effect of an $\mathrm{FIO}_{2}$ of $30 \%$ on a group of 16 cyclists; 7 of which maintained normal haemoglobin saturation levels during maximal exercise and 9 subjects whose $\mathrm{SaO}_{2}$ decreased by $>5 \%$ under the same conditions (EIH). The authors demonstrated a significantly greater $(\mathrm{P}<0.001)$ increase in $\dot{\mathrm{VO}}_{2}$ max in the EIH subjects compared to the normal subjects ( $12.8 \mathrm{v} 4.2 \%$, respectively) however, maximal power was only moderately improved ( 3\%), and was consistent for both EIH and normal subjects. Maximum values for heart rate, minute ventilation, RER and lactate production did not change significantly from normoxic values following hyperoxia which may indicate an efficiency in the utilisation of available oxygen in the EIH subjects which exceeds that of the normal subjects. Investigation into the arterial oxygen content $\left(\mathrm{CaO}_{2}\right)$ of these two groups demonstrates a proportionally larger increase in the EIH group (7.6 v 
3.0\%) with hyperoxia; however the authors do not suggest why this greater increase in $\mathrm{CaO}_{2}$ does not lead to a greater increase in maximal power.

Whilst current research presents an accord on the effect of supplemental oxygen on the $\dot{\mathrm{VO}}_{2}$ max of those who undergo haemoglobin desaturation during heavy or maximal exercise, there is no consistent effect shown with regard to an improved performance beyond that of normal subjects. Furthermore, there is no indication that the desaturation observed in the EIH-classified subjects has a detrimental effect on their performance, regardless of their reduced $\dot{\mathrm{VO}}_{2}$ max. More so, it is well known that $\dot{\mathrm{VO}}_{2}$ max is not the ultimate predictor of performance (Kanstrup and Ekblom, 1984; Sjodin and Svedenhag, 1985; Scrimgeour, Noakes et al, 1986; Greenhaff, Greeson et al, 1988; Peltonen, Rantamaki et al, 1995) which indicates the effect of this desaturation on exercise performance at a competitive level is still in need of further research.

\subsection{MEASUREMENT OF OXYGEN LEVELS IN BLOOD}

The measurement of changes to the oxygenation of blood can be performed both directly and indirectly. The measurement of haemoglobin saturation (percent of oxygenated haemoglobin, $\% \mathrm{SaO}_{2}$ ) by pulse oximetry results in the indirect estimation of this variable (also known as $\mathrm{SpO}_{2}$ ) and is more prone to errors stemming from outside influences (ambient light, probe placement, movement artefact) and the method of measurement as compared to 
the direct measurement which requires a blood sample to be taken. Whilst the accuracy of pulse oximetry has been shown to sufficiently demonstrate qualitative changes in $\mathrm{SaO}_{2}$ (Poppius and Viljanen, 1977; Ries, Farrow et al, 1985; Smyth, D’Urzo et al, 1986; Wood, Gore et al, 1997; Rice, Scroop et al, 1999, Beck and Weisman, 2002) it is still widely acknowledged that measurement of $\mathrm{SaO}_{2}$ and $\mathrm{PaO}_{2}$ are best measured directly with arterial blood samples (Brown, Knowlton et al, 1993; McGovern, Sasse et al, 1996; Rice, Scroop et al, 1999; American Association for Respiratory Care, 2001; American Thoracic Society, 2003).

With regard to the use of pulse oximetry to detect EIH, Dempsey and Wagner (1999) suggest that, as the majority of subjects would not undergo a $>10 \%$ drop in $\mathrm{SaO}_{2}$ during their exercise bouts, any changes in the oxygenation levels of the blood occur on the relatively flat portion of the oxyhaemoglobin dissociation curve. This makes it almost impossible to accurately quantify any change in $\mathrm{PaO}_{2}$ using pulse oximetry as it may be greatly more influenced by exercise than the $\mathrm{SaO}_{2}$ within this range. Therefore the collection of arterial blood samples for the direct measurement of $\mathrm{PaO}_{2}$ and $\mathrm{SaO}_{2}$ will allow considerably more accurate measurement of changes to the blood gas status of an athlete exercising at an intensity capable of causing hypoxaemia and/or haemoglobin desaturation.

\subsubsection{Reproducibility of Blood Gases during Exercise}

Whilst the reproducibility of such measurements as $\dot{\mathrm{VO}}_{2}$ max and maximal power output are well known (Aunola and Rusko, 1984; McLellan and Jacobs, 
1993; Billat, Renoux et al, 1995; Johnston, Jenkins et al, 2005), that of the arterial blood gas response to exercise in healthy, well-trained athletes is undocumented. Various authors (Yoshida, Udo et al, 1989a and b; Anselme, Caillaud et al, 1994; Prefaut, Anselme-Poujol et al, 1997; Aguilaniu, Flore et al, 1998; Durand, Mucci et al, 1999; McKenzie, Lama et al, 1999) have used subjects in multiple experiments based on their displaying EIH in a single exercise test. These tests have either been on the same day to assess the effect of prior exercise or following a confounding treatment with the exercise test performed at a later date, without any reference as to the reproducibility of the athletes' blood gas response.

The reproducibility of blood gas measurements has been tested on resting individuals (Ladegaard-Pedersen, 1978) where a sample of arterial blood was taken from each of the subjects' arms and compared. The author utilised 30 subjects, some of whom were ventilated such that changes in respiratory rate would not influence blood gas results and found that the standard deviation of $\mathrm{PO}_{2}$ was $4.4 \mathrm{mmHg}$ for between-arm samples whilst duplicate analysis of a sample produced a standard deviation of only $2.5 \mathrm{mmHg}$. With regard to sampling error, Kampelmacher and colleagues (1997) performed multiple analyses of a single blood sample (anaerobically stored on ice) on different equipment and concluded that the variability of the results depends more on the pre-analytical phase of blood gas analysis than the analyser or measurement technique. In comparison with Laadegard-Pedersen (1978), this experiment resulted in a standard deviation of only $0.3 \mathrm{mmHg}$ for the repeat analysis of a 
sample which may be due to improved sampling technique and / or improved gas analyser equipment.

In a recent experiment by Hodges, Lynn and co-workers (2005), 9 healthy males were assessed during repeated incremental cycle test to exhaustion. Whilst arterial blood samples were not taken (pulse oximetry was used) the subjects all met the selection criterion of exhibiting a reproducible change in $\mathrm{SpO}_{2}$ of greater than $4 \%$ from rest during exercise during both maximal tests. During the placebo arm of the experiment however, at least two of the subjects showed a significantly reduced reduction in oxyhaemoglobin saturation whereby their $\% \mathrm{SpO}_{2}$ did not meet the reproducibility selection criteria. Whilst this was not acknowledged by the authors in the comparison of treatment arms, the shortcoming of not utilising ABG analysis for EIH assessment was noted.

\subsection{BODY TEMPERATURE AT REST AND DURING EXERCISE}

\subsubsection{Body Temperature Regulation at Rest}

The maintenance of the body's temperature is essential to ensure the efficient operation of biochemical reactions that, in turn, preserve homeostasis. In the resting state, the human body is able to regulate internal body temperature to within a single degree Celsius under most conditions and, to do so, detects internal and external temperature changes and responds in an opposing manner to either cool the body or produce heat. 
Thermal regulation is controlled by an almost entirely nervous feedback from both peripheral and central receptors with the overall regulation centred in the hypothalamus. This area, located in the anterior hypothalamus, has been termed the preoptic area (POAH) and contains both heat sensitive and heatinsensitive neurons. Whilst this area is able to sense local changes in brain temperature and take corrective action to maintain a stable temperature, it also receives afferent sensory information from thermoreceptors throughout the body (peripheral thermoreceptors; e.g spinal cord, skin) (Boulant and Hardy, 1974). By integrating the input received from local and peripheral thermoreceptors the POAH is able to adjust its output for the thermoregulatory response that is most appropriate for maintaining body temperature.

In cold conditions, the "cold" receptors in the skin and some mucous membranes feed afferent nerve impulses into the POAH. In response the sympathetic system is stimulated, leading to heat conserving responses such as skin vasoconstriction, piloerection, increased muscle tone (and if cold enough, shivering) and thyroxine secretion. Of these, thyroxine secretion is a predominantly chronic response leading to adaptation to cold conditions. The increased thyroxine secretion is caused when the neurosecretory hormone thyrotropin-releasing hormone is released from the hypothalamus and is transported to the adenohypophysis via the hypothalamic portal veins. This leads to the stimulation of the secretion of thyroid-stimulating hormone (TSH), and once the thyroid gland has adapted to the increased stimulus by increasing size, the increased release of thyroxine. Increased thyroxine production, in turn, leads to an increase in cellular metabolism by stimulating the breakdown of fat 
in the body. The metabolic rate is also increased by its effect on the stimulation of beta receptors for epinephrine and norepinephrine, hormones which stimulate the catabolism of glycogen and triglycerides.

The acute response in cold conditions causes an increase in vasoconstriction through the stimulation of the vasomotor centre of the brainstem by the posterior hypothalamus. The sympathetic vasoconstrictor transmitter substance norepinephrine also increases vasoconstriction, acting on the smooth muscles of the vessels. Shivering in cold conditions is driven by signals from the skin and the spinal cord. The primary motor centre for shivering is activated (it is normally inhibited by heat signals from the preoptic area) and transmits signals to the anterior motoneurons via the brainstem. These signals pass into the lateral columns of the spinal cord which leads to an increase in muscle tone. Above a critical activation threshold the increased tone lends to shivering which has the effect of increasing metabolic rate up to 5 times that of normal.

In conditions where the body is being warmed, either by external heat or by muscular activity, the "warm" receptors in the preoptic area of the anterior hypothalamus are stimulated. The stimulus of heat is detected in numerous receptor sites in the skin, the central nervous system, the spinal cord, and other sites such as the abdomen, deep leg veins and the abdomen (Hensel, 1974); however, the preoptic area is also sensitive to local increases in temperature (Cabanac, 1975). Stimulation of the preoptic area has, as occurs in the cold response, multiple effects which integrate to dissipate excess heat in the body. The two dominant responses to a heat stimulus are an increase in sweating rate 
and increased vasodilation. Full vasodilation can increase the transfer of heat to the skin by up to 8 fold and is caused by the inhibition of the sympathetic centres in the posterior hypothalamus which cause vasoconstriction. Coupled with this increase in skin blood flow is an increased sweating rate. The heat-induced stimulation of the preoptic area causes increased firing of efferent neurons to the sweat glands which in turn increase the release of sweat.

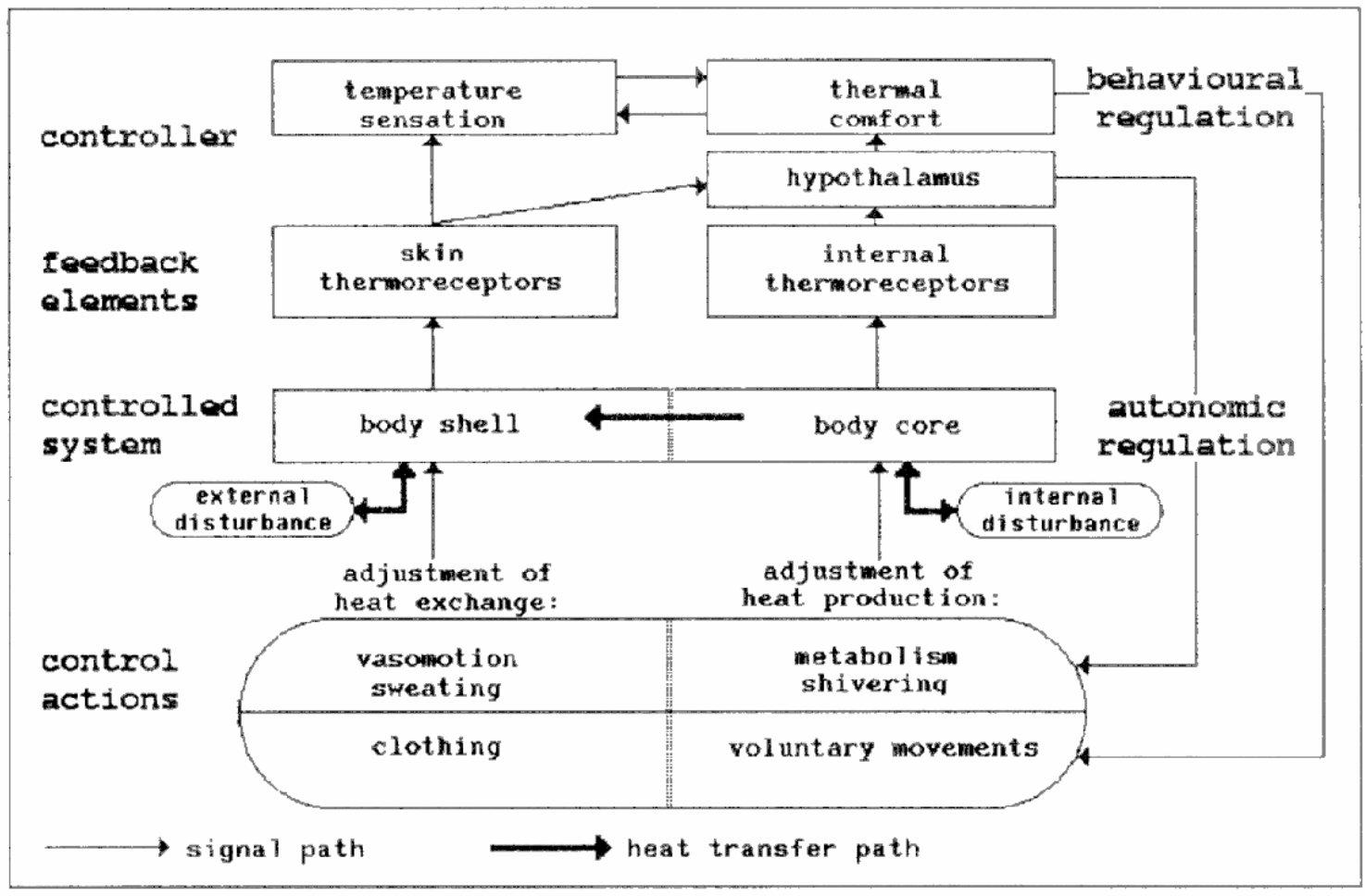

Figure 1.4 Control mechanisms for body temperature regulation

As shown in Figure 1.4, the control processes required to regulate temperature changes by the body is complex; however, there are few conditions under which the body's normal resting temperature is unable to be maintained, the most common of which are fever and exercise (Boulant, 2000), where the temperature of the body may increase up to $40^{\circ} \mathrm{C}$ or more for a short period of 
time. Of interest in this thesis is the effect of an incremental exercise test on body temperature, both central and peripheral and its corresponding impact on oxygen delivery and uptake.

\subsubsection{Body Temperature During Exercise}

Whilst the term “core” temperature has regularly been used in exercise physiology research, usually denoting some integrated deep body temperature, the entire body is a system of thermal gradients from the body's trunk and head to the extremities of the limbs that differ in magnitude quite significantly, depending on ambient temperature (Aschoff and Wever, 1958). At rest, rectal temperature, measured at least $8 \mathrm{~cm}$ from the anal sphincter, is approximately $37^{\circ} \mathrm{C}$ and is the classic measurement site for most studies looking at changes in body temperature. Rectal temperature is almost identical to that measured in the hypothalamus, responds to temperature changes in the same magnitude as this central thermoregulatory area and, as such, it has been considered to be representative of the "core” temperature of the body (Gerbrandy et al, 1954). While this may be intuitive, this applies only in the case of steady state conditions where thermal stability has been reached within the body. Whilst the studies using rectal temperature during exercise are too numerous to consider mentioning, it is obvious from only a handful of studies (Saltin and Hermansen, 1966; Aulick, Robertson et al, 1978; Shiraki, Konda et al 1986) that this temperature is inadequate to describe the range of thermal changes that occur in the body during any study but that which reports resting results or steady state responses. 
The value of rectal temperature as an index of the body's “core" temperature has been questioned as far back as the early 1960’s (Hardy, 1961; Nielsen and Nielsen, 1962), and research into the effect of exercise on oesophageal, rectal and muscle temperatures by Saltin and Hermansen (1966) further debated the use of this temperature as an indicator of rapid changes. In this latter study, the authors measured the effect of three submaximal workloads on the oesophageal, rectal and muscle (lateral quadriceps) temperatures. At the cessation of all submaximal workloads (the only time-point of muscle temperature measurement) the temperature observed in the muscle was greater than that at either the rectal or oesophageal measurement sites. Oesophageal temperature at the end of the workloads was directly proportional to the relative intensity of the exercise bout and whilst at the lowest workload (27\% $\dot{\mathrm{VO}}_{2}$ max) a steady state was reached within approximately 10 minutes from the start of the exercise bout, at the highest workload of only $70 \% \dot{\mathrm{VO}}_{2}$ max, a thermal equilibrium at either the rectal or oesophageal measurement site took over 25 minutes to reach. Similarly, Aulick and colleagues (1981) demonstrated a long lag phase between the start of exercise at $40 \% \dot{\mathrm{VO}}_{2}$ max and the attainment of a steady rectal temperature, in this case over 1 hour. The slow response time of rectal temperature to changes in body heat content has been universally recognised (Bazett, Love et al, 1949; Eichna, Berger et al, 1951; Cooper and Kenyon, 1957; Molnar and Read, 1974, Edwards, Belyavin et al, 1978) and has been attributed to its relative thermal inertia (Fox, Solman et al, 1973), indicating its lack of correlation with acute exercise-induced thermogenesis. 
Various studies have used external heating and cooling to assess the thermodynamic response and their effect on performance in humans using measurement sites other than the rectum (Edwards, Belyavin et al, 1978; Shiraki, Konda et al, 1986; Febbraio, Carey et al, 1996; Robinson, Seal et al, 1998; Gonzalez-Alonso, Teller et al, 1999; Parkin, Carey et al, 1999). Early work by Edwards, Belyavin and colleagues (1978) measured the magnitude of transient changes in auditory canal, mouth, rectal and oesophageal temperatures induced both by hot water immersion and light exercise. In this study oesophageal temperature probe placement was set at $42 \mathrm{~cm}$ from the lips and rectal probe placement at $8 \mathrm{~cm}$ beyond the anal sphincter. Light exercise consisted of pedalling a cycle ergometer for $10 \mathrm{~min}$ at $100 \mathrm{~W}$ (males) or $75 \mathrm{~W}$ (females), a 10 min rest and a further $10 \mathrm{~min}$ at the gender-determined workload. Due to the relatively low intensity of this exercise bout only small changes were observed at any of the measurement sites; however, the results did substantiate previous findings of a relatively inert rectal temperature response during the initial exercise bout. In contrast, immersion in a hot water bath for 11 min caused a significantly larger and faster oesophageal temperature response compared with rectal temperature. Oesophageal temperature increased by almost $1.5^{\circ} \mathrm{C}$ and reached its zenith within 2 min of the end of submersion whilst rectal temperature only rose $0.5^{\circ} \mathrm{C}$ and continued to rise for a further 5 min following cessation of the submersion.

Similarly, Robinson and co-workers (1998) found oesophageal temperature in children to be most closely associated with pulmonary artery temperature when compared with tympanic, rectal, bladder and axillary 
temperatures. The case for oesophageal temperature as the most appropriate measurement of the body's temperature was further supported when the authors compared their correlations between oesophageal and pulmonary temperature with previous work (Eichna, Berger et al, 1951) which had shown pulmonary artery temperature to be within $0.2^{\circ} \mathrm{C}$ of the blood returning from the central thermoregulatory centre in the brain (as measured in the high internal jugular vein).

The correct placement of an oesophageal temperature probe is critical because, as noted by Brengelmann, Johnson and co-authors (1979), there exists a short section $(5-7 \mathrm{~cm})$ of the oesophageus where the descending aorta runs directly posterior to the oesophagus and the left atrium is in contact with the oesophagus. Along this length of the oesophagus the measured temperature is demonstrated to be within $0.1^{\circ} \mathrm{C}$ of pulmonary artery blood temperature (Shiraki, Konda et al, 1986). By careful positioning of the oesophageal temperature probe such that it sits at least $24 \mathrm{~cm}$ beyond the corniculate cartilages (Whitby and Dunkin, 1968) and the maximal local temperature is measured, it is possible to record a temperature that is almost identical to that which would normally require a complicated and risky (Matthay and Chatterjee, 1988) procedure of catheterisation and probe insertion (direct measurement of pulmonary artery blood temperature).

In two studies into muscle metabolism and the effect of heat, a contingent of Australian researchers (Febbraio, Carey et al, 1996; Parkin, Carey et al, 1999) observed a significantly greater increase in post-exercise muscle temperature $\left(\Delta \mathrm{T}=1.8^{\circ} \mathrm{C}\right)$, measured at a depth of $4 \mathrm{~cm}$ in the vastus lateralis compared with 
rectal temperature $\left(\Delta \mathrm{T}=0.1^{\circ} \mathrm{C}\right)$, measured $10 \mathrm{~cm}$ beyond the anal sphincter (Febbraio, Carey et al, 1996). Supra-maximal workloads (115\% $\dot{\mathrm{VO}}_{2}$ max) were performed on a cycle ergometer for 2 minutes with either a heating pre-treatment (thigh muscle wrapped in a heating blanket for 60 min pre-exercise) or under normal conditions. Whilst the pre-heating treatment caused a significant increase in muscle temperature $\left(\Delta \mathrm{T}=1.9^{\circ} \mathrm{C}\right)$, rectal temperature did not undergo a similar response $\left(\Delta \mathrm{T}=0.4^{\circ} \mathrm{C}\right)$. Following exercise in this treatment protocol, rectal temperature only increased by $0.1^{\circ} \mathrm{C}$ whilst a significant increase in muscle temperature $\left(0.5^{\circ} \mathrm{C}\right)$ was again observed.

In the latest study performed by this group (Parkin, Carey et al, 1999) eight subjects cycled at a workload intensity of $70 \% \mathrm{VO}_{2}$ max to fatigue, whereupon rectal and muscle temperature were measured. As with the previous study (Febbraio, Carey et al, 1996), muscle temperature was shown to be higher under all ambient conditions (cold $\left[3^{\circ} \mathrm{C}\right]$, normal $\left[20^{\circ} \mathrm{C}\right]$ or hot $\left[40^{\circ} \mathrm{C}\right]$ ) compared with rectal temperature. Whilst the differences in temperature were not as significant as in the supra-maximal test it is worthwhile noting that rectal temperature was taken at the point of fatigue whereas muscle temperature was measured following muscle biopsy when it is likely that muscle temperature would be lower than that which exists at the cessation of exercise.

In an attempt to characterise the response of intestinal temperature to supine exercise Lee, Williams and colleagues (2000) employed seven subjects to perform supine cycle ergometry at 40 and $60 \% \dot{\mathrm{VO}}_{2}$ max while rectal, oesophageal and intestinal temperatures were measured. As with previous 
research the authors noted a slower and smaller increase in rectal temperature when compared with oesophageal temperature during both exercise bouts as well as a more rapid decrease in muscle temperature following the cessation of exercise. While intestinal temperature changes, both during exercise and following its cessation, were similar to those in the oesophagus, the intestinal changes showed a delayed response. These results and those in previous studies further undermine the use of rectal temperature as an indicator of body temperature responses during exercise and support the notion of the need to measure temperature at more appropriate areas of the body, depending on the hypothesis being researched.

In addition to the experiments concerned with temperature changes in humans, further research into those of exercising animals has also been performed. In 1986, Pan, Forster and Kaminski compared the response of rectal and arterial temperatures during exercise in 17 ponies. After $11 \mathrm{~min}$ at the highest exercise workload (6 miles/hour, 5\% grade) there was a significant difference in rectal and arterial blood temperatures, with the arterial temperature responses being almost double those of rectal temperature. In 13 of the ponies pulmonary artery temperature was also measured and a response similar to that of arterial blood temperature was elicited at all workloads performed. The authors noted that the magnitude of the difference between arterial and rectal temperature was dependent upon both exercise intensity and duration, and that these differences could induce analytical errors in the measurement of blood gases. 
In 1989, Jones, Taylor and colleagues measured the pulmonary arterial, muscular and rectal temperatures in a set of horses. In their maximal 6 minute run there were minimal responses at the rectal site of temperature measurement $\left(1.5^{\circ} \mathrm{C}\right)$ whilst pulmonary artery temperature and active muscle temperatures increased significantly (3.6 and $4.2^{\circ} \mathrm{C}$, respectively). In agreement with the work of Pan, Forster and Kaminski (1986) the authors noted thermal responses were dependent on both exercise intensity and duration with the use of each temperature measurement site having an impact on the calculation of blood gas values.

Similar research by Taylor, Kronfeld and co-authors (1998) measured rectal, muscle, pulmonary artery and skin temperatures in seven Arabian horses during an incremental treadmill exercise test. The results of this research were also consistent with previous work, with both blood and muscle temperature responses exceeding that of rectal temperature during the exercise period. When comparing the effect of correcting $\mathrm{PaO}_{2}$ levels for each temperature to that of the analyser default of $37^{\circ} \mathrm{C}$ the authors noted a significantly higher value for both muscle and blood temperature-corrected values compared with rectal temperature-corrected values during the exercise period.

Remembering that there are two outstandingly important sites of gas transfer of oxygen in the blood; loading of oxygen into the blood in the pulmonary capillaries and unloading of oxygen from the blood into (with regard to exercise) the active muscles, it is not difficult to speculate that the temperature at these two sites, in addition to the temperature at which blood arrives at the muscle (arterial blood temperature), are of much more importance than that 
measured in the rectum during an exercise bout where steady state conditions are difficult to attain.

The use of the rectal site for temperature measurement seems to be a default option in exercise physiology due to the ease of probe insertion. The use of the oesophageal site for temperature measurement is increasing as the insertion techniques improve and the awareness of its applicability increases; however, the use of muscle temperature and arterial blood temperature are two extremely relevant temperatures which generally have gone under-reported. Arterial blood temperature can be assumed to be the temperature at which the blood is transported to the muscle site, and muscle temperature can, obviously, be assumed as the temperature at which the transfer of oxygen and carbon dioxide occurs in the active muscle. To date, few researchers have utilised the measurement of arterial blood temperature during exercise (Hammond, Gale et al, 1986; Pan, Forster et al, 1989; Wagner, Gillespie et al, 1989; Rice, Thornton et al, 1999; Hopkins, Barker et al, 2000); and whilst numerous studies have measured the temperature in the active muscle during exercise (Saltin and Hermansen, 1966; Saltin, Gagge et al, 1968; Blomstrand, Kaijser et al, 1986; Gonzalez-Alonso, Teller et al, 1999; Febbraio, Carey et al, 1996; Parkin, Carey et al, 1999), none have applied this measurement for use as the correction factor for blood gas values in humans. 


\subsection{TEMPERATURE CORRECTION OF ARTERIAL BLOOD GASES}

The effect of altering blood temperature on $\mathrm{PaO}_{2}$ from its usually reported $37^{\circ} \mathrm{C}$ has been of topic since the 1950 's. With regard to the clinical aspect of blood gas analyses it has been considered unnecessary and somewhat confusing to practitioners for the temperature dependent variables of blood gas results to be corrected for any increase or decrease in core body temperature (Hansen, 1989; Shapiro, 1995). Hansen's review does, however, qualify this conclusion with the statement “(t)here are limited occasions when it may be appropriate....during prolonged heavy exercise when the body temperature normally rises”. Yet the importance of such corrections has been ignored or applied inappropriately in the majority of studies on the phenomenon of EIH.

As discussed by Hansen, Syben et al (1999), the solubilities of oxygen and carbon dioxide are altered by changes in body (and hence blood) temperature such that, in hypothermia, solubility is reduced leading to a decrease in the tension of these gases. This also has the opposite effect when the temperature of the blood is increased, such that for every degree increase in blood temperature between $30^{\circ} \mathrm{C}$ and $44^{\circ} \mathrm{C}$ there is an increase in the partial pressure of the gases of approximately 5\%. Severinghaus and colleagues (Severinghaus, Stupfel et al, 1956; Severinghaus, 1966; Severinghaus, 1968; Severinghaus, 1979) undertook a series of experiments which produced correction factors for $\mathrm{PO}_{2}$ when the sample blood temperature differed from the normal $37^{\circ} \mathrm{C}$. The equations affecting $\mathrm{PO}_{2}, \mathrm{PCO}_{2}$ and $\mathrm{pH}$ were all initially 
verified by only a small data set; however, in 1981, Andritsch, Muravchick and Gold reviewed the current equations for the temperature correction of blood gas values and concluded that the Severinghaus equations (Equations 1.2, 1.3 and 1.4) were the most useful due to the ease of use and the accuracy obtained.

$\mathrm{PaO}_{2}$ (corrected) $=\mathrm{PaO}_{2}\left(37^{\circ} \mathrm{C}\right) \times 10^{(((0.0252 /((0.243 \times \mathrm{PaO}} 2{ }_{2}^{\left.\left.\left.\left.\left.\left.\left.\left(37^{\circ} \mathrm{C}\right) / 100\right)^{\wedge} 3.88\right)\right)+1\right)\right)+0.00564\right) \times(\mathrm{T}-37)\right)}$

$\mathrm{PaCO}_{2}($ corrected $)=\mathrm{PaCO}_{2}\left(37^{\circ} \mathrm{C}\right) \times 10^{(0.021 \times(\mathrm{T}-37)}$

$\mathrm{pH}($ corrected $)=\mathrm{pH}\left(37^{\circ} \mathrm{C}\right)+\left(-0.0146+0.0065 \times\left(7.4-\mathrm{pH}\left(37^{\circ} \mathrm{C}\right)\right)\right) \times(\mathrm{T}-37)$

where $\mathrm{T}=$ core temperature measured

Equations 1.2( $\left(\mathrm{PaO}_{2}\right)$, 1.3 $\left(\mathrm{PaCO}_{2}\right)$ and 1.4(pH). Correction of blood gas values to measured core temperature values (from Severinghaus, 1966)

Three years later Gøthgen (1984) also performed a review of the currently available equations for the correction of blood gas variables. He observed that the Severinghaus equation (1966) for the correction of $\mathrm{PO}_{2}$ to changing temperatures correlated best with samples where the $\mathrm{PO}_{2}$ was measured at the actual temperature between $37^{\circ} \mathrm{C}$ and $44^{\circ} \mathrm{C}$.

In recent reviews of EIH, the effect of correcting $\mathrm{PaO}_{2}$ and $\mathrm{SaO}_{2}$ for the thermogenic effect of exercise has been generally seen as unnecessary, insignificant or not worthy of discussion (Powers and Williams, 1987; Prefaut, Durand et al, 2000; Nielsen, 2004). The importance of correcting for changes in core body temperature was, however, acknowledged in the review by Dempsey 
and Wagner (1999) who demonstrated a failure to correct $\mathrm{PaO}_{2}$ would lead to an underestimation of this variable, as well as an overestimation of ideal alveolar $\mathrm{PO}_{2}$ and, hence, $(\mathrm{A}-\mathrm{a}) \mathrm{DO}_{2}$. The authors state that EIH "must be identified by direct measurements of arterial blood gas”, and that errors produced by uncorrected or incorrectly temperature-corrected blood gas values "are equal to the suggested minimum decrements in $\mathrm{PaO}_{2}$ for defining EIAH”. No indication was given as to the correct temperature for which to recalculate blood gas results, however.

Early research by Holmgren and McIlroy (1964) into the effect of temperature on blood gas tensions and $\mathrm{pH}$ during exercise reported the changes caused by correcting arterial blood gas values for the arterial blood or oesophageal temperature during exercise to exhaustion. The authors tested 10 volunteers, 5 of whom had the arterial blood sample temperature measured during exercise, and 5 where oesophageal temperature was measured at the same time points. Whilst the subjects were not highly trained (average cycle ergometer workload of 200 watts, range 150-250W), significant changes in $\mathrm{PaO}_{2}, \mathrm{PaCO}_{2}$ and $\mathrm{pH}$ were observed when these measurements were corrected for the heat generated during exercise. From these results the authors acknowledged the importance of the use of temperature correction factors, especially “during severe exercise”.

The effect of correcting arterial blood gas tensions for the heat produced during exercise was thoroughly investigated by Jones, Taylor and co-workers (1989). In a study utilising horses and steers, the authors compared the effect of correcting arterial blood gas samples from the exercising animals for the 
temperature measured at the rectum, in the pulmonary artery and intramuscularly (gluteal muscle). The authors postulated that there may exist an inherent error in correcting blood gas values for rectal temperature rather than to the temperature of the blood where gas exchange occurs. Blood samples were corrected for the temperatures taken after a maximal-intensity 6-min run, simultaneous to blood sampling using the equation developed by Severinghaus (1966) which accounts for the effect of temperature on $\mathrm{PO}_{2}$ and has been used in various research projects where blood gases have been corrected for temperature changes (Rowell, Taylor et al, 1964; Whipp and Wasserman, 1969; Pan, Forster et al, 1989; Powers, Dodd et al, 1991; Powers, Martin et al, 1992; Rice, Scroop et al, 1999; Rice, Thornton et al 1999; Zavorsky, Walley et al, 2002).

Jones and colleagues (1989) demonstrated a significant difference in the calculation of arterial $\mathrm{PO}_{2}, \mathrm{PCO}_{2}$ and $\mathrm{pH}$ when uncorrected values of these variables were recalculated at the temperature measured in the rectum, the pulmonary artery and the active muscle. Rectal temperature was shown to rise slowly during the exercise period (6 min at $\mathrm{VO}_{2}$ max) whilst the lower resting temperatures in the pulmonary artery and muscle increase rapidly and to a much higher nadir during the exercise period. Muscle and pulmonary artery temperature receded rapidly following cessation of exercise; however, rectal temperature continued to rise with one highlighted example exhibiting a continual rise in $\mathrm{T}_{\mathrm{re}}$ up to 11 minutes post-exercise. With regard to the differences, the authors theorised that if blood gas samples taken during exercise are corrected for rectal temperature rather than the more relevant pulmonary artery temperature (and / or active muscle temperature) then large errors will 
occur, the magnitude of which would be "a function of both the duration and intensity of the workload and thus relative rates of heat production and storage”. Furthermore, the authors acknowledged that the bias introduced by rectal temperature correction would over-inflate the actual $(A-a) \mathrm{DO}_{2}$ by the combined effects of increasing the inspired $\mathrm{PO}_{2}$ value (through water vapour pressure and $\mathrm{PaCO}_{2}$ being undervalued) and the aforementioned underestimation of $\mathrm{PaO}_{2}$.

Taking in to mind the, now obvious, need to measure $\mathrm{PaO}_{2}$ using an arterial blood sample and, furthermore, the need to correct any obtained results for temperature changes that occur during exercise, review of the studies presented in Table 1.1 shows some interesting facts on the measurement of EIH. Rectal temperature has been utilised in studies as recent as 1999; however, there have been a number of studies since then that have utilised the more relevant measurement of arterial blood and oesophageal temperature. In all, $\mathrm{PaO}_{2}$ has been measured in only 54\% of the summarised studies (32 of the 59 presented), and of these only $56 \%$ have corrected $\mathrm{PaO}_{2}$ for changes in body temperature during exercise. Therefore only $30 \%$ of the total number of studies presented have utilised an acceptable method for defining EIH. Of the $\mathrm{PaO}_{2}$ results corrected for exercise-induced thermogenesis, 4 utilised $\mathrm{T}_{\text {re }}, 6$ utilised $\mathrm{T}_{\text {oes}}$, a further 6 applied $\mathrm{T}_{\text {art }}$ and the final 2 used other correction values. In these studies the relevance of the temperature correction site was not explained, and no study made a statement regarding the comparative value of the correction factor utilised. 


\subsection{OXYGEN - HAEMOGLOBIN DISSOCIATION, TEMPERATURE AND OXYGEN CONTENT}

\subsubsection{The Oxygen-Haemoglobin Dissociation Curve and Temperature}

Under normal conditions $\left(\mathrm{T}=37^{\circ} \mathrm{C}, \mathrm{pH}=7.4\right)$, the relationship between oxygen partial pressure and haemoglobin saturation produces a sigmoid curve (see Figure 1.5). At a $\mathrm{PO}_{2}$ of $60 \mathrm{mmHg}$ haemoglobin saturation $\left(\mathrm{SaO}_{2}\right)$ is $~ 90 \%$ with significant increases in $\mathrm{PO}_{2}$ above this level resulting in marginal increases in $\mathrm{SaO}_{2}$ and small decrements in $\mathrm{PO}_{2}$ below this level resulting in significant reductions in $\mathrm{SaO}_{2}$. The nature of this relationship between oxygen and haemoglobin, with respect to the relative affinity of binding, ensures haemoglobin remains highly oxygenated in all but the most extreme conditions of reduced $\mathrm{PO}_{2}$. Therefore the oxygen content of the blood is maintained and supply of oxygen to the tissues remains constant and uninterrupted. 


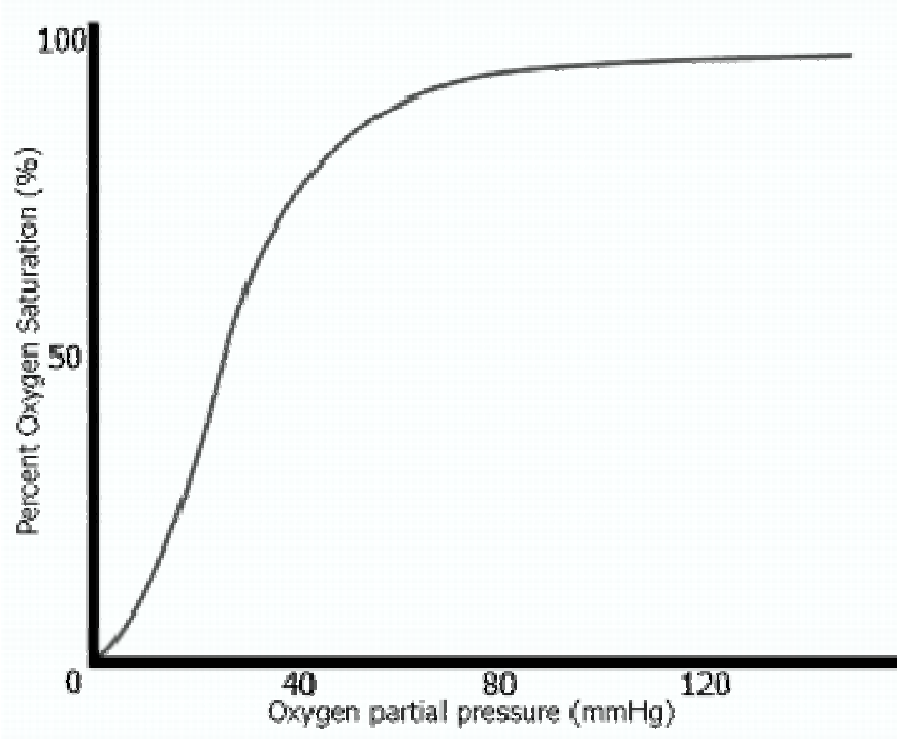

Figure 1.5 The Oxygen-Haemoglobin Dissociation curve (adapted from unreferenced internet image)

In normal pulmonary circulation blood has a $\mathrm{PO}_{2}$ of $\sim 100 \mathrm{mmHg}$ and subsequently a $\mathrm{SaO}_{2}$ of almost $100 \%$. During exercise this blood circulates (although not exclusively) to the active muscle where $\mathrm{PO}_{2}$ is significantly lower ( $<40 \mathrm{mmHg}$ ). The low $\mathrm{PO}_{2}$ reduces the affinity of haemoglobin to oxygen resulting in a decrease of the oxygenated haemoglobin and the release of oxygen from the molecule which is then able to be taken up by the muscle. On return to the heart, mixed venous $\mathrm{PO}_{2}$ is $\sim 40 \mathrm{mmHg}$ and $\mathrm{SvO}_{2}$ is $75 \%$, which indicates a less than complete extraction of oxygen from the blood. With perfusion through the lungs, oxygen loading back into the haemoglobin is facilitated by the high $\mathrm{PO}_{2}$ within the alveoli.

Specific changes in the affinity of oxygen for haemoglobin result in response to changes in the conditions of the blood. An increase in $\mathrm{pH}$ and a decrease in $\mathrm{PCO}_{2}$ and 2,3-DPG (an organic phosphate) causes an increased affinity for oxygen which is seen as a left shift in the oxygen-haemoglobin 
dissociation curve, whilst increased 2,3-DPG and $\mathrm{PCO}_{2}$ and a decrease in $\mathrm{pH}$ result in a right shift in the curve and a decreased affinity for oxygen.

Temperature affects the affinity of due to its site-specific denaturing effect on the haemoglobin protein. An increase in temperature decreases the affinity of haemoglobin to oxygen, with a lowering of the temperature of the blood having the opposite effect. In the situation of the active muscle during exercise, the heat produced by the muscle will effectively increase the availability of oxygen by facilitating the release of oxygen from the blood. In fact, all conditions in the active muscle (increased $\mathrm{PCO}_{2}$ and decreased $\mathrm{pH}$, in particular) facilitate the unloading of oxygen from its carrier. Furthermore, the changing conditions as blood moves from the muscle and through the lungs, where it experiences a decrease in $\mathrm{PCO}_{2}$ and a increase in $\mathrm{pH}$ and, if ambient conditions are agreeable, a decrease in temperature, assist the loading of oxygen back into the haemoglobin for transport back to the muscle. These changing conditions therefore increase the loading and unloading of oxygen as required at the various sites.

\subsubsection{Oxygen Content}

The capacity for blood to carry oxygen (the oxygen content or $\mathrm{CaO}_{2}$ ) is largely dependent on the degree of oxy-haemoglobin saturation and the concentration of haemoglobin in the blood (Equation 1.5). The small amount of oxygen present in blood as dissolved gas $\left(\mathrm{PO}_{2}\right)$ adds to the total content but is largely insignificant and has previously been excluded from $\mathrm{CaO}_{2}$ calculations 
(Ciba-Geigy, 1990). However, the most accurate calculation of this parameter can be defined by the equation:

$$
\mathrm{CaO}_{2}=\left[(1.34 \times[\mathrm{Hb}]) \times \mathrm{SaO}_{2}\right]+\left(0.0031 \times \mathrm{PaO}_{2}\right)
$$

$$
\begin{aligned}
& \text { Where: } \quad \begin{aligned}
\mathrm{CaO}_{2} & =\text { arterial oxygen content }(\mathrm{vol} \cdot \%) \\
{[\mathrm{Hb}] } & =\text { haemoglobin concentration }\left(\mathrm{g} \cdot \mathrm{dL}^{-1}\right) \\
\mathrm{SaO}_{2} & =\text { oxy-haemoglobin saturation }(\%) \\
\mathrm{PaO}_{2} & =\text { arterial oxygen partial pressure }(\mathrm{mmHg})
\end{aligned}
\end{aligned}
$$

\section{Equation 1.5 Arterial Oxygen content equation}

At a $\mathrm{PaO}_{2}$ of $100 \mathrm{mmHg}$, a [Hb] of $15 \mathrm{~g} \cdot \mathrm{dL}$ and a $\mathrm{SaO}_{2}$ of $97 \%, \mathrm{CaO}_{2}$ is almost exactly $20 \mathrm{vol} \%$. This degree of oxygen availability easily exceeds that necessary to perform at least moderate levels of exercise as shown by Wolfel and colleagues (1998). These authors had their subjects perform submaximal exercise workloads before and following non-selective beta-adrenergic blockade which effectively decreased the heart rate response during exercise. Oxygen delivery (as caused by decreased cardiac output) was reduced in the treatment arm; however, oxygen consumption was maintained. The researchers attributed this to a greater oxygen extraction which indicates the presence of an oxygen "pool” in the blood which is in excess of that utilised under normal conditions. Conversely, in research where arterial oxygen content itself has been reduced there has been a concomitant reduction in exercise performance (Ekblom, Hout 
et al, 1975; Lindstedt, Wells et al, 1988; Amann, Eldridge et al, 2006) which implies that EIH, if severe enough, would impact on performance also.

A relative decrease in $\dot{\mathrm{VO}}_{2}$ max has been shown to occur when arterial oxygen content and hence oxygen delivery is reduced (Ekblom, Hout et al, 1975; Lindstedt, Wells et al, 1988) and this reduction in $\dot{\mathrm{VO}}_{2}$ max has also led to a decrease in performance. However, that this reduction occurs in subjects undergoing EIH has not been ascertained, and certainly has never been calculated utilising temperature corrected $\mathrm{PaO}_{2}$ or $\mathrm{SaO}_{2}$.

\subsection{SUMMARY AND AIMS OF THESIS}

The mechanism of EIH in trained athletes, normal subjects, women and the young and old has been attributed to many physiological insufficiencies or disturbances during high intensity or maximal exercise. Whilst there is an abundance of data on the role of each possible mechanism in EIH, there is also a great deal of conflicting evidence as to its cause, effect and incidence. Because the accuracy of arterial blood gas measurements is much greater in comparison to pulse oximetry; because changes in body temperature have marked, and quantifiable effect on these blood gas measurements; and because the repeatability of blood gas values during exercise remains uncertain, this thesis has focussed on these areas.

The aim of this doctoral thesis is to clarify the effect of exercise-induced body temperature increases on EIH in highly-trained athletes, and to observe the reproducibility of the phenomenon of any observed EIH during an incremental 
exercise test to exhaustion. More specifically this thesis will aim to measure the effect incremental exercise has on a range of simultaneously-measured core temperature sites and how the application of these temperature changes to blood gas analysis can affect the prevalence of EIH. 


\section{CHAPTER 2}

\section{General Methods}

\section{$2.1 \quad$ LABORATORY ENVIRONMENT}

The general arrangement of the laboratory is shown in Figure 2.1. All experiments were conducted in an air-conditioned environment with mean values $( \pm \mathrm{SD}$ ) for room temperature, relative humidity and barometric pressure of, respectively, $23.0 \pm 0.2^{\circ} \mathrm{C}$ (NATA certified spirit thermometer, Cameron Industries, Adelaide, Australia), $40.2 \pm$ 1.3\% (whirling hygrometer, GH Zeal Ltd., London, England) and $758.8 \pm 1.0 \mathrm{mmHg}$ (ABL 520, Radiometer, Copenhagen, Denmark.

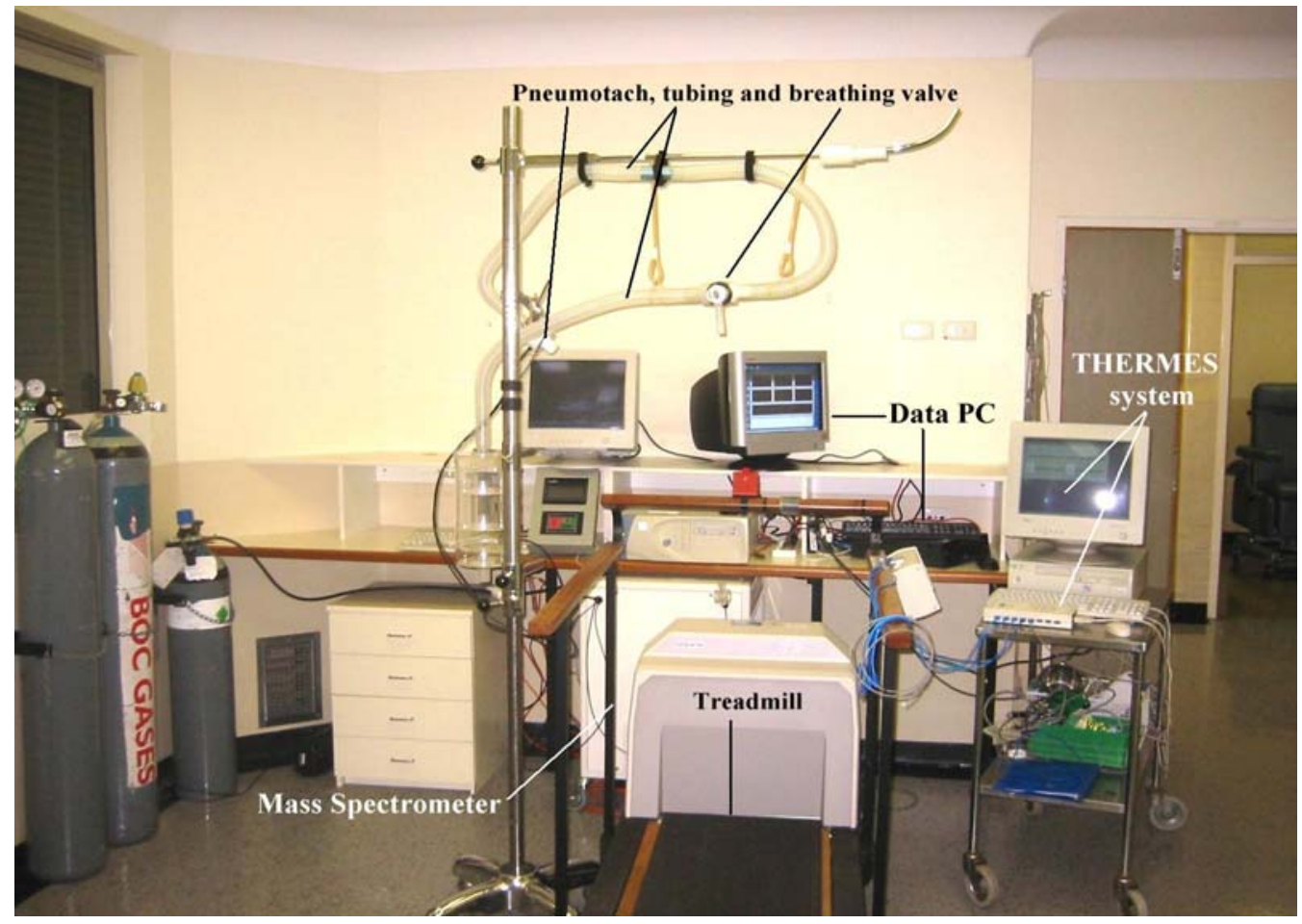

Figure 2.1

The Exercise laboratory 


\section{$2.2 \quad$ SUBJECTS}

\subsubsection{General}

Twenty-three endurance-trained male athletes volunteered for the experiments reported in this thesis, with all completing a questionnaire designed to exclude any subject with a history of cardio-respiratory dysfunction. All subjects signed a consent form acknowledging their understanding and acceptance of the testing requirements and experimental protocol, including the possibility of associated adverse events (Appendix 7.1). The experimental protocols were scrutinised and approved by the Human Research Ethics Committee of the Royal Adelaide Hospital. Of the 23 subjects, all participated in the experiments described in Chapters 3 and 4, whilst 10 subjects participated in the experiments of Chapter 5. Anthropometric data for these subject sets are presented in Table 2.1.

\subsubsection{Measurement of Resting Pulmonary Function}

In the week prior to their first exercise session subjects attended the laboratory to familiarise themselves with the laboratory personnel and equipment and to discuss any questions regarding the experimental protocols. At this session they also participated in a series of tests to document resting pulmonary function in terms of forced expiratory volume $\left(\mathrm{FEV}_{1}\right)$, forced vital capacity (FVC) and lung diffusing capacity for carbon monoxide $\left(\mathrm{D}_{\mathrm{L}} \mathrm{CO}\right)$. Results of these tests are presented in Table 2.1. 


\subsubsection{Spirometry Measurement}

$\mathrm{FEV}_{1}, \mathrm{FVC}$ and PEF (peak expiratory flow rate) were performed in triplicate for each subject using a Micro DL portable spirometer (Micro Medical Ltd., Rochester, England). Subjects were required to sit upright in a chair and had a nose clip fitted to prevent loss of expired air. Upon inhaling as deeply as possible, the subject was instructed to insert the disposable cardboard mouthpiece of the spirometer into their mouth, ensure a tight seal with the lips, then exhale as forcefully as possible for as long as possible. $\mathrm{FEV}_{1}$ and FVC measurements were compared with predicted values for age and height for males (Crapo, Morris et al., 1981) using the equations:

$$
\begin{aligned}
& \operatorname{FEV}_{1}(\mathrm{~L}) \quad=(0.0414 \times \text { Height }(\mathrm{cm}))-(0.0244 \times \text { Age }(\text { years }))-2.19 \\
& \text { FVC }(\mathrm{L}) \quad=(0.06 \times \text { Height }(\mathrm{cm}))-(0.0214 \times \text { Age }(\text { years }))-4.65 .
\end{aligned}
$$

Equations 2.1 and 2.2 Calculations for normal $\mathrm{FEV}_{1}$ and FVC values

\subsubsection{Diffusing Capacity for Carbon Monoxide Measurement $\left(\mathrm{D}_{\mathrm{L}} \mathrm{CO}\right)$}

$\mathrm{D}_{\mathrm{L}} \mathrm{CO}$ was measured using a single breath holding technique, performed on a V-max 22 Pulmonary Function Analysis Instrument (Sensormedics, California, USA). Subjects were required to sit upright in a chair and place the mouthpiece of the V-max system in their mouth, maintaining a tight seal with the lips during the entire test. A nose clip was fitted to prevent loss of expired air during the manoeuvre. After obtaining a baseline tidal volume reading, with the subject breathing normally, the subject was required to perform a maximal expiration followed by a maximal inspiration. The inspired test gas comprised 
medical air with $\sim 0.3 \%$ each of carbon monoxide (CO) and methane $\left(\mathrm{CH}_{4}\right)$. The subject was required to hold this inspiration for 10 seconds then exhale until an adequate sample had been collected. This sample was then analysed automatically for $\mathrm{CO}$ and $\mathrm{CH}_{4}$ concentrations and the calculation of diffusing capacity of the subject's lungs based on the following equation:

$$
\begin{aligned}
& \mathrm{D}_{\mathrm{L}} \mathrm{CO}=\frac{\mathbf{6 O V}_{\mathrm{A}}(\mathbf{S T P D})}{(\mathbf{P B}-47) \mathrm{T}} \ln \left(\left(\mathbf{F}_{\mathrm{E}} \mathbf{C H}_{4} / \mathbf{F}_{\mathrm{I}} \mathbf{C H} \mathbf{H}_{4}\right)\left(\mathbf{F}_{\mathrm{I}} \mathbf{C O} / \mathbf{F}_{\mathrm{E}} \mathbf{C O}\right)\right) \\
& \text { Where: } \quad \mathrm{V}_{\mathrm{A}} \quad=\text { alveolar gas volume (ml, STPD) } \\
& =\mathrm{V}_{\mathrm{I}}\left(\mathrm{F}_{\mathrm{I}}{ }^{\prime} \mathrm{CH}_{4} / \mathrm{F}_{\mathrm{E}} \mathrm{CH}_{4}\right) \\
& \mathrm{V}_{\mathrm{I}} \quad=\text { inspired volume (L, BTPS) } \\
& \mathrm{F}_{\mathrm{I}}{ }^{\prime} \mathrm{CH}_{4}=\left(1-\mathrm{V}_{\mathrm{D}} / \mathrm{V}_{\mathrm{I}}\right) \mathrm{F}_{\mathrm{I}} \mathrm{CH}_{4} \\
& \text { VD = breathing valve dead space plus } 0.15 \mathrm{~L} \text { patient } \\
& \text { anatomical dead space } \\
& \mathrm{F}_{\mathrm{E}} \mathrm{CH}_{4}=\text { concentration of exhaled } \mathrm{CH}_{4} \\
& \mathrm{~PB} \quad=\text { barometric pressure }(\mathrm{mmHg}) \\
& \mathrm{T}=\text { breath-hold time (seconds) } \\
& \mathrm{F}_{\mathrm{I}} \mathrm{CH}_{4}=\text { concentration of } \mathrm{CH}_{4} \text { inspired } \\
& \mathrm{F}_{\mathrm{I}} \mathrm{CO}=\text { concentration of } \mathrm{CO} \text { inspired } \\
& \mathrm{F}_{\mathrm{E}} \mathrm{CH}_{4}=\text { alveolar concentration of } \mathrm{CH}_{4} \text { expired } \\
& \mathrm{F}_{\mathrm{E}} \mathrm{CO}=\text { alveolar concentration of } \mathrm{CO} \text { expired }
\end{aligned}
$$

Equation 2.3 Diffusing capacity for Carbon Monoxide equation (MacIntyre et al, 2005)

All measurements (expressed as $\mathrm{ml} \cdot \mathrm{min}^{-1} \cdot \mathrm{mmHg}^{-1}$ ) obtained were compared with predicted values for age and height for males (Crapo and Morris, 1981) using the equation: 


$$
\mathrm{D}_{\mathrm{L}} \mathrm{CO}=(0.416 \times \text { Height }(\mathrm{cm}))-(0.219 \times \text { Age }(\text { years }))-26.34
$$

Equation 2.4 Calculation for normal diffusing capacity values

Table 2.1 Mean values ( \pm SD) for the physical characteristics and pulmonary function of all subject sets.

\begin{tabular}{ccc}
\hline & $\begin{array}{c}\text { Subjects for Chapters 3 and } 4 \\
(\mathrm{n}=23)\end{array}$ & $\begin{array}{c}\text { Subjects for Chapter 5 } \\
(\mathrm{n}=10)\end{array}$ \\
\hline Age (yrs) & $26.0 \pm 4.8$ & $25.2 \pm 5.5$ \\
Height (cm) & $181.0 \pm 7.4$ & $181.4 \pm 8.7$ \\
Mass (kg) & $71.6 \pm 8.7$ & $69.0 \pm 9.7$ \\
FEV $(\mathrm{L})$ & $4.6 \pm 0.8$ & $4.4 \pm 1.1$ \\
FVC (L) & $5.6 \pm 0.8$ & $5.6 \pm 0.9$ \\
DLCO & $36.6 \pm 7.2$ & $37.8 \pm 9.4$
\end{tabular}

$\mathrm{FEV}_{1}$ (forced expiratory volume in 1 sec.); FVC (forced vital capacity), PEF (peak expiratory flow rate); DLCO (pulmonary diffusing capacity).

\subsection{BODY TEMPERATURE}

\subsubsection{General}

To minimise inter-subject variations in starting body temperatures due to the normal diurnal rhythm (Waterhouse, Drust et al, 2005), all subjects arrived between 0900 and 1000 hrs on their testing day.

\subsubsection{Rectal Temperature}


The temperature probes utilised were either Series 4000 Mon-a-therm (Mallinckrodt Inc. Missouri, USA; Fig. 2.2) or ESO-1 Physitemp Instruments probes (New Jersey, USA; Fig. 2.3), the latter being reusable after low temperature (STERRAD) sterilization. Response times of these probes was less than 5.0 seconds.

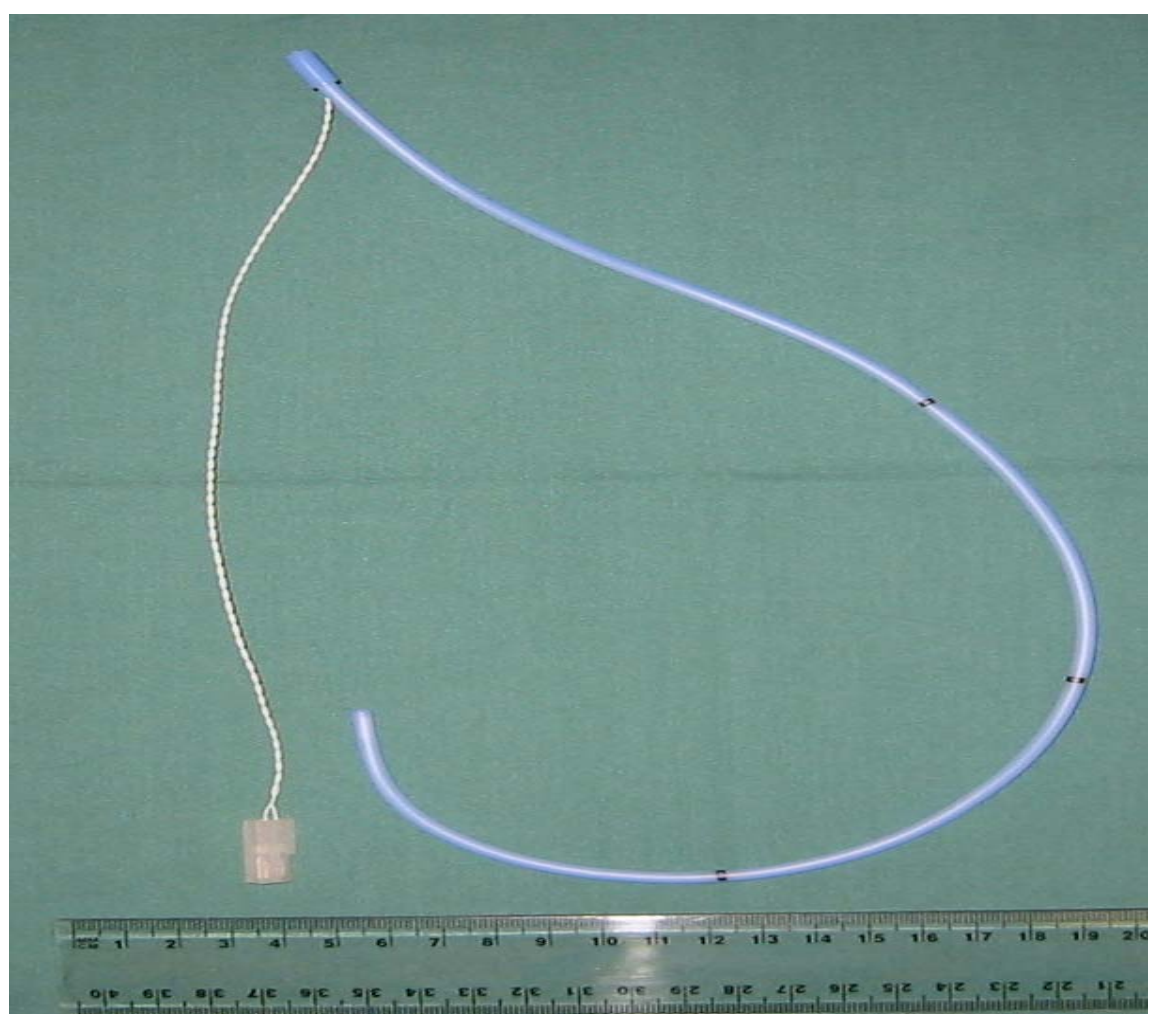

Figure 2.2 Series 400 Mon-a-therm ${ }^{\mathrm{TM}}$ (9-French Gauge shown; for rectal and oesophageal temperature measurement) 


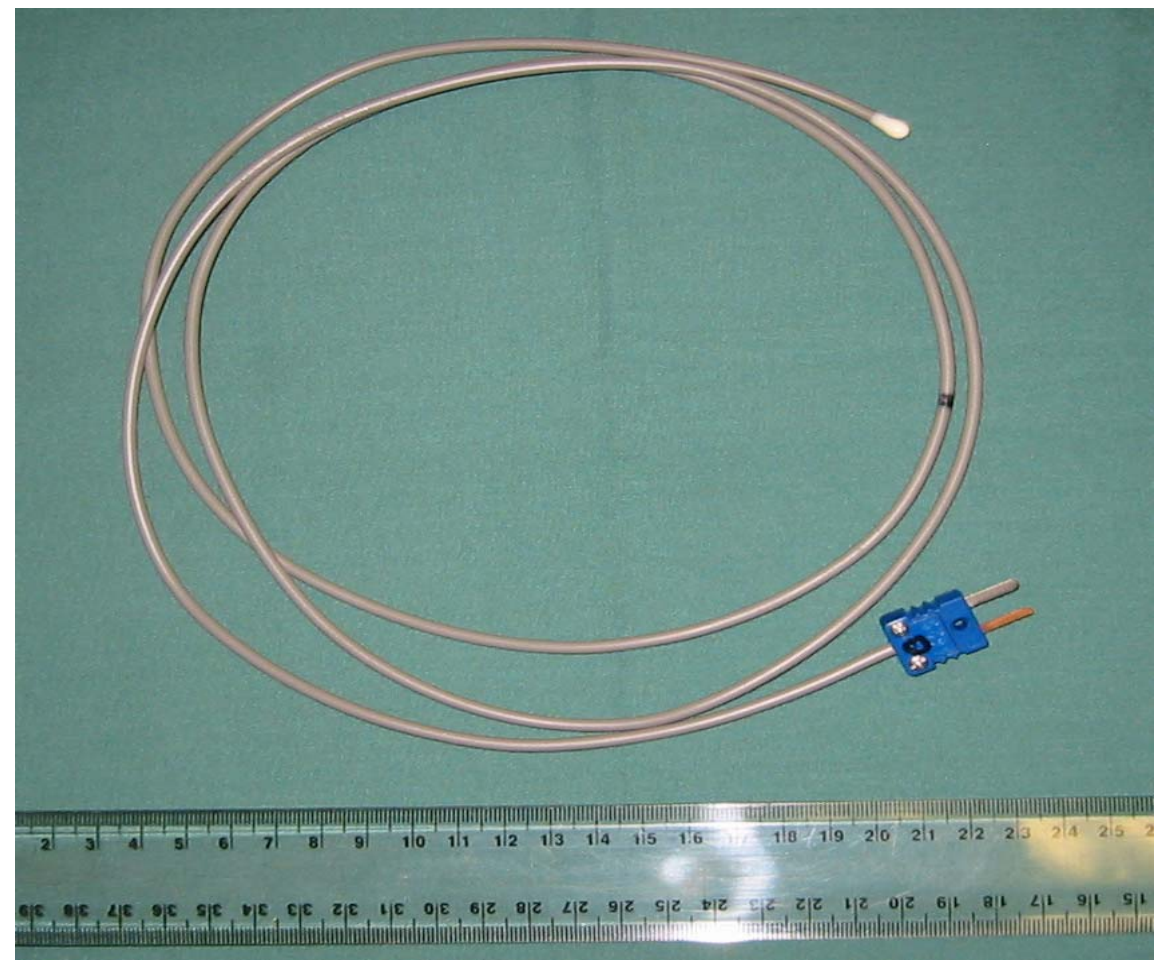

Figure 2.3 ESO-1 temperature probe.

On arrival at the laboratory subjects were given a small amount of Vaseline, a disposable glove and the temperature probe with instructions on selfinsertion. Subjects then entered a bathroom to empty their bowels and bladder if so desired, insert the probe and change into their exercise clothing. On the temperature probe a mark was drawn to indicate the maximal insertion depth $(10 \mathrm{~cm})$ and a small piece of tape (Micropore ${ }^{\mathrm{TM}}$, 3M Health Care, Minnesota, USA) attached approximately 1-2cm proximal to this mark to ensure no further insertion. To prevent accidental displacement during exercise, two pieces of cotton umbilical tape $(75 \mathrm{~cm}$, United States Surgical, Connecticut, USA) were attached to the probe approximately $1 \mathrm{~cm}$ proximal to the $10 \mathrm{~cm}$ maximal insertion point indicated on the probe. After probe insertion the subject was instructed to pull one piece of the tape up the front of their body and the second 
piece up the back and tie both pieces to a loop of cotton tape tied around their waist. The connecting wire from the probe to the temperature display unit was run upwards between the buttocks and fixed to the top of the gluteal groove using adhesive tape (Transpore, 3M Health Care, Minnesota, USA).

\subsubsection{Oesophageal Temperature}

The temperature probe was either a Series 4000 Mon-a-therm (Mallinkrodt Inc. Missouri, USA; Fig. 2.2) or an ESO-1 Physitemp Instruments probe (New Jersey, USA; Fig. 2.3). The oesophageal thermistor probe was inserted immediately after the subject had returned to the laboratory following selfinsertion of the rectal temperature probe. The subject was seated in a chair and $\sim 5 \mathrm{~mL}$ of local anaesthetic gel (Xylocaine ${ }^{\mathrm{TM}}$ Viscous, Astra Pharmaceuticals Pty. Ltd., New South Wales, Australia) introduced into the nasal passage on one side using a 5-mL plastic syringe (Terumo Corporation, Laguna, Philippines). The oropharynx was also partially anaesthetised by spraying Xylocaine (Astra Pharmaceuticals Pty. Ltd.) on to the back of the throat through an open mouth. Allowing sufficient time for the anaesthetic to function (approximately 5 minutes), the probe was threaded into the opening of the anterior naris and directed into the oropharynx taking care to not push the probe into the sinus cavity. When the probe made contact with the epiglottis it was withdrawn a few centimetres and the subject was instructed to swallow sips of water taken through a straw in a glass of water. As the subject was doing this, the probe was assisted past the epiglottis until $\sim 45 \mathrm{~cm}$ of the probe had been inserted (as measured from the anterior naris). The probe was temporarily attached to a digital readout and the position of the thermistor tip adjusted to elicit the highest 
temperature reading, this being assumed to closely reflect pulmonary artery blood temperature (Shiraki, Konda et al. 1986). To prevent displacement of the probe during the exercise test it was affixed to the nostril using adhesive tape (Micropore $^{\mathrm{TM}}$, 3M Health Care, Minnesota, USA) and the attached cable looped back over the subject's ear for taping to the subject's back. At all fixation points the cable was given enough slack to allow for adequate head movement throughout the exercise test. The cable was finally connected to an extension lead and monitor to obtain a digital readout.

\subsubsection{Arterial Blood Temperature}

Arterial blood temperature was measured using a rapid response, teflon-coated, thermocouple (IT-21, Physitemp Instruments, New Jersey, USA, Fig. 2.4) which had a time constant of $0.08 \mathrm{~s}$ and a range of 0 to $150^{\circ} \mathrm{C}$. Accuracy to $0.1^{\circ} \mathrm{C}$ was guaranteed by the manufacturer between 0 and $50^{\circ} \mathrm{C}$.

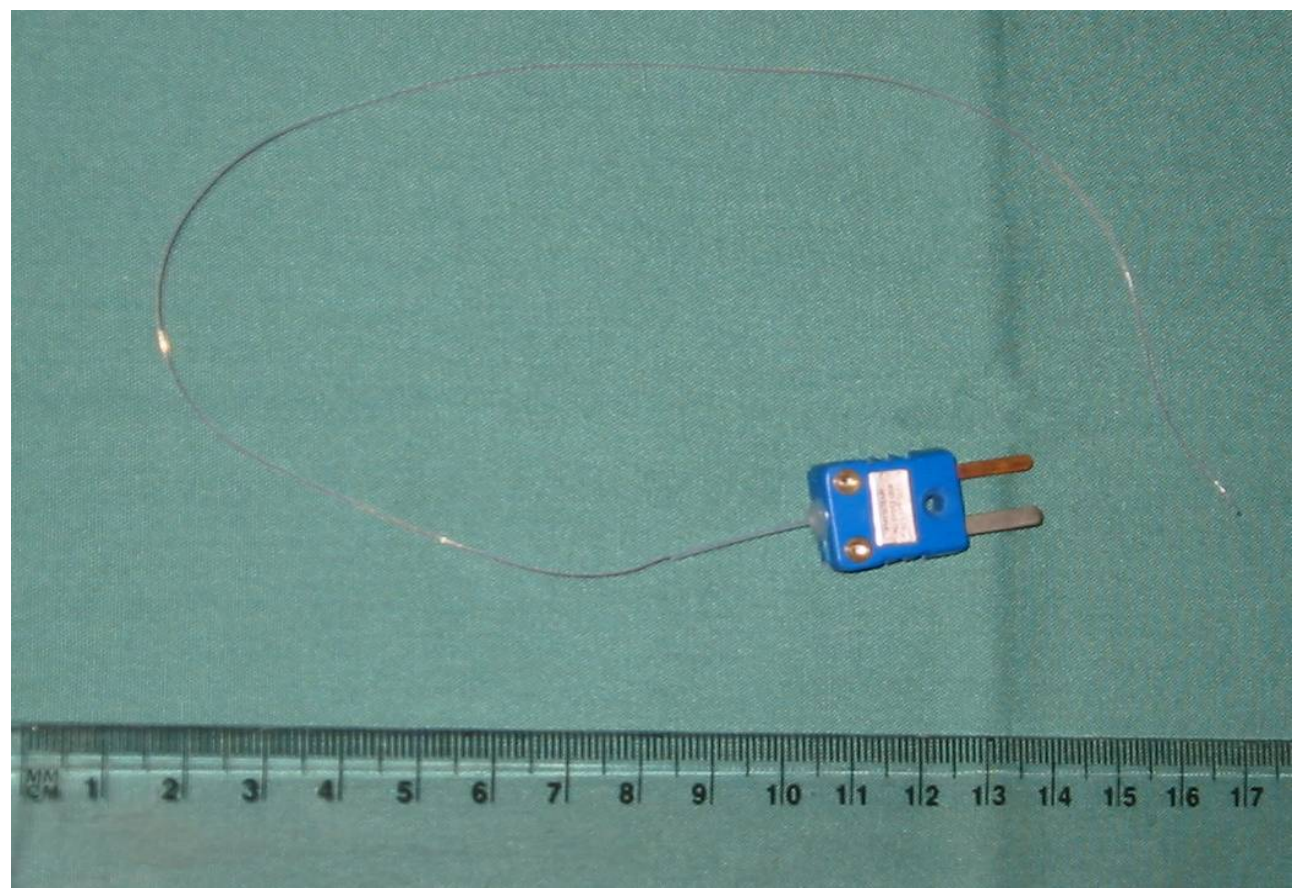

Figure 2.4 IT-21 temperature probe. 
The tip of the thermocouple was positioned to lie in the radial artery in the following manner. A $10 \mathrm{~cm}$ J-loop, Y-adaptor, minimum volume extension tubing sample line and attached 3-way tap were filled with heparinized saline and connected in the manner shown in Fig. 2.5.

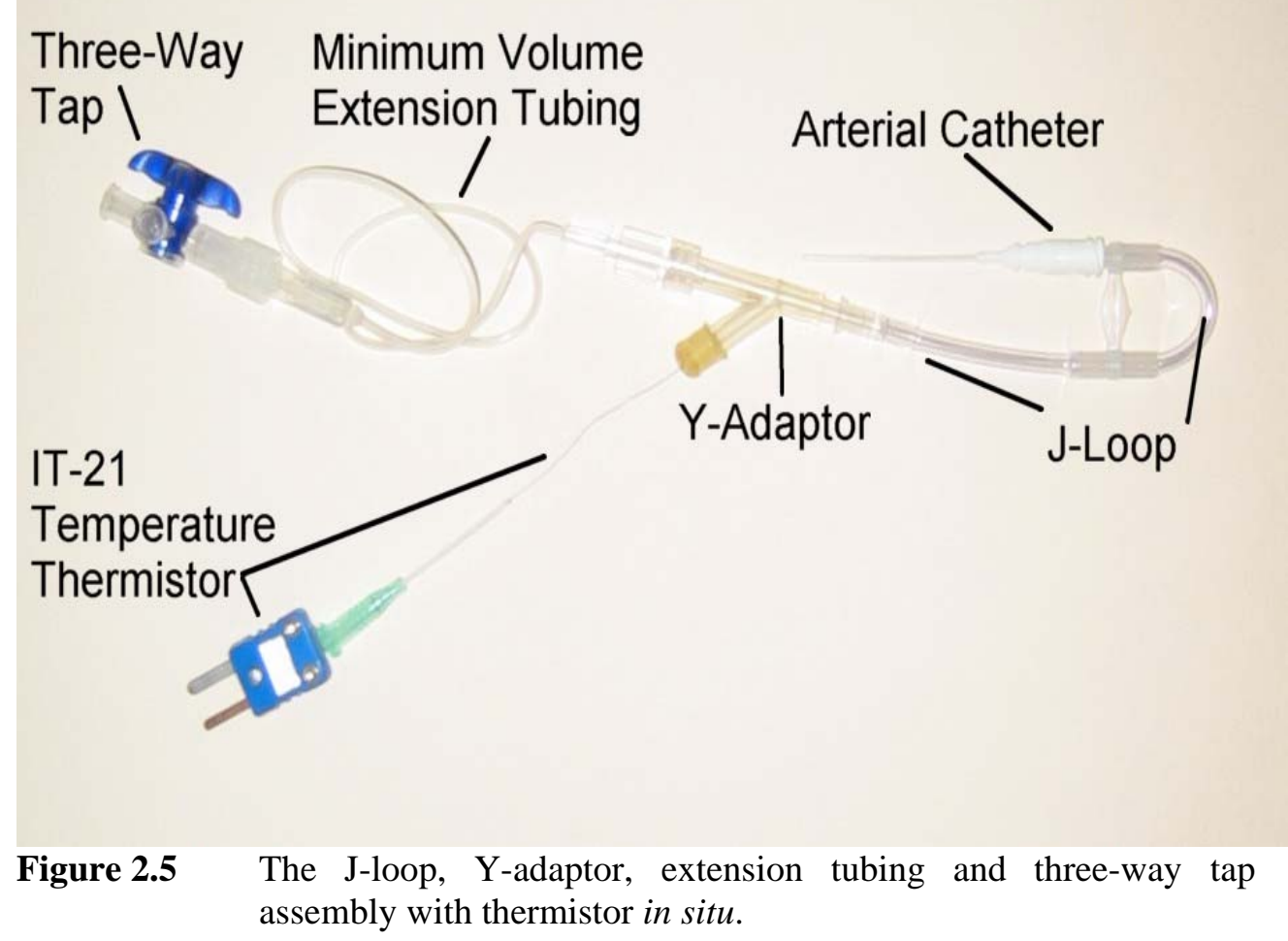

A 21-gauge needle was then inserted into the yellow rubber cap covering the injection port of the $\mathrm{Y}$-adaptor and the thermistor inserted through the needle lumen into the J-loop and passed distally to emerge $3 \mathrm{~cm}$ beyond the exit port prior to its attachment to the catheter hub. The thermocouple was held in place whilst the needle was removed from the rubber cap of the injection port by sliding it towards the plug of the thermocouple. The thermocouple cable was then taped in place (Micropore ${ }^{\mathrm{TM}}$ Surgical Tape, 3M Health Care, Minnesota, 
USA) at the rubber cap of the Y-adaptor and the needle taped to the plug (Fig. 2-

5). Once the radial artery catheter had been inserted the heparinized-saline filled connecting line was removed from the catheter butt, while at the same time an assistant compressed the radial artery proximal to catheter insertion point to prevent untoward bleeding. The exposed thermistor tip was then manoeuvred into the catheter such that its tip lay in the radial artery just beyond the catheter tip and a junction then made between the J-loop port and catheter hub while a small flow of heparinized saline was encouraged to avoid air bubbles. Once all this had been completed the whole catheter and J-loop assembly was taped to the arm (Transpore, 3M Health Care) (Fig. 2.10). An extension lead was attached to the thermistor plug and taped along the arm and over the shoulder so as not to impede the running motion. This extension lead was then attached to the readout device.

\subsubsection{Muscle Temperature}

Muscle temperature was initially measured using the Physitemp IT-21 probes (Fig. 2.4). However these probes were extremely fragile and would rarely last more than a single test due to constant flexion at the fascia-muscle interface. With the assistance of Physitemp Instruments (New Jersey, USA) a sturdier temperature probe was developed, the T204-A being the initial incarnation that was later slightly modified into the T204-B. These probes (Figure 2.6) were made of a thicker copper wire with a dual thickness Teflon outer; a double layer along most of the thermistors' length which was reduced to a single layer approximately $1 \mathrm{~cm}$ from the tip of the thermistor. This provided 
more resistance to flex at the fascia-muscle interface but ensured an excellent response time ( 0.1 seconds) to temperature changes in the muscle belly.

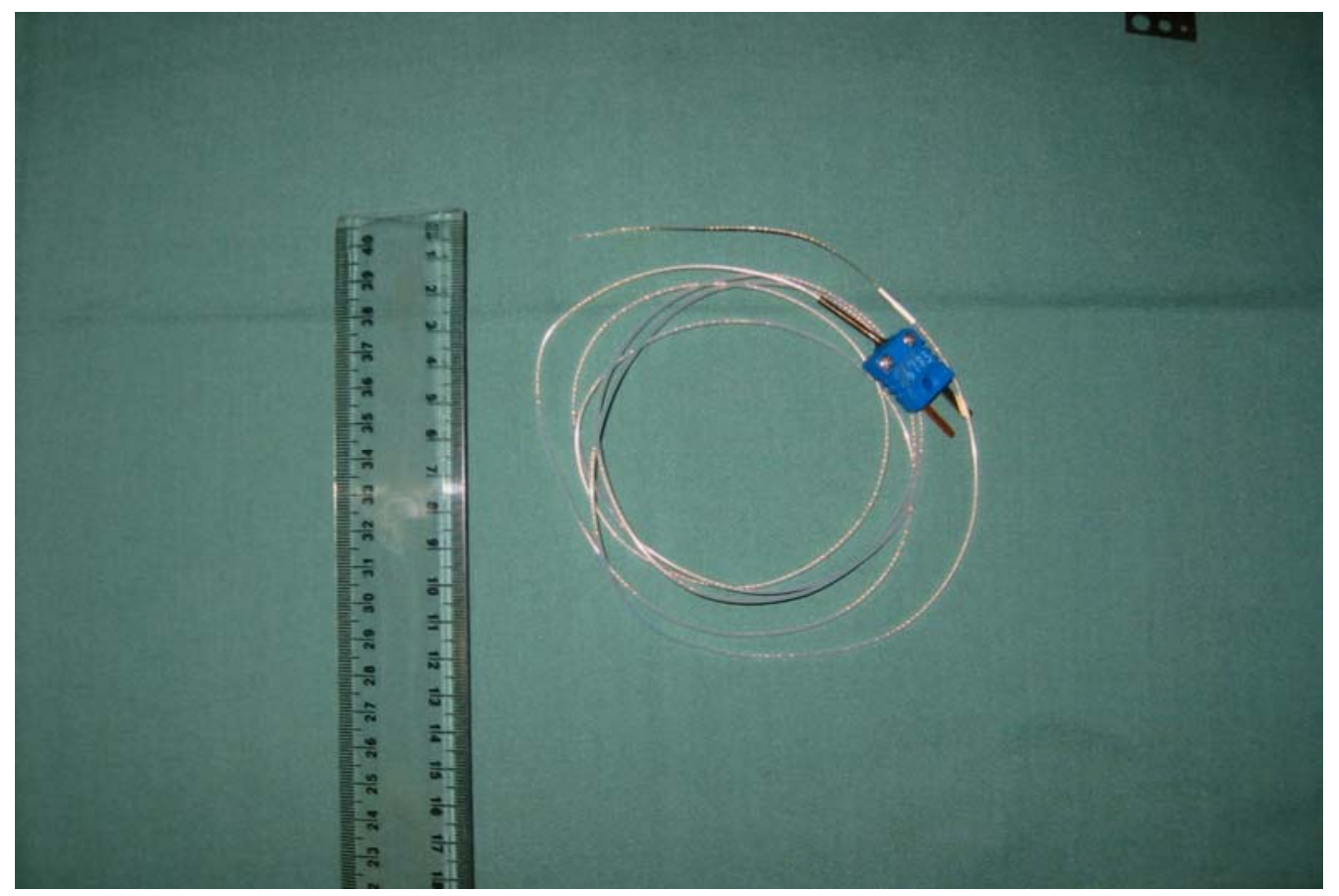

Figure 2.6 T204-A/B temperature probe

The active muscle temperature was measured in the belly of the vastus lateralis muscle, approximately 5-cm from the head of the muscle, and at a depth of 3-cm. Upon locating the site of temperature probe insertion the skin surface was prepared by shaving the area and swabbing with an iodine solution (Povidone-Iodine). A small amount of local anaesthetic was administered subcutaneously before a needle was inserted intramuscularly to a depth of 3-cm. As the needle was introduced into the muscle, $5 \mathrm{ml}$ of local anaesthetic was ejected from the attached syringe to anaesthetise the muscle to a depth slightly exceeding that to which the temperature thermistor was to be inserted. A needle 
catheter (18G, Terumo,) was then inserted into the muscle, the needle withdrawn and the lumen firmly taped to the surrounding skin. The temperature thermistor (IT-21 or T204-A/B, Physitemp Instruments, New Jersey, USA) was then inserted into the lumen and taped to the lumen's hub. The thermistor lead was taped up along the subject's leg following which the entire set-up was fixed with a transparent adhesive dressing (Tegaderm 1626, 3M Canada Inc) (Figure 2.7).

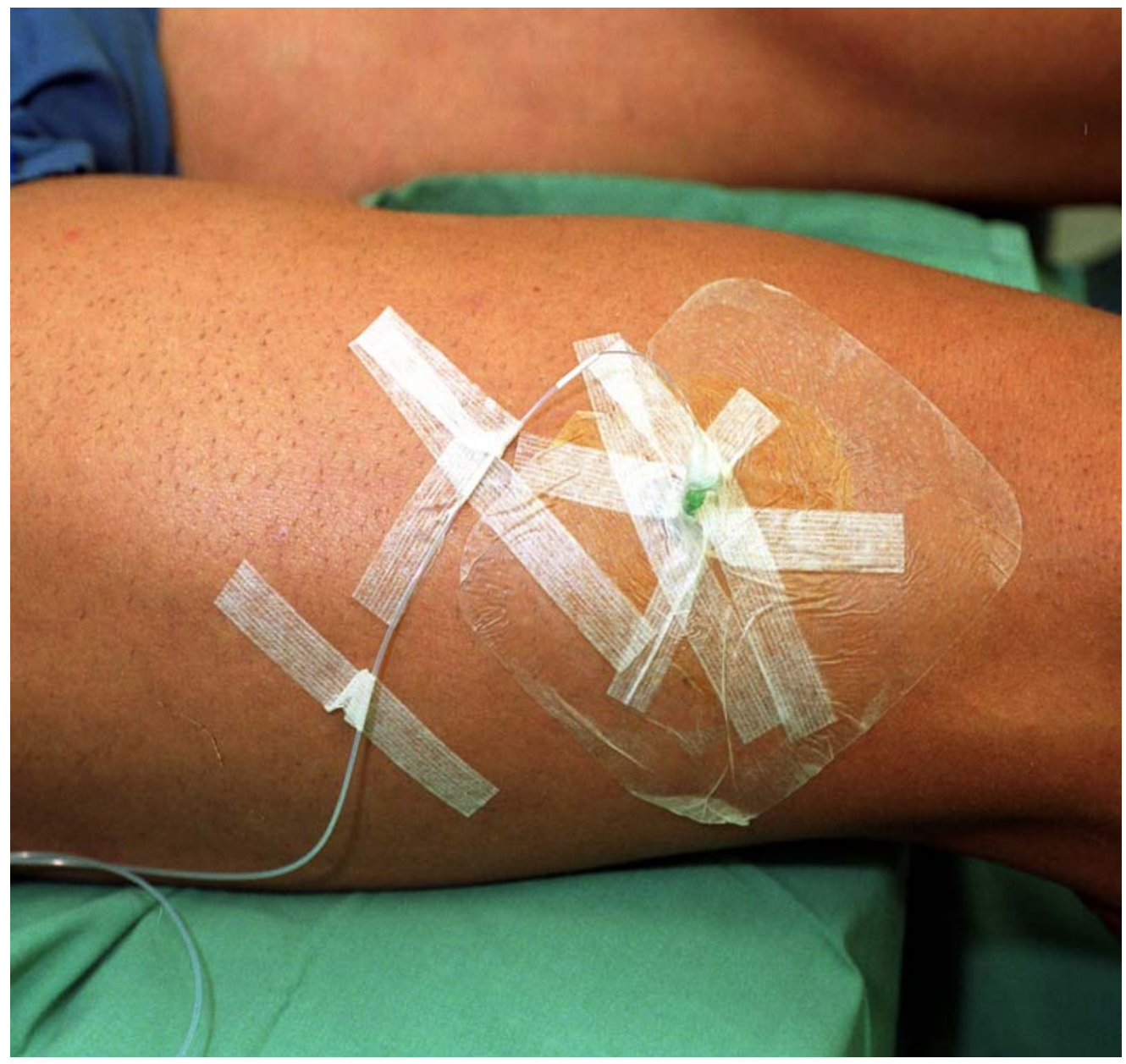

Figure 2.7 Muscle temperature probe in situ 


\subsubsection{Calibration of Temperature Probes and Thermistors}

Temperature probes and thermistors were all calibrated utilising a spirit-filled National Association of Testing Authorities (NATA) certified thermometer (Cameron Industries, Adelaide, Australia). The thermistor or probe was taped directly to the thermometer and then inserted into a water bath that was stirred using a magnetic stirrer. The temperature of the water bath was allowed to slowly decrease from $43^{\circ} \mathrm{C}$ to $32^{\circ} \mathrm{C}$ whilst simultaneous measurements of the thermometer and the thermistor/probe were recorded. From these data a regression equation was created for each thermistor or probe and all temperature measurements from the experiment were corrected against the appropriate regression equation for the corresponding thermistor or probe (Figure 2.8). Thermistors and probes that were used multiple times were calibrated every few tests, and the regression values of these probes were found to be unchanged over time. 


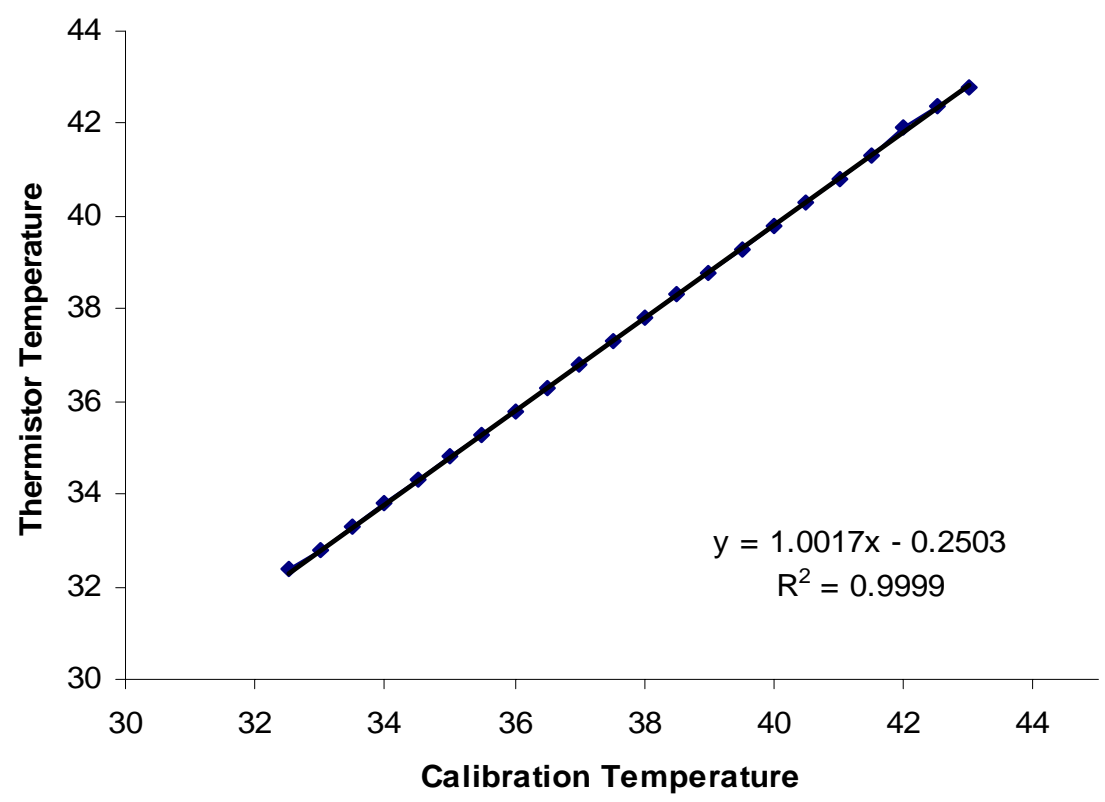

Figure 2.8 An example of temperature thermistor calibration against a spirit-filled, NATA certified, thermometer.

Readouts of temperature were taken from various devices. In early experiments the rectal and oesophageal temperature probes were attached to a dual-input digital thermometer (CIG Industries, Adelaide, Australia) and the IT21 thermistor was attached to a TH-5 digital thermometer (Physitemp Instruments, New Jersey, USA). In later experiments all temperaturemeasurement devices were attached to an optically isolated junction box which produced real-time readouts of temperature on a PC. This system (THERMES, Physitemp Instruments, New Jersey, USA) also allowed automated logging of temperature during the exercise test. 


\subsection{ARTERIAL CATHETERISATION AND BLOOD SAMPLING}

\subsubsection{Arterial Catheterisation}

After insertion of the rectal and oesophageal probes subjects lay supine on a couch with their non-dominant arm (usually the left) extended and the position of the radial artery at the wrist identified (Fig. 2.9). To ensure that tissue viability would be preserved in the event of a radial artery misadventure, during or after catheterisation, a modified Allen's Test (Allen, 1929) was performed in all subjects. This involved the subject making a tight fist, causing the palmar skin to blanch, while the experimenter applied finger pressure to occlude the subject's ulnar and radial arteries. The subject was then instructed to open their fist, exposing the blanched palmar skin, and the pressure on the ulnar artery released. The rapid and complete return of normal colour to the entire palmar skin, despite continued radial artery occlusion, was taken to indicate that the anastomotic flow from the ulnar artery was sufficient to maintain the palmar arch circulation. 


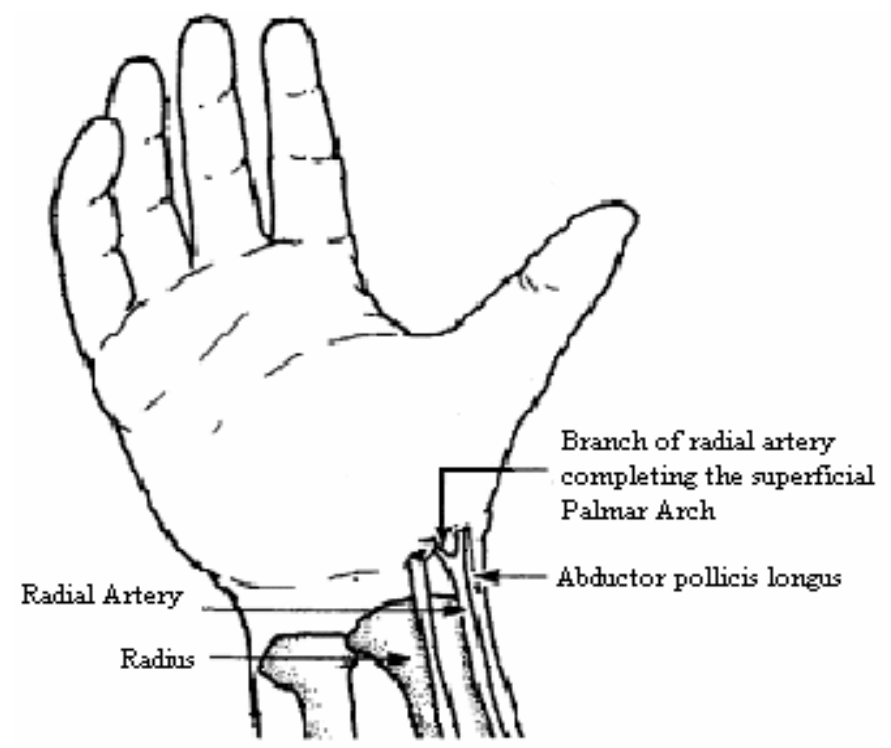

Figure 2.9

Location of Radial Artery

The area of the proposed arterial puncture site was cleaned using a Povidone-Iodine Swabstick (Professional Disposals, Inc., Ontario, Canada) and a small amount of local anaesthetic $(<0.5 \mathrm{~mL} ; 2 \%$ lignocaine hydrochloride, Xylocaine) injected subcutaneously using a $1 \mathrm{ml}$ syringe with a small gauge needle (BD Ultra-Fine ${ }^{\mathrm{TM}}$, Becton, Dickinson and Company, Franklin Lakes, NJ, USA 07417-1883). A Quickflash ${ }^{\circledR}$ Radial Artery Catheter (20 gauge/38-mm, Arrow International, Pennsylvania, USA) was then inserted with the tip directed towards the heart and a polyethylene extension tube (Minimum Volume Extension Tubing, $30 \mathrm{~cm}$, dead space $0.3 \mathrm{~mL}$; B. Braun Melsungen AG, Melsungen, Switzerland) sealed with a three-way tap (B. Braun) attached to the catheter hub, the entire system having been filled with heparinised normal saline (2,500 Units/L) prior to attachment. Once all was secure, firm finger pressure was exerted on skin overlying the radial artery upstream from the catheter entry site to obstruct blood flow and the extension tube connector removed from the 
catheter butt. This was replaced with the J-loop-Y-adaptor assembly, with the tip of previously inserted arterial temperature thermistor protruding $~ 2 \mathrm{~cm}$ from the tip (Fig. 2.5). The protruding thermistor tip was threaded into the catheter (while heparinized saline dribbled from the catheter assembly to avoid trapped air bubbles), a firm junction with the connecting line assured and then the entire assembly positioned to lie flat on the subject's wrist. To prevent accidental displacement of the catheter during the exercise test a small stitch (3-O black silk, Ethicon, Inc., Somerville, USA) was used to secure the catheter hub to the nearby skin. To support the sampling configuration during the exercise test the entire set up was covered with a sterile, adhesive, transparent dressing (Tegaderm 1626, 3M Canada Inc, Ontario, Canada) (Fig. 2.10).

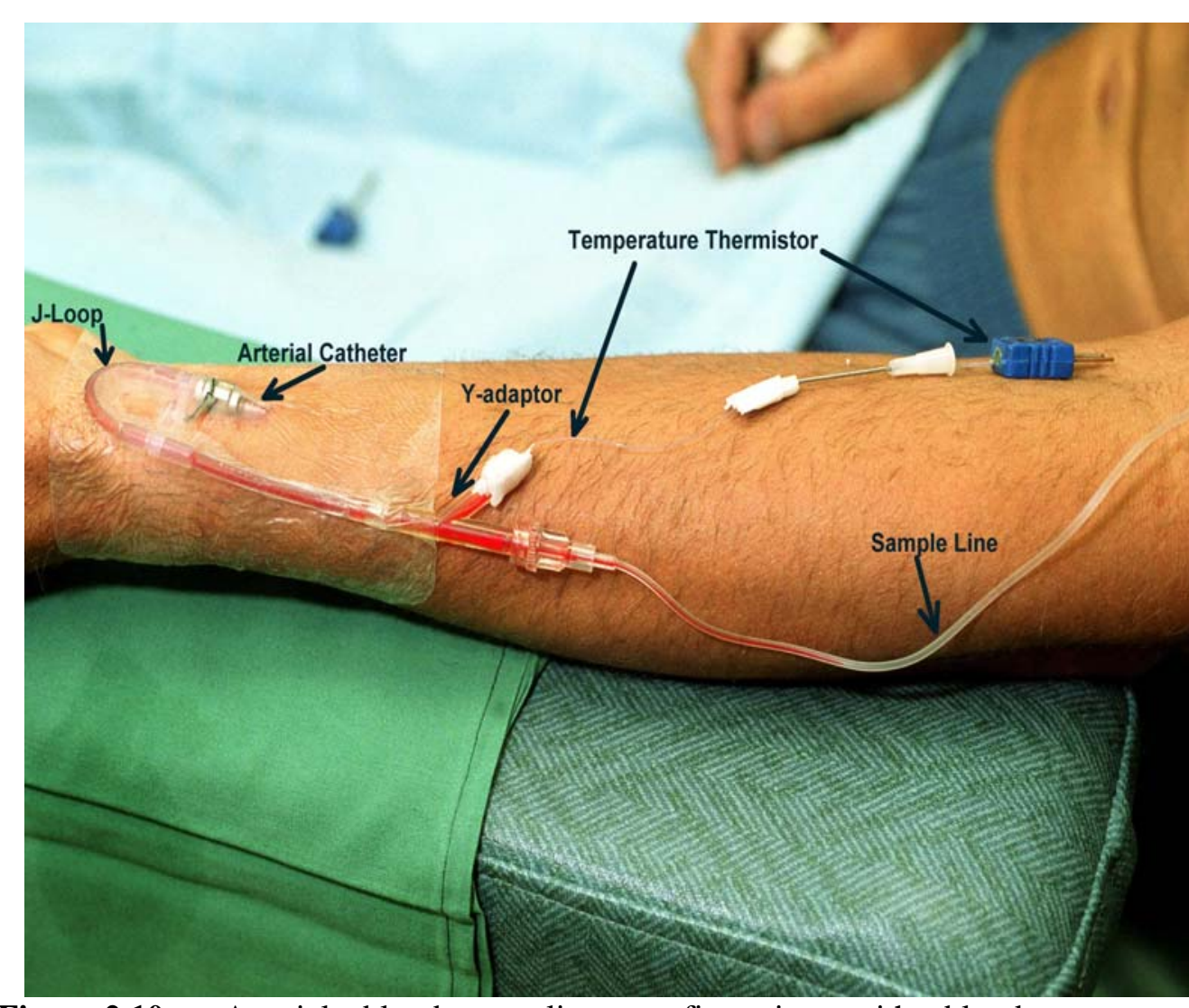

Figure 2.10 Arterial blood sampling configuration with blood temperature thermistor 


\subsubsection{Blood Sampling}

Prior to obtaining each whole blood sample for assay, the initial $\sim 4-\mathrm{mL}$ of the contents of the catheter system (“dead-space”, blood-saline mixture) were drawn into a separate sterile plastic disposable syringe. The assay sample $(5 \mathrm{~mL})$ was then drawn anaerobically into a pre-heparinised ground-glass syringe (Becton Dickinson, New Jersey, USA), capped immediately and stored vertically in a slurry of melting ice. Prior to the glass syringe being capped, any air bubbles that may have been present from the sampling procedure were removed to maintain the blood gas integrity of the sample. The "dead space" sample was re-injected after each blood sampling and the catheter system flushed with heparinised saline (2500 U/L) to prevent the development of blood clots in the sampling line.

Three whole-blood samples $(5 \mathrm{~mL})$ for blood gas analysis were drawn preexercise for documentation as "resting" baselines. The first of these resting samples was drawn with the subject in the supine position, approximately 20 minutes after the insertion of the arterial catheter and 20 minutes prior to the start of the exercise test $\left(T_{-20}\right)$. The second sample was drawn with the subject standing astride the stationary treadmill without the nose clip or mouthpiece applied $\left(\mathrm{T}_{-2}\right)$, and the final sample with these apparatus applied and the treadmill running at its starting speed $\left(\mathrm{T}_{0}\right)$. Blood samples during the exercise test were taken in the final 15-s of each 2-min workload, until exhaustion. 


\subsubsection{Blood Gas Analysis}

The instrument used for blood gas analysis was an ABL520 (Radiometer; Copenhagen, Denmark) with the partial pressures of oxygen $\left(\mathrm{P}_{\mathrm{a}} \mathrm{O}_{2}\right)$ and carbon dioxide $\left(\mathrm{P}_{\mathrm{a}} \mathrm{CO}_{2}\right)$, haemoglobin saturation and $\mathrm{pH}$ measured at $37^{\circ} \mathrm{C}$ in all samples. The manufacturer's testing of the "Imprecision Parameters" of the blood gas analyser demonstrated the repeatability of a single sample measured using 1) the same instrument, 2) the same measurement procedure and 3) the same operator of $\sim 0.675 \mathrm{mmHg}$ (sample $\mathrm{PaO}_{2}=100 \mathrm{mmHg}$ ). The ABL520 was part of a busy clinical respiratory testing laboratory and, as such, was stringently maintained to retain such repeatability as well as meet the requirements of NATA accreditation. With regard to each test, one- and two-point calibrations were made prior to, during and following analysis of experimental samples.

To ensure homogeneity of assayed whole blood sub-samples, all were remixed prior to analysis by gently rolling the syringe between the hands. After expelling a small amount of blood on to a gauze swab the sample was introduced into the blood gas analyser with each analysis performed in duplicate. If the duplicated results in any sample differed by more than $0.6 \mathrm{mmHg}$, a third measurement was taken and the closest two results used in data analysis.

\subsubsection{Temperature correction of blood gas values}

To account for body temperature changes during exercise all blood gas measurements (made at $37^{\circ} \mathrm{C}$ ) were corrected for the temperatures measured simultaneously with the several temperature probes. These corrections were 
performed utilising the partial pressure gas equations of Severinghaus (1979) such that:

$$
\begin{aligned}
& \mathrm{PaO}_{2} \text { (corrected) }=\mathrm{PaO}_{2}\left(37^{\circ} \mathrm{C}\right) \times 10^{\left(\left(\left(0.0252 /\left(\left(0.243 \times\left(\left(\mathrm{PaO}\left(37^{\circ} \mathrm{C}\right) / 100\right) 3.88\right)\right)+1\right)\right)+0.00564\right) \times(\mathrm{Tb}-37)\right)} \\
& \text { where : } \mathrm{PaO}_{2}\left(37^{\circ} \mathrm{C}\right)=\mathrm{PaO}_{2} \text { as reported by the ABL520 } \\
& \qquad \begin{aligned}
\mathrm{T}_{\mathrm{b}} & \text { Body temperature as measured at rectal, } \\
& \text { oesophageal, muscle or arterial sampling } \\
& \text { site. }
\end{aligned}
\end{aligned}
$$

Equation 2.5 Correction of $\mathrm{PaO}_{2}$ for temperature.

To account for the temperature effect on $\mathrm{CaO}_{2}, \mathrm{SaO}_{2}$ was calculated using temperature-corrected values of $\mathrm{PO}_{2}$ and $\mathrm{pH}$ using the equation from SiggaardAndersen, Wimberley et al (1984):

$$
y-y_{0}=x-x_{0}+h \cdot \tanh \left[k \cdot\left(x-x_{0}\right)\right]
$$

and

$$
y=\ln [s /(1-s)], x=\ln \left(\mathrm{PO}_{2} / 7.5\right)
$$

where

$$
\begin{aligned}
& \text { where } \quad \begin{aligned}
y_{0} & =1.875 \\
x_{0} & =1.946+a+b \\
h & =3.5+a \\
k & =0.5343 \\
a & =1.04 \cdot(7.4-\mathrm{pH})-0.0025 \\
\text { and } \quad b & =0.055 \cdot(\mathrm{T}-37) .
\end{aligned}
\end{aligned}
$$

Equation 2.6 Temperature correction of $\mathrm{SaO}_{2}$. 


\subsubsection{Measurement of hematocrit}

The hematocrit of all blood samples was measured in triplicate following blood gas analysis. A small volume of mixed, whole blood was extracted from the glass syringes and drawn into heparinised, plastic-clad micro-hematocrit tubes (Becton Dickinson and Co., New Jersey, USA) via capillary action. One end of the tube was blocked using a plasticine compound and the tube placed into the centrifuge (Hema-C, Hawksley, Sussex, UK) making sure the position of each tube was identified by noting its position in the base. The centrifuge lid was closed and fixed down and the timer set to spin the tubes for 5 minutes at 10,000rpm. Following this the lid was removed and the volume of packed red blood cells measured as a percent of the whole blood volume utilising a dedicated hematocrit ruler (Hawksley, Sussex, UK).

\subsection{OXYGEN CONSUMPTION AND CARBON DIOXIDE PRODUCTION.}

\subsubsection{Measurement procedures}

The measurement of metabolic variables was performed on-line using an indirect calorimetry system (Figure 2.1). A Hans Rudolph pneumotachograph (3813 series, 0-800 L.min ${ }^{-1}$; Hans Rudolph, inc., Missouri, USA) was used to measure the subject's inspiratory volume that was converted to $V_{E}$ ( $L$. $\mathrm{min}^{-1}$, BTPS and STPD) utilising the Haldane transformation (Haldane, 1912). The pneumotachograph was connected via wide bore tubing (9000 series, Hans Rudolph, inc., Missouri, USA) to a Hans Rudolph one-way breathing valve 
(2700 series) which was in turn connected to a 5L baffled mixing chamber (Vacu-Med, California, USA), also by wide bore tubing. Oxygen $\left(\mathrm{O}_{2}\right)$ and carbon dioxide $\left(\mathrm{CO}_{2}\right)$ gas concentrations of the subject's expirate were measured with an AMIS2000 mass spectrometer (Odense, Denmark) which continuously sampled the subject's expirate from the distal end of the mixing chamber. Measurements of gas concentrations were performed with the water vapour (ATPC) correction of the mass spectrometer turned on. A personal computer was programmed to perform the calculations for expired ventilation rate (minute ventilation, $\dot{\mathrm{V}}_{\mathrm{E}}$, L.min ${ }^{-1}$, STPD), oxygen consumption $\left(\dot{\mathrm{VO}}_{2}, \mathrm{~L} \cdot \mathrm{min}^{-1}\right.$, STPD) and carbon dioxide production $\left(\dot{\mathrm{V} C O}{ }_{2}, \mathrm{~L} \cdot \mathrm{min}^{-1}\right.$, STPD) and from these latter two, respiratory exchange ratio (RER). All calculations took into account the dead space of the mouthpiece, the lag phase between the expired breath and the subsequent sampling of expiratory gas, and were expressed as averages over the 30 seconds of sample time. Maximal oxygen uptake ( $\dot{\mathrm{VO}}_{2}$ max) was defined as the highest value of $\dot{\mathrm{VO}}_{2}$ reached during any 30s measurement interval and divided by the subjects body mass for conversion into units of $\mathrm{ml} \cdot \mathrm{kg}^{-1} \cdot \mathrm{min}^{-1}$.

\subsubsection{Pre-test calibration procedures.}

The mass spectrometer was calibrated using a precision grade gas concentration (BOC Gases, New South Wales, Australia) of physiological significance as per the manufacturer's instructions. The AMIS2000 was periodically "peaked" to validate the atomic weight of each measured gas $\left(\mathrm{O}_{2}\right.$, $\mathrm{CO}_{2}$, Nitrogen $\left(\mathrm{N}_{2}\right)$ and Argon (Ar)), also as per manufacturers' instructions to ensure accuracy of analysis. 
The pneumotachograph system was linearised using at least 25 strokes of a 3 litre calibration syringe (MultiFlow ${ }^{\mathrm{TM}}$, Pulmonary Data Service Instrumentation, Colorado, USA), followed by a test calibration of at least 10 strokes of the same syringe.

\subsubsection{Validation of Metabolic System.}

The combined pneumotachograph/spectrometer/computer system for the measurement of metabolic variables was validated using the MAX2 metabolic system as developed by the Australian Institute of Sport (Canberra, ACT, Australia). The MAX2 system produces a specific “ $\dot{\mathrm{V}} \mathrm{O}_{2}$ ” utilising a known gas concentration flowing at a known rate (variable and determined by the MAX2's operator). This $\dot{\mathrm{VO}}_{2}$ is measured simultaneously by the system being validated for a direct comparison of its accuracy. The validation study results from our system are presented in Appendix 7.2.

\subsubsection{Technical Error of Measurement of $\dot{\mathrm{V}} \mathrm{O}_{2}$ max.}

As with the collection of any data there is a degree of uncertainty as to the reliability and reproducibility of the measurement. To ascertain the reliability of the measurement of $\dot{\mathrm{VO}}_{2}$ max, five subjects performed repeat exercise tests to exhaustion with all metabolic measures recorded. From these data the most

important variable with regard to this series of experiments, $\mathrm{VO}_{2}$ max, was compared for repeat tests (Table 2.2) and the Technical Error of Measurement (TEM) and Intraclass Correlation Coefficient (ICC) calculated. 
The TEM is the square root of the error mean square $(\sqrt{ } \mathrm{MSe})$, within groups, and has units equal to that of the variable being measured and the following value obtained:

$\begin{aligned} \text { Technical Error of Measurement } & = & \text { MSe } \\ & = & \sqrt{ } 0.00259 \\ & = & 0.05 \mathrm{~L} \cdot \mathrm{min}^{-1}\end{aligned}$

The ICC is a measure of the reliability of the testing procedure, and ranges between the values 0 and 1 . It is calculated using the formula:

$$
\mathrm{ICC}=\frac{\text { MSs }-\mathrm{MSe}}{\mathrm{MSs}+\mathrm{MSe}}
$$

Values approaching 1.0 indicate a high degree of reliability, and are due to the excellent level of accord in test-retest values as the ICC is calculated utilising the mean square errors between and within subjects. From the results of the ANOVA in the preceding text the following value was obtained:

$\begin{array}{ll}\text { Intraclass Correlation Coefficient } \quad= & \frac{0.42906-0.00259}{0.00259+0.42906} \\ & =0.99\end{array}$


Table 2.2. Test-retest results for $\dot{\mathrm{V}} \mathrm{O}_{2}$ max reproducibility

\begin{tabular}{ccc}
\hline Subject Number & Trial 1 & Trial 2 \\
\hline Subject 1 & 5.001 & 4.987 \\
Subject 2 & 4.051 & 4.004 \\
Subject 3 & 4.472 & 4.33 \\
Subject 4 & 4.647 & 4.699 \\
\hline Subject 5 & 5.176 & 5.201 \\
\hline
\end{tabular}

Table 2.3 ANOVA result for $\dot{\mathrm{V}}_{2}$ max reproducibility.

\begin{tabular}{|c|c|c|c|c|c|}
\hline Groups & Count & Sum & Average & Variance & \\
\hline Row 1 & 2 & 9.99 & 4.9940 & 0.00010 & \\
\hline Row 2 & 2 & 8.06 & 4.0275 & 0.00110 & \\
\hline Row 3 & 2 & 8.80 & 4.4010 & 0.01008 & \\
\hline Row 4 & 2 & 9.35 & 4.6730 & 0.00135 & \\
\hline Row 5 & 2 & 10.38 & 5.1885 & 0.00031 & \\
\hline \multicolumn{6}{|l|}{ ANOVA } \\
\hline $\begin{array}{l}\text { Source of } \\
\text { Variation }\end{array}$ & SS & $d f$ & $M S$ & $F$ & P-value $F$ crit \\
\hline Between Groups & 1.7162 & 4 & 0.42906 & 165.67366 & 0.000025 .19216 \\
\hline Within Groups & 0.0129 & 5 & 0.00259 & & \\
\hline Total & 1.7292 & 9 & & & \\
\hline
\end{tabular}




\subsection{TREADMILL \\ INCREMENTAL EXERCISE}

PROTOCOL

FOR

Exercise began with the subject standing astride the treadmill belt, a nose clip applied and an externally supported breathing valve (Hans Rudolph, HR2700) inserted into the mouth for collection of expired gases. All leads for the measurement of temperature were attached securely to the treadmill allowing enough slack for the subject to move freely during the exercise test. The treadmill was started at zero gradient and a speed set of $4 \mathrm{~km} \cdot \mathrm{h}^{-1}$. After 2-min standing astride the treadmill belt the subject was instructed to begin walking. After 2 minutes, and every 2-min thereafter the belt speed was increased by 2 $\mathrm{km} \cdot \mathrm{h}^{-1}$, until a speed of $12 \mathrm{~km} \cdot \mathrm{h}^{-1}$ was reached. Following 2-min at this speed the grade of the treadmill was increased by $2 \%$ and further work loads generated by increasing the grade $2 \%$ every 2-min thereafter, until volitional exhaustion. The test was terminated when the subject was unable to maintain the applied workload and pressed the stop button on the treadmill. During the exercise period and particularly as age-predicted maximal heart rate was approached the subject was given verbal encouragement in an attempt to elicit a maximal effort.

\subsection{HEART RATE AND ECG MEASUREMENT}

Immediately prior to the subject mounting the treadmill a heart rate monitor strap / transmitter (Polar Sport Tester; Polar Electro Oy, Kempele, Finland) was placed around their chest. Three chest electrodes were positioned 
on the subjects' chest and the Nihon-Kodon transmitter leads and transmitter attached. The leads were run over the subjects' right shoulder and, along with the transmitter, taped to the subject to prevent displacement whilst allowing freedom of movement (see Figure 2.11). Heart rate was recorded at 5 second intervals on the Sport Tester receiver, whilst the ECG trace was regularly monitored for signs of abnormal heart wave responses. Heart rate data were manually transcribed from the Sport Tester heart rate receiver ensuring metabolic data and heart rate data measurements were temporally aligned.

\section{$2.8 \quad$ DATA ANALYSIS}

Values are expressed as mean \pm standard deviation $( \pm$ SD). Alpha was set at $P<0.05$ and confidence levels, where expressed, 95\%. All statistics were

performed using SigmaStat statistical software (Systat Software, Inc., Version 3.5, California, USA) or EXCEL (Microsoft Corporation, Washington, USA).

Specific statistics for each chapter are outlined in the Data Analysis sections 3.2.3, 4.2.4 and 5.2.7. 


\section{CHAPTER 3}

\section{Thermal Status During Incremental}

\section{Exercise}

\subsection{INTRODUCTION}

While resting central body temperature (“core temperature”) is often cited in human physiological studies as $37^{\circ} \mathrm{C}$, use of a single, defined value has long been recognised as a simplification. Rather, the body's thermal status at any activity level is more accurately characterised as a spectrum of temperatures with a range extending from the warmer internal organs of the abdominal and thoracic cavities to the cooler skin surfaces of the extremities (Aschoff and Wever, 1958). This spectrum fluctuates from moment to moment in concert with biorhythms and the changing internal and external environments associated with normal daily activities.

With regard to the thermal response to exercise, the most commonly measured reference is rectal temperature (Saltin and Hermansen, 1966; Aulick, Robinson et al, 1981; Febbraio, Carey et al, 1996; Robinson, Seal et al, 1998; Parkin, Carey et al, 1999; Lee, Williams et al, 2000; Morris, Nevill et al, 2005), yet its ability to accurately track the sudden changes in thermal load has been questioned (Saltin and Hermansen, 1966; Aulick, Robertson et al, 1978; Shiraki, 
Konda et al 1986). Measurements at other sites in the body, including the mouth (Gerbrandy, Snell et al, 1954; Mairiaux, Sagot et al, 1983), oesophagus (Gerbrandy, Snell et al, 1954; Gass, Camp et al, 1988; Shiraki, Konda et al, 1986; Gonzalez-Alonso, Teller et al, 1999), arterial blood (Hammond, Gale et al, 1986), intestine (Lee, Williams et al, 2000) and muscle (Buchthal, Hencke et al, 1944; Blomstrand, Kaijser, et al, 1986; Drust, Rasmussen et al, 2005) demonstrate faster response times but, not unexpectedly, display a broad spectrum of temperatures.

While the above deliberations must be borne in mind when investigating the mechanisms of thermoregulation during exercise, they are of particular significance when such studies also involve measurements of the arterial blood gases, which are critical to the research studies reported in this thesis. The reason for this is that most blood gas machines use the "normal" body core temperature of $37^{\circ} \mathrm{C}$ as the reference, yet increments of $2-3^{\circ} \mathrm{C}$ are not uncommon during exercise. Failure to make appropriate corrections to the blood gas values will produce an error of $\sim 5 \mathrm{mmHg}$ for every ${ }^{\circ} \mathrm{C}$ differential in "core" temperature from the machine reference (Severinghaus, 1979). This will be particularly critical in establishing the degree of arterial hypoxemia in athletes during incremental exercise (exercise induced hypoxemia, EIH), yet several reviews on the topic have considered such corrections unnecessary, insignificant or not worthy of discussion (Powers and Williams, 1989; Prefaut, Durand et al, 2000; Nielsen, 2004). An exception is the review by Dempsey and Wagner (1999) whose authors report that failure to make appropriate temperature corrections of arterial blood gas values produces errors that "are equal to the 
suggested minimum decrements in $\mathrm{PaO}_{2}$ for defining exercise-induced arterial hypoxemia". While this review does not suggest the most appropriate measurement site from which to determine the temperature correction, the earlier discussion suggests a site should be chosen with a response time appropriate to the rapid changes in heat load during exercise. In this regard it would also seem intuitive to choose a site or sites where the transfer of metabolic gases occurs, i.e. the lungs and working muscles.

To explore these issues, and determine the optimum site or sites to track exercise responses, a group of male athletes performed treadmill exercise to volitional exhaustion while arterial blood samples were collected and temperature responses measured simultaneously at several different sites. Rectal temperature was measured for comparison with previous work; radial arterial temperature was measured as it reflects the temperature of blood arriving at inactive muscle and could be measured simultaneously with blood sampling; oesophageal temperature was measured as it reflects the temperature of pulmonary artery blood, and, hence, is close to the temperature of blood in the lungs where oxygen loading occurs; and finally, active muscle temperature (vastus lateralis) was measured as this is the site of $\mathrm{O}_{2}$ uptake by the working muscles. 


\subsection{METHODS}

\subsubsection{Subjects and Experimental Protocol}

Twenty-three subjects participated in the study. Of these, 12 did not have a temperature probe inserted into their vastus lateralis muscle. All subjects were trained in running and completed a medical questionnaire to ensure no past or present medical condition which would normally exclude them from performing a maximal exercise test. On the day of the incremental exercise test the subjects arrived at the laboratory having abstained from vigorous exercise within the previous 24 hours and from caffeinated products for 12 hours. All tests were performed at the same time of the day to minimise the effect of diurnal temperature rhythms both within and between subjects.

\subsubsection{Temperature Probe Placement and Exercise Test Protocol}

On arrival the subjects were re-acquainted with the laboratory and exercise protocol and then given the rectal temperature probe for self-insertion. The rectal probe was positioned such that the thermistor tip was inserted $10 \mathrm{~cm}$ past the anal sphincter and the probe secured to prevent displacement during the exercise test (see Section 2.3.2). The arterial catheter and temperature probe was then inserted under local anaesthetic (see Sections 2.3.4 and 2.4.1) following an Allen's test for adequate circulation of the hand (see Section 2.4.1). Following application of a local anaesthetic gel to the nasal cavity the oesophageal temperature probe was inserted and positioned such that the highest temperature 
reading was measured (see Section 2.3.3). In the 11 subjects where muscle temperature was measured, a fine temperature thermistor was inserted, again under local anaesthetic, to a depth of $3 \mathrm{~cm}$ into the vastus lateralis muscle (see Section 2.3.5).

Once all temperature probes were in place, three ECG leads were placed on the subject and a Polar heart rate monitor strap was positioned for the measurement of heart rate during the exercise test (see Section 2.7). Heart rate was recorded on the Polar receiver at 5 second intervals during and following the exercise test whilst the ECG pattern was monitored during the exercise test for any possible contra-indications.

Resting body temperature was recorded simultaneously at each probe site on three occasions; the first set was taken 20 min following the insertion of the arterial catheter $\left(\mathrm{T}_{-20}\right)$ and the second with the subject astride the treadmill $\left(\mathrm{T}_{-2}\right)$. The treadmill was then started at the speed and grade appropriate to the first workload and the Hans Rudolph one-way breathing valve placed in the subject's mouth. During the next 2 minutes the subject's expirate was collected to flush the mixing box of the metabolic measurement system (see Section 2.5.1) and the third set of resting temperatures taken $\left(\mathrm{T}_{0}\right.$, see Section 2.4.2). The subject then began walking on the treadmill and at the end of the first 2 minutes and every 2 minutes thereafter the treadmill speed or grade was increased according to a standard protocol until the subject reached volitional exhaustion (see Section 2.6). 
The temperatures at each of the 4 sites were measured simultaneously at the end of every workload. Following termination of the exercise test the subject was told to stand astride the treadmill and continue breathing through the one-way breathing valve. The treadmill was the returned to zero grade and the speed set at a slow walking pace. The subject was then instructed to step back on to the treadmill and walk for several minutes of recovery (see Section 2.6). The time of cessation of the incremental test was noted and every minute, for 10 minutes, following test cessation the temperatures at all measurement sites recorded simultaneously.

\subsubsection{Data Analysis}

Differences between resting temperatures at each site, the end-exercise temperatures at each site and the mean changes in temperature from rest to endexercise were analysed by means of a one way repeated measures ANOVA. Where a significant difference was obtained a Holm-Sidak t-test for multiple comparisons was performed to determine the differences between means. These tests were performed for each temperature site to ascertain the existence of differences from rest to maximal exercise when temperatures were expressed as relative to $\dot{\mathrm{V}} \mathrm{O}_{2}$ peak. Correlation between each temperature site was performed using a Pearson product moment correlation analysis. $\mathrm{R}$ values and subsequent trendline equations were used to evaluate the predictability of one temperature measurement from another. All statistics were performed using Statsoft statistical software (Version 3.5, Systat Software, Inc., California, USA). 


\subsection{RESULTS}

\subsubsection{General Anthropometric and Metabolic Data}

The mean $\dot{\mathrm{V}} \mathrm{O}_{2}$ peak of the subjects taking part in the experiment was $66.2 \pm 7.5 \mathrm{ml} \cdot \mathrm{kg}^{-1} \cdot \mathrm{min}^{-1}$, indicating that they were well-trained endurance athletes. These and further anthropometric data including height, age and resting pulmonary function results are presented in Table 3.1.

\subsubsection{Incremental Exercise Test}

The metabolic results of the incremental treadmill exercise test at volitional exhaustion are presented in Table 3.2. These data are not necessarily the peak data recorded by each subject. 
Table 3.1 Anthropometric, metabolic and respiratory function data of 23 trained subjects.

\begin{tabular}{|c|c|c|}
\hline & Mean & $\mathrm{SD}$ \\
\hline Age (years) & 26.0 & 4.8 \\
\hline Height (cm) & 181 & 7.4 \\
\hline Weight (kg) & 71.6 & 8.7 \\
\hline$\dot{\mathrm{V}} \mathrm{O}_{2 \text { peak }}\left(\mathrm{L} \cdot \mathrm{min}^{-1}\right)$ & 4.73 & 0.7 \\
\hline$\dot{\mathrm{VO}}{ }_{2 \text { peak }}\left(\mathrm{mL} \cdot \mathrm{kg}^{-1} \cdot \mathrm{min}^{-1}\right)$ & 66.2 & 7.5 \\
\hline $\mathrm{D}_{\mathrm{L}} \mathrm{CO}\left(\mathrm{mL} \cdot \mathrm{mmHg}^{-1} \cdot \mathrm{min}^{-1}\right)$ & 38.6 & 7.2 \\
\hline $\mathrm{FEV}_{1}(\mathrm{~L})$ & 4.60 & 0.8 \\
\hline FVC (L) & 5.60 & 0.8 \\
\hline
\end{tabular}


Table 3.2 Metabolic data at the cessation of an incremental treadmill test to exhaustion.

\begin{tabular}{lcc}
\hline & Mean & SD \\
\hline $\mathrm{HR}\left(\right.$ beats $\left.\cdot \mathrm{min}^{-1}\right)$ & 190 & 1 \\
$\dot{\mathrm{V}}_{\mathrm{E}}, \mathrm{L} \cdot \mathrm{min}^{-1}$ & 168.9 & 5.1 \\
$\mathrm{~V}$ & 2.96 & 0.15 \\
$\dot{\mathrm{VO}}_{2}\left(\mathrm{~L} \cdot \mathrm{min}^{-1}\right)$ & 4.68 & 0.15 \\
$\dot{\mathrm{VO}}_{2}\left(\mathrm{~mL} \cdot \mathrm{kg}^{-1} \cdot \mathrm{min}^{-1}\right)$ & 65.2 & 1.6 \\
$\dot{\mathrm{V} C O}_{2}\left({\left.\mathrm{~L} \cdot \mathrm{min}^{-1}\right)}\right.$ & 5.26 & 0.15 \\
$\mathrm{RER}$ & 1.13 & 0.02 \\
$\dot{\mathrm{V}}_{\mathrm{E}} / \dot{\mathrm{VO}}_{2}$ & 36.4 & 0.90 \\
$\dot{\mathrm{V}}_{\mathrm{E}} / \dot{\mathrm{V} C O}_{2}$ & 32.2 & 0.53 \\
$f\left(\mathrm{breaths} \cdot \mathrm{min}^{-1}\right)$ & 59 & 2 \\
\hline \hline
\end{tabular}

HR = heart rate, $\dot{\mathrm{V}}_{\mathrm{E}}=$ minute ventilation, $\mathrm{V}_{\mathrm{t}}=$ tidal volume, $\dot{\mathrm{V}}_{2}=$ rate of oxygen consumption, $\dot{\mathrm{V}} \mathrm{CO}_{2}=$ rate of carbon dioxide production, RER = respiratory exchange ratio, $\dot{\mathrm{V}}_{\mathrm{E}} / \dot{\mathrm{VO}}_{2}=$ ventilatory equivalent for oxygen, $\dot{\mathrm{V}}_{\mathrm{E}} / \dot{\mathrm{V} C O}_{2}=$ ventilatory equivalent for carbon dioxide, $f=$ breath frequency. 


\subsubsection{Body Temperature Responses During and Immediately Following Incremental Exercise Test}

\subsubsection{Temperature responses during incremental exercise test}

The individual rectal, arterial, oesophageal and muscle temperature responses for each subject during an incremental exercise test to exhaustion are presented in Figure 3.1. Subjects for which incomplete data sets were obtained have been included in this figure but were not included in any statistical analysis of the results. In the situation where a temperature reading progressively decreased with increasing exercise intensity it was assumed the probe had either moved from its correct position or was inserted incorrectly and the complete data set was excluded from both Figure 3.1 and statistical analysis.

With the exception of rectal temperature, all temperature responses show a decrease in recorded temperature at the start of exercise $(2 \mathrm{~min})$ with a nadir reached within $\sim 6$ minutes. From this nadir the temperature increased as exercise intensity increased, with each temperature measurement site exhibiting a different rate of temperature increase with exercise duration. In comparison rectal temperature remained fairly constant at the start of the exercise test with a slow increase in temperature noted in most subjects from approximately minute 10 of exercise onwards. 

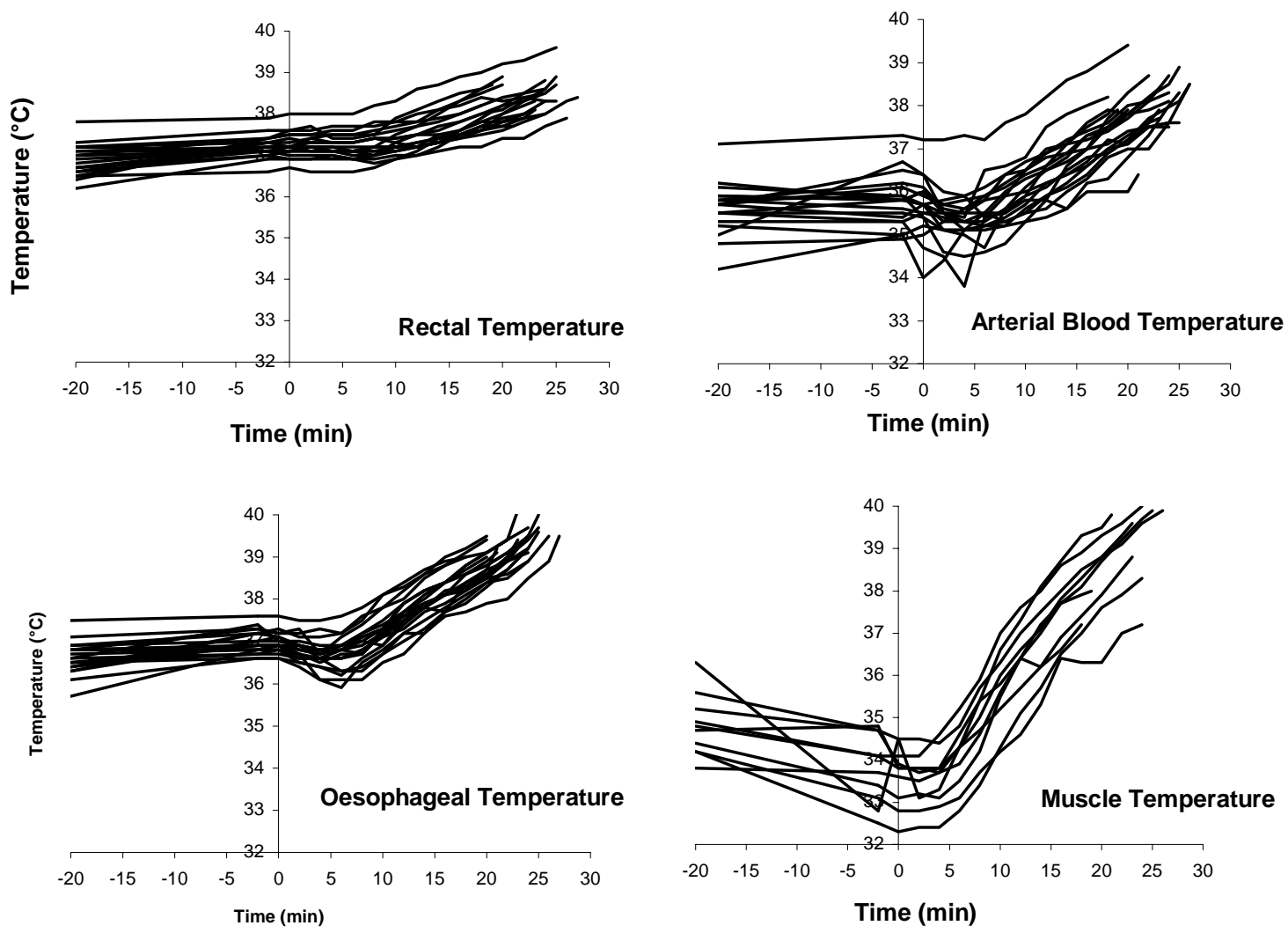

Figure 3.1 Individual temperature responses during incremental treadmill exercise. Rectal temperature $(n=20)$, Arterial blood temperature $(n=20)$, Oesophageal temperature $(\mathrm{n}=23)$, Muscle (Vastus lateralis) temperature $(\mathrm{n}=10)$.

Averaged rest $\left(T_{0}\right)$ and end-exercise temperatures as measured at the site of the rectal, arterial, oesophageal and muscle temperature probes are summarised in Table 3.3 Analysis of variance (ANOVA) of these temperature changes from rest to the end of exercise $(\Delta \mathrm{T})$ showed significant differences $(\mathrm{P}<$ 0.001), dependent on the site of measurement. Whilst there was no difference (P $=0.86)$ between $\Delta \mathrm{T}$ for arterial blood temperature $\left(\Delta \mathrm{T}_{\text {art }}\right)$ and oesophageal temperature $\left(\Delta \mathrm{T}_{\text {oes }}\right)$ from rest to end exercise $\left(2.5{ }^{\circ} \mathrm{C}\right.$ for each), the increases in both $\mathrm{T}_{\text {art }}$ and $\mathrm{T}_{\text {oes }}$ were more than double that observed for rectal temperature ( $\left.\mathrm{T}_{\text {re }}\right)(\mathrm{P}<0.05)$. Muscle temperature $\left(\mathrm{T}_{\mathrm{mu}}\right)$, whilst lower than all other measurement sites at rest $(\mathrm{P}<0.05)$, exhibited the largest average increase of 
$5.23{ }^{\circ} \mathrm{C}$ and this increase was significantly greater when compared to all other measurement sites $(\mathrm{P}=0.009-0.013)$.

Table 3.3 Resting, end-exercise and temperature changes at each measurement site during the incremental exercise test.

\begin{tabular}{|c|c|c|c|}
\hline & $\begin{array}{c}\text { Resting }\left(\mathrm{T}_{0}\right) \\
\left({ }^{\circ} \mathrm{C}\right)\end{array}$ & $\begin{array}{l}\text { End-Exercise } \\
\qquad\left({ }^{\circ} \mathrm{C}\right)\end{array}$ & $\begin{array}{c}\Delta \mathrm{T} \\
\left(\text { rest }- \text { end-exercise, }{ }^{\circ} \mathrm{C} \text { ) }\right.\end{array}$ \\
\hline Rectal Temperature & $37.2^{\text {bd }}$ & $38.4^{\text {§cd }}$ & $1.2^{\mathrm{bcd}}$ \\
\hline Arterial Temperature & $35.7^{\text {acd }}$ & $38.1^{\S \mathrm{cd}}$ & $2.5^{\text {ad }}$ \\
\hline Oesophageal Temperature & $37.0^{\text {bd }}$ & $39.4^{\S a b}$ & $2.5^{\text {ad }}$ \\
\hline Muscle Temperature & $33.6^{\mathrm{abc}}$ & $38.9^{\S a b}$ & $5.2^{\mathrm{abc}}$ \\
\hline
\end{tabular}

\subsubsection{Temperature responses relative to workload.}

Recorded temperatures were matched to $\% \dot{\mathrm{V}}{ }_{2}$ peak in 10 percent increments (Figures 3.2, 3.3, 3.4 and 3.5), beginning at $10 \%$ which is the level of $\mathrm{O}_{2}$ uptake coinciding with the subject standing stationary on the treadmill prior to the beginning of the incremental exercise test $\left(\mathrm{T}_{0}\right)$.

Rectal temperature did not differ significantly from its starting value until a workload of $80 \% \dot{\mathrm{V}} \mathrm{O}_{2}$ peak had been reached. In comparison, $\mathrm{T}_{\text {art }}$ and $\mathrm{T}_{\text {oes }}$ were significantly increased $(\mathrm{P}<0.05)$ above starting values from $70 \% \dot{\mathrm{VO}}_{2}$ peak and $\mathrm{T}_{\mathrm{mu}}$ from $60 \% \dot{\mathrm{V}} \mathrm{O}_{2}$ peak. As noted with the individual responses to the incremental exercise test, when presented as relative workload each 
measurement site, with the exception of $\mathrm{T}_{\mathrm{re}}$, showed an initial temperature decrease. This decrease was significant only at the $\mathrm{T}_{\text {oes }}$ site, and only at $40 \% \dot{\mathrm{V} O}{ }_{2}$ peak.

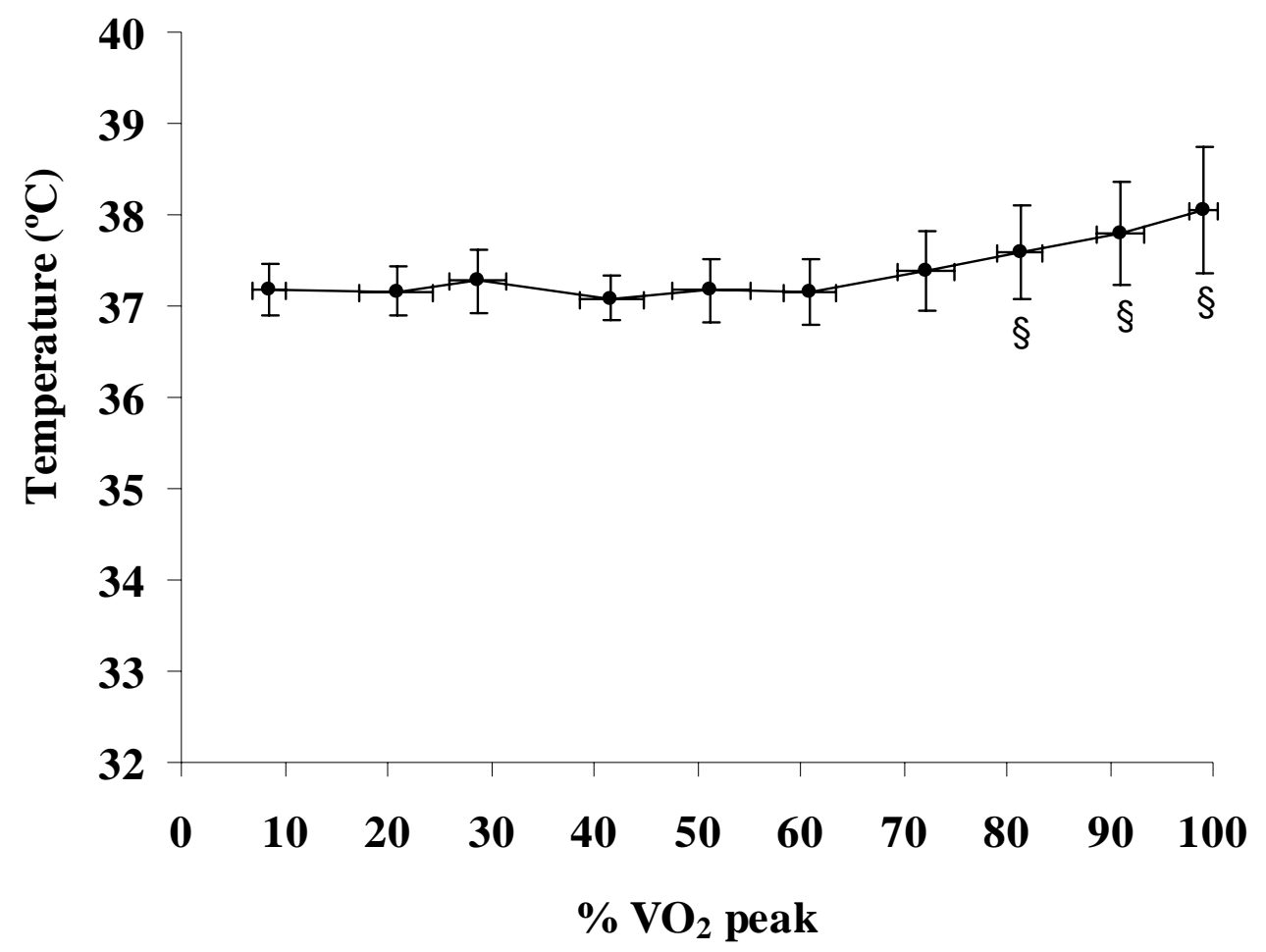

Figure 3.2 Rectal temperature during incremental exercise test relative to percent of peak oxygen uptake (\% $\dot{\mathrm{VO}}{ }_{2}$ peak). $\S=$ significantly different $(\mathrm{P}<$ $0.05)$ from resting $(10 \%)$ value. 


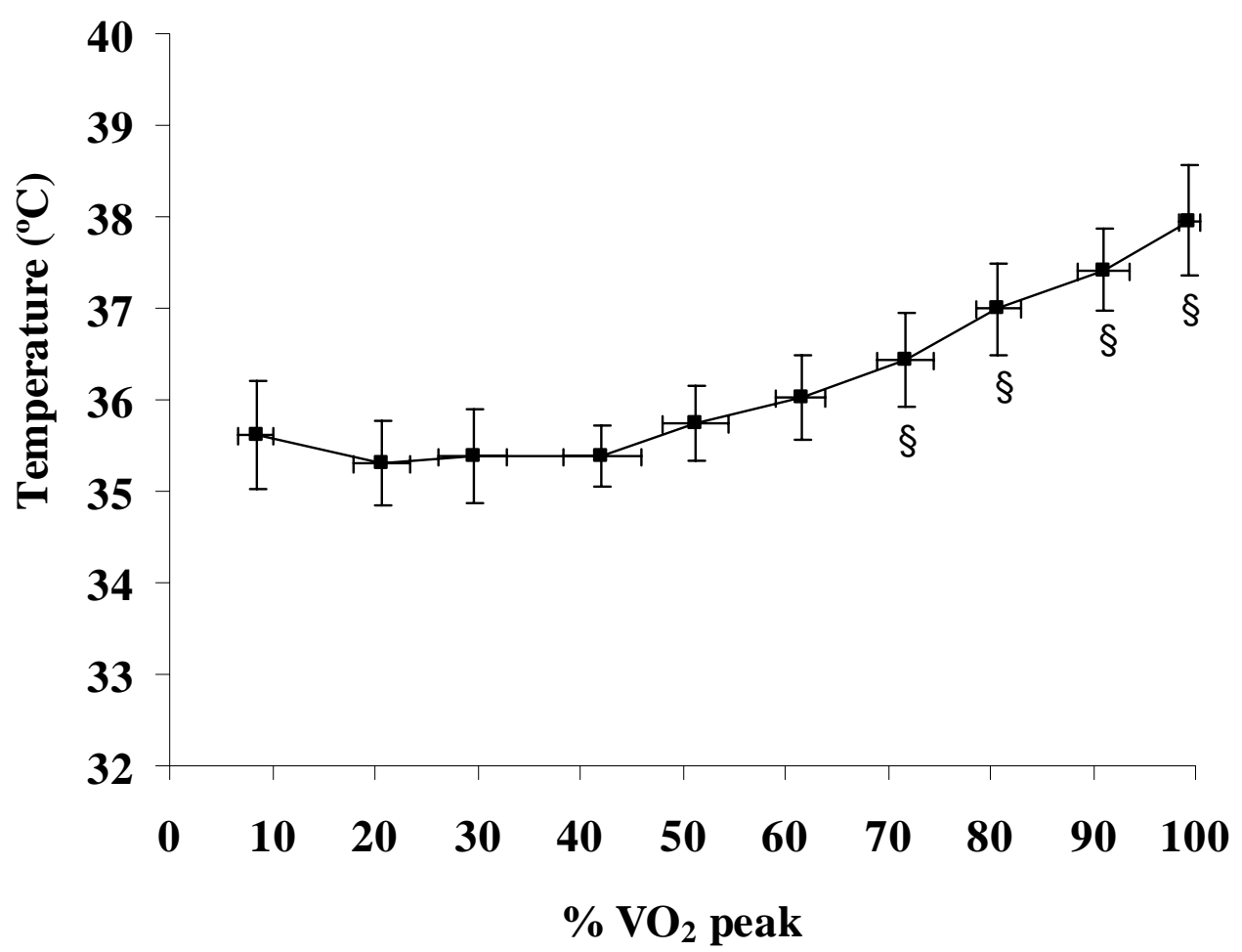

Figure 3.3 Arterial temperature during incremental exercise test relative to percent of peak oxygen uptake (\% $\dot{\mathrm{V} O}{ }_{2}$ peak). $\S=$ significantly different $(\mathrm{P}<$ $0.05)$ from resting $(10 \%)$ value. 


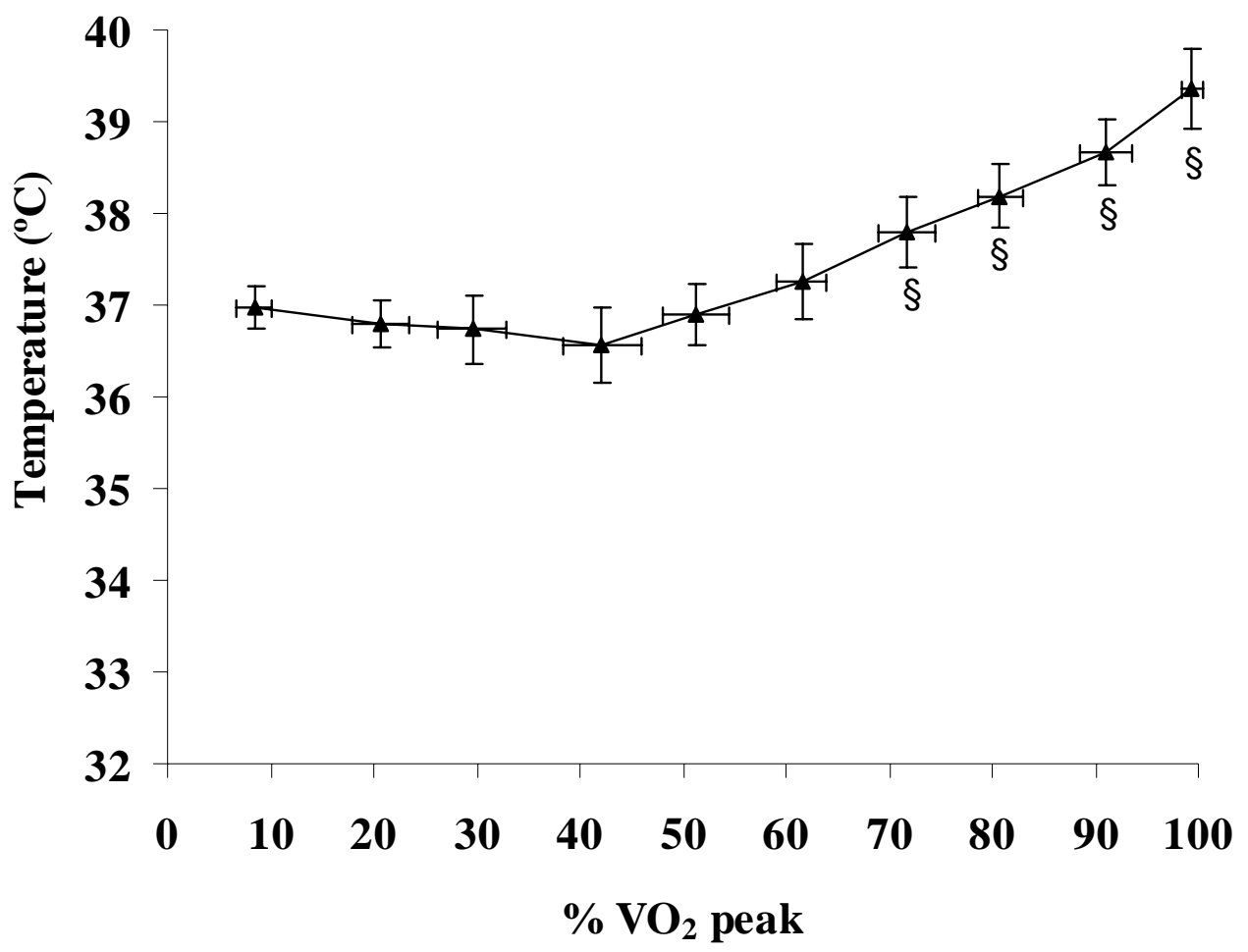

Figure 3.4 Oesophageal temperature during incremental exercise test relative to percent of peak oxygen uptake (\% $\mathrm{V}_{2}$ peak). $\S=$ significantly different $(\mathrm{P}<0.05)$ from resting $(10 \%)$ value. 


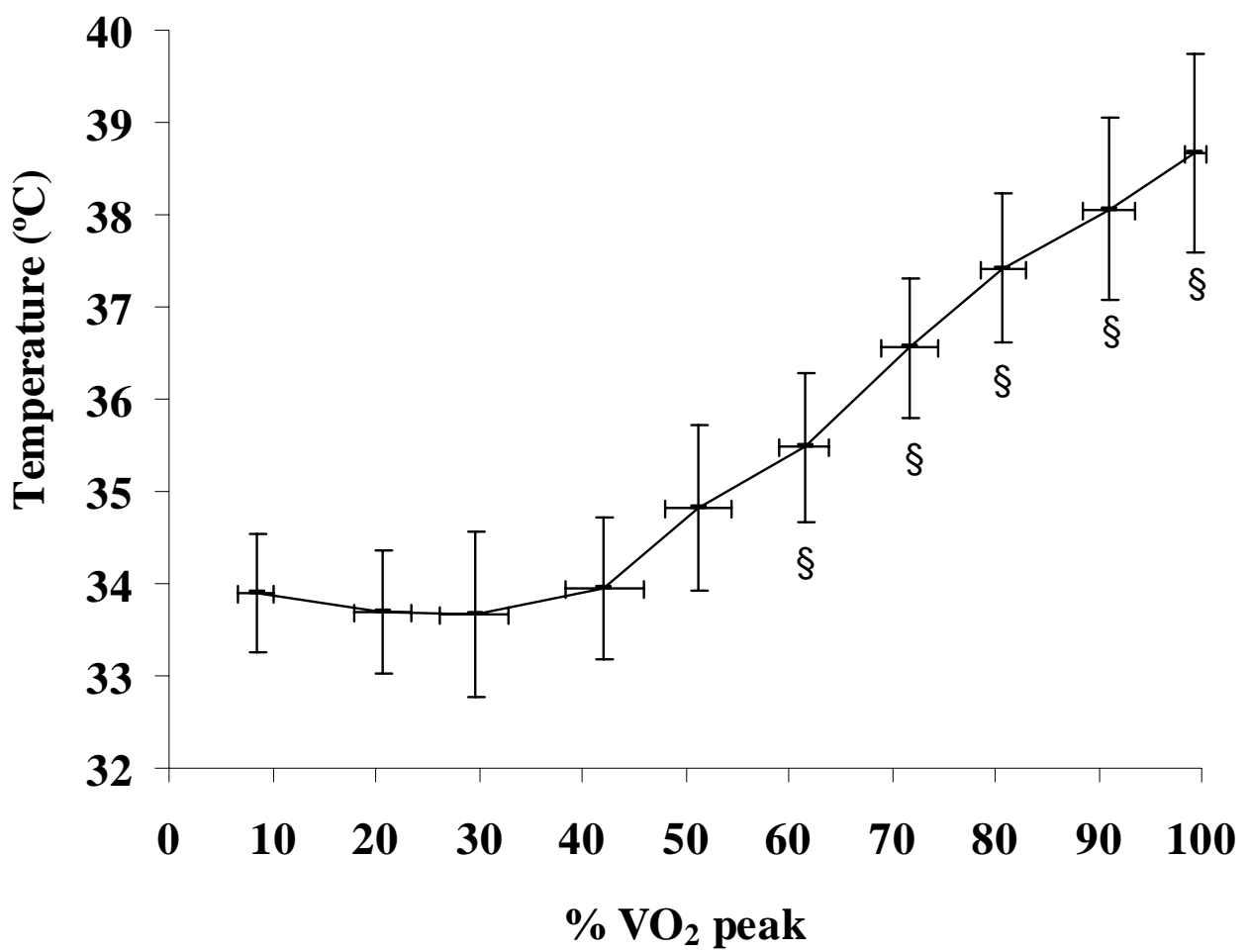

Figure 3.5 Muscle temperature during incremental exercise test relative to percent of peak oxygen uptake (\% $\dot{\mathrm{V}}{ }_{2}$ peak). $\S=$ significantly different $(\mathrm{P}<$ $0.05)$ from resting $(10 \%)$ value.

\subsubsection{Correlation and Prediction of Temperature Responses.}

Temperature responses relative to $\% \dot{\mathrm{V}}{ }_{2}$ peak were subjected to a Pearson Product Moment Correlation analysis, the results illustrated in Table 3.4. All temperature responses were highly correlated, $\mathrm{T}_{\text {art }}$ and $\mathrm{T}_{\text {oes }}$ responses during the incremental exercise test showing the highest degree of correlation. 
Table 3.4 Pearson Product Moment Correlation analysis of temperatures at relative workloads (\% $\dot{\mathrm{V} O}$ 2 peak).

\begin{tabular}{c|ccc}
\hline & & & \\
& $\mathrm{T}_{\text {oes }}$ & $\mathrm{T}_{\text {art }}$ & $\mathrm{T}_{\mathrm{mu}}$ \\
\hline \multirow{2}{*}{$\mathrm{T}_{\mathrm{re}}$} & 0.981 & 0.968 & 0.926 \\
& $<0.00001$ & $<0.00001$ & 0.00012 \\
& & & \\
$\mathrm{~T}_{\text {oes }}$ & & 0.994 & 0.970 \\
& & $<0.00001$ & $<0.00001$ \\
$\mathrm{~T}_{\text {art }}$ & & 0.986 \\
\hline \hline
\end{tabular}

Values are correlation coefficient (top) and P value (bottom).

A linear regression analysis to compare the temperature responses indicated a significant association between each temperature response during incremental exercise. Figure 3.6 illustrates the close association $(\mathrm{P}<0.01)$ between the responses of each temperature measurement site during the exercise test. The relationship between $\mathrm{T}_{\text {art }}$ and $\mathrm{T}_{\text {oes }}$ exhibit the highest interdependence with application of the regression equation shown in Figure 3.6 showing a maximal difference of $0.16^{\circ} \mathrm{C}$ between measured and calculated $\mathrm{T}_{\text {oes }}$ temperature using the $\mathrm{T}_{\text {art }}$ regression equation (Table 3.5). 


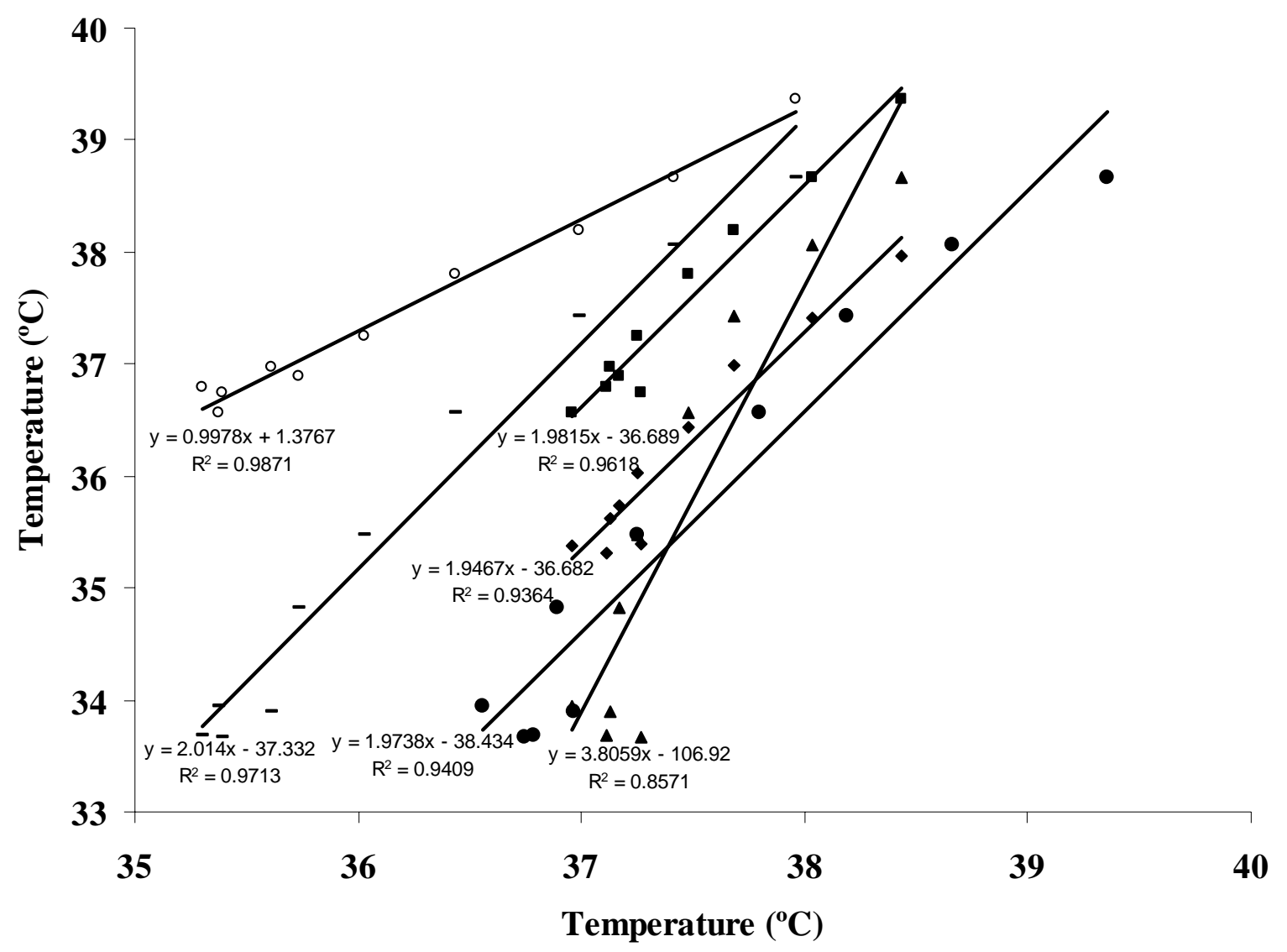

Figure 3.6 Regression results for temperature responses during incremental exercise. $=\mathrm{T}_{\text {re }} \mathrm{v} \mathrm{T}_{\text {art }}\left(\mathrm{R}^{2}=0.936\right), \boldsymbol{\|}=\mathrm{T}_{\text {re }} \mathrm{V} \mathrm{T}_{\text {oes }}\left(\mathrm{R}^{2}=0.962\right), \boldsymbol{\Delta}=\mathrm{T}_{\text {re }}$ $\mathrm{v} \mathrm{T}_{\text {mu }}\left(\mathrm{R}^{2}=0.857\right), 0=\mathrm{T}_{\text {art }} \mathrm{V} \mathrm{T}$ oes $\left(\mathrm{R}^{2}=0.987\right),-=\mathrm{T}_{\text {art }} \mathrm{V} \mathrm{T}$ mu $\left(\mathrm{R}^{2}=\right.$ $0.971), \bullet=\mathrm{T}_{\text {oes }} \mathrm{V} \mathrm{T}_{\text {mu }}\left(\mathrm{R}^{2}=0.941\right)$ 
Table 3.5 Temperature difference $\left({ }^{\circ} \mathrm{C}\right)$ between measured and calculated values from regression equations at relative $\% \mathrm{VO}_{2}$ peak.

\begin{tabular}{|c|c|c|c|c|c|c|}
\hline \multirow{2}{*}{$\% \mathrm{VO}_{2}$ peak } & \multicolumn{6}{|c|}{ Difference between measured and calculated values } \\
\hline & $\mathrm{T}_{\mathrm{re}} \mathrm{V} \mathrm{T}_{\mathrm{art}}$ & $\mathrm{T}_{\mathrm{re}} \mathrm{V} \mathrm{T}_{\text {oes }}$ & $\mathrm{T}_{\mathrm{re}} \mathrm{V} \mathrm{T}_{\mathrm{mu}}$ & $\mathrm{T}_{\text {art }} \mathrm{V} \mathrm{T}_{\text {oes }}$ & $\mathrm{T}_{\mathrm{art}} \mathrm{V} \mathrm{T}_{\mathrm{mu}}$ & $\mathrm{T}_{\mathrm{oes}} \mathrm{V} \mathrm{T}_{\mathrm{mu}}$ \\
\hline 10 & 0.02 & 0.09 & 0.48 & 0.06 & 0.50 & 0.64 \\
\hline 20 & 0.26 & 0.07 & 0.64 & 0.18 & 0.08 & 0.49 \\
\hline 30 & 0.48 & 0.41 & 1.24 & 0.06 & 0.27 & 0.42 \\
\hline 40 & 0.11 & 0.02 & 0.21 & 0.12 & 0.03 & 0.22 \\
\hline 50 & 0.05 & 0.07 & 0.28 & 0.13 & 0.20 & 0.44 \\
\hline 60 & 0.19 & 0.12 & 0.61 & 0.08 & 0.25 & 0.39 \\
\hline 70 & 0.15 & 0.22 & 0.83 & 0.06 & 0.51 & 0.39 \\
\hline 80 & 0.32 & 0.22 & 0.93 & 0.09 & 0.25 & 0.47 \\
\hline 90 & 0.05 & 0.02 & 0.22 & 0.05 & 0.04 & 0.19 \\
\hline 100 & 0.17 & 0.10 & 0.68 & 0.11 & 0.45 & 0.59 \\
\hline Mean \pm SD & $0.18 \pm 0.14$ & $0.13 \pm 0.12$ & $0.61 \pm 0.33$ & $0.09 \pm 0.04$ & $0.26 \pm 0.18$ & $0.42 \pm 0.14$ \\
\hline
\end{tabular}

\subsubsection{Temperature responses following cessation of the incremental exercise test}

Figure 3.3 contains the mean data for all temperature measurement sites in the 10 min immediately following cessation of the incremental test. The rate of decrease in temperature from the cessation of exercise is rapid in all bar the $T_{\mathrm{re}}$ 
measurement site. Average $\mathrm{T}_{\mathrm{re}}$ continues to rise in the $4 \mathrm{~min}$ following cessation of the exercise test and does not return to a baseline level in any of the subjects. In contrast, both $\mathrm{T}_{\text {art }}$ and $\mathrm{T}_{\text {oes }}$ show significant decreases $(\mathrm{P}<0.05)$ from the temperature recorded at the cessation of exercise (Time $=0)$ from min 4 post-exercise until measurement ceased at 10 min post-exercise.

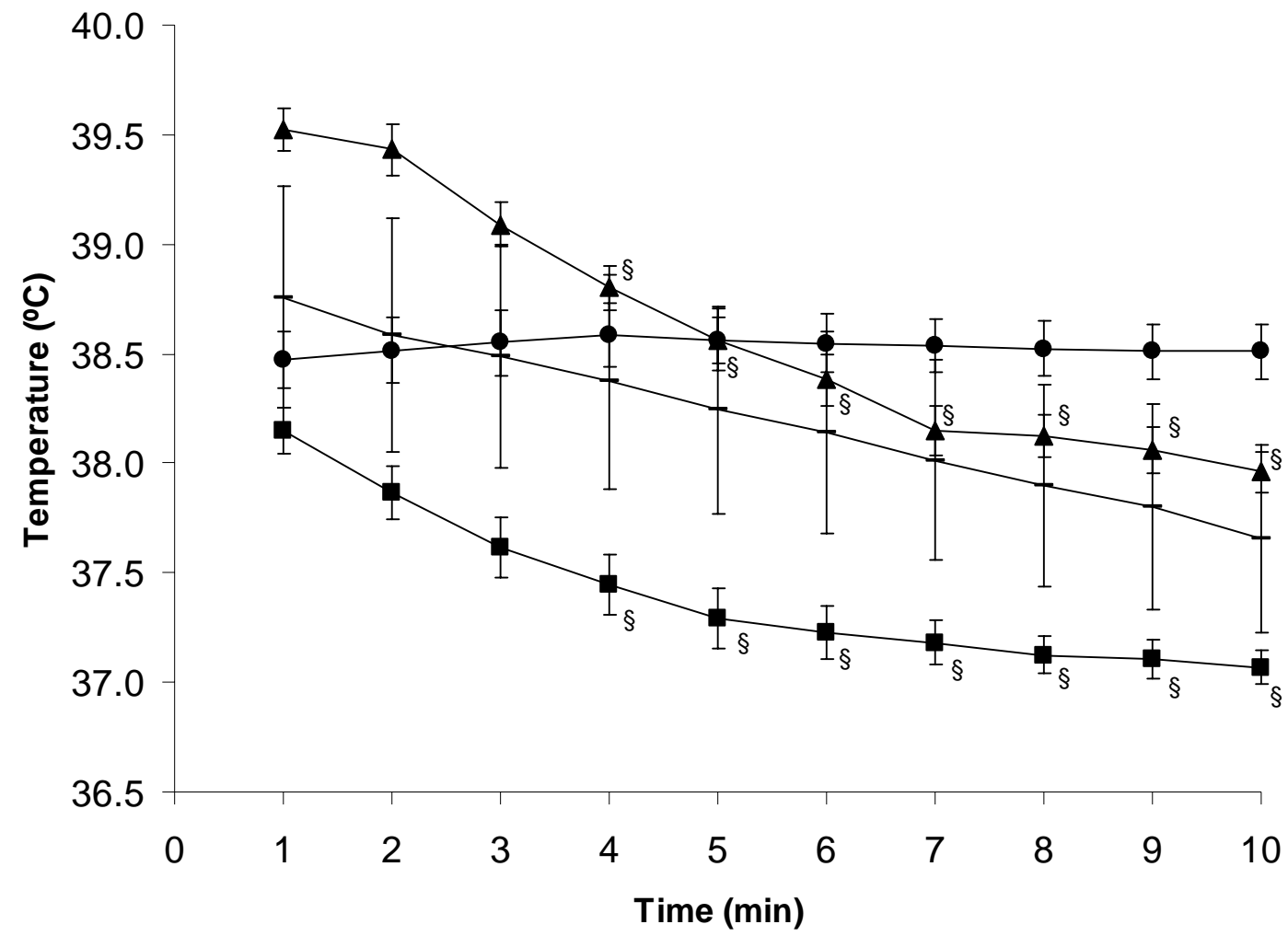

Figure 3.7 Temperature responses at each measurement site in the $10 \mathrm{~min}$ following cessation of the incremental exercise test (Time $=0$ ). $\bullet=$ Rectal temperature, $\mathbf{m}=$ Arterial temperature, $\boldsymbol{\Delta}=$ Oesophageal temperature, $-=$ Muscle temperature. $\S=$ significantly different $(\mathrm{P}<$ 0.05 ) from end-exercise temperature.

Muscle temperature decreased approximately $1.2^{\circ} \mathrm{C}$ in the 10 minute period following cessation of the incremental exercise test. This is comparable with both $\mathrm{T}_{\text {art }}$ and $\mathrm{T}_{\text {oes }}$ temperature decreases $\left(1.1^{\circ} \mathrm{C}\right.$ and $1.5^{\circ} \mathrm{C}$, respectively); however, the number of observations was severely reduced $(n=7)$ compared to 
arterial and oesophageal measurement sites $(n=16, n=20$, respectively) resulting in a significantly increased $(\mathrm{P}<0.05)$ standard deviation $\left(1.26^{\circ} \mathrm{C}\right)$. 


\subsection{DISCUSSION}

The principal findings in this study were that both resting body temperatures and the responses during and after incremental exercise to exhaustion are dependent on the site of temperature measurement. While these results have some support in the literature (Saltin and Hermansen, 1966; Edwards, Belyavin et al, 1978; Shiraki, Konda et al, 1986; Febbraio, Carey et al, 1996; Robinson, Seal et al, 1998; Gonzalez-Alonso, Teller et al, 1999; Parkin, Carey et al, 1999), this is the first study to measure rectal, arterial blood, oesophageal and active muscle temperatures simultaneously, allowing direct comparisons of such thermal status to be made.

While the measured values for resting oesophageal and rectal temperatures reported in the present study agree with the often quoted value of $37^{\circ} \mathrm{C}$ for resting central body (core) temperature, the temperature at the 2 sites which should most directly reflect the temperature of the environments where oxygen is transported (arterial blood) and utilised (skeletal muscle), were significantly lower. Yet it is the temperature responses at these sites which intuitively should have more significance in analysing the impact of any exercise-induced reduction in $\mathrm{PaO}_{2}$ on tissue oxygen utilisation. On the other hand, oesophageal temperature, where the mean value at rest was precisely $37^{\circ} \mathrm{C}$, is regarded to most closely reflect the temperature of pulmonary artery blood at the time of oxygen loading and therefore must also be a factor in any analysis. The clear outlier in all this discussion is rectal temperature which, although the most frequently accessed temperature measurement site in EIH studies, probably has the least commonality with any aspect of oxygen loading, transport or utilisation. 
Similar considerations come into play when considering the time-dependent responses at these several sites during incremental exercise.

Rectal temperature. The slow rise in rectal temperature with increasing exercise intensity which has been shown previously (Bazett, Love et al, 1949; Eichna, Berger et al, 1951; Cooper and Kenyon, 1957; Molnar and Read, 1974, Edwards, Belyavin et al, 1978; Aulick, Robinson et al, 1981) was confirmed in the present study, an effect considered to reflect the thermal “inertia” imparted by the surrounding tissues (Fox, Solman et al, 1973). Such was the slow time constant of rectal temperature during exercise that the maximum mean change from rest to end-exercise was less than half that recorded at the 3 other sites with a significant increase from resting not being observed until exercise intensity reached $80 \% \mathrm{VO}_{2}$. Furthermore, there was a trend for rectal temperature to increase further during the first 4 minutes postexercise, a finding supported by the studies of Edwards and colleagues (1978) and more recently by Lee and co-workers (2000). The mean temperature at the end of the 10 minute post-exercise observation period was higher in absolute terms than that at the end of exercise, and all post-exercise values remained significantly above rest for the measured post-exercise period,

These several features of the rectal site in monitoring thermal responses during exercise make it unsuitable for the measurement of transient changes in core body temperature (Cranston, Gerbrandy et al, 1954; Gerbrandy, Snell et al, 1954; Molnar and Read, 1974; Edwards, Belyavin et al, 1978; Pan, Forster et al, 1986; Lee, Williams et al, 2000). Certainly, the significant thermal inertia, emphasised in the present study, and its lack of clear import at the sites of blood 
gas exchange, makes rectal temperature particularly unsuitable in studying the interaction between exercise hyperthermia and EIH.

Oesophageal temperature. The use of $\mathrm{T}_{\text {oes }}$ has been considered a more relevant site as an indicator of the thermal status of the body than $\mathrm{T}_{\mathrm{re}}$ as it can be considered to be an indirect measure of pulmonary arterial blood leaving the heart (Cooper and Kenyon, 1957). This is important as it is at this temperature that the blood arrives in the lungs for the uptake of oxygen and the release of carbon dioxide. Due to the nature of the oxy-haemoglobin dissociation curve, temperature has a direct effect on the uptake and release of oxygen, as well as causing changes to the partial pressure of dissolved gases in the blood (See Section 1.8). Measurement of $\mathrm{T}_{\text {oes }}$ must be performed precisely as there is only a small area of the oesophagus where the temperature is reflective of pulmonary arterial blood temperature (Whitby and Dunkin, 1968; Brengelmann, Johnson et al, 1979; Shiraki, Konda et al, 1986; Robinson, Seal et al, 1998) and this was taken into consideration when performing this measurement in the current study. In preference to using a nominated length for probe insertion or have placement depend on the probes' position on x-ray, the position of the probe was based on in-situ temperature readings with the understanding that temperature falls as the probe moves either proximally or distally from the section of the oesophagus where the pulmonary artery runs closest. Mean resting $T_{\text {oes }}$ for the subjects in this study was that which is usually reported as being normal core body temperature $\left(37^{\circ} \mathrm{C}\right)$. However, current results show $\mathrm{T}_{\text {oes}}$, in all but one subject, decreased from resting values at the start of the incremental exercise test, as has been reported in other studies (Saltin and Hermansen, 1966; Edwards, Belyavin 
et al, 1978; Lee, Williams et al, 2000). Although unexplained, it is possible that while muscular heat production is increased marginally at the start of exercise, the increased heat loss through ventilation results in an overall fall in $\mathrm{T}_{\text {oes. }} \mathrm{A}$ similar temperature decline was not seen at the rectal site, presumably again reflecting a relatively inert thermal mass. After reaching a nadir at $\sim 40 \% \dot{\mathrm{VO}}_{2}$ peak, mean $\mathrm{T}_{\text {oes }}$ increased with increasing exercise intensity such that from $70 \%$ to $100 \% \dot{\mathrm{V}} \mathrm{O}_{2}$ peak it was significantly elevated above resting temperature. The mean maximal $\mathrm{T}_{\text {oes }}$ of $39.4^{\circ} \mathrm{C}$ was higher in absolute terms than that recorded at all other sites, reaching statistical significance for $\mathrm{T}_{\text {art }}$ and $\mathrm{T}_{\mathrm{re}}$. The mean changes in $\mathrm{T}_{\text {oes }}$ and $\mathrm{T}_{\text {art }}$ were the same but half that for $\mathrm{T}_{\mathrm{mu}}$ and double that for $\mathrm{T}_{\mathrm{re}}$.

Post-exercise values of $\mathrm{T}_{\text {oes }}$ did not begin to fall immediately following the cessation of exercise. In the period between exercise cessation and the $1 \mathrm{~min}$ post-exercise measurement of $\mathrm{T}_{\text {oеs }}$ this temperature increased to $39.6^{\circ} \mathrm{C}$ and then began a rapid decline such that it was significantly below the end-exercise value by 4 min post-exercise. Again, it may be hypothesised that the hyperventilation which occurs following a maximal exercise test has the effect of cooling pulmonary artery blood in excess of the warming effect of muscular activity. This causes a net loss of heat in the system which continues due to a lack of muscular heat input, but heat storage in the body is such that $T_{\text {oes }}$ does not return to resting levels within the post-exercise measurement period $(\mathrm{P}<0.05)$.

Arterial Blood Temperature. The arterial blood temperature $\left(\mathrm{T}_{\text {art }}\right)$ response is one which follows closely that of $\mathrm{T}_{\text {oes }}$ both during and following the exercise test. As with $\mathrm{T}_{\text {oes}}, \mathrm{T}_{\text {art }}$ shows an initial drop at the start of exercise 
followed by a rapid increase towards the end of the exercise test reaching a significant increase above resting levels from $70 \% \dot{\mathrm{VO}}_{2}$ peak onwards. The increase in $\mathrm{T}_{\text {art }}$ of $2.5^{\circ} \mathrm{C}$ is exactly that measured for $\mathrm{T}_{\mathrm{oes}}$, and is comparable to increases seen in previous research (Wetter, St Croix et al, 2001). Similarly, post-exercise values diminish rapidly and from the 4 min post-exercise measurement onwards are significantly lower than end-exercise temperatures. Whilst the response rates at $T_{\text {art }}$ and $T_{\text {oes }}$ sites during exercise were almost identical $\left(\mathrm{R}^{2}=0.99\right)$, they were offset by approximately $1.3^{\circ} \mathrm{C}$ for the entire exercise test $(\mathrm{P}<0.05)$. This significant difference is maintained from rest

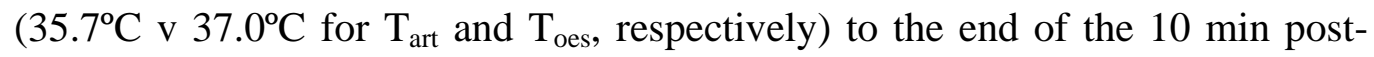
exercise period $\left(37.1^{\circ} \mathrm{C} v 38.0^{\circ} \mathrm{C}\right)$. This may be explained by two phenomena; firstly $\mathrm{T}_{\text {art }}$ is measured after the pulmonary artery blood $\left(\mathrm{T}_{\text {oes }}\right)$ has passed through the lungs where it is cooled by the colder ambient air used in ventilation and, secondly, arterial blood is cooled further due to counter-current heat exchange of blood as it makes its way to the extremities, a phenomenon which has been postulated to maintain central body temperature (Bazett, Love, et al, 1948; Schmidt-Nielsen, 1963). An initial rapid decrease in $\mathrm{T}_{\text {art }}$ was seen in the postexercise period with a significant decrease from the point of exercise termination reached by the 4 min measurement which was maintained to the end of the measurement period. The calculation of oesophageal temperature from arterial temperature at work-loads relative to $\% \dot{\mathrm{V}}{ }_{2}$ peak showed an excellent correlation (see Table 3.5), with the maximum deviation of predicted temperature from measured temperature being less than $0.2^{\circ} \mathrm{C}$ with an average difference of less than $0.1^{\circ} \mathrm{C}$. Using $\mathrm{T}_{\text {re }}$ to calculate $\mathrm{T}_{\text {oes }}$ has a similarly low 
mean difference; however, the fluctuation of temperature differences between these two measurement sites, their different response rates during exercise and the continual rise of $T_{\text {re }}$ following exercise cessation indicates that $T_{r e}$ is not a good indicator of $\mathrm{T}_{\text {oes }}$ changes during exercise. With regard to future experiments it may be that, in preference to inserting an uncomfortable oesophageal temperature probe, $\mathrm{T}_{\text {oes }}$ can be calculated from more easily measured arterial blood temperatures taken during arterial blood sampling.

Active Muscle Temperature. Muscle temperature at rest was significantly lower than all other temperatures measured during this period which might be expected due to its relative metabolic inactivity and a high degree of cooling due to a larger surface area and counter-current heat exchange. The resting $\mathrm{T}_{\mathrm{mu}}$ of less than $34^{\circ} \mathrm{C}$ decreased minimally at the onset of exercise and then began an upward trajectory reaching almost $39^{\circ} \mathrm{C}$ by the cessation of exercise. From a workload of $60 \% \dot{\mathrm{V}}{ }_{2}$ peak onwards this temperature was significantly higher than at rest, demonstrating the huge metabolic demand of this tissue during exercise. The change in $\mathrm{T}_{\mathrm{mu}}$ of over $5^{\circ} \mathrm{C}$ during the reported incremental exercise tests indicates the significant increase in utilisation of oxygen and the concomitant increase in heat released from the exercising muscle. As demonstrated, to utilise a constant of $37^{\circ} \mathrm{C}$ to characterise the conditions within the muscle both at rest and during exercise is completely inadequate and would misrepresent the effort required of the body to maintain thermoregulation at rest as well as the thermal changes an active muscle undergoes during intense exercise. Within the first minute of the post-exercise measurement period $\mathrm{T}_{\mathrm{mu}}$ began to decrease. The cessation of heat production in 
the muscle coupled with heat loss to the cooler incoming arterial blood ensures a rapid temperature loss which, in turn, may prevent any further possible heatinduced muscle damage. As with $\mathrm{T}_{\text {oes }}$ and $\mathrm{T}_{\text {art }}$, there is a large decrease in the absolute values for post-exercise $\mathrm{T}_{\mathrm{mu}}$, but possibly due to a lower sample population the decrease did not reach statistical significance at any time point. The fast response rate of $\mathrm{T}_{\mathrm{mu}}$ during exercise supports its use as an indicator of the body's thermal response, and as it is at the muscle site that the transfer of oxygen from the blood to the muscle cells occurs it would seem to be of particular import when discussing any changes in blood gas levels and with regard to exercise.

The relative response rates of the temperature measurement sites utilised in the present experiments are in agreement with other studies (Saltin and Hermansen, 1966; Saltin, Gagge et al, 1968; Blomstrand, Kaijser et al, 1986; Edwards, Belyavin et al, 1978; Hammond, Gale et al, 1986; Shiraki, Konda et al, 1986; Pan, Forster et al, 1989; Wagner, Gillespie et al, 1989; Febbraio, Carey et al, 1996; Robinson, Seal et al, 1998; Gonzalez-Alonso, Teller et al, 1999; Rice, Thornton et al, 1999; Parkin, Carey et al, 1999; Hopkins, Barker et al, 2000), but none has measured $\mathrm{T}_{\text {re, }}, \mathrm{T}_{\text {art }}, \mathrm{T}_{\text {oes }}$ and/or $\mathrm{T}_{\mathrm{mu}}$ simultaneously. The only comparable research is that in steers and horses by Jones, Taylor et al (1989) and Taylor, Kronfeld et al (1998). They measured body temperatures at various sites during exercise and found responses consistent with those measured in the human subjects in the present study.

CONCLUSION This study demonstrates the inadequacy of utilising rectal temperature as a measure of the body's thermal response during incremental 
exercise. Rectal temperature's lagging response time to significant heat production increases in the active muscle, its delayed response to cessation of exercise and the relative isolation of the rectal site from important gas exchange areas all combine to underline the need for a more appropriate measurement of thermal response during exercise. The use of oesophageal temperature and active muscle temperature enables the researcher to analyse temperature responses at the most important sites during exercise, these being the sites of oxygen transfer into the blood and into the muscle, respectively. Finally, from a practical point of view, if arterial blood temperature alone is measured simultaneously with blood sampling, then $\mathrm{T}_{\text {oes }}$ can be calculated with reasonable accuracy and the logistical or ethical issues relating to oesophageal probe insertion avoided. 


\title{
CHAPTER 4
}

\section{Oxygen Status during Incremental}

\author{
Exercise
}

\subsection{INTRODUCTION}

The partial pressure of oxygen in arterial blood $\left(\mathrm{PaO}_{2}\right)$ is a commonly measured variable in exercise studies. Healthy young males have a mean resting value of $100 \mathrm{mmHg}$ and while no major fluctuations are expected during exercise (Wasserman, Hansen et al, 1994; Crapo, Jensen et al, 1999) a significant decrease has been reported in $\sim 50 \%$ of trained males. This phenomenon has been termed exercise-induced hypoxemia (EIH) with a decrement in $\mathrm{PaO}_{2}$ of $\geq 10 \mathrm{mmHg}$ commonly used as the delimiting change (Dempsey, Hanson et al, 1984; Prefaut, Anselme et al, 1994; St Croix, Harms et al, 1998; Dempsey and Wagner, 1999; Rice, Thornton et al, 1999; Prefaut, Durand et al, 2000; Durand, Mucci et al, 2004).

Given that $37^{\circ} \mathrm{C}$ is regarded as resting body "core" temperature, it is normally at this temperature that blood gas samples are analysed and reported. But there is a significant thermogenic effect with exercise and failure to temperature-correct the blood gas values reported at $37^{\circ} \mathrm{C}$ will underestimate 
any change in $\mathrm{PaO}_{2}$ by $\sim 5 \mathrm{mmHg}$ for each $1^{\circ} \mathrm{C}$ increase (Holmgren and Mcllroy, 1964; Severinghaus, 1968; Jones, Taylor et al, 1989; Taylor, Kronfeld, et al 1998; Hansen, Syben et al, 1999).

The need to temperature-correct blood gas values is widely accepted in pulmonary gas exchange studies, yet with regard to EIH, apart from a 1999 review by Dempsey and Wagner, most reviews (Powers and Williams, 1987; Powers, Martin et al, 1993; Prefaut, Durand et al, 2000; Nielsen, 2004), and many single research studies (Table 1.1) have failed to acknowledge the importance of such corrections. This makes the interpretation of their data and any assessment of the prevalence or physiological significance of EIH difficult. Of those studies which have corrected for body temperature changes ( 50\%), most have used rectal temperature $\left(\mathrm{T}_{\mathrm{re}}\right)$ as the reference (Whipp and Wasserman, 1969; Dempsey, Hanson et al, 1984; Powers, Dodd et al, 1991; Taylor, Kronfeld et al, 1998; Rice, Scroop et al, 1999), although more recent research has utilised oesophageal (Harms, McClaran et al, 1998; St Croix, Harms et al, 1998; Harms, McClaran et al, 2000; Aguilaniu, Flore et al, 2002; Wetter, St Croix et al, 2001; Wetter, Xiang et al, 2002) and arterial blood (Powers, Martin et al, 1992; Hopkins, McKenzie et al , 1994; Rice, Thornton et al, 1999; Hopkins, Barker et al, 2000; Olfert, Balouch et al, 2004) temperatures.

Despite this diversity, no study appears to have scientifically rationalised the temperature site choice, yet this choice may well impact on 2 aspects of EIH. Firstly, in terms of assessing the physiological significance of any exerciseinduced change in $\mathrm{PaO}_{2}$, it would seem logical to correct the values recorded at $37^{\circ} \mathrm{C}$ for the temperatures measured, simultaneously, at the principal sites of 
oxygen loading and unloading, namely the pulmonary circulation and active muscle, respectively. The second issue to flow from choice of measurement site is the prevalence of EIH in a given population, because the changes in body temperature during incremental exercise are site-dependent (see Chapter 3), and so too will be the degree of change in $\mathrm{PaO}_{2}$, and hence, depending on the definition applied, the prevalence of EIH. While neither issue has been addressed in studies reported to date, a clearer understanding of both is essential if we are to further our understanding of EIH. This was the purpose of the present study. A group of trained individuals completed incremental treadmill exercise to volitional exhaustion while radial arterial blood samples were collected at regular intervals for blood gas analysis. All blood gases were measured at $37^{\circ} \mathrm{C}$ and the values corrected for body temperature recorded simultaneously at rectal, arterial, oesophageal and active muscle sites. 


\subsection{METHODS}

\subsubsection{Subjects and Experimental Protocol}

Twenty-three male subjects participated in the study in conjunction with the temperature measurement experiment from Chapter 3. All subjects were trained in running, duathlon or triathlon and completed a medical history questionnaire to ensure no past or present medical condition which would normally exclude them from performing a maximal exercise test. Of the 23 subjects, 12 did not have a temperature probe inserted into their vastus lateralis as this measurement was added on evaluation of the initial temperature responses. On the day of the incremental exercise test the subjects arrived at the laboratory having abstained from vigorous exercise within the previous 24 hours and from caffeinated products for 12 hours. All tests were performed at the same time of the day to minimise the effect of diurnal rhythms both within and between subjects.

\subsubsection{Temperature Probe Placement}

Subjects self-inserted a rectal temperature probe following re-acquaintance with the laboratory and exercise protocol (see Section 2.3.2). Following a satisfactory Allen’s Test result, a radial artery catheter was inserted under local anaesthetic (see Section 2.4.1). When in-situ, a sampling line and a Y-shaped adaptor were attached to the catheter (see Figure 2.10). This set-up allowed the simultaneous sampling of arterial blood and the measurement of its temperature. An oesophageal temperature probe was inserted following the application of 
local anaesthetic gel and fixed externally. Probe depth was initially approximately $45 \mathrm{~cm}$ and then moved proximally or distally to obtain the highest temperature measurement (see Section 2.3.3). A further thermistor was then inserted into the subjects' right vastus lateralis muscle under local anaesthetic at a set depth of $30 \mathrm{~mm}$ (see Section 2.3.5).

Once all temperature probes were in place, three ECG leads were placed on the subject and a Polar heart rate monitor strap was positioned for the measurement of heart rate during the exercise test (see Section 2.7). Heart rate was recorded on the Polar receiver at 5 second intervals during and following the exercise test whilst the ECG pattern was monitored during the exercise test for any possible contra-indications.

The simultaneous measurement of resting body temperature and arterial blood sampling was performed on three occasions; the first was taken 20 min following the insertion of the arterial catheter $\left(\mathrm{T}_{-20}\right)$, the second with the subject astride the treadmill $\left(\mathrm{T}_{-2}\right)$ and the final resting measurements and blood sample with the subject in position just prior to the start of the exercise test $\left(T_{0}\right.$, see Section 2.4.2). Prior to the start of the exercise test the subject was positioned astride the treadmill with the Hans Rudolph one-way breathing valve in place to flush the mixing box of the metabolic measurement system with the subject's expirate for 2 minutes (see Section 2.5.1). To start the exercise test the subject was instructed to begin walking on the treadmill which was running at the speed of the first workload. Every 2 minutes thereafter the treadmill speed or grade was increased until the subject reached volitional exhaustion (see Section 2.6). 
At the end of every workload simultaneous temperature measurements were recorded for each site of probe placement and an arterial blood sample was taken (see Section 2.4.2). The arterial blood sample was capped, ensuring no air bubbles in the pre-heparinised glass syringe and immediately stored in ice slurry. Following termination of the exercise test the subject was told to remain breathing through the one-way breathing valve and to stand astride the treadmill. The treadmill was returned to a flat position and set at a slow walking speed and the subject instructed to step on to the treadmill and walk for recovery (see Section 2.6). The time of cessation of the test was noted and every minute, for 10 minutes, the temperature at each measurement site was recorded simultaneous to the sampling of arterial blood.

\subsubsection{Blood gas temperature correction and arterial content equations}

Simultaneous to the sampling of arterial blood, temperatures were recorded from each of the measurement sites, namely rectal, arterial blood, oesophageal and active muscle. Following analysis of blood gas values for each sample the results for $\mathrm{PaO}_{2}, \mathrm{PaCO}_{2}$, and $\mathrm{pH}$ were corrected for the hyperthermic effect of the incremental exercise test using the equations of Severinghaus et al (1966):-

$$
\begin{aligned}
& \mathrm{PaO}_{2}=\mathrm{PaO}_{2}\left(37^{\circ} \mathrm{C}\right) \times 10^{\left[\left(\left(0.0252 /\left(\left(0.243 \times \mathrm{PaO}_{2}\left(37^{\circ} \mathrm{C}\right) / 100\right)^{\wedge} 3.88\right)+1\right)+0.00564\right) \times(\mathrm{T}-37)\right]} \\
& \mathrm{PaCO}_{2}=\mathrm{PaCO}_{2}\left(37^{\circ} \mathrm{C}\right) \times 10^{[0.021 \times(\mathrm{T}-37)]} \\
& \mathrm{pH} \quad=\mathrm{pH}\left(37^{\circ} \mathrm{C}\right)+\left[-0.0146+0.0065 \times\left(7.4-\mathrm{pH}\left(37^{\circ} \mathrm{C}\right)\right) \times(\mathrm{T}-37)\right]
\end{aligned}
$$


where

$$
\begin{array}{cl}
\mathrm{T} & =\text { measured temperature } \\
\mathrm{PaO}_{2}\left(37^{\circ} \mathrm{C}\right) & =\mathrm{PaO}_{2} \text { as reported by ABG analyser } \\
\mathrm{PaCO}_{2}\left(37^{\circ} \mathrm{C}\right) & =\mathrm{PaCO}_{2} \text { as reported by ABG analyser } \\
\mathrm{pH}\left(37^{\circ} \mathrm{C}\right) & =\mathrm{pH} \text { as reported by ABG analyser. }
\end{array}
$$

Arterial content $\left(\mathrm{CaO}_{2}, \mathrm{~mL} \%\right)$, uncorrected for temperature, was calculated from the equation:

$\mathrm{CaO}_{2}=[\mathrm{Hb}] \times 1.34 \times \mathrm{SaO}_{2}+\left(\mathrm{PaO}_{2} \times 0.0031\right)$.

To account for the temperature effect on $\mathrm{CaO}_{2}, \mathrm{SaO}_{2}$ was calculated using temperature-corrected values of $\mathrm{PO}_{2}$ and $\mathrm{pH}$ using the equation from SiggaardAndersen et al (1984):

$$
y-y_{0}=x-x_{0}+h \cdot \tanh \left[k \cdot\left(x-x_{0}\right)\right]
$$

and

$$
y=\ln [s /(1-s)], x=\ln \left(\mathrm{PO}_{2} / 7.5\right)
$$

where

$$
y_{0} \quad=1.875
$$

$$
x_{0}=1.946+a+b
$$$$
h \quad=3.5+a
$$$$
k \quad=0.5343
$$$$
a \quad=1.04 \cdot(7.4-\mathrm{pH})-0.0025
$$

and

$$
b \quad=0.055 \cdot(\mathrm{T}-37) \text {. }
$$


The temperature-corrected $\mathrm{CaO}_{2}$ was calculated using the above $\mathrm{SaO}_{2}$ result and the temperature-corrected $\mathrm{PaO}_{2}$.

\subsubsection{Data Analysis}

Differences between resting $\mathrm{PaO}_{2}$ values at each site, the end-exercise values and the mean change in $\mathrm{PaO}_{2}$ from rest to end-exercise were analysed by means of a one-way, repeated measure, ANOVA in both their uncorrected form and as corrected for each temperature measurement site. Where a significant difference was obtained a Holm-Sidak t-test for multiple comparisons was performed to determine the differences between means. These tests were performed for each temperature site to ascertain the existence of differences from rest to maximal exercise when $\mathrm{PaO}_{2}$ was expressed at relative $\dot{\mathrm{VO}}{ }_{2}$ peak. All statistics were performed using SigmaStat statistical software (Version 3.5, Systat Software, Inc., California, USA). 


\subsection{RESULTS}

\subsubsection{Uncorrected Oxygen Partial Pressures During Incremental Exercise}

The individual results $(\mathrm{n}=23)$ for the change in $\mathrm{PaO}_{2}$ reported at analyser measurement temperature $\left(37^{\circ} \mathrm{C}\right)$ during incremental treadmill exercise to volitional exhaustion are illustrated in Figure 4.1. Average resting $\mathrm{PaO}_{2}$ was $95.9 \mathrm{mmHg}\left(\mathrm{SD}=6.7\right.$, taken at $\left.\mathrm{T}_{0}\right)$ and decreased in all subjects to an endexercise average of $75.1 \mathrm{mmHg}(3.9, \mathrm{P}<0.05)$.

Only a single subject demonstrated a change in $\mathrm{PaO}_{2}\left(\Delta \mathrm{PaO}_{2}\right)$ of less than $10 \mathrm{mmHg}$ whilst 11 had a $\Delta \mathrm{PaO}_{2}$ of between 10 and $20 \mathrm{mmHg}$, the remaining 11 having a $\Delta \mathrm{PaO}_{2}>20 \mathrm{mmHg}$. The maximum deviation from rest to end-exercise was $36.5 \mathrm{mmHg}$.

Average uncorrected $\mathrm{PaO}_{2}$ values at relative workloads (\% $\dot{\mathrm{VO}}{ }_{2}$ peak) are shown in Figure 4.6. A significant decrease was first seen at a workload of $50 \%$ $\dot{\mathrm{V}} \mathrm{O}_{2}$ peak. 


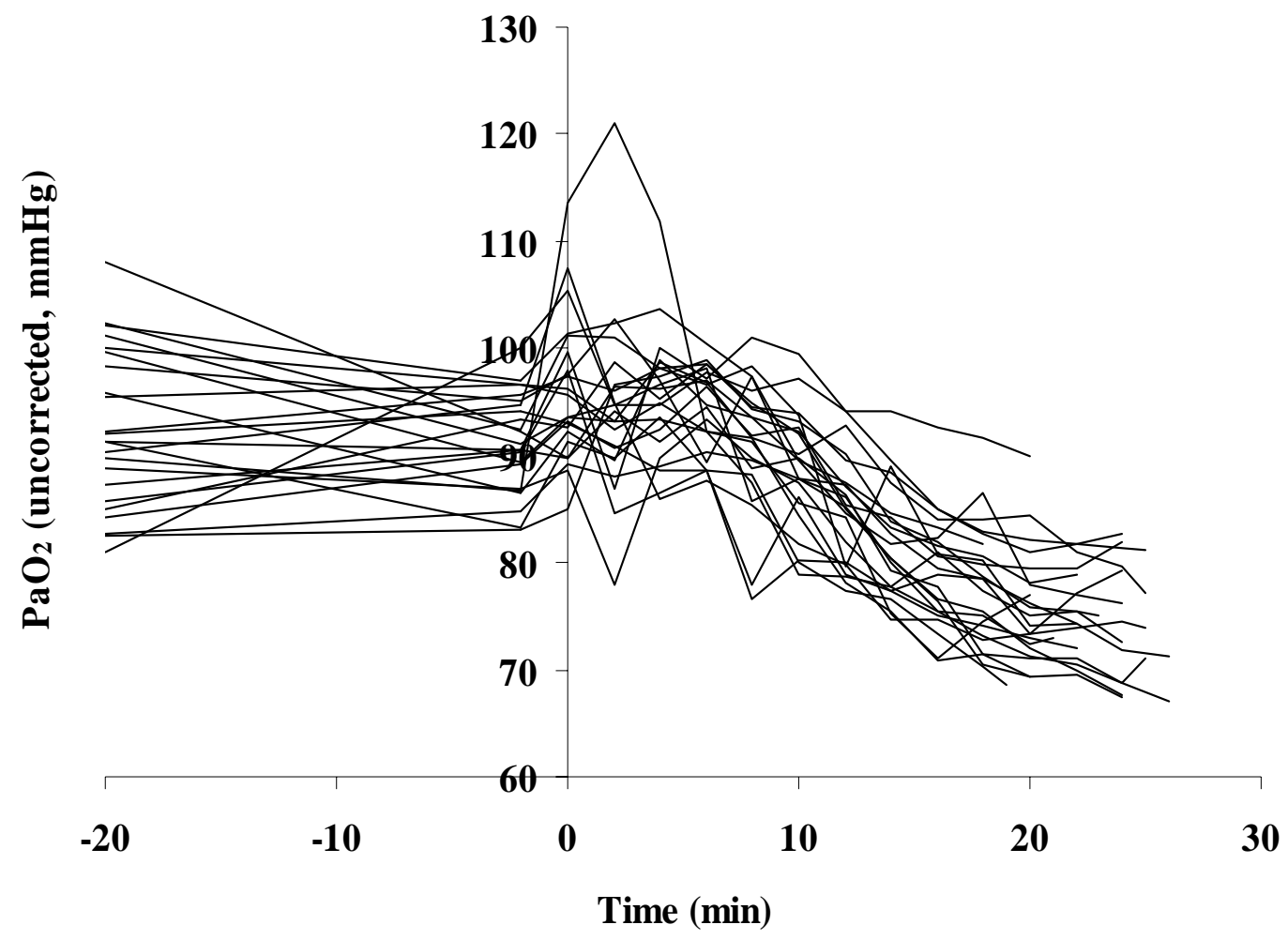

Figure 4.1 Individual uncorrected $\mathrm{PO}_{2}$ values $(\mathrm{n}=23)$ for arterial blood during the incremental exercise test.

\subsection{2 $\mathrm{PaO}_{2}$ Corrected for Rectal Temperature During Incremental Exercise}

The individual results $(\mathrm{n}=22)$ for the change in $\mathrm{PaO}_{2}$ corrected for the temperature measured in the rectum at the time of blood sampling during incremental treadmill exercise to volitional exhaustion are illustrated in Figure 4.2. Average $\mathrm{PaO}_{2}$ was $97.1 \mathrm{mmHg}$ (7.5) at rest (taken at $\mathrm{T}_{0}$ ) and decreased in all subjects to an end-exercise average of $82.4 \mathrm{mmHg}(7.1, \mathrm{P}<0.05)$. Six subjects had a $\Delta \mathrm{PaO}_{2}<10 \mathrm{mmHg}, 9$ a $\Delta \mathrm{PaO}_{2}$ of $10-20 \mathrm{mmHg}$ while the remaining 7 had a $\Delta \mathrm{PaO}_{2}>20 \mathrm{mmHg}$. 


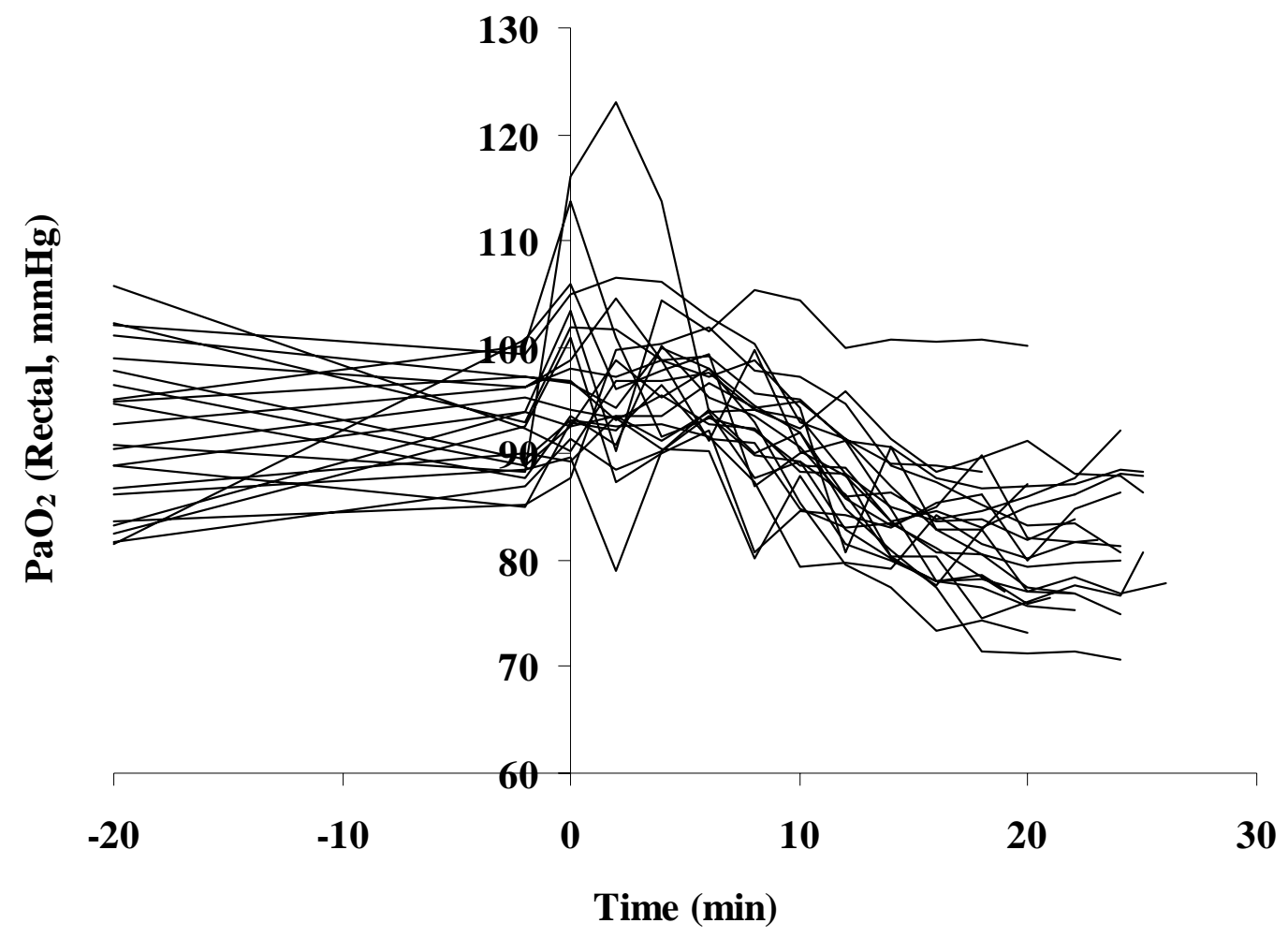

Figure 4.2 Individual $\mathrm{PO}_{2}$ values $(\mathrm{n}=20)$ for arterial blood corrected for rectal temperature during the incremental exercise test

The change in $\mathrm{PaO}_{2}$ ranged from an increase of $0.7 \mathrm{mmHg}$ to a decrease of $29.8 \mathrm{mmHg}$ (mean $\pm \mathrm{SD}=-14.7 \pm 7.8$ ). $\mathrm{PaO}_{2}$ values averaged at their relative workloads (\% $\dot{\mathrm{VO}} 2$ peak) are shown in Figure 4.6.

\subsection{3 $\mathrm{PaO}_{2}$ Corrected for Arterial Blood Temperature During Incremental Exercise}

The individual results $(n=20)$ for the change in $\mathrm{PaO}_{2}$ corrected for the temperature of the arterial blood at the time of sampling during incremental treadmill exercise to volitional exhaustion are illustrated in Figure 4.3. Average resting $\mathrm{PaO}_{2}$ was $88.3 \mathrm{mmHg}(8.4)$ (taken at $\mathrm{T}_{0}$ ) and decreased to an end- 
exercise average of $80.6 \mathrm{mmHg}(6.5, \mathrm{P}<0.05)$. Two subjects had an increase in $\mathrm{PaO}_{2}$ of $<3 \mathrm{mmHg}, 11$ subjects a decrease of $<10 \mathrm{mmHg}$, with a decrease of 10-20 mmHg in the remaining 7.

The change in $\mathrm{PaO}_{2}$ ranged from an increase of $2.7 \mathrm{mmHg}$ to a decrease of $19.0 \mathrm{mmHg}$ (mean $\pm \mathrm{SD}=-7.7 \pm 6.5$ ). $\quad \mathrm{PaO}_{2}$ values averaged at their relative workloads (\% $\dot{\mathrm{VO}}{ }_{2}$ peak) are shown in Figure 4.6.

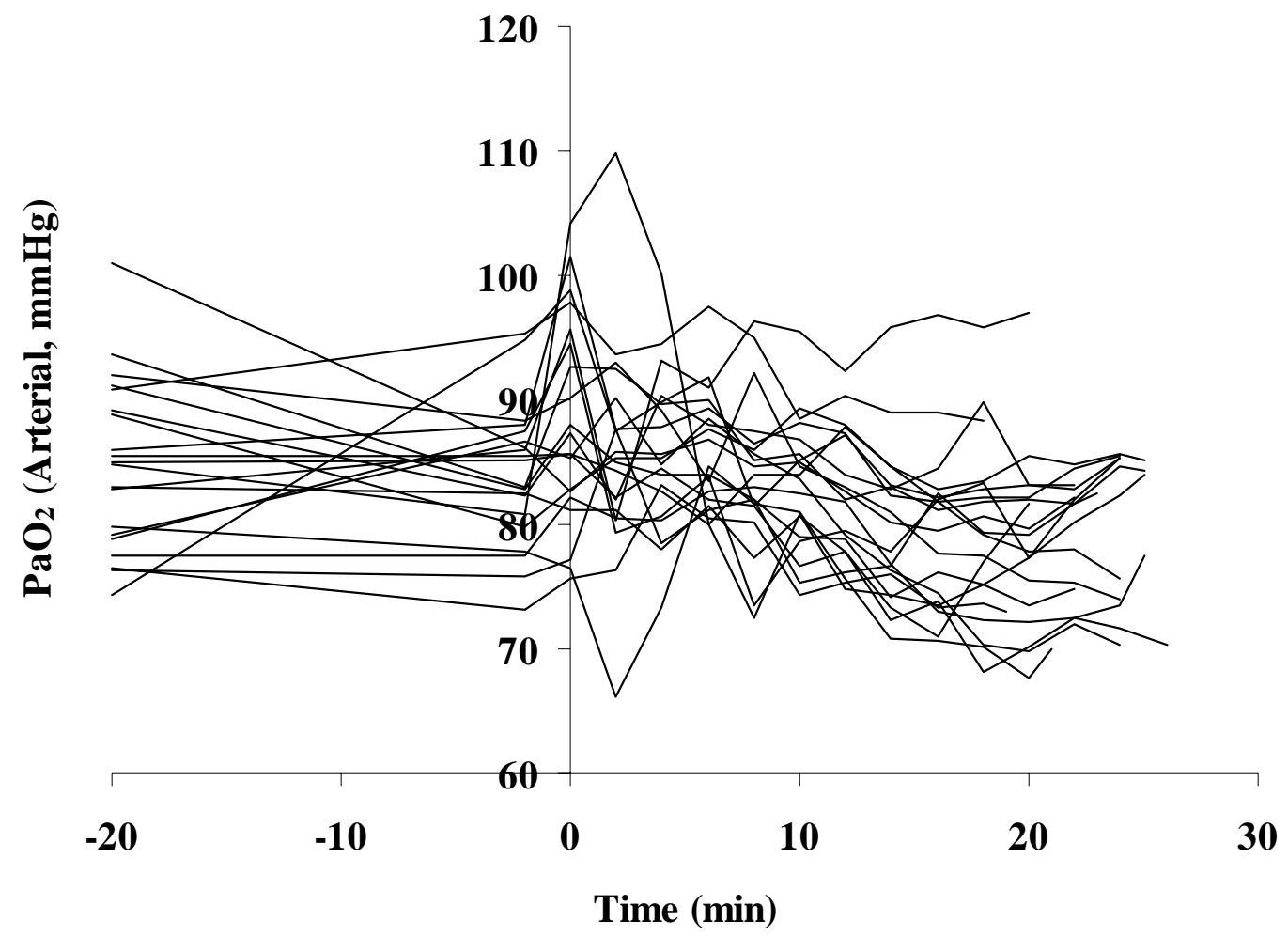

Figure 4.3 Individual $\mathrm{PO}_{2}$ values $(\mathrm{n}=20)$ for arterial blood corrected for arterial blood temperature during the incremental exercise test 


\subsection{4 $\mathrm{PaO}_{2}$ Corrected for Oesophageal Temperature During Incremental Exercise}

The individual results $(\mathrm{n}=23)$ for the change in $\mathrm{PaO}_{2}$ corrected for the temperature measured within the oesophagus at the time of blood sampling during incremental treadmill exercise to volitional exhaustion are illustrated in Figure 4.4. Average $\mathrm{PaO}_{2}$ was $95.6 \mathrm{mmHg}(7.2)$ at rest (taken at $\mathrm{T}_{0}$ ) and decreased in all subjects to an end-exercise average of $87.6 \mathrm{mmHg}(7.7, \mathrm{P}<$ 0.05). Four subjects had an increase in $\mathrm{PaO}_{2}$ of $<10 \mathrm{mmHg}, 8$ subjects a decrease of $<10 \mathrm{mmHg}, 10$ a decrease of $10-20 \mathrm{mmHg}$ and a single subject a decrease of $>20 \mathrm{mmHg}$.

The change in $\mathrm{PaO}_{2}$ ranged from an increase of $5.0 \mathrm{mmHg}$ to a decrease of $20.2 \mathrm{mmHg}$ (mean $\pm \mathrm{SD}=-8.1 \pm 7.7$ ). $\quad \mathrm{PaO}_{2}$ values averaged at their relative workloads (\% $\dot{\mathrm{VO}}{ }_{2}$ peak) are shown in Figure 4.6. 


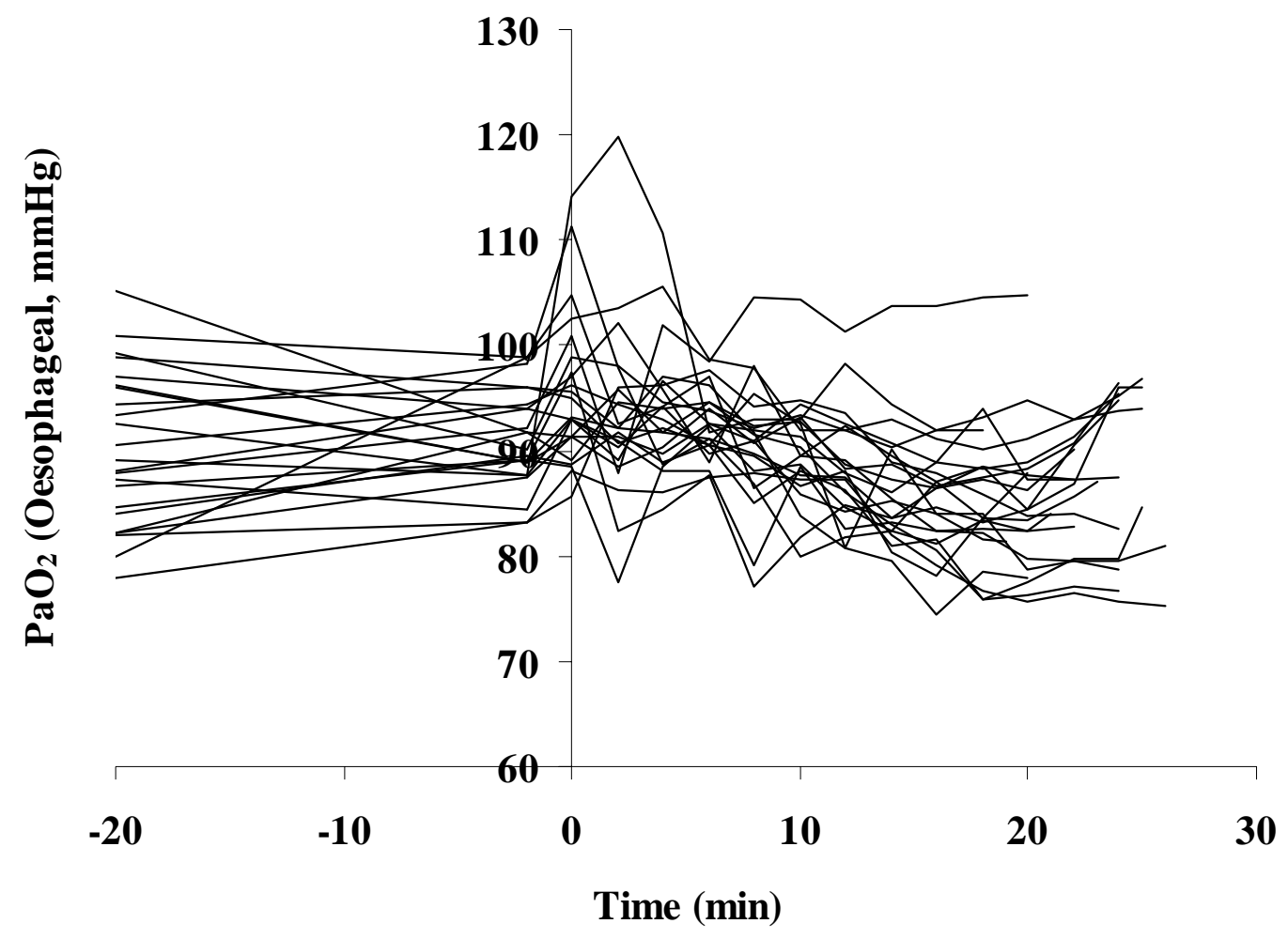

Figure 4.4 Individual $\mathrm{PO}_{2}$ values $(\mathrm{n}=23)$ for arterial blood corrected for oesophageal temperature during the incremental exercise test

\subsection{5 $\mathrm{PaO}_{2}$ Corrected for Active Muscle Temperature During Incremental Exercise}

The individual results $(\mathrm{n}=10)$ for the change in $\mathrm{PaO}_{2}$ corrected for the temperature measured within the active leg muscle (vastus lateralis) at the time of blood sampling during incremental treadmill exercise to volitional exhaustion are illustrated in Figure 4.5. Average $\mathrm{PaO}_{2}$ was $76.0 \mathrm{mmHg}$ (5.0) at rest (taken at $\mathrm{T}_{0}$ ) and increased in all subjects, bar one, to an end-exercise average of 84.1 mmHg (5.7, $\mathrm{P}<0.05$ ). Four subjects had an increase in $\mathrm{PaO}_{2}$ of between $10-20$ mmHg, 5 subjects an increase of $<10 \mathrm{mmHg}$, and one a decrease of $<5 \mathrm{mmHg}$. 
The change in $\mathrm{PaO}_{2}$ ranged from an increase of $20.0 \mathrm{mmHg}$ to a decrease of $4.7 \mathrm{mmHg}$ (mean $\pm \mathrm{SD}=+8.2 \pm 7.8$ ). $\mathrm{PaO}_{2}$ values averaged at their relative workloads (\% $\dot{\mathrm{V} O}{ }_{2}$ peak) are shown in Figure 4.6.

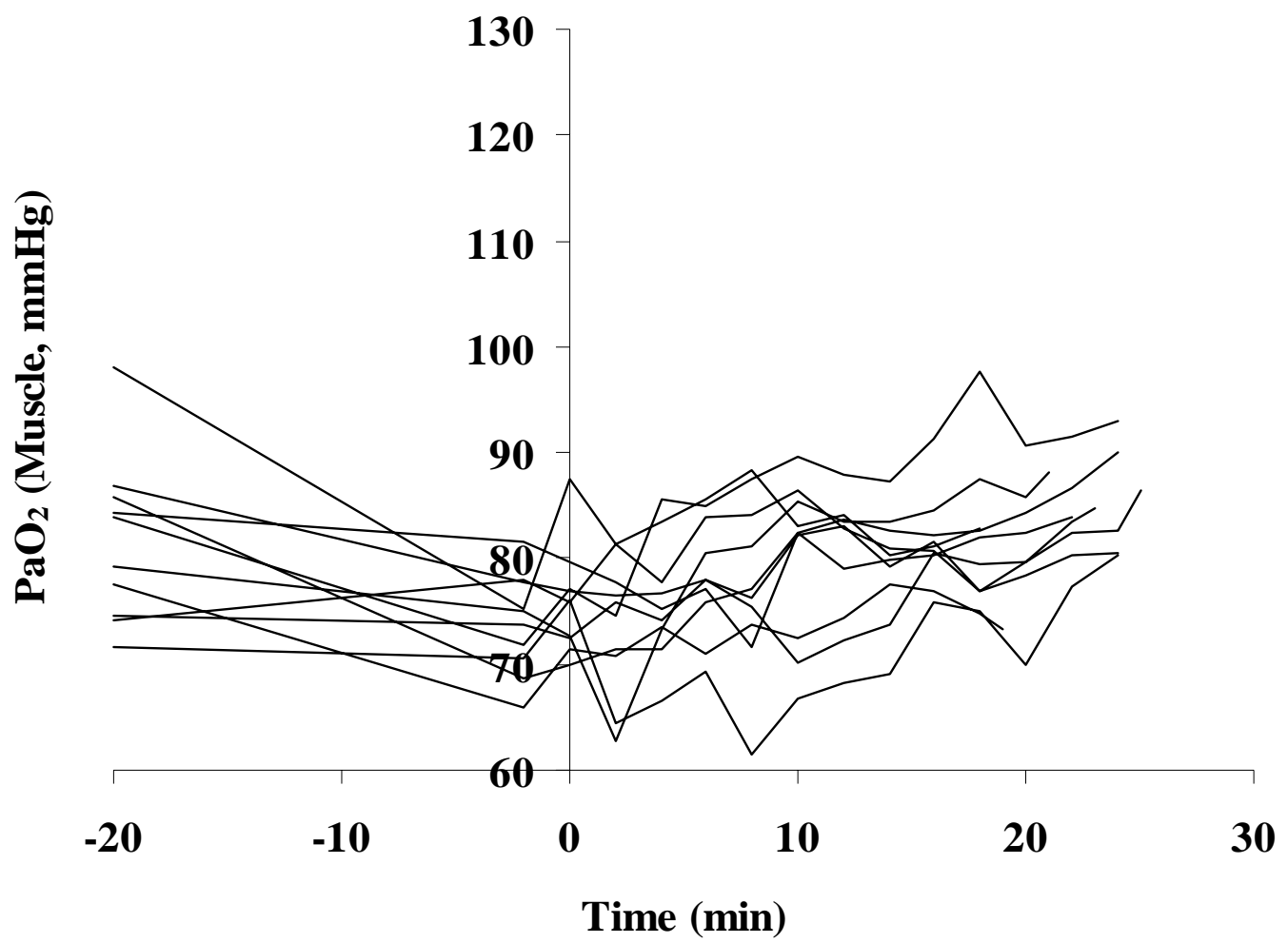

Figure 4.5 Individual $\mathrm{PO}_{2}$ values $(\mathrm{n}=10)$ for arterial blood corrected for active muscle temperature during the incremental exercise test

\subsection{6 $\quad \mathrm{PaO}_{2}$ values relative to workload intensity}

Figures 4.6 illustrates the changes in $\mathrm{PaO}_{2}$ during exercise relative to the percentage of $\% \dot{\mathrm{V} O}{ }_{2}$ peak and corrected for the temperature at each measurement site. When represented as such, the mean change ( \pm SD) in $\mathrm{PaO}_{2}$ from rest to cessation of the incremental exercise test is -21.0 (7.3) $\mathrm{mmHg}$ for uncorrected values, -15.0 (7.9) $\mathrm{mmHg}$ for values corrected for rectal temperature, -8.1 (6.5) $\mathrm{mmHg}$ when arterial blood temperature is used, -8.4 
(7.6) $\mathrm{mmHg}$ for oesophageal temperature corrected values and +8.3 (7.6) $\mathrm{mmHg}$ for values corrected for active muscle temperature.

The uncorrected values for $\mathrm{PaO}_{2}$ and those corrected for rectal, arterial blood and oesophageal temperatures all exhibited a significant downward trend from rest to end-exercise whereas the $\mathrm{PaO}_{2}$ values corrected for active muscle temperature showed a significant upward trend over the same time period.

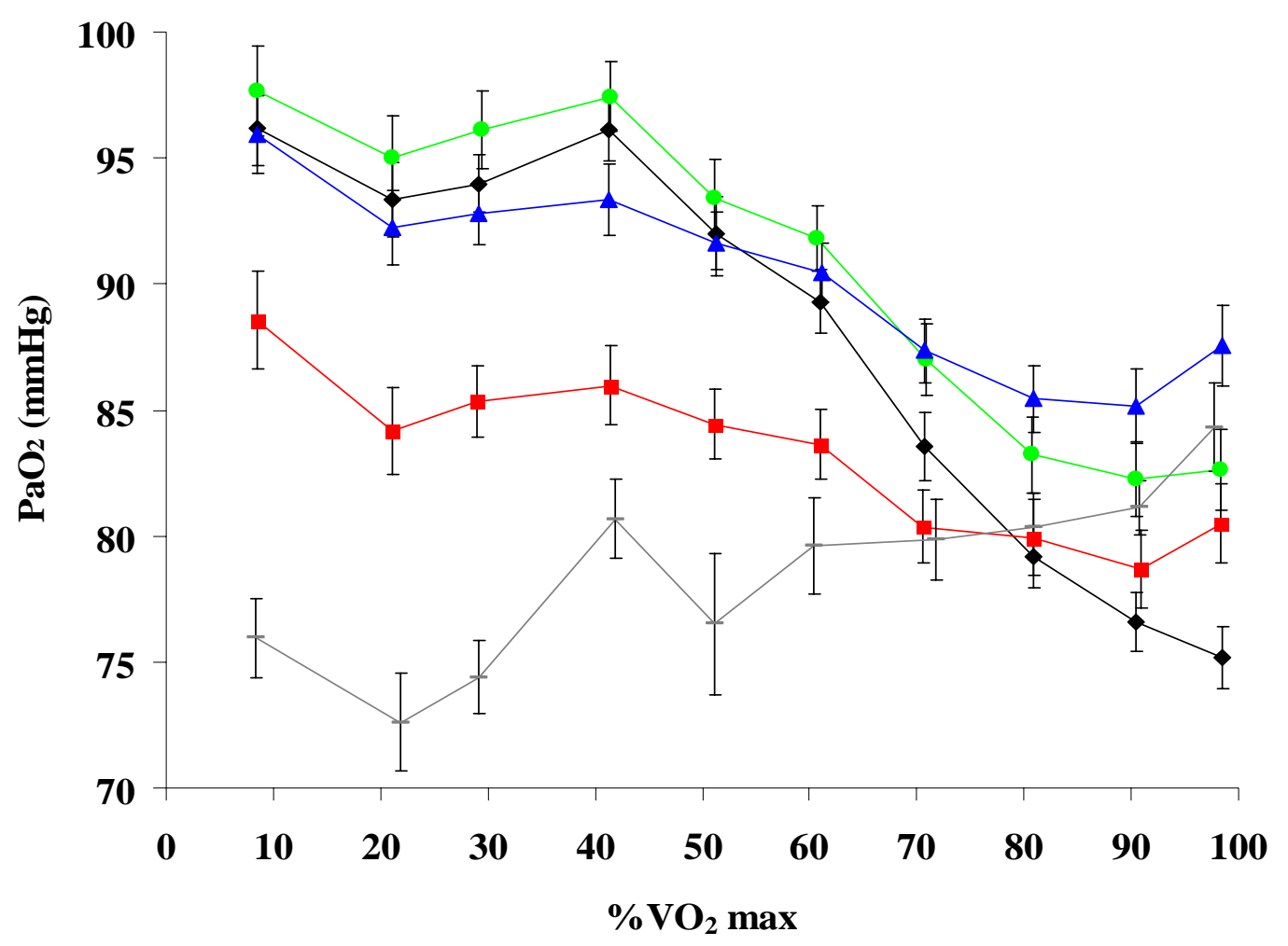

Figure 4.6 Mean $\mathrm{PaO}_{2}$ (for all subjects) relative to peak aerobic power ( $\dot{\mathrm{VO}}{ }_{2}$ peak). $\downarrow=\mathrm{PaO}_{2}$ uncorrected for change in body temperature, $\mathrm{PaO}_{2}$ corrected for; $\bullet=$ Rectal temperature, $\mathbf{\square}=$ Arterial blood temperature, $\boldsymbol{\Delta}$ = Oesophageal temperature, $-=$ Muscle temperature. Error bars indicate SEM. 


\subsection{7 $\quad \mathrm{PaO}_{2}$ Following Cessation of an Incremental Exercise Test.}

Figure 4.7 illustrates the trends in $\mathrm{PaO}_{2}$ in the 10 minutes following cessation of the incremental treadmill exercise test to volitional exhaustion. The figure includes $\mathrm{PaO}_{2}$ values uncorrected for temperature changes during the post-exercise period and those corrected for body temperature as measured at the rectal, oesophageal, arterial and muscle temperature probe sites.

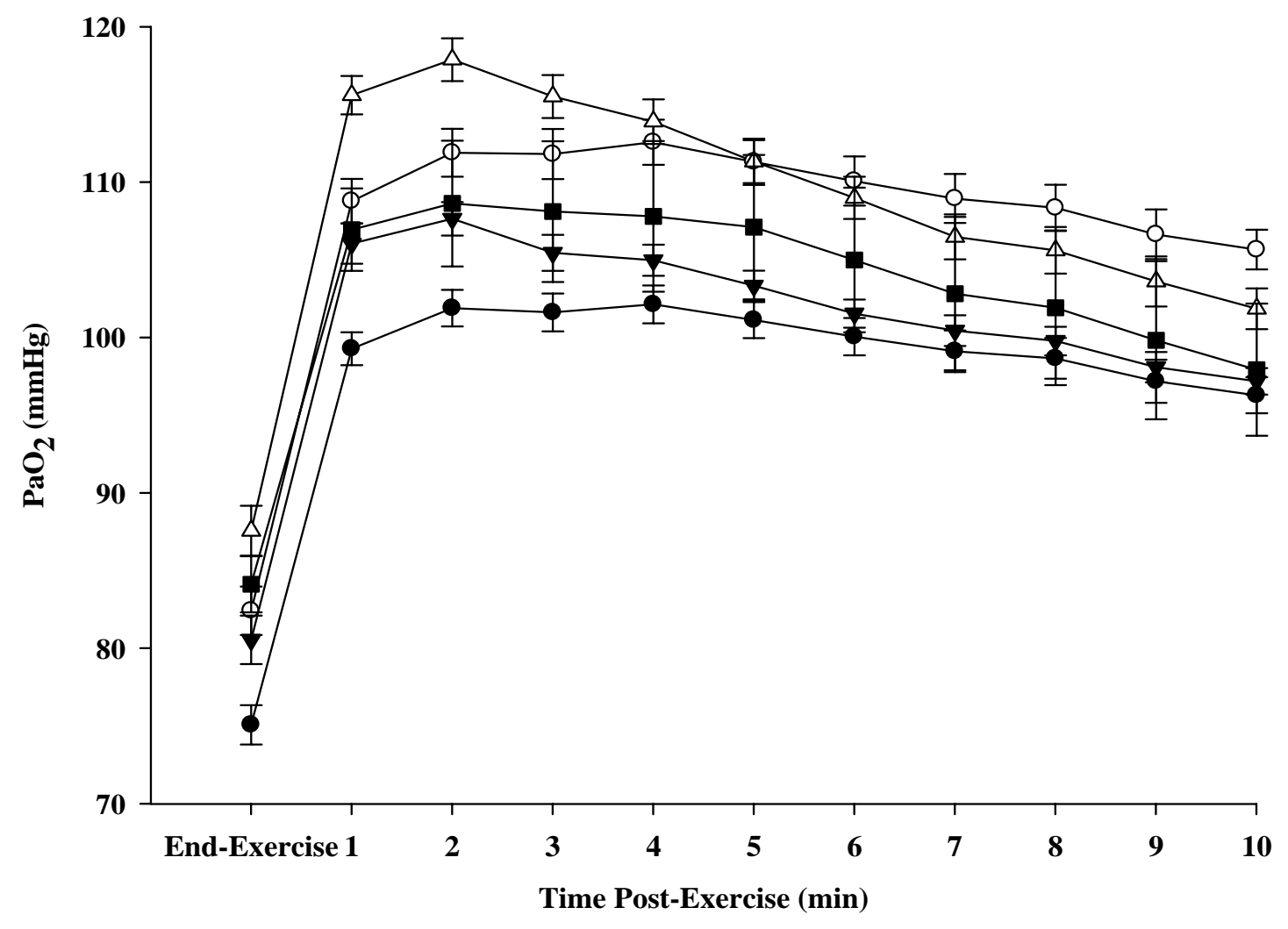

Figure 4.7 Mean $\mathrm{PaO}_{2}( \pm \mathrm{SD})$ following cessation of the incremental exercise test. - $=\mathrm{PaO}_{2}$ uncorrected for change in body temperature, $\mathrm{PaO}_{2}$ corrected for; $\bigcirc=$ Rectal temperature, $\boldsymbol{\nabla}=$ Arterial blood temperature, $\Delta=$ Oesophageal temperature, $\mathbf{\square}=$ Muscle temperature. 
By the end of the first minute following exercise all uncorrected and temperature-corrected $\mathrm{PaO}_{2}$ values had increased from end-exercise values to exceed pre-exercise resting values. While there was a brief period of stabilisation thereafter, followed by a slow downward trend, even at 10 minutes post-exercise all temperature-corrected values remained significantly above preexercise values. Values uncorrected for body temperature in the first minute post-exercise and minutes 7-10 post exercise were not different from resting values.

\subsubsection{Prevalence of EIH}

Table 4.1 compares the prevalence of EIH using both the arbitrary definition of a decrease of $\geq 10 \mathrm{mmHg} \mathrm{PaO}_{2}$ and the more statistically sound approach of a decrease $>2$ standard deviations (SD) from the mean. Using the mean resting data, the 2SD values for uncorrected and rectal, arterial, oesophageal and muscle temperature corrected $\mathrm{PaO}_{2}$ 's were 13.4, 15.0, 16.8, 14.4 and $10 \mathrm{mmHg}$, respectively. 
Table 4.1 Temperature correction site, definition and prevalence of EIH.

\begin{tabular}{|c|c|c|}
\hline $\mathrm{PaO}_{2}$ & $\mathrm{EIH}=\Delta \mathrm{PaO}_{2} \geq 10 \mathrm{mmHg}$ & $\mathbf{E I H}=\Delta \mathrm{PaO}_{2} \geq 2 \mathrm{SD}$ \\
\hline Uncorrected (n = 23) & $22(96 \%)$ & $18(78 \%)$ \\
\hline $\begin{array}{l}\text { Rectal Temperature } \\
\text { Corrected }(n=22)\end{array}$ & $16(73 \%)$ & $9(41 \%)$ \\
\hline $\begin{array}{l}\text { Arterial Temperature } \\
\text { Corrected }(n=20)\end{array}$ & $7(35 \%)$ & $2(10 \%)$ \\
\hline $\begin{array}{c}\text { Oesophageal } \\
\text { Temperature } \\
\text { Corrected }(n=23)\end{array}$ & $11(48 \%)$ & $7(30 \%)$ \\
\hline $\begin{array}{l}\text { Muscle Temperature } \\
\text { Corrected }(n=10)\end{array}$ & $0(0 \%)$ & $0(0 \%)$ \\
\hline
\end{tabular}

\subsubsection{Arterial Oxygen Content during Exercise}

The arterial oxygen content $\left(\mathrm{CaO}_{2}\right)$ both at rest and at end exercise is shown in Table 4.2 with values presented as mean \pm SD. This data was calculated using the $[\mathrm{Hb}]$ from the corresponding arterial blood sample which increased with increasing exercise intensity (haemoconcentration). Additionally, this table includes $\mathrm{CaO}_{2}$ calculated with end-exercise [Hb] maintained at resting levels i.e. as if there was no haemoconcentration during exercise (end-exercise, constant $\mathrm{Hb})$. 
Table 4.2 $\mathrm{CaO}_{2}$ resting and end-exercise values

\begin{tabular}{c|ccc}
\hline & Rest & End-Exercise & $\begin{array}{c}\text { End Exercise, } \\
\text { Constant [Hb] }\end{array}$ \\
\hline Uncorrected & $19.36 \pm 1.2^{\mathrm{ab}}$ & $19.13 \pm 1.0^{\mathrm{ac}}$ & $18.27 \pm 1.2^{\mathrm{bc}}$ \\
Rectal & $19.83 \pm 1.2^{\mathrm{b} \S}$ & $19.78 \pm 1.0^{\mathrm{b}^{*}}$ & $18.92 \pm 1.2^{\mathrm{ac} \dagger}$ \\
Arterial Blood & $19.85 \pm 1.3^{\mathrm{b}}$ & $19.88 \pm 1.0^{\mathrm{b} *}$ & $19.01 \pm 1.2^{\mathrm{ac}}$ \\
Oesophageal & $19.89 \pm 1.2^{\mathrm{b}}$ & $20.10 \pm 1.0^{\mathrm{b} \theta}$ & $19.19 \pm 1.2^{\mathrm{ac} \ddagger}$ \\
Muscle & $19.74 \pm 0.8^{\mathrm{b} \S}$ & $20.00 \pm 0.8^{\mathrm{b} \theta}$ & $19.19 \pm 0.6^{\mathrm{ac} \ddagger}$ \\
\hline \hline
\end{tabular}

$\mathrm{a}=$ significantly different from end-exercise, $\mathrm{b}=$ significantly different from constant $[\mathrm{Hb}], \mathrm{c}=$ significantly different from rest $(\mathrm{P}<0.05)$. Symbols matched vertically indicate no significant difference $(\mathrm{P}<0.05)$. 


\subsection{DISCUSSION}

The clear conclusion from the data reported in this chapter is that both the prevalence and physiological significance of EIH (defined in this chapter as a $\Delta \mathrm{PaO}_{2} \geq 10 \mathrm{mmHg}$ ) are dependent upon the temperature correction applied to the data.

With regard to prevalence, when no correction was applied to the data the prevalence was $96 \%$, whereas when corrected for active muscle temperature, the prevalence fell to $0 \%$. A spectrum of prevalence between these extremes was then found when other sites were used for temperature correction, ranging through 35\% (arterial blood), 48\% (oesophageal) and 73\% (rectal). This is clearly a previously unidentified problem in the field of EIH research for without universal agreement on the appropriate reference site for temperature correction any designation of prevalence within and between study populations will be totally misleading. Given the divergent, site-dependent, thermal responses to exercise reported in the previous chapter, these results on prevalence are not unexpected, but they raise the question: what is the appropriate temperature correction for blood gas data obtained during incremental exercise?

Certainly, there is little dissent that blood gas data, when collected for the study of pulmonary gas exchange must be corrected for body temperature (Severinghaus, 1959; Ashwood, Kost et al, 1983). With regard to oxygen exchange during exercise it would seem most appropriate to look at the effect of temperature correction on oxygen status at the principal sites of oxygen loading (pulmonary blood) and unloading (active muscle). Provided there is agreement on what constitutes a "significant" change in $\mathrm{PaO}_{2}$, prevalence of a phenomenon 
such as EIH can then be determined. While a decrease across exercise of $\geq 10$ mmHg has consensus acceptance as a "significant" change, it is an arbitrary choice. A more acceptable definition, in scientific and statistical terms, should be a fall $\geq 2$ standard deviations from the mean resting value. This would indicate any change in exercise blood gas levels is occurring outside of the $95 \%$ confidence interval of the resting mean (1.96 standard deviations rounded up to 2SD) which results in these changes being more closely associated with subject numbers, resting conditions and measurement accuracy. Both definitions were applied to the current results.

Given that EIH must reflect a problem in oxygen loading in the pulmonary circulation, the most appropriate temperature to use in correcting blood gas values would be that of the pulmonary blood (as represented by the oesophageal temperature measurement). Then the number of individuals in a given study population who demonstrate a "significant" exercise-induced reduction in $\mathrm{PaO}_{2}$, should provide the true prevalence of the phenomenon. When the 2 definitions suggested above were applied to the present data, corrected for oesophageal temperature, the prevalence was $48 \%$ (>10 $\mathrm{mmHg}$ ) and 30\% (>2 SD), respectively. Whichever definition is accepted, there can be no argument that EIH is a real phenomenon. What remains uncertain is (1) whether the prevalence of the phenomenon is affected by training status, age or sex, (2) what is its mechanism and (3) is it of physiological significance? The first 2 questions cannot be answered from either published or present data, but some suggestions can be made with regard to the third option when one 
examines the effect of correcting the blood gas data for active muscle temperature.

While correcting $\mathrm{PaO}_{2}$ values for pulmonary blood temperature identifies EIH as a real phenomenon in terms of blood oxygen status in the lungs, with a prevalence between 30 and $48 \%$ in the study population, the prevalence fell to zero when the $\mathrm{PaO}_{2}$ values were corrected for active muscle temperature. Furthermore, the oxygen content of the arterial blood was also unchanged. Hence, EIH would appear to have no significance in terms of oxygen uptake because active muscle is the major site for this during exercise with $>80 \%$ of the cardiac output being delivered under maximal conditions. This finding is critical to our appreciation of the physiological significance of the phenomenon because the primary interest created by EIH among exercise physiologists over the past 30 years has been its potential to affect aerobic performance. It was presented as a phenomenon with a prevalence of $\sim 50 \%$ in highly trained male athletes, identified as an issue likely to affect performance and therefore a matter of great importance to understand the mechanism. Yet, in many studies there was no correlation with maximal aerobic power, a finding repeated in the present experiments and a seemingly inexplicable observation if EIH impacted upon (muscle) oxygen uptake. This was particularly so because earlier studies certainly raised alarm, with substantial falls in $\mathrm{PaO}_{2}$ reported, although we now know that in many cases these were exaggerated by the absence of a temperature correction. The present data on $\mathrm{PaO}_{2}$ and oxygen content provide a possible answer to this apparent paradox. 
A final area of EIH research needs to be addressed. Many previous studies have utilised haemoglobin saturation measurements to examine the exerciseinduced changes in blood oxygen status. Yet a relatively small decline in haemoglobin saturation (i.e. from $98 \%$ to $95 \%$ ), which would be difficult to quantify reliably in terms of directly measured saturation $\left(\mathrm{SaO}_{2}\right)$ and almost impossible with oximetry $\left(\mathrm{SpO}_{2}\right)$, the $\mathrm{PaO}_{2}$ falls from 100 mmHg to $70 \mathrm{mmHg}$, a change, if measured across exercise, would represent severe exercise-induced hypoxaemia. Nevertheless, due to haemoconcentration caused by a plasma shift to the extravascular interstitium (Harrison, Edwards et al, 1975), this same decline in saturation and oxygen partial pressure is reflected in no significant change in oxygen content, which is of course a critical aspect of oxygen delivery and uptake. It must also be recognised that no significant change in the oxygen content of arterial blood will occur under normal, resting conditions until $\mathrm{PaO}_{2}$ falls below $\sim 60 \mathrm{mmHg}$ although the relationship between $\mathrm{PaO}_{2}$, saturation and content will change dramatically with arterial blood temperature, $\mathrm{PCO}_{2}$ and $\mathrm{pH}$ and some other ions as well. One must also factor into any determination of oxygen status during exercise the known immediate haemoconcentration of $\sim 15 \%$. Precisely how all these several variables change and operate at the cellular level of oxygen transfer, both in the lungs and in the active muscle, remain essentially indeterminate.

Therefore, when the present results are considered in terms of the prevalence and physiological significance of $\mathrm{EIH}$, the following clear conclusions can be drawn: 
When investigating metabolic oxygen exchange across exercise, blood oxygen status must be measured directly in arterial blood samples and all data must be corrected for pulmonary blood and active muscle temperatures.

- There is an exercise-induced fall in $\mathrm{PaO}_{2}$ in pulmonary blood that, depending on the definition applied, provides a prevalence of EIH of between $30 \%$ and $48 \%$ in the present study population of active males.

- Neither the $\mathrm{PaO}_{2}$ nor $\mathrm{CaO}_{2}$ of the blood delivered to active muscle are significantly reduced during incremental exercise to exhaustion in the present subject cohort. Therefore, EIH is not a phenomenon of physiological significance in the context of aerobic performance.

- All blood gas values measured in future studies of EIH must be corrected for changes in temperature measured simultaneously with oesophageal and active muscle probes if meaningful conclusions are to be drawn with regard to prevalence, mechanisms and physiological significance.

While the present data provide no conclusions with regard to the mechanism of $\mathrm{EIH}$, the reversal of all temperature-corrected values for $\mathrm{PaO}_{2}$ to significantly above resting levels, within the first minute of recovery indicates that this is a mechanism with a remarkably short half-time. 


\section{CHAPTER 5}

\section{Reproducibility of $\mathrm{PaO}_{2}$ changes during incremental exercise}

\subsection{INTRODUCTION}

That exercise can cause a fall in $\mathrm{PaO}_{2}$ is documented both in this thesis and much published work over the past 30 years. When the fall is $\geq 10 \mathrm{mmHg}$ this response has been identified as the phenomenon of exercise-induced hypoxemia (EIH) with a suggested prevalence of $\sim 50 \%$ in trained individuals. The results in previous chapters of this thesis underscore the critical importance of temperature correcting the blood gas data, standardising the "resting" value and choice of definition (i.e. $\geq 10 \mathrm{mmHg}$ or \pm 2 SD's from resting mean) when determining the physiological significance and prevalence of EIH. Although the possible mechanism of EIH has been the subject of considerable research much of this work is potentially flawed because it has been assumed that the phenomenon is reproducible allowing the effect of a given intervention to be tested (Anselme, Caillaud et al, 1994; Prefaut, Anselme-Poujol et al, 1997; Yoshida, Udo et al, 1989; Aguilaniu, Flore et al, 1998; McKenzie, Lama et al, 1999). While the accuracy, precision and repeatability of modern blood gas 
analyses on a given machine and sample (whether taken at rest or during exercise) are accepted (Kampelmacher, van Kesteren et al, 1997), there have been no studies documenting the reproducibility of the pattern of blood gas response in a given set of individuals to a standard exercise test. Only with such information can the phenomenon of EIH achieve real status and be the subject of appropriate investigation. This lack of documented evidence of reproducibility gave rise to the current aim of the series of experiments reported in this chapter where a group of 10 male runners performed incremental treadmill exercise to exhaustion on 2 occasions and their metabolic, thermal and blood gas responses compared. 


\subsection{METHODS}

\subsubsection{Subjects}

Ten male subjects participated in the study in conjunction with the previously described experiments in Chapters 3 and 4 . All subjects were trained in running and completed a medical history questionnaire to ensure no past or present medical condition existed to exclude them from performing a maximal exercise test. On the day of each incremental exercise test the subjects arrived at the laboratory having abstained from vigorous exercise for the previous 24 hours and from caffeinated products for 12 hours. To allow full recovery a minimum of three days was allowed between tests.

\subsubsection{Experimental Control}

In any project designed to assess reproducibility of a metabolic response to exercise, then, as far as practicable, subject status, the experimental conditions and the analytical apparatus must be reproduced for both tests. Maintaining an unchanged training program and repeating the tests within a 3 to 14 day window ensured stable exercise status between tests in the 10 subjects who were investigated in the present experiments. Both incremental exercise tests were conducted using the same protocol, within the same laboratory environment, and at the same time of day. All analytical equipment was appropriately calibrated prior to each test using the methods outlined earlier (see Sections 2.3.6, 2.5.2) and issues of repeatability and reproducibility of metabolic analyses addressed. Reproducibility of the exercise paradigm was adjudged by comparing the 
common metabolic measures of maximal oxygen uptake, heart rate and ventilation and the time to exhaustion in the 2 tests and ensuring that the established criteria for defining a maximal effort were met in each test (Howley et al. 1995).

While the methods of calibration and the technique for placement of the temperature probes were identical between tests, exact duplication of placement of the 4 temperature probes with respect to individual anatomy could not be guaranteed. Because any consequent variation in their recorded hyperthermic responses could impact on temperature-corrected $\mathrm{PaO}_{2}$ values, the primary determination of reproducibility was adjudged from the uncorrected values. Nevertheless, because the thermal responses can provide an index of the reproducibility of the test paradigm and the temperature corrections applied to the $\mathrm{PaO}_{2}$ values can affect prevalence of $\mathrm{EIH}$, all data subsets have been presented in the Results section.

\subsubsection{Temperature Probe Placement}

Rectal Temperature: - All 10 subjects self-inserted the rectal temperature probes for the measurement of rectal temperature. Each subject was given instructions to position the rectal probe such that the thermistor tip was inserted $10 \mathrm{~cm}$ past the anal sphincter and to secure the probe to prevent displacement during the exercise test (see Section 2.3.2). All rectal temperature measurements were included in the data analysis with the exception of one $(n=9)$. In the case of the excluded data set, the temperature probe dislodged during the exercise test 
and was not considered to be measuring rectal temperature at the prescribed depth.

Arterial Temperature: - All 10 subjects underwent the measurement of arterial blood temperature. Arterial blood temperature was measured by inserting a temperature thermistor into the side-port of a catheter set-up for the sampling of arterial blood (see Section 2.3.4). Arterial blood temperature was measured simultaneous with blood sampling, the highest temperature recorded during blood sampling being taken as the true arterial blood temperature.

Oesophageal Temperature: - Following application of a local anaesthetic gel to one nasal cavity the oesophageal temperature probe was inserted and positioned in the oesophagus of all subjects. The probe was initially positioned at a depth of $45 \mathrm{~cm}$ and then moved marginally proximally or distally until the highest temperature reading was obtained (see Section 2.3.3). In all but two subjects the oesophageal probe remained active throughout exercise giving a data set of 8 subjects.

Muscle Temperature: - The measurement of muscle temperature was performed using a fine-gauge temperature thermistor (IT-21, Physitemp) inserted under local anaesthesia into the vastus lateralis muscle to a depth of 30 mm (see Section 2.3.5). This temperature probe was inserted in all subjects, but while a complete data set was obtained in all subjects performing the initial exercise test $(n=10)$, due to the nature of muscular movement during exercise the muscle probe failed in 5 subjects during the second exercise test $(n=5)$. 


\subsubsection{Arterial Catheter Insertion}

Following a satisfactory Allen's Test result a radial artery catheter was inserted under local anaesthesia (see Section 2.4.1). A sampling line and a Yshaped adaptor were then attached to the catheter (see Figure 2.10) to allow the simultaneous sampling of arterial blood and measurement of its temperature.

\subsubsection{Temperature measurement and Arterial Blood Sampling}

Resting body temperature was recorded simultaneously at each probe site on three occasions; the first with the subject supine, 20 min following the insertion of the arterial catheter $\left(\mathrm{T}_{-20}\right)$, the second with the subject standing astride the treadmill $\left(\mathrm{T}_{-2}\right)$ and the final with the subject standing astride the treadmill just prior to the start of the exercise test ( $\mathrm{T}_{0}$, see Section 2.4.2).

During the exercise test temperature measurements were recorded from each probe simultaneously with arterial blood sampling at the end of every workload. At the voluntary cessation of the exercise test the time was noted and at every minute for 10 minutes following test cessation the temperature at each measurement site was simultaneously recorded, again in concert with the drawing of an arterial blood sample. All arterial blood samples were capped, ensuring no air bubbles in the pre-heparinised glass syringe and immediately stored in an ice slurry (see Section 2.4.2).

All blood samples were analysed in duplicate and in order of their sampling time. If duplicates differed in $\mathrm{PaO}_{2}$ by more than $\pm 0.6 \mathrm{mmHg}$ a third 
analysis of that sample was performed and the mean of the closest two measurements used in data analysis.

\subsubsection{Exercise Test Protocol}

Prior to the start of the exercise test the subject was positioned astride the treadmill with the nose clip and Hans Rudolph one-way breathing valve in place and the mixing box was flushed with the subject's expirate for 2 minutes prior to starting exercise (see Section 2.5.1). The treadmill was then started and the subject instructed to begin walking and at every 2 minutes thereafter the treadmill speed or grade was increased until the subject reached volitional exhaustion (see Section 2.6).

Following termination of the exercise test the subject stood astride the treadmill belt and continued breathing through the one-way valve. The treadmill was returned to zero grade, set at a slow walking speed and the subject instructed to step on to the treadmill and walk during recovery (see Section 2.6).

\subsubsection{Data Analysis}

The reproducibility of $\mathrm{PaO}_{2}$, metabolic and thermal responses were analysed using an internet-available EXCEL (Microsoft Corporation) spreadsheet (Hopkins, 2000). This spreadsheet allows for the calculation of typical error and Pearson coefficients in both raw and log-transformed data formats. Pairwise t-tests and further correlation statistics were performed using SigmaStat statistical software (Version 3.5, Systat Software, Inc., California, USA), including the analysis of 95\% confidence limits. 


\subsection{RESULTS}

\subsubsection{Metabolic Variables}

In both tests the values for $\dot{\mathrm{V}} \mathrm{O}_{2}$ max exceeded the age-predicted values (42.5 $\mathrm{mL} \cdot \mathrm{min}^{-1} \cdot \mathrm{kg}^{-1}$ or $2933 \mathrm{~mL} \cdot \mathrm{min}^{-1}$ ), consistent with the subjects' endurancetraining status, and a plateau in $\dot{\mathrm{VO}}_{2}$ was observed in at least 7 out of 10 subjects in each test. When these findings are combined with values for $\mathrm{HR}$ max (age-predicted, $190 \pm 10$ beats $\cdot \mathrm{min}^{-1}$ ) and $\mathrm{RER}_{\text {max }}(\geq 1.10$ ), they provide a data set consistent with a maximal effort (see Methods) in both tests (Table 5.1).

The metabolic variables and time to exhaustion in Tests 1 and 2 are presented in Table 5.1. Pair wise t-test analysis of the metabolic data demonstrates no significant difference existing between any data pairs. Furthermore, with the exception of RER $\max$ (correlation coefficient $=0.581$ ), the metabolic variables show a significant relationship (as defined by the Pearson Correlation Coefficient analysis) between Tests 1 and 2. For these tests the confidence level was set at $95 \%$. Whilst the typical error as a coefficient of variation value for $\dot{\mathrm{V} O}{ }_{2} \max (6.1 \%)$ is larger than would be expected this is due to a single adverse test-retest value which, if omitted, would reduce this to $3.8 \%$ and typical error from 251.4 to $163.2 \mathrm{~mL} \cdot \mathrm{min}^{-1}$. Removal of this datum point also increases the Pearson correlation coefficient to 0.969 . 
Table 5.1 Mean values $( \pm$ SD) for metabolic variables and time to exhaustion in Tests 1 and 2 .

\begin{tabular}{|c|c|c|c|c|c|c|c|c|}
\hline & Test 1 & Test 2 & $\begin{array}{c}95 \% \\
\text { confidence } \\
\text { interval }\end{array}$ & t statistic & $P$ value & $\begin{array}{c}\text { Pearson } \\
\text { Correlation } \\
\text { Coefficient }\end{array}$ & $\begin{array}{c}\text { Typical } \\
\text { Error }\end{array}$ & $\begin{array}{c}\text { Typical } \\
\text { Error as } \\
\text { CV }\end{array}$ \\
\hline$\dot{\mathrm{VO}}{ }_{2} \max \left(\mathrm{mL} \cdot \mathrm{min}^{-1}\right)$ & $4539 \pm 831$ & $4541 \pm 861$ & -797 to 794 & -0.005 & 0.996 & 0.912 & 251.4 & 6.1 \\
\hline Heart Rate $_{\text {max }}$ (beats/min) & $192 \pm 6$ & $190 \pm 6$ & -4.1 to 7.1 & 0.562 & 0.581 & 0.753 & 3.0 & 1.6 \\
\hline$\dot{\mathrm{V}}_{\mathrm{E} \max }\left(\mathrm{L} \cdot \mathrm{min}^{-1}\right)$ & $158.7 \pm 25.4$ & $163.9 \pm 31.3$ & -31.2 to 22.34 & -0.349 & 0.731 & 0.833 & 12.3 & 9.9 \\
\hline $\mathrm{RER}_{\text {max }}$ & $1.10 \pm 0.09$ & $1.11 \pm 0.08$ & -0.09 to 0.07 & -0.338 & 0.739 & 0.581 & 0.06 & 5.1 \\
\hline Time to Exhaustion (min) & $24.8 \pm 2.3$ & $24.1 \pm 2.7$ & -1.7 to 3.1 & 0.619 & 0.544 & 0.779 & 1.2 & 6.0 \\
\hline
\end{tabular}

$\dot{\mathrm{VO}}_{2} \max =$ maximal oxygen consumption, $\dot{\mathrm{V}}_{\mathrm{E} \text { max }}=$ maximal minute ventilation, $\mathrm{RER}_{\text {max }}=$ maximal respiratory exchange ratio. $\mathrm{CV}=$ coefficient of variation (\%). 95\% confidence interval is for the difference of means. 


\subsubsection{Reproducibility of resting and end-exercise temperatures}

The resting and end-exercise temperatures at all 4 sites are shown in Table 5.2. While there were differentials between resting values and endexercise values at the four sites within tests there were no differences at any given site between tests, confirming the reproducibility of resting and end-exercise temperature measurements at a given site. 
Table 5.2 Reproducibility of resting and end-exercise temperatures ( \pm SD).

\begin{tabular}{|c|c|c|c|c|c|c|c|c|}
\hline & \multicolumn{2}{|c|}{ Rectal Temperature $\left({ }^{\circ} \mathrm{C}\right)$} & \multicolumn{2}{|c|}{ Arterial Temperature $\left({ }^{\circ} \mathrm{C}\right)$} & \multicolumn{2}{|c|}{ Oesophageal Temperature $\left({ }^{\circ} \mathrm{C}\right)$} & \multicolumn{2}{|c|}{ Muscle Temperature $\left({ }^{\circ} \mathrm{C}\right)$} \\
\hline & Test 1 & Test 2 & Test 1 & Test 2 & Test 1 & Test 2 & Test 1 & Test 2 \\
\hline $\mathrm{T}_{-20}$ & $36.6 \pm 0.2^{* \mathrm{bd}}$ & $36.7 \pm 0.2^{* \mathrm{bd}}$ & $35.3 \pm 0.5^{\mathrm{acd}}$ & $35.6 \pm 0.7^{\mathrm{ac}}$ & $36.3 \pm 0.3^{* \mathrm{bd}}$ & $36.5 \pm 0.3^{* \mathrm{bd}}$ & $34.7 \pm 0.7 *$ abc & $35.1 \pm 1.0^{* a \mathrm{c}}$ \\
\hline $\mathrm{T}_{-2}$ & $37.2 \pm 0.2^{\mathrm{bd}}$ & $37.1 \pm 0.3^{\mathrm{bd}}$ & $35.7 \pm 0.6^{\text {acd }}$ & $35.9 \pm 0.5^{\mathrm{acd}}$ & $37.1 \pm 0.3^{\mathrm{bd}}$ & $37.0 \pm 0.2^{\mathrm{bd}}$ & $33.7 \pm 0.8^{\mathrm{abc}}$ & $33.5 \pm 1.4^{\mathrm{abc}}$ \\
\hline $\mathrm{T}_{0}$ & $37.2 \pm 0.2^{\mathrm{bd}}$ & $37.2 \pm 0.2^{\text {bd }}$ & $35.4 \pm 0.8^{\text {acd }}$ & $35.8 \pm 0.6^{\mathrm{acd}}$ & $37.0 \pm 0.2^{\mathrm{bd}}$ & $37.1 \pm 0.2^{\mathrm{bd}}$ & $33.4 \pm 0.6^{\mathrm{abc}}$ & $33.2 \pm 1.3^{\mathrm{abc}}$ \\
\hline End Exercise & $38.2 \pm 0.4^{* c}$ & $38.1 \pm 0.3^{*}$ & $38.0 \pm 0.7^{* \mathrm{c}}$ & $37.8 \pm 0.7 *^{\mathrm{c}}$ & $39.3 \pm 0.2^{* a b}$ & $39.0 \pm 0.6^{* b}$ & $38.7 \pm 1.2^{*}$ & $38.5 \pm 1.4^{*}$ \\
\hline
\end{tabular}

$*$ = Significantly different within tests $(\mathrm{P} \leq 0.05) . \mathrm{a}=$ significantly different from rectal temperature $(\mathrm{P} \leq 0.05) . \mathrm{b}=$ significantly different from arterial temperature $(\mathrm{P} \leq 0.05)$. $\mathrm{c}=$ significantly different from oesophageal temperature $(\mathrm{P} \leq 0.05) . \quad \mathrm{d}=$ significantly different from muscle temperature $(\mathrm{P}<0.05)$. Statistics a, b, c and d describe within-test analysis only. 


\subsubsection{Resting $\mathrm{PaO}_{2}$ values}

There were no significant differences between the uncorrected $\left(37^{\circ} \mathrm{C}\right)$ values at $\mathrm{T}_{-20}, \mathrm{~T}_{-2}$ and at $\mathrm{T}_{0}$, either within or between Tests 1 and 2 (Table 5.3).

Table 5.3 Reproducibility of uncorrected $\left(37^{\circ} \mathrm{C}\right)$ resting $\mathrm{PaO}_{2}$ values $(\mathrm{n}=10)$.

\begin{tabular}{c|cccc}
\hline $\begin{array}{c}\text { Resting } \\
\text { Sample }\end{array}$ & $\begin{array}{c}\text { Test 1 } \\
(\mathrm{mmHg})\end{array}$ & $\begin{array}{c}\text { Test 2 } \\
(\mathrm{mmHg})\end{array}$ & $\mathrm{P}$ & $\begin{array}{c}\text { Correlation } \\
\text { Coefficient }\end{array}$ \\
\hline $\mathrm{T}_{-20}$ & $93.2 \pm 6.2$ & $91.6 \pm 6.2$ & 0.551 & 0.840 \\
$\mathrm{~T}_{-2}$ & $90.3 \pm 4.0$ & $90.6 \pm 4.9$ & 0.865 & 0.810 \\
$\mathrm{~T}_{0}$ & $93.4 \pm 3.8$ & $94.7 \pm 7.5$ & 0.622 & 0.485 \\
\hline \hline
\end{tabular}

Values are mean \pm SD.

\subsubsection{Exercise $\mathrm{PaO}_{2}$ values}

The uncorrected $\left(37^{\circ} \mathrm{C}\right)$ individual and mean values for $\Delta \mathrm{PaO}_{2}$ and the minimum $\mathrm{PaO}_{2}$ observed during Tests 1 and 2 are shown in Table 5.4. As previous definitions of EIH have not been based on a specific resting value $\Delta \mathrm{PaO}_{2}$ was calculated for each of the three "at rest” blood values ( $\mathrm{T}$. 20, $\mathrm{T}_{-2}$ and $\mathrm{T}_{0}$ ). No significant differences were observed between any of the "rest" to end-exercise $\Delta \mathrm{PaO}_{2}$ values or for minimum $\mathrm{PaO}_{2}$ either within or between tests (Table 5.5). 
Table 5.4 Uncorrected $\left(37^{\circ} \mathrm{C}\right)$ individual and mean $( \pm \mathrm{SD})$ values for $\Delta \mathrm{PaO}_{2}$ and minimum $\mathrm{PaO}_{2}$ for Tests 1 and 2 .

\begin{tabular}{|c|c|c|c|c|c|c|c|c|}
\hline \multirow[t]{2}{*}{ Subject } & \multicolumn{2}{|c|}{$\begin{array}{c}\Delta \mathrm{PaO}_{2} \\
\text { (end exercise }-\mathrm{T}_{-20} \text { ) }\end{array}$} & \multicolumn{2}{|c|}{$\begin{array}{c}\Delta \mathrm{PaO}_{2} \\
\text { (end exercise }-\mathrm{T}_{-2} \text { ) }\end{array}$} & \multicolumn{2}{|c|}{$\begin{array}{c}\Delta \mathrm{PaO}_{2} \\
\text { (end exercise }-\mathrm{T}_{0} \text { ) }\end{array}$} & \multicolumn{2}{|c|}{ Minimum $\mathrm{PaO}_{2}$} \\
\hline & Test 1 & Test 2 & Test 1 & Test 2 & Test 1 & Test 2 & Test 1 & Test 2 \\
\hline 001 & 18.5 & 11.1 & 8.4 & 6.1 & 11.0 & 10.2 & 81.1 & 81.3 \\
\hline 002 & 20.4 & 19.2 & 15.4 & 18.8 & 19.7 & 18.9 & 81.7 & 81.6 \\
\hline 003 & 6.4 & 10.7 & 11.0 & 16.6 & 18.6 & 22.7 & 73.3 & 74.3 \\
\hline 004 & 22.6 & 27.3 & 14.7 & 23.6 & 22.7 & 30.0 & 68.6 & 59.4 \\
\hline 005 & 20.2 & 27.7 & 19.6 & 25.0 & 18.9 & 23.8 & 68.8 & 66.2 \\
\hline 006 & 24.6 & 16.3 & 14.3 & 11.1 & 18.6 & 14.7 & 75.1 & 78.6 \\
\hline 007 & 20.4 & 16.2 & 28.9 & 20.1 & 28.0 & 42.5 & 64.6 & 68.7 \\
\hline 008 & 19.8 & 22.7 & 10.5 & 17.0 & 16.1 & 16.5 & 76.2 & 75.2 \\
\hline 009 & 15.9 & 11.4 & 13.9 & 12.9 & 15.6 & 12.5 & 72.5 & 72.0 \\
\hline 010 & 20.1 & 23.2 & 22.1 & 22.6 & 21.0 & 22.8 & 72.0 & 72.4 \\
\hline Mean \pm SD & $18.9 \pm 4.9$ & $18.6 \pm 6.5$ & $15.9 \pm 6.1$ & $17.4 \pm 6.0$ & $19.0 \pm 4.5$ & $21.4 \pm 9.5$ & $73.4 \pm 5.4$ & $73.0 \pm 6.9$ \\
\hline
\end{tabular}


Table 5.5 Reproducibility analysis of uncorrected $\left(37^{\circ} \mathrm{C}\right)$ values $( \pm \mathrm{SD})$ for $\Delta \mathrm{PaO}_{2}$ and minimum $\mathrm{PaO}_{2}$.

\begin{tabular}{|c|c|c|c|c|c|c|c|c|}
\hline & Test 1 & Test 2 & $\begin{array}{c}95 \% \\
\text { confidence } \\
\text { interval }\end{array}$ & t statistic & $\begin{array}{c}\text { Pearson } \\
\text { Correlation } \\
\text { Coefficient }\end{array}$ & $P$ value & $\begin{array}{l}\text { Typical } \\
\text { Error }\end{array}$ & $\begin{array}{c}\text { Typical } \\
\text { Error as CV } \\
(\%)\end{array}$ \\
\hline $\begin{array}{c}\Delta \mathrm{PaO}_{2} \\
\text { (end exercise }-\mathrm{T}_{-20} \text { ) }\end{array}$ & $18.9 \pm 4.9$ & $18.6 \pm 6.5$ & -3.62 to 4.28 & -0.186 & 0.561 & 0.856 & 3.9 & 26.9 \\
\hline $\begin{array}{c}\Delta \mathrm{PaO}_{2} \\
\text { (end exercise }-\mathrm{T}_{-2} \text { ) }\end{array}$ & $15.9 \pm 6.1$ & $17.4 \pm 6.0$ & -5.37 to 2.39 & 0.868 & 0.598 & 0.408 & 3.8 & 26.1 \\
\hline $\begin{array}{c}\Delta \mathrm{PaO}_{2} \\
\text { (end exercise }-\mathrm{T}_{0} \text { ) }\end{array}$ & $19.0 \pm 4.5$ & $21.4 \pm 9.5$ & -6.37 to 1.52 & 1.389 & 0.933 & 0.198 & 3.9 & 16.5 \\
\hline Minimum $\mathrm{PaO}_{2}$ & $73.4 \pm 5.4$ & $73.0 \pm 6.9$ & -2.23 to 3.05 & 0.352 & 0.850 & 0.733 & 2.6 & 4.0 \\
\hline
\end{tabular}

$\mathrm{CV}=$ coefficient of variation. 95\% confidence interval is for the difference of the means. 


\subsubsection{Prevalence of EIH in Repeat Tests}

Given the results in Table $5.5 \mathrm{PaO}_{2}$ at $\mathrm{T}_{0}$ (this being the onset of exercise) was chosen to calculate $\mathrm{PaO}_{2}$ in examining the prevalence of $\mathrm{EIH}$ between tests. The results in Table 5.6 indicate that both the temperature correction applied and the $\Delta \mathrm{PaO}_{2}$ chosen to define EIH affect prevalence both within and between tests.

Table 5.6 Prevalence of EIH in Tests 1 and 2.

\begin{tabular}{c|cccc}
\hline \multirow{2}{*}{} & \multicolumn{2}{c}{$\Delta \mathrm{PaO}_{2} \geq 10 \mathrm{mmHg}$} & \multicolumn{2}{c}{$\Delta \mathrm{PaO}_{2} \geq 2 \mathrm{SD}$} \\
\cline { 2 - 5 } & Test 1 (n) & Test 2 (n) & Test 1 (n) & Test 2 (n) \\
\hline Uncorrected & $100 \%(10)$ & $100 \%(10)$ & $100 \%(10)$ & $70 \%(10)$ \\
Rectal & $89 \%(9)$ & $70 \%(10)$ & $89 \%(9)$ & $40 \%(10)$ \\
Arterial & $20 \%(10)$ & $40 \%(10)$ & $100 \%(10)$ & $20 \%(10)$ \\
Oesophageal & $40 \%(10)$ & $13 \%(8)$ & $40 \%(10)$ & $13 \%(8)$ \\
Active Muscle & $0 \%(10)$ & $20 \%(5)$ & $0 \%(10)$ & $0 \%(5)$ \\
\hline
\end{tabular}

Values are expressed as a percentage of subjects tested calculated using both the general definition of EIH (a change in $\mathrm{PaO}_{2} \geq 10 \mathrm{mmHg}$ and the alternative definition $\left(\Delta \mathrm{PaO}_{2} \geq 2 \mathrm{SD}\right)$ and values for both uncorrected $\Delta \mathrm{PaO}_{2}$ and $\Delta \mathrm{PaO}_{2}$ temperature-corrected for each measurement site. 


\subsection{DISCUSSION}

Before an assessment of reproducibility of EIH in consecutive exercise tests can be made four caveats must be applied to the data.

Firstly, one must be assured that the metabolic environment in the two exercise tests has been reproduced. For this to occur such factors as subject training status, test protocol and laboratory environment must be held constant between tests and the criteria for a maximal effort met within each test. This was the case in the present study. It is known that when a given individual performs incremental exercise to exhaustion within this framework, the maximal values for $\dot{\mathrm{V}} \mathrm{O}_{2}$, HR and $\mathrm{V}_{\mathrm{E}}$ and exercise time are highly reproducible (Foster, Hume et al, 1986; Billat, Renoux et al, 1995; Seeherman and Morris, 2000; Hopkins, Schabort et al, 2001; Watt, Hopkins et al, 2002), and this was the case in the present study. Further evidence of the reproducibility of the metabolic environment in the two tests is provided by the reproducibility of the thermal responses recorded at four separate sites in the two tests (Table 5.2). Therefore, the current exercise paradigm seemed an appropriate one in which to examine the reproducibility of EIH.

Secondly, given that the definition of EIH applied to the present data was a fall in $\mathrm{PaO}_{2}$ of $\geq 10 \mathrm{mmHg}$ from resting to end-exercise, the conditions under which the resting (pre-exercise) measurements of $\mathrm{PaO}_{2}$ are made needs to be defined. To this end three resting samples were taken in the present study, namely $T_{-20}, T_{-2}$ and $T_{0}$. When uncorrected for temperature there were no significant differences between the three samples, either within or between tests. 
However, significant differences were found when the values were corrected for the temperatures recorded at the four sites. Given that the definition of EIH is met by a relatively small $\Delta \mathrm{PaO}_{2}$, even small non-significant differences in resting $\mathrm{PaO}_{2}$ can impact significantly on $\Delta \mathrm{PaO}_{2}$ and, therefore, reproducibility and prevalence. Therefore, when studying the phenomenon of EIH, it is essential to define the paradigm under which resting samples are taken, an issue that has not been addressed in the previously published literature in this field. The resting measurement chosen for calculating $\Delta \mathrm{PaO}_{2}$ in the present study was $\mathrm{T}_{0}$ as this was the point at which exercise and the measurement of metabolic variables began. That it was appropriate to the present study of reproducibility is supported by the observations that the $\Delta \mathrm{PaO}_{2}$ calculated from $\mathrm{T}_{0}$ to endexercise had the highest test-retest correlation of all three resting measurements as well as the lowest typical error as a percentage of the coefficient of variation.

The third caveat to be applied in examining the issue of reproducibility is to recognise of the potential impact of applying temperature corrections to the $\mathrm{PaO}_{2}$ data. As identified in previous chapters, the pattern of the thermal response to exercise is dependent on the site of temperature measurement with a consequent effect on the prevalence of EIH. Therefore the temperature correction chosen to apply to the data must be appropriate to the research questions being asked. As discussed in the previous chapter, if one is concerned about physiological significance of EIH it would seem logical to correct the $\mathrm{PaO}_{2}$ values for active muscle temperature, because this is the principal site of oxygen consumption, whereas if one is concerned about the cause of EIH a correction for oesophageal temperature is more appropriate, as this is the closest 
parallel with the temperature at the alveolar-capillary membrane where oxygen exchange is occurring. However, when examining the reproducibility of the phenomenon, a problem can arise when temperature-corrected data are used because the placement of the oesophageal or any other temperature probe, and the resulting temperature measurements, cannot be guaranteed to be identical between experiments. That the end-exercise temperatures were not significantly different between tests, however, indicates an excellent degree of reproducibility of these measurements in the present series. Furthermore, whilst the end exercise temperature differences are small (maximum $1.3^{\circ} \mathrm{C}$ ) between temperature measurement sites, the values for $\Delta \mathrm{T}\left({ }^{\circ} \mathrm{C}\right)$, and hence $\Delta \mathrm{PaO}_{2}$, were different from each other and also the $\Delta \mathrm{PaO}_{2}$ for the uncorrected values and affected calculations of prevalence, regardless of the EIH definition used. Therefore, on balance, in terms of assessing reproducibility (and hence prevalence), it seemed most appropriate in the present study to use the uncorrected $\mathrm{PaO}_{2}$ data.

The fourth caveat was the definition of EIH. It has been argued in this thesis that although a fall in $\mathrm{PaO}_{2} \geq 10 \mathrm{mmHg}$ is the most common definition, this is an arbitrary choice based, tenuously, on it representing the threshold for a performance affect (Dempsey and Wagner, 1999). A more scientifically acceptable definition, on purely statistical grounds, would seem to be to define EIH as a fall in $\mathrm{PaO}_{2}$ of $\geq 2$ SD's from the mean resting value. Essentially this asks the more appropriate question, namely, does incremental exercise induce a significant fall in $\mathrm{PaO}_{2}$ ? The definition applied will obviously affect reproducibility and hence prevalence, additional to the further affect of the 
temperature correction applied and dependent on the definition of "resting". Nevertheless, given that this thesis has been directed at examining the reported phenomenon of EIH, in assessing its reproducibility the primary definition applied to the present data was that of a fall in $\mathrm{PaO}_{2} \geq 10 \mathrm{mmHg}$.

Therefore in assessing the reproducibility of $\mathrm{EIH}$ in the present experiments, the following four caveats were met with regard to the data obtained in the two tests, namely, the metabolic environment was reproduced, the resting $\mathrm{PaO}_{2}$ value was that immediately prior to starting exercise, the $\mathrm{PaO}_{2}$ values were not corrected for temperature and the primary definition of EIH was applied. With these caveats in place the results from the present experiments show for the first time that EIH is a $100 \%$ reproducible phenomenon implying a clearly reproducible mechanism. Any one or more of the suggested mechanisms in previous research could play a role and the evidence for and against these suggestions has been reviewed elsewhere in this thesis.

However, further analysis of the results in this chapter highlights a serious issue. When the corrected and uncorrected $\Delta \mathrm{PaO}_{2}$ data are compared there are clear differences in reproducibility (and therefore prevalence) both within and between tests, regardless of the definition chosen for EIH. One conclusion that can be drawn from this observation is that both definitions are suspect when applied to the assessing the frequency of significant hypoxemia per se in response to exercise. Indeed, between Test 1 and 2, neither the uncorrected $\Delta \mathrm{PaO}_{2}$ values, nor the minimum $\mathrm{PaO}_{2}$, temperature-corrected or not, were significantly different, the implication being that alveolar-capillary oxygen 
exchange and/or haemoglobin loading with oxygen is/are significantly affected by exercise through as yet indeterminate mechanisms.

This is a further critical result from the present experiments established to assess reproducibility and gives support to the argument that issues of prevalence are unimportant and dependent only on the nature of the temperature correction applied and the arbitrary definition chosen to denote a "significant" change in $\mathrm{PaO}_{2}$. It would seem logical that future research in this area should be directed at exploring the mechanisms and impact of a significant hypoxemia induced by exercise rather than an arbitrarily defined phenomenon of exerciseinduced hypoxemia. 


\section{CHAPTER 6}

\section{Summary and Conclusions}

\subsection{Summary of the Problem}

The phenomenon of exercise-induced hypoxaemia (EIH) has been unquestioned for over three decades, and primarily viewed as a peculiarity of the well trained athlete (Dempsey and Wagner, 1999; Prefaut, Durand et al, 2000; Nielsen, 2003). The most recent reviews consider the phenomenon to occur in approximately $50 \%$ of well trained athletes, both males and females, and across the span of ages. There have been numerous experiments aimed at uncovering the aetiology (see Table 1.1), with the main focus on the Fick Equation and physiological limitations imposed by exercise performed at a high intensity. A ventilation / perfusion ( $\dot{\mathrm{V}}_{\mathrm{A}} / \dot{\mathrm{Q}}$ ) inequality, whereby a type of physiological shunt develops resulting in pulmonary artery blood returning to the heart without complete or proper re-oxygenation, has been suggested as causing a widening of the (A-a) $\mathrm{DO}_{2}$ gradient during exercise (Gledhill, Froese et al, 1977; Gale, TorreBueno et al, 1985; Torre-Bueno, Wagner et al, 1985; Hammond, Gale et al, 1986 (a and b); Wagner, Gale et al, 1986; Manier, Moinard et al, 1991; Schaffartzik, Poole et al, 1992; Wagner, 1992; Hopkins, McKenzie et al, 1994; Eldridge, Podolsky et al, 1996; Hopkins, Gavin et al, 1998; Rice, Thornton et al, 1999; Rice, Scroop et al, 2000; Olfert, Balouch et al, 2004; Verges, Flore et al, 2005). However, there also exists a pool of research which indicates $\dot{\mathrm{V}}_{\mathrm{A}} / \dot{\mathrm{Q}}$ inequality 
has only a small, if not insignificant, impact on $\mathrm{PaO}_{2}$ (Hammond, Gale et al, 1986a; Wagner, Gale et al, 1986).

The inability to maintain alveolar $\mathrm{PO}_{2}$ during intense exercise due to inadequate hyperventilation (Dempsey, Hanson et al, 1984; Powers, Martin et al, 1993; Harms and Stager, 1995; Rice, Scroop et al, 1999; Durand, Mucci et al, 2000), caused by reduced chemosensitivity (Byrne-Quinn et al, 1971; Harms and Stager, 1995), flow limitation (Hesser, Linnarsson et al, 1983) or respiratory muscle fatigue (Bye, Farkas et al, 1983), has also been suggested as a mechanism of EIH. Once again, however, there exists conflicting evidence as to the possible effect of this mechanism (Buono and Maly, 1996; Chapman, Emery et al, 1998; Hopkins and McKenzie, 1989; Mota, Casan et al, 1999; Norton, Squires et al, 1995; Powers, Martin et al, 1992).

As could be expected, a limitation to the diffusion in the lungs has been the focus of a significant amount of research into EIH. With this mechanism attributed to an inadequate pulmonary capillary transit time (Warren, Cureton et al, 1991; Hopkins, Belzberg et al, 1996), a change in blood rheological characteristics (Aguilaniu, Flore et al, 1995; Aguilaniu, Flore et al, 1998; Connes, Bouix et al, 2004; Galy, Hue et al, 2005) and pulmonary oedema (Younes, Bshouty et al, 1987; Caillaud, Serre-Cousine et al, 1995; Anholm, Milne et al, 1999; Sosa Leon, Hodgson et al, 2002). Whilst both research and intuitive thinking support diffusion limitation as a probable cause of EIH there exists conflicting evidence in the literature to this mechanism of EIH as well (Miles, Doerr et al, 1983; Miles, Enoch et al, 1986; St. Croix, Harms et al, 1998; Wetter, Xiang et al, 2002). 
Finally, the advent of veno-arterial shunt has been proposed as a further mechanism of EIH (Asmussen and Neilsen, 1960; Eldridge, Dempsey et al, 2004) however, the paucity of available data suggests that it is negligible during high intensity exercise. Whilst not a focus of this thesis, such conflicting evidence as to the cause of EIH could lead to the assumption that it may be a transient phenomenon and both methodologically and definitively dependent.

Given the lengthy history of EIH research it would seem improbable that an ultimate definition of the phenomenon would not exist. This lack of definition is, however, the present situation with EIH and different research studies define it as changes in both $\mathrm{SaO}_{2}$ and $\mathrm{PaO}_{2}$, without robust delimitation or any statistical validity as to the degree of change required for definition. Whilst Dempsey and Wagner attempted to differentiate degrees of EIH in their 1999 review, the authors undermined their own theories by confounding the use of $\mathrm{SpO}_{2}, \mathrm{SaO}_{2}$ and $\mathrm{PaO}_{2}$ measurements for accurate determination of the phenomenon. Whilst the use of pulse oximetry has been largely argued against, and the accuracy of $\mathrm{PaO}_{2}$ measurements argued for in assessing EIH (Brown, Knowlton et al, 1993; McGovern, Sasse et al, 1996; Rice, Scroop et al, 1999; American Association for Respiratory Care, 2001; American Thoracic Society, 2003), both pulse oximetry and arterial saturation measures are still in use in assessing possible mechanisms and performance effects of EIH (see Table 1.1). Given that EIH would seem to be the result of a disturbance in the Fick equation of diffusion (be it via any of the possible variables in this equation, see Equation 1.1) it would seem most prudent to utilise $\mathrm{PaO}_{2}$ measurements in assessing the phenomenon. Furthermore, data using $\mathrm{SpO}_{2}$ and $\mathrm{SaO}_{2}$ in defining EIH overlook 
the fact that, as defined by the $\mathrm{O}_{2}-\mathrm{Hb}$ dissociation curve, significant changes in $\mathrm{PaO}_{2}$ occur with almost negligible differences in oxygen saturation. These changes may indicate a significant limitation to gas transfer which is masked by the limited changes seen in oxygen saturation and therefore confound any possible physiological effect of EIH.

With regard to using a delimiting definition of EIH, possibly the most often used is a fall from resting $\mathrm{PaO}_{2}$ of $\geq 10 \mathrm{mmHg}$ (Anselme, Caillaud, et al, 1994; Prefaut, Anselme et al, 1994; Harms, McClaran et al, 1998; St Croix, Harms et al, 1998; Dempsey and Wagner, 1999; Durand, Mucci et al, 1999; Rice, Thornton et al, 1999; Rice, Scroop et al, 1999; Durand, Mucci, et al, 2000; Harms, McClaran et al, 2000; Prefaut, Durand et al, 2000; Wetter, St Croix et al, 2001; Durand, Mucci, et al, 2004). This fall supposedly represents a decrease of 3\% in $\mathrm{SaO}_{2}$ (Dempsey and Wagner, 1999), the significance of this being that, it is postulated, beyond this decrease in $\mathrm{SaO}_{2}$ there is a reduction in $\dot{\mathrm{V}}{ }_{2}$ max and hence performance (O’Kroy and Martin, 1989; Powers, Lawler et al, 1989). Whilst this definition has been widely utilised it has, however, been generally overlooked that $\mathrm{PaO}_{2}$ is heavily influenced by the temperature at which it is measured (Severinghaus, 1979). Temperature correction of $\mathrm{PaO}_{2}$ has been factored into some EIH research but no consistent use or measurement site is evident in the research to date (see Table 1.1). The review by Dempsey and Wagner (1999) acknowledged both sample and temperature correction effects, stating that EIH "must be identified by direct measurements of arterial blood gas”, and that errors produced by uncorrected or incorrectly temperature- 
corrected blood gas values "are equal to the suggested minimum decrements in $\mathrm{PaO}_{2}$ for defining EIAH”

In addition to problems associated with defining $\mathrm{EIH}$, the use of indirect or direct measurements of blood gas status and failing to apply a temperature correction to $\mathrm{PaO}_{2}$, there has been no consistency in exercise test protocol, in terms of either mode or intensity, which makes direct comparison of results almost impossible. Given all of these inconsistencies and disparities it may, therefore, be necessary to forgo using any published literature to date which utilises $\mathrm{SpO}_{2}$ data or $\mathrm{PaO}_{2}$ data which is not corrected for temperature changes during exercise in evaluating the phenomenon of EIH. Furthermore the affect of the exercise protocol utilised in testing for mechanism or prevalence must be taken into consideration in all remaining data.

With the abundance of inconsistencies in the current data investigating $\mathrm{EIH}$, the design of this thesis was structured to clarify some of the more basic constructs which have been previously ignored or considered unimportant. Initially, the thermal response to an incremental exercise protocol at several physiologically important and research-relevant sites was observed. From this it was possible to judge if there was any significant site-dependent temperature variation which could impact on the temperature-dependent measurement of $\mathrm{PaO}_{2}$. As a flow on from the initial experiment, the number of temperature measurement sites was expanded to include muscle temperature in combination with those of rectal, arterial blood and oesophageal temperatures. 
To measure the actual site-dependent effect of temperature changes during exercise, arterial blood samples were taken simultaneous to all temperature measurements at every workload throughout the exercise test. The Severinghaus (1966, see Section 2.4.4) temperature correction was applied to the values of $\mathrm{PaO}_{2}$ and each corrected value compared against the other site-corrected $\mathrm{PaO}_{2} \mathrm{~S}$. The effect of temperature correction on total arterial oxygen content was also measured as a means of elucidating any decrement in oxygen supply to the working muscles which may impact on exercise performance. Within this series of experiments the prevalence of EIH was also assessed using the oft-used definition of a fall in $\mathrm{PaO}_{2}$ of $\geq 10 \mathrm{mmHg}$ with these results compared to a more statistically sound definition of $\mathrm{a} \geq 2 \mathrm{SD}$ (standard deviation) drop in $\mathrm{PaO}_{2}$ from rest.

Finally, as a means of validating the use of $\mathrm{PaO}_{2}$ in the assessment of $\mathrm{EIH}$, the final experiments calculated the reproducibility of the blood gas response under conditions maintained as constant as possible between tests. This allowed direct comparison of the $\mathrm{PaO}_{2}$ response, the effect of temperature correction of $\mathrm{PaO}_{2}$ with physiologically-important measurement sites between tests and the effect of these corrections on the prevalence of EIH in repeat tests.

\subsection{Results and conclusions}

In performing the series of experiments described in the previous chapters of this thesis a number of insights into the phenomenon of EIH were uncovered. These discoveries will further the debate on the existence and any presumed effect of EIH and are summarised as follows: 
- This thesis was the first to measure simultaneous temperatures in the rectum, within the oesophagus, of arterial blood as it was sampled and in the active muscle during an incremental exercise test to exhaustion. The results support previous research (Saltin and Hermansen, 1966; Aulick, Robertson et al, 1978; Shiraki, Konda et al 1986) which indicate rectal temperature is not a good indicator of the body's thermal response to an incremental exercise test and, as such, should not be used to assess this parameter. Physiologically, oesophageal and muscle temperature are the most important sites with regard to oxygen exchange and should be used in assessing the loading (oesophageal) and unloading (muscle) conditions of the blood during exercise. Due to their relatedness, and in the case of subject comfort, arterial blood temperature may be utilised in place of oesophageal temperature when an appropriate correction factor is applied.

- Given the temperature dependent nature of $\mathrm{PaO}_{2}$ and the thermal response of the body to an incremental exercise test to exhaustion, all $\mathrm{PaO}_{2}$ values measured during exercise should be corrected for body temperature, with oesophageal and active muscle temperature sites the most appropriate. Use of these correction factors impacts significantly on $\mathrm{PaO}_{2}$ results, particularly with those corrected for active muscle temperature. These $\mathrm{PaO}_{2}$ results are in complete contrast to uncorrected values and show an exercise-induced HYPEROXIA from rest to end exercise. 
- No comparison of temperature-corrected $\mathrm{CaO}_{2}$ values has been reported previously in the literature on EIH, and analysis of such results in this thesis indicates that there is no compromise to oxygen delivery in individuals who, when defined as an uncorrected $\Delta \mathrm{PaO}_{2}$ of $10 \mathrm{mmHg}$ or more, undergo $\mathrm{EIH}$. Without specific data it is impossible to totally discard the theory; however, this data demonstrates that any influence of EIH on performance would be non-existent.

- Utilising the definition of $\mathrm{EIH}$ as a $\Delta \mathrm{PaO}_{2}$ of $10 \mathrm{mmHg}$ or more reveals significant differences in prevalence which depend on the resting value utilised as a baseline as well as any temperature correction utilised. Results indicate the blood gas sample taken immediately prior to exercise as the most reliable resting measurement.

- Defining EIH as an arbitrary decrement from rest to end exercise has little statistical validity and has dubious connections to reduced exercise performance. This thesis suggests any further research utilise a more statistically sound definition of $\mathrm{EIH}$ as a $\Delta \mathrm{PaO}_{2} \geq 2 \mathrm{SD}$ from rest to end exercise, the SD defined as that of the resting sample mean described in the previous point.

- EIH is a reproducible phenomenon with $100 \%$ prevalence in this subject population when using uncorrected $\mathrm{PaO}_{2}$ data. However, using the temperature corrections suggested alters the prevalence both within and between tests and therefore reduces the effective reproducibility of the phenomenon. 
While no experiments in this thesis were specifically performed to evaluate the mechanisms of EIH directly, a number of data analyses were performed to explore the impact of previous suggestions. Firstly, given that within the first minute after cessation of the exercise test all $\mathrm{PaO}_{2}$ values, uncorrected and temperature corrected, exceeded resting values (Fig. 6.1), the proposal that exercise-induced pulmonary oedema or vascular damage contributes to EIH can be confidently excluded.

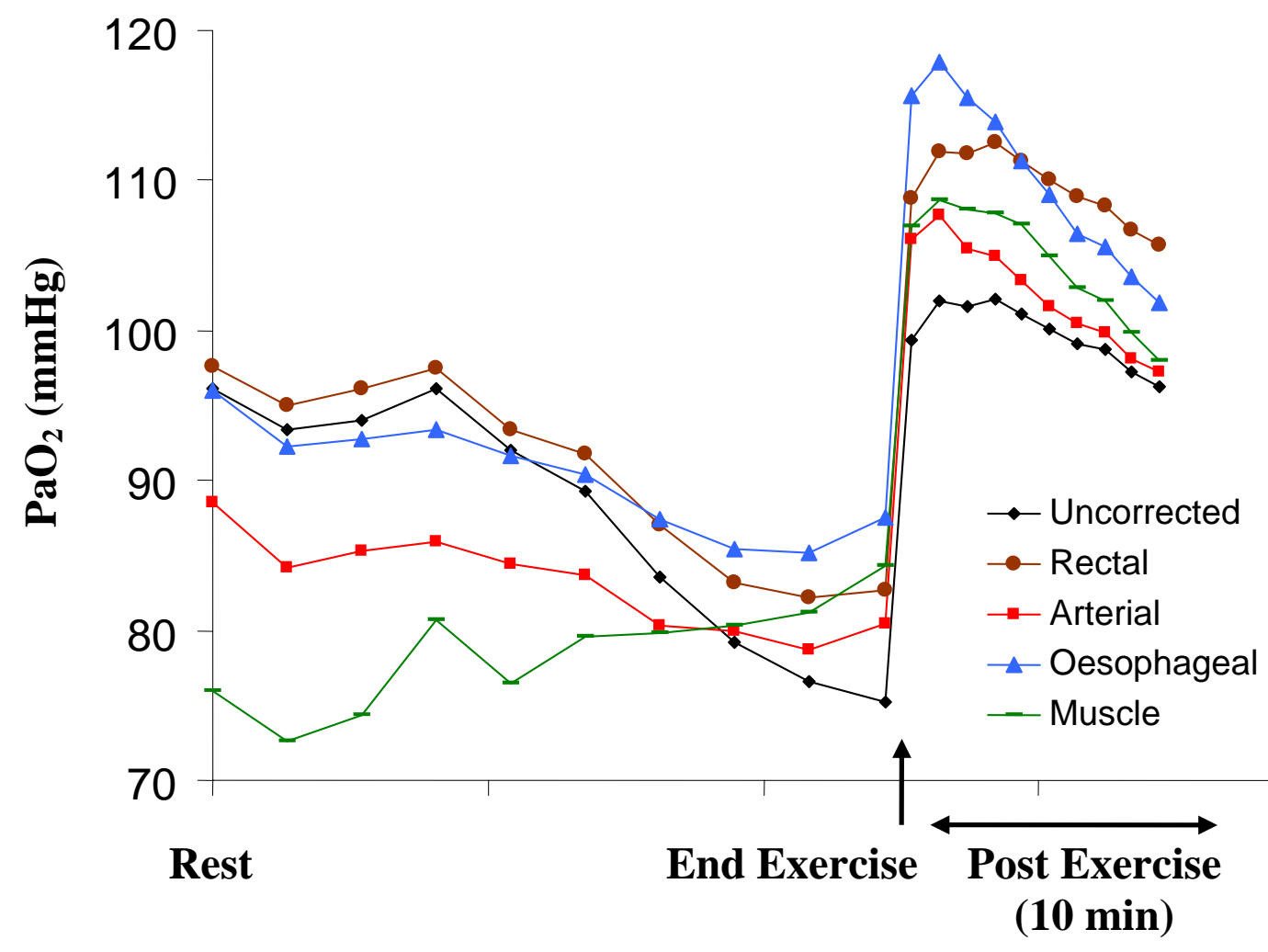

Figure 6.1 $\mathrm{PaO}_{2}$ from Rest $\left(\mathrm{T}_{0}\right)$ to the end of the $10 \mathrm{~min}$ post exercise period 
Furthermore, there is a well-known and accepted linear relationship between $\dot{\mathrm{VO}}_{2}$ max and cardiac output, and hence pulmonary blood flow. With the total absence of a relationship between either minimum $\mathrm{PaO}_{2}$ or maximum $\Delta \mathrm{PaO}_{2}$ and $\dot{\mathrm{VO}}_{2}$ max in the present experiments (Fig. 6.2 and 6.3), it may be implied that any contribution of reduced pulmonary capillary transit time to decreased blood oxygenation can also be excluded.

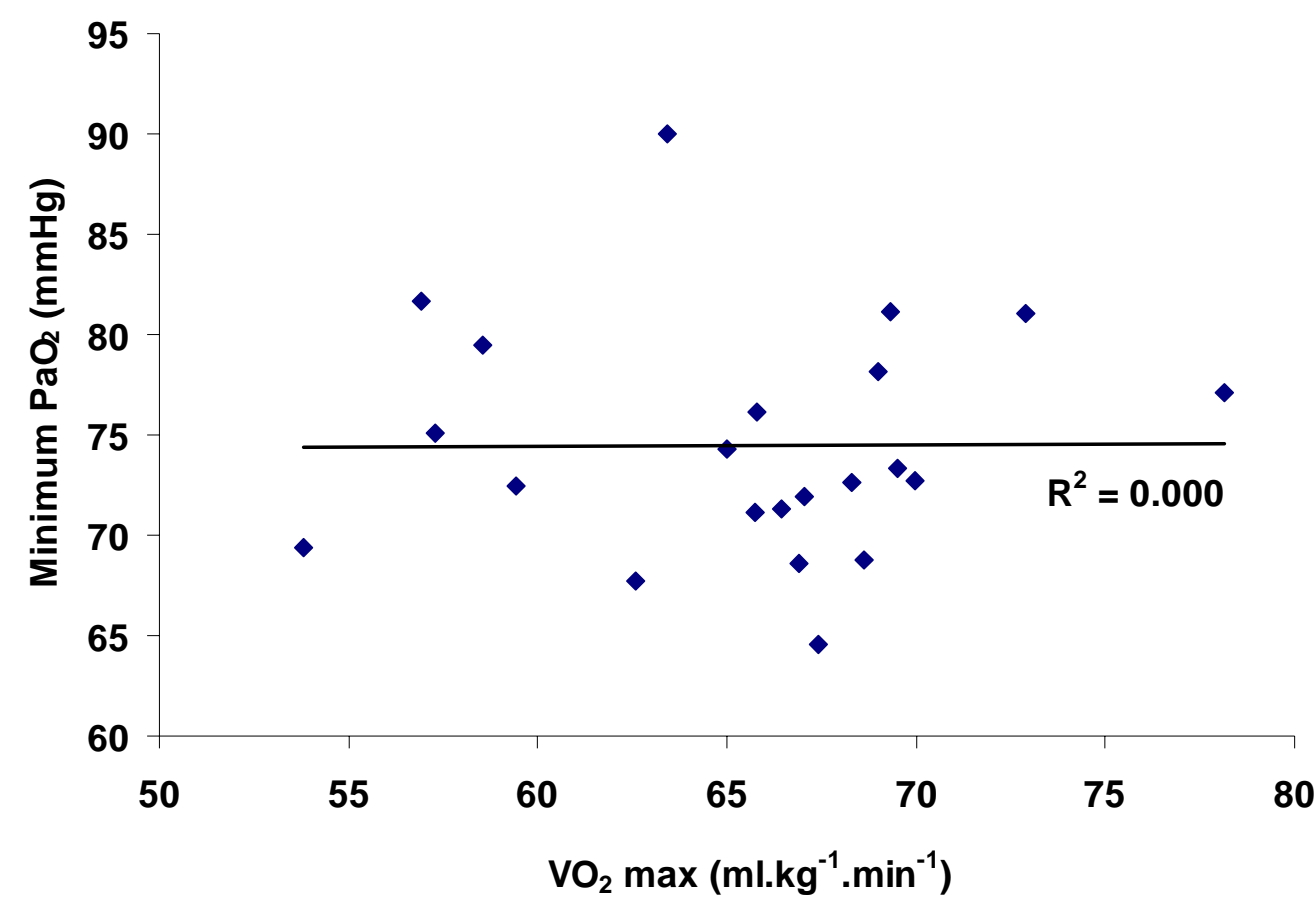

Figure 6.2 Relationship between $\dot{\mathrm{V}} \mathrm{O}_{2}$ max and minimum $\mathrm{PaO}_{2}$ 


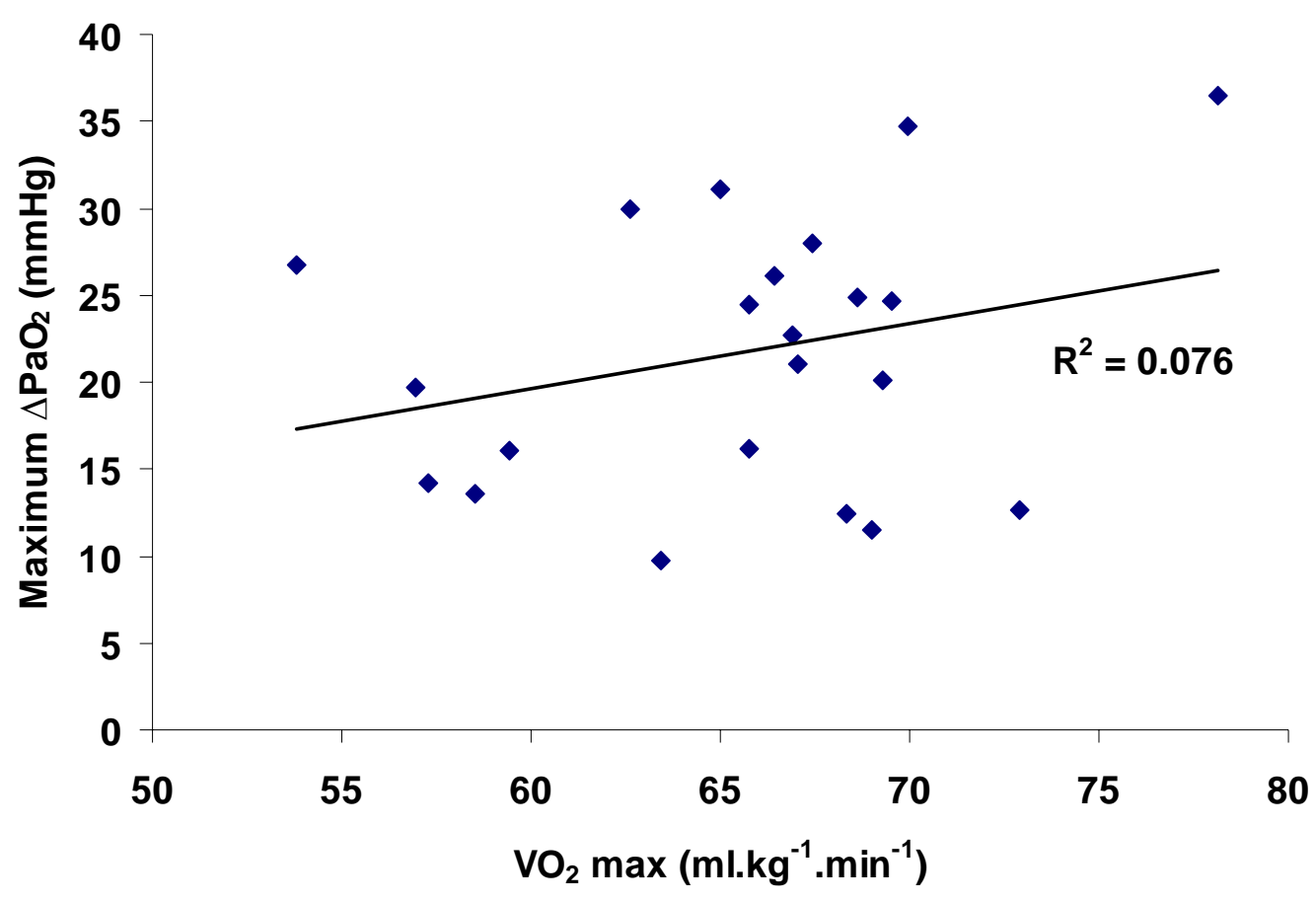

Figure 6.3 Relationship between $\dot{\mathrm{VO}}_{2}$ max and maximum $\Delta \mathrm{PaO}_{2}$

Finally, a similar lack of correlation between maximal ventilation ( $\dot{\mathrm{V}}_{\mathrm{E}}$ max) and either minimum $\mathrm{PaO}_{2}\left(\mathrm{R}^{2}=0.053\right)$ or maximum $\Delta \mathrm{PaO}_{2}\left(\mathrm{R}^{2}=0.010\right)$ in the present experiments also excludes the theory of inadequate hyperventilation. By implication, this probably means that the alveolarcapillary oxygen gradient at peak exercise is also a non-contributor to EIH and focuses the mechanism more squarely on the dynamics of haemoglobin during exercise. This is, however, pure speculation at this time point and requires much further investigation.

In conclusion, the studies in this thesis have made significant contributions to our understanding of EIH. In terms of a statistically significant 
change in the $\mathrm{PaO}_{2}$ from rest to the end of incremental exercise it is a real phenomenon in the pulmonary capillary blood but not in the blood delivered to the exercising muscle. It is reproducible suggesting a common physiological mechanism and the studies in this thesis suggest that pulmonary oedema, insufficient pulmonary capillary transit time and inadequate hyperventilation can be excluded. Any further investigations into mechanism should ensure that the changes in all 3 parameters of the oxygen status $\left(\mathrm{PO}_{2}, \mathrm{SO}_{2}\right.$ and $\left.\mathrm{CO}_{2}\right)$ in arterial blood are monitored and that all parameters be corrected for simultaneous measurements of oesophageal (or corrected arterial blood) and active muscle temperatures. 


\section{CHAPTER 7}

\section{Appendices}

7.1 Subject Information, Consent Forms and Medical Questionnaire. 


\section{SUBJECT INFORMATION SHEET}

PROJECT TITLE: The incidence, nature, reproducibility and mechanisms of exerciseinduced hypoxemia (EIH) in trained athletes and its impact on performance.

\section{PURPOSE OF STUDY: $\quad$ EIH is a phenomenon occurring in many endurance athletes. It results in a loss of oxygen from the blood during high intensity exercise which may affect exercise performance. While it may occur in many athletes its true incidence, nature, mechanisms, reproducibility and impact on performance remain uncertain. It is the purpose of this study to explore these aspects of the phenomenon in greater depth.}

POTENTIAL BENEFITS: In personal terms, as a result of the exercise testing in these experiments, you will receive confidential information regarding your maximal aerobic capacity, maximal heart rate and lactate threshold. This information may prove beneficial to your training program. With regard to the results affecting the sporting community as a whole, the information obtained from the study will provide valuable information into factors affecting the performance of elite athletes.

\section{EXPERIMENTAL PROCEDURES:}

This will involve 3 separate trips to the Exercise Laboratory in the Department of Thoracic Medicine at the Royal Adelaide Hospital, Outpatients Department, Level 7

- Visit 1 - In this visit you will be familiarised with the study testing protocol, have a medical check performed by a qualified investigator and complete a routine lung function test.

- Visits 2 and 3 - This will involve a 3 1/2-hour visit to the exercise laboratory in the Royal Adelaide Hospital during which time you will perform a maximal exercise test.

- Before you begin the test during Visit 2 and 3 we will ask you to self-insert a small $2 \mathrm{~mm}$ diameter, soft probe (like a short piece of thin electrical flex) into your rectum to measure your body temperature during exercise. This is a common procedure in exercise testing and is without any danger or discomfort. The covered wire emerging from your anus is then taped to the skin between your buttocks. This procedure is conducted by you in the privacy of a nearby examination room.

- On leaving the examination room you will be asked to insert, with our assistance, another temperature probe into your nose. Before doing so you will be able to apply a local anaesthetic jelly to avoid any discomfort (minor) from the probe. You will be asked to pass it slowly back into your throat and then be given a glass of water and asked to swallow. This will allow the probe to enter your esophagus where it will stay during the experiment to allow us to measure body core temperature. There is normally no discomfort associated with this but if need be it can easily be withdrawn.

- Following this you will return to the laboratory and have your height and weight measured. We will then apply three sticky patches ("electrodes"), each about the size of a 50 cent piece, to your chest to record heart rate and the heart's electrical pattern.

- You will then be directed to a bed in the exercise laboratory for insertion of the arterial catheter.

- A small local anaesthetic will be injected in the skin overlying the radial artery at the wrist of your non-dominant arm. This will be done by a qualified intensive care physician who will then will insert a plastic tube (catheter) into your artery. A single stitch (also covered by the anaesthetic) will be used to prevent any movement of this catheter. This catheter will be used to draw arterial blood samples during the exercise test. You will be unaware of this procedure. 
- Whilst on the bed another local anaesthetic will be injected into the skin and muscle of your mid/lower thigh. A needle will then be introduced into your leg muscle and a small temperature probe inserted into the muscle. The needle will be removed and the probe will be secured in place during the exercise test

- Following this you will be asked to perform a maximal exercise test on a running treadmill, which should last 15-30 minutes. The work loads start at a very low speed and then increases every 2 minutes until you reach exhaustion

- In order to measure your oxygen uptake a breathing valve will be placed in your mouth (like a snorkel mouthpiece) and a spring clip applied to your nose. The gases you breathe in and out can then be measured for volume and composition.

- The tests will be supervised during the entire session by at least one qualified physician.

- Upon completion of these tests you will receive \$150 for your involvement. If you are unable to complete this test, for whatever reason, you will be compensated for any time volunteered at a rate of $\$ 20$ per hour.

FORESEEABLE RISKS, SIDE EFFECTS AND DISCOMFORTS: Participation in this study may involve additional risks and discomforts. These may include

1. Discomfort of local anaesthetic used for the insertion of needles into the artery at the wrist of your non-dominant hand.

2. Risk of the catheter in the artery temporarily preventing adequate blood flow to your hand. The symptoms of this will be full explained to you and should this occur, the catheter will be immediately removed to prevent injury. There is a remote risk of continuing problems of obstruction of the artery which could lead to loss of hand function.

3. Remote risk of the tubes causing blood clots in your artery or vein.

4. Remote risk of infection at the site where the catheter is inserted.

5. Mild bruising around the site of catheter and muscle probe insertion.

6. Very remote risk of heart attack from exercising.

7. Heparin will be used in this study and if you have sensitivity to this agent, its use in this study could decrease its effectiveness if you ever needed to use it in the future.

None of these complications has occurred in previous studies of this kind and at all times the comfort and well-being of you, the subject, are of paramount importance. Any suggestion of a problem results in the experiment being immediately terminated.

\section{CONTACT NUMBERS FOR ANY CONCERNS OR QUESTIONS}

1. Nicholas Shipp mobile 0403291281

2. Dr Garry Scroop

3. Dr Christopher Gore

4. Dr Mark Holmes

5. Dr Andrew Thornton

6. Dr Michael James (Research Ethics Committee)

Dr James is only available to discuss general aspects of the research project. 


\title{
STANDARD CONSENT FORM \\ FOR PEOPLE WHO ARE SUBJECTS IN A RESEARCH PROJECT
}

\author{
8 \\ 2 \\ THE UNIVERSITY OF ADELAIDE \\ ROYAL ADELAIDE HOSPITAL HUMAN RESEARCH ETHICS COMMITTEE
}

1. I, (please print name)

consent to take part in the research project entitled:

The incidence, nature, mechanisms and reproducibility of exercise-induced hypoxemia $(\mathrm{EIH})$ in trained athletes and its impact on performance

2. I acknowledge that I have read the attached Information Sheet entitled:

The incidence, nature, mechanisms and reproducibility of exercise-induced hypoxemia (EIH) in trained athletes and its impact on performance.

3. I have had the project, so far as it affects me, fully explained to my satisfaction by the research worker. My consent is given freely.

4. Although I understand that the purpose of this research project is to improve the quality of medical care, it has also been explained that my involvement may not be of any benefit to me.

5. I have been given the opportunity to have a member of my family or a friend present while the project was explained to me.

6. I have been informed that, while information gained during the study may be published, I will not be identified and my personal results will not be divulged.

7. I understand that I am free to withdraw from the project at any time and that this will not affect medical advice in the management of my health, now or in the future.

8. I am aware that I should retain a copy of this Consent Form, when completed, and the attached Information Sheet.

9. I understand the statement concerning payment for my participation in this study, which is contained in the Subject Information Sheet.

(signature)

(date)

\section{WITNESS}

I have described to (name of subject)

the nature of the procedures to be carried out. In my opinion she/he understood the explanation.

Status in Project:

Name: 


\section{Medical History Screening Questionnaire}

NAME:

ADDRESS:

HOME PHONE:

E-MAIL:

SPORT:

Next of Kin:

Phone no:
D.O.B:

MOBILE:

EVENT / LEVEL:

Relationship to you:

Mobile:

\section{Yes No Unsure}

$\square \quad \square \quad \square \quad$ Have you ever passed out, become dizzy or had chest pain during or after exercise?

$\square \quad \square \quad \square \quad$ Has anyone in the family died suddenly and unexpectedly before the age of 50 ?

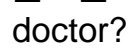

Do you have any problems with your skin? (e.g. rashes, moles, acne) Do you have a chronic illness or see a physician regularly for any particular problem? (e.g. diabetes, epilepsy, thyroid problems, bowel disorder)

PLEASE LIST

exercise?

Do you experience 'gastro-intestinal' problems generally or during

(e.g. reflux, diarrhea, upset stomach)

Please list:

Have you ever had surgery or required hospitalization?

Please list, including approximate dates:

Do you take any prescribed medicine?

Please list type and dose: 
Please list:

Do you take or have any 'over the counter' supplements / medication / herbal remedies?

\section{Yes No Unsure}

$\square \quad \square \quad \square \quad$ Do you have any allergies to any medication, insects or other agents?

$\square \quad \square \quad \square \quad$ Do you smoke? If yes, how many/day?

$\square \quad \square \quad$ Do you drink alcohol? If yes, average glasses/week?

Type (e.g. beer, spirits)

$\square \quad \square \quad$ Do you use any other forms of 'social drugs'?

$\square \quad \square \quad$ Do you suffer anxiety/stress related to your sport?

$\square \quad \square \quad \square \quad$ Have you, or a close relative, ever suffered from depression?

$\square \quad \square \quad \square \quad$ Have you ever suffered from excessive fatigue or overtraining?

FAMILY MEDICAL HISTORY: Is there a family history of any of the following? Yes No Unsure

$\square \quad \square \quad \square \quad$ Heart disease / sudden death

$\square \quad \square \quad \square \quad$ Arthritis (e.g. Rheumatoid Arthritis)

$\square \quad \square \quad \square \quad$ Diabetes

Specify details:

\section{INJURIES:}

Yes No Unsure

$\square \quad \square \quad$ Have you had any injuries / medical conditions that have For each injury / condition: interfered with your sporting career?

Nature of injury Date of Injury

Any residual problems?

Do you have any current injuries?

Nature of injury Date of Injury

Signed

Date 
Metabolic System Calibration Data 


\section{CHECKING RAH $\mathrm{VO}_{2}$ SYSTEM vS LSAS "MAXII" \\ CALIBRATOR}

\subsection{Limitation:}

The accuracy and reliability of the predictions of the MaxII metabolic calibrator are similar to that of the first Max calibrator that was explained in a publication ${ }^{1}$ that evaluated this calibrator. The accuracy of the predictions is also limited in part by the accuracy of the temperature, barometric pressure and relative humidity measurements provided at the test laboratory (RAH). As a guide, the accuracy of predicted $\mathrm{F}_{\mathrm{E}} \mathrm{O}_{2}$ and $\mathrm{F}_{\mathrm{E}} \mathrm{CO}_{2}$ are approximately $\pm 0.10 \%$ absolute and ventilation is accurate to within $\pm 1 \%$. Consequently predictions of $\dot{\mathrm{VO}}_{2}$ and $\dot{\mathrm{V}}$ $\mathrm{CO}_{2}$ are accurate to within $\pm 3-5 \%$; if all errors are minimal a $0.10 \%$ absolute error in $\mathrm{F}_{\mathrm{E}} \mathrm{O}_{2}$ will change $\mathrm{O}_{2}$ by $3 \%$ but if errors in gas fractions, ventilation and environmental conditions are cumulative then the total predicted error might be as large as $5 \%$.

\subsection{Overview:}

The RAH $\dot{\mathrm{VO}}_{2}$ system was assessed against the MaxII metabolic calibrator in two phases.

- Phase I: The MaxII calibrator was run in a dry mode. The gas fractions, $\dot{V}$ $\mathrm{E}_{\mathrm{BTPS}}, \dot{\mathrm{VO}}_{2}$ and $\dot{\mathrm{V}} \mathrm{CO}_{2}$ measured by the $\mathrm{RAH} \dot{\mathrm{VO}}_{2}$ system were compared with those values predicted from MaxII. (As explained in the previous manuscript ${ }^{1}$, the predicted gas fractions from MaxII depend upon mixing know volumes of alpha standard gas (21.00 \pm $0.02 \% \mathrm{CO}_{2}$ balance $\mathrm{N}_{2}$ ) with known volumes of room air $\left(20.93 \% \mathrm{O}_{2}, 0.03 \%\right.$ $\mathrm{CO}_{2}$, balance $\mathrm{N}_{2}$ ). MaxII uses two pistons; a small piston to deliver precise volumes of $21 \% \mathrm{CO}_{2}$ into the big piston that contains precise volumes of air. By using a variety of 'tidal volumes' for the small and big pistons, a range of expired gas fractions can be generated to span the physiological range. Similarly, by varying the piston frequency the 'minute ventilation' of MaxII can vary between 10 and $400 \mathrm{~L}^{\mathrm{min}}{ }^{-1}$, although these extremes were not assessed. 
- Phase II: The MaxII calibrator was used in conjunction with a customised, airtight waterbath run in both DRY and WET modes, about 1 hour apart. The deadspace of the waterbath and connecting tubing was matched on both occasions to assess the effectiveness of the AMIS 2000 approach (called ATPC mode) to "ignore" the partial pressure of water vapour. The measured $\mathrm{F}_{\mathrm{E}} \mathrm{O}_{2}$ and $\mathrm{F}_{\mathrm{E}} \mathrm{CO}_{2}$ with and without hot $\left(37^{\circ} \mathrm{C}\right)$ and humid $(100 \% \mathrm{RH})$ expirate should be the same.

For both testing phases, the expiratory port of the $\mathrm{RAH} \mathrm{VO}_{2}$ system was connected to the 'mouth' of MaxII using a standard Hans Rudolph R2700 respiratory valve.

\subsection{1 $\mathrm{RAH} \mathrm{VO} 2$ system}

- AMIS 2000 mass spectometer (Innovision, Denmark), calibrated to measure $\mathrm{O}_{2}, \mathrm{CO}_{2}, \mathrm{~N}_{2}$ and $\mathrm{Ar}$

- Hans Rudolph (3813) Pnuemotachograph flow sensor (0-800 L. $\mathrm{min}^{-1}$ )

- Mixing box on expiratory side, $\sim 5000 \mathrm{~cm}^{3}$

- Total tubing from HR2700 to mixing box is $1.0 \mathrm{~m}$ of Clean-bor tubing. Micro-capillary tubing from mixing box to Mass Spectometer $\sim 1.0 \mathrm{~m}$

\subsubsection{Calibration of $\mathrm{RAH} \mathrm{VO}_{2}$ system:}

The RAH $\dot{\mathrm{VO}}_{2}$ system was routinely calibrated for "gas fractions" prior to each MaxII setting. Calibration of the mass spectrometer used a two point check with room air $\left(20.93 \% \mathrm{O}_{2}\right.$ and $\left.0.03 \% \mathrm{CO}_{2}\right)$ and a one point check with alpha grade gas $\left(15.00 \% \mathrm{O}_{2}, 5.10 \% \mathrm{CO}_{2}, 0.996 \% \mathrm{Ar}\right)$.

It was not apparent whether the software included a criterion (e.g. within $\pm 0.02 \%$ of the target values) for the measured $\mathrm{O}_{2}$ and $\mathrm{CO}_{2}$ gas fractions to be accepted by the software. Mr Nick Shipp who is trouble-shooting this system in preparation for his PhD data collection conducted all calibrations.

A "volume calibration" was conducted at the start of the MaxII testing session and not repeated. The system calibration was established using 25 x 3.0 L strokes of a manual calibration syringe (SensorMedics Syringe - 763722) and the current calibration was verified by $5 \times 3.0 \mathrm{~L}$ strokes of the calibration syringe. Again, it was not apparent whether the software included a criterion (e.g. within $\pm 0.02 \%$ of the target values) for the measured volumes to be accepted by the software. 


\subsubsection{MAXII Calibrator at RAH:}

Dry, no waterbath: The calibrator was set to run for 3-4 min at 9 different small/big piston configurations to span the range of $\mathrm{F}_{\mathrm{E}} \mathrm{O}_{2}$ and $\mathrm{F}_{\mathrm{E}} \mathrm{CO}_{2}$ and ventilation of athletes. Analyser linearity was investigated using settings ranging from $\dot{\mathrm{VO}}_{2}$ of $\sim 2-7 \mathrm{~L} \cdot \mathrm{min}^{-1}$. The performance of the Pnuemotachograph flow sensor was evaluated at flow rates ranging $\sim 55-265$ L.min ${ }^{-1}$ BTPs. Therefore, testing was quite comprehensive to evaluate the accuracy of both the mass spectrometer as well as the Pnuemotachograph. (Note that depending on the piston frequency, the calibrator generates virtually identical $\mathrm{F}_{\mathrm{E}} \mathrm{O}_{2}$ and $\mathrm{F}_{\mathrm{E}} \mathrm{CO}_{2}$ values over a wide range of $\dot{\mathrm{VO}}_{2}$ and $\dot{\mathrm{VCO}}_{2}$, that causes up to three data points to overlie each other for the measured versus predicted $\mathrm{F}_{\mathrm{E}} \mathrm{O}_{2}$ and $\mathrm{F}_{\mathrm{E}} \mathrm{CO}_{2}$ values shown in the respective graphs-(e.g. page 6).

Dry waterbath: The MaxII calibrator was fitted with a custom waterbath valve connected to a 31L waterbath made of 6-mm aluminium plate. Two ports of the four port custom valve were attached with $1.0 \mathrm{~m}$ of Hans Rudolph Cleanbor tubing (28.6 mm ID) to each end of the waterbath; and the central common port of the custom valve was attached both to the MaxII calibrator and to a Hans Rudolph R2700 respiratory valve. The switching mechanism on the custom valve is such that inspired air (via the HR pnuemotach) is ambient room air, while expired air passes through the waterbath before exiting through the Hans Rudolph valve to the mixing chamber. In the dry mode, the waterbath uses an aluminium plate that sits on rails that match the water level when the waterbath is used in the 'wet' mode. The waterbath has been verified to be airtight.

Wet waterbath: The set-up was identical to that for the dry waterbath, except that the waterbath was filled to the marked level at the top of the rails with hot water $\left(\sim 60^{\circ} \mathrm{C}\right)$. A thermostatic heating element maintained water temperature. In this arrangement the inspired air was ambient room air while expired air passed across the waterbath and exited fully saturated with water vapour at about $37^{\circ} \mathrm{C}$. The common port of the custom valve is thus designed to provide the machine equivalent of a human mouth; inspired air is ambient and expired air is hot and saturated with water vapour. A calibrated temperature sensor was used to measure temperature on leaving the waterbath $\left(\sim 36^{\circ} \mathrm{C}\right)$ and of the expirate ( $\left.28^{\circ} \mathrm{C}\right)$.

For both the Dry and Wet waterbath a total of 10 settings were used on the MaxII calibrator to span the human physiological range for untrained subjects. 


\subsection{Analysis for $\mathrm{RAH} \mathrm{VO}_{2}$ system:}

Dry with no waterbath: Predicted values from the calibrator were regressed against mean values obtained from the $\mathrm{RAH} \dot{\mathrm{VO}_{2}}$ system for $\mathrm{F}_{\mathrm{E}} \mathrm{O}_{2}, \mathrm{~F}_{\mathrm{E}} \mathrm{CO}_{2}, \dot{\mathrm{V}}$ ${ }_{\mathrm{E}} \mathrm{BTPS}, \dot{\mathrm{VO}_{2}}$ and $\dot{\mathrm{VCO}}_{2}$. Correlation and standard error of estimate (SEE) were also calculated for measured versus predicted values. The optimum result is to have a correlation near to 1.00 and a small SEE (e.g. $0.03 \%$ for $\mathrm{F}_{\mathrm{E}} \mathrm{O}_{2}$ ). In addition, but not quite as critical if measurements are conducted over a small range such as $16-18 \% \mathrm{O}_{2}$, the regression intercept should be near zero and the slope near 1.00 .

Note that the 'mean' measured $\mathrm{F}_{\mathrm{E}} \mathrm{O}_{2}, \mathrm{~F}_{\mathrm{E}} \mathrm{CO}_{2}, \dot{\mathrm{V}}_{\mathrm{E}} \mathrm{BTPS}, \dot{\mathrm{VO}}_{2}$ and $\dot{\mathrm{VCO}}_{2}$ was obtained from 3-4 minutes of 'steady-state' data collected by the $\mathrm{RAH} \mathrm{VO}_{2}$ system. Data collection from the $\mathrm{RAH} \dot{\mathrm{VO}}_{2}$ system was in breath-by-breath mode, and these files which included 20 second averages of the breath-by-breath data, were exported into Excel. The Excel average function was then used to calculate the relevant means of 4-6 consecutive 20 second 'averages' values, usually during the last 2-3 minutes of each data collection interval.

Plots were made of these regressions and also of the difference between the measured and predicted values as a function of respiratory flow.

Dry versus wet waterbath: The modelling equations that predict the gas fraction and ventilation of MaxII in the mode of "Dry with no waterbath" were not used when the waterbath was incorporated since the extensive deadspace compromises the accuracy of these calculations. Rather, measured values in dry versus wet waterbath conditions were regressed against each other for $\mathrm{F}_{\mathrm{E}} \mathrm{O}_{2}$, $\mathrm{F}_{\mathrm{E}} \mathrm{CO}_{2}, \dot{\mathrm{V}}_{\mathrm{E}} \mathrm{BTPS}, \dot{\mathrm{VO}}_{2}$ and $\dot{\mathrm{VCO}}_{2}$. In addition, differences between dry waterbath versus wet waterbath data were calculated for all 5 variables and these were plotted as a function of total ventilation (L. $\mathrm{min}^{-1}$ ). The subtraction is such that, if the results of Wet are lower than those Dry, the values will be negative indicating a depression in the presence of water vapour.

Based upon previous wet and dry waterbath testing of a mixing chamber system using Ametek analysers and $\mathrm{CaCl}_{2}$ drying crystals, target ranges were set as follows: 
- the dry and wet gas fractions should be within $0.10 \%$ absolute since an error of this size will alter the calculated $\dot{\mathrm{VO}}_{2}$ by $3 \%$.

- the dry and wet $\dot{V E}_{\text {BTPS }}$ should be within 3\% of each other.

- the dry and wet $\dot{\mathrm{VO}}_{2}$ and $\dot{\mathrm{V} C O}{ }_{2}$ should be within $5 \%$ of each other.

\subsection{Results}

\subsubsection{Dry, no waterbath:}

Compared with the MaxII calibrator, the $\mathrm{RAH} \mathrm{VO}_{2}$ system measured gas fractions that were generally within $\pm 0.05 \%$ difference for both $\mathrm{F}_{\mathrm{E}} \mathrm{O}_{2}$ and for $\mathrm{F}_{\mathrm{E}} \mathrm{CO}_{2}$. The small deviations between measured and predicted gas fractions were also reflected by small SEE values of $0.05 \%$ for $\mathrm{F}_{\mathrm{E}} \mathrm{O}_{2}$ and $0.03 \%$ for $\mathrm{F}_{\mathrm{E}} \mathrm{CO}_{2}$; where it should be appreciated that an error of $0.035 \%$ will alter $\mathrm{VO}_{2}$ by $\sim 1 \%$.

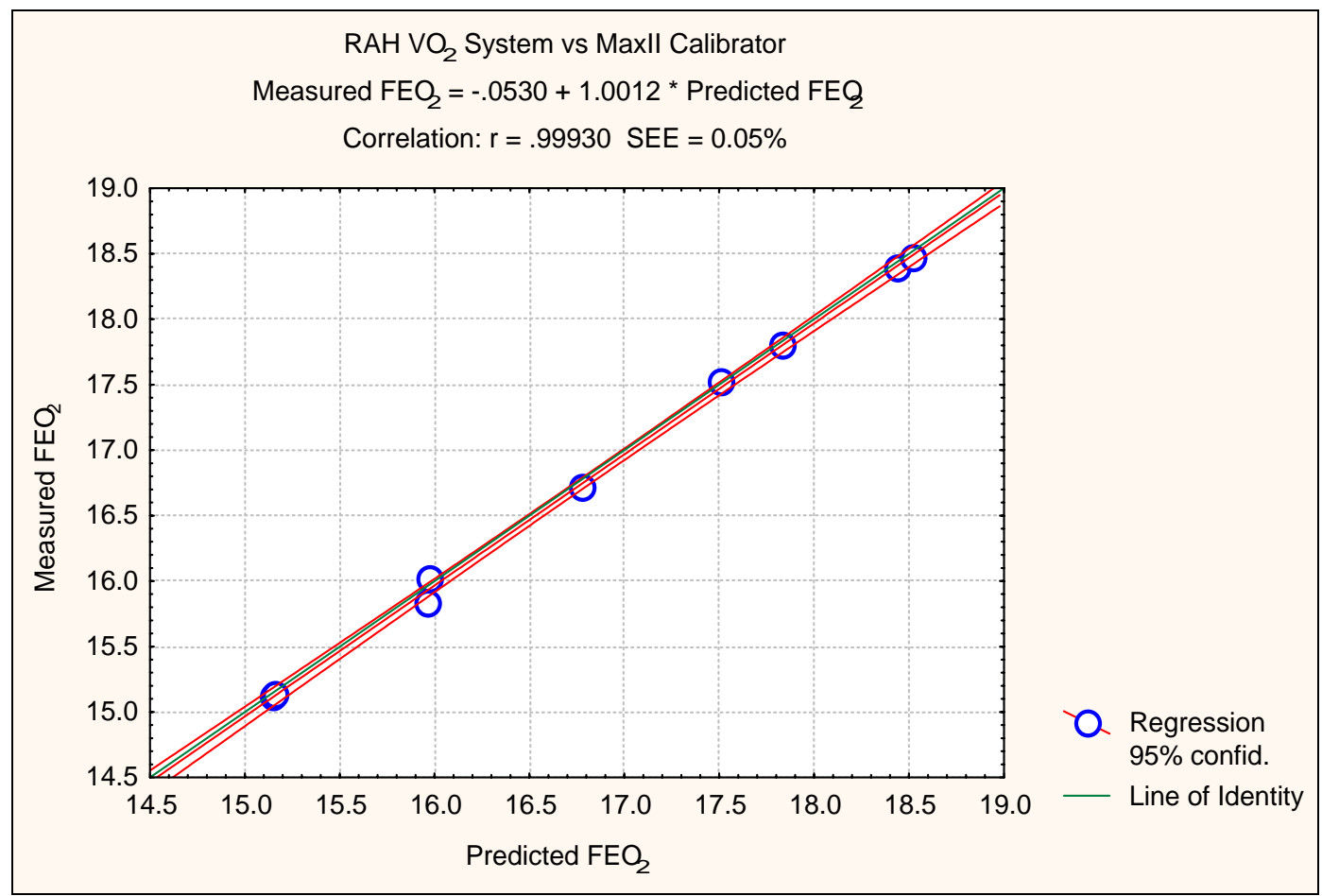




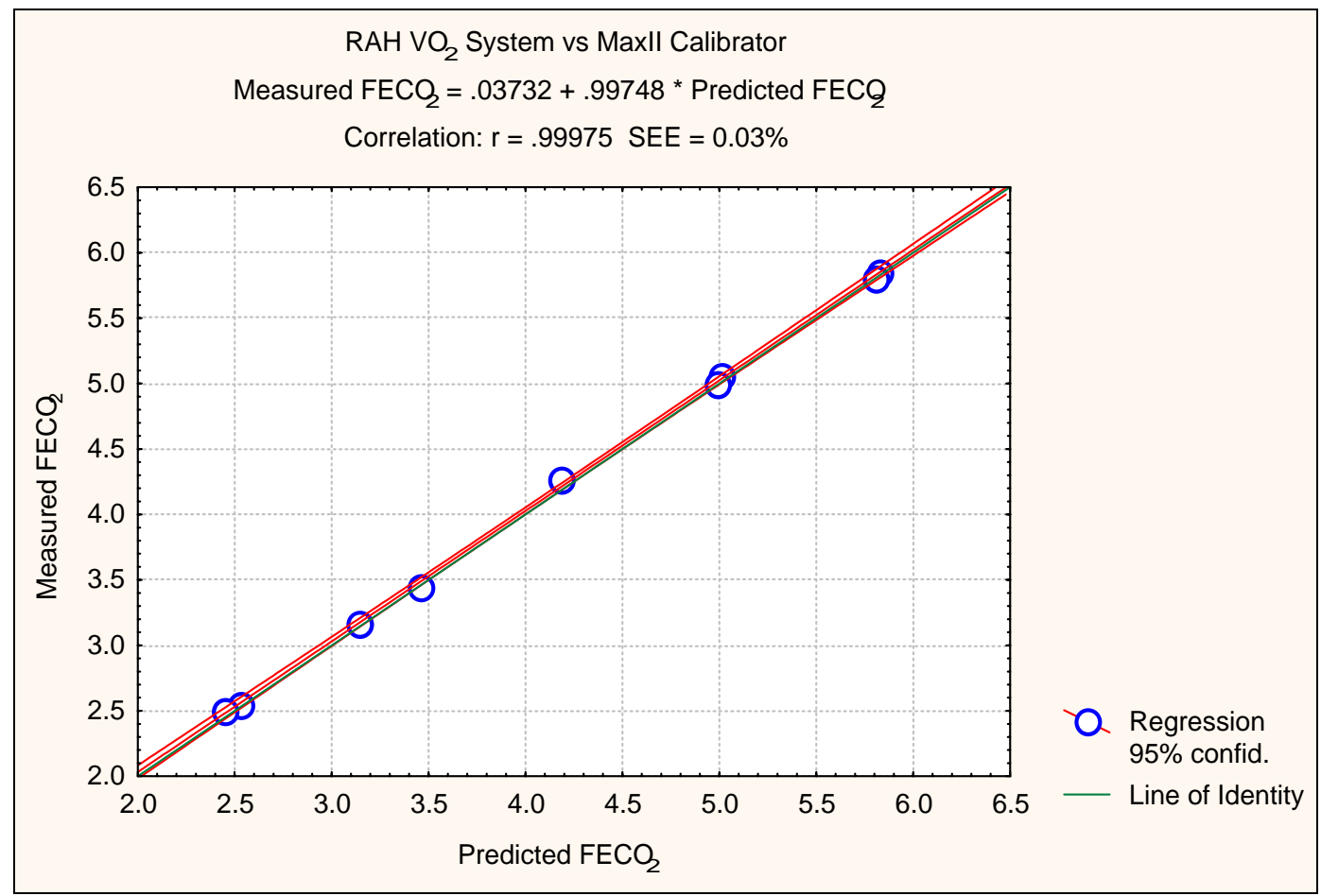

The absolute errors in the measured $\mathrm{F}_{\mathrm{E}} \mathrm{O}_{2}$ and $\mathrm{F}_{\mathrm{E}} \mathrm{CO}_{2}$ on the $\mathrm{RAH} \dot{\mathrm{VO}}_{2}$ system were also graphed as a function of the target or predicted $\mathrm{F}_{\mathrm{E}} \mathrm{O}_{2}$ and $\mathrm{F}_{\mathrm{E}} \mathrm{CO}_{2}$ (L.min ${ }^{-1}$ ) to determine if errors in were affected by gas concentrations. All measurements of $\mathrm{F}_{\mathrm{E}} \mathrm{O}_{2}$ apart from one were within the target band for accuracy of predicted gas fractions of $\pm 0.1 \%$. Since the difference between measured and predicted values is within the resolution of the calibrator the gas fraction must be considered as accurate.

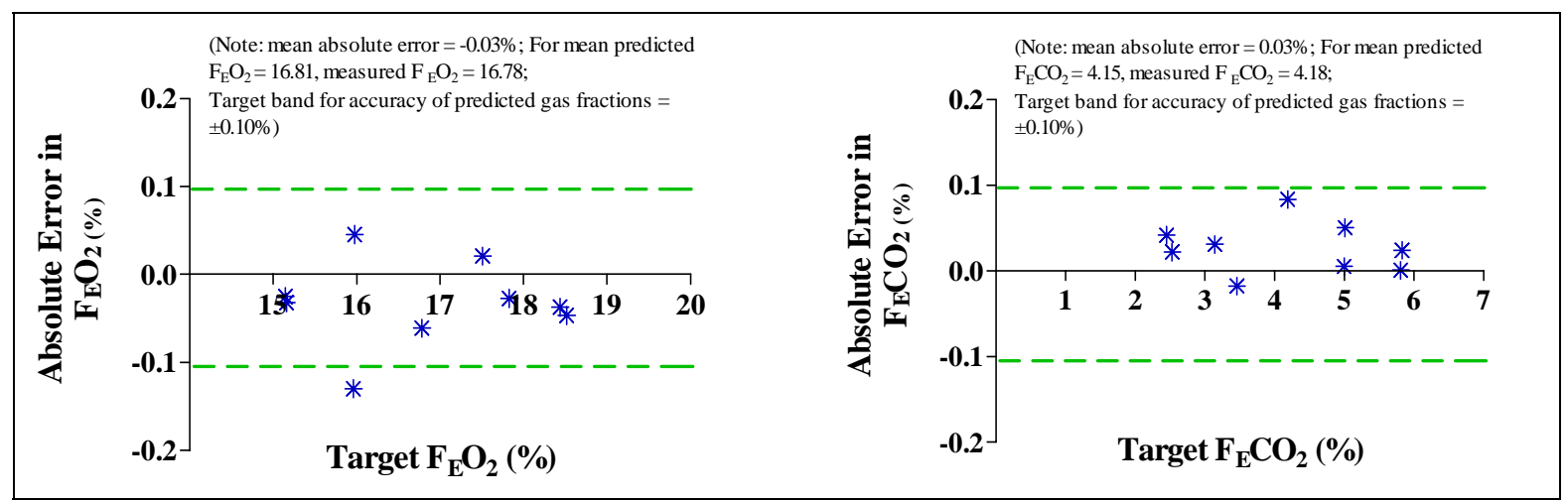

The RAH $\dot{\mathrm{VO}}_{2}$ system Pnuemotachograph flow sensor was mostly within $1 \%$ of predicted values from $55-270 \mathrm{~L} \cdot \mathrm{min}^{-1}$ BTPS with the average relative error 
being $0.2 \%$ higher than those predicted by MaxII. This is excellent accuracy and within the accepted standard for volume calibration according to the American Thoracic Society, which is $\pm 3 \%$.

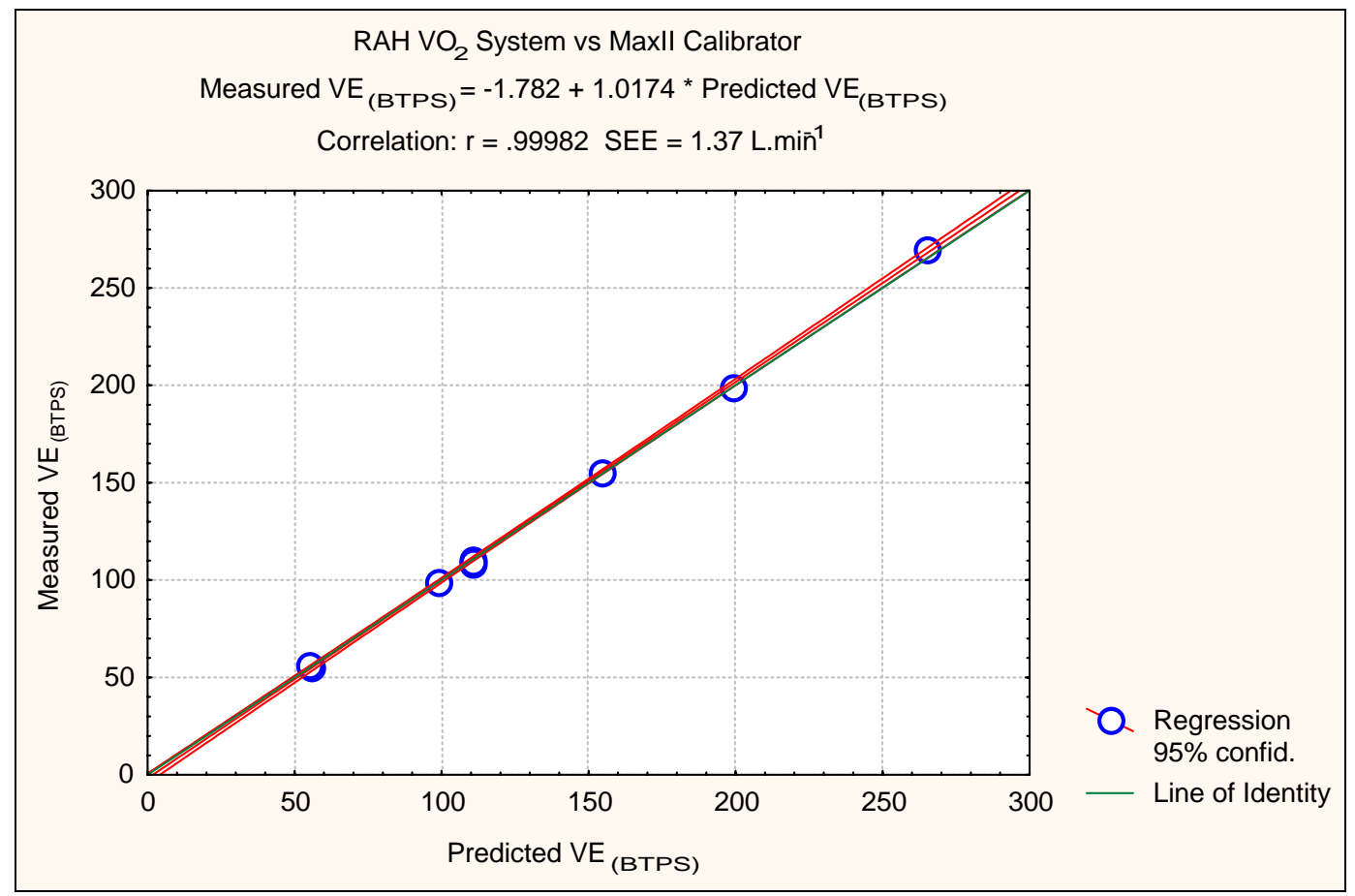

When graphed as a function of predicted total ventilation (L.min ${ }^{-1}$ ) from the calibrator, as well as a function of the target or predicted $\dot{\mathrm{V}}_{\mathrm{E}}$ BTPS, results demonstrated that the measured $\dot{\mathrm{V}}_{\mathrm{E} \text { BTPS }}$ for the $\mathrm{RAH} \dot{\mathrm{VO}}_{2}$ system were all within the target band of $\pm 3 \%$. Errors ranged from $-1.7 \%$ to $+2.1 \%$ in relative terms and from $-1.9 \mathrm{~L} . \mathrm{min}^{-1}$ to $4.5 \mathrm{~L} \cdot \mathrm{min}^{-1}$ in absolute terms. It should be appreciated that every $+1 \%$ error in $\dot{\mathrm{V}}_{\mathrm{E}}$ will translate directly into a $+1 \%$ error in $\dot{\mathrm{VO}}_{2}$ if there are not other sources of error. Additionally, there was no real trend for errors to be associated with flow rate. 

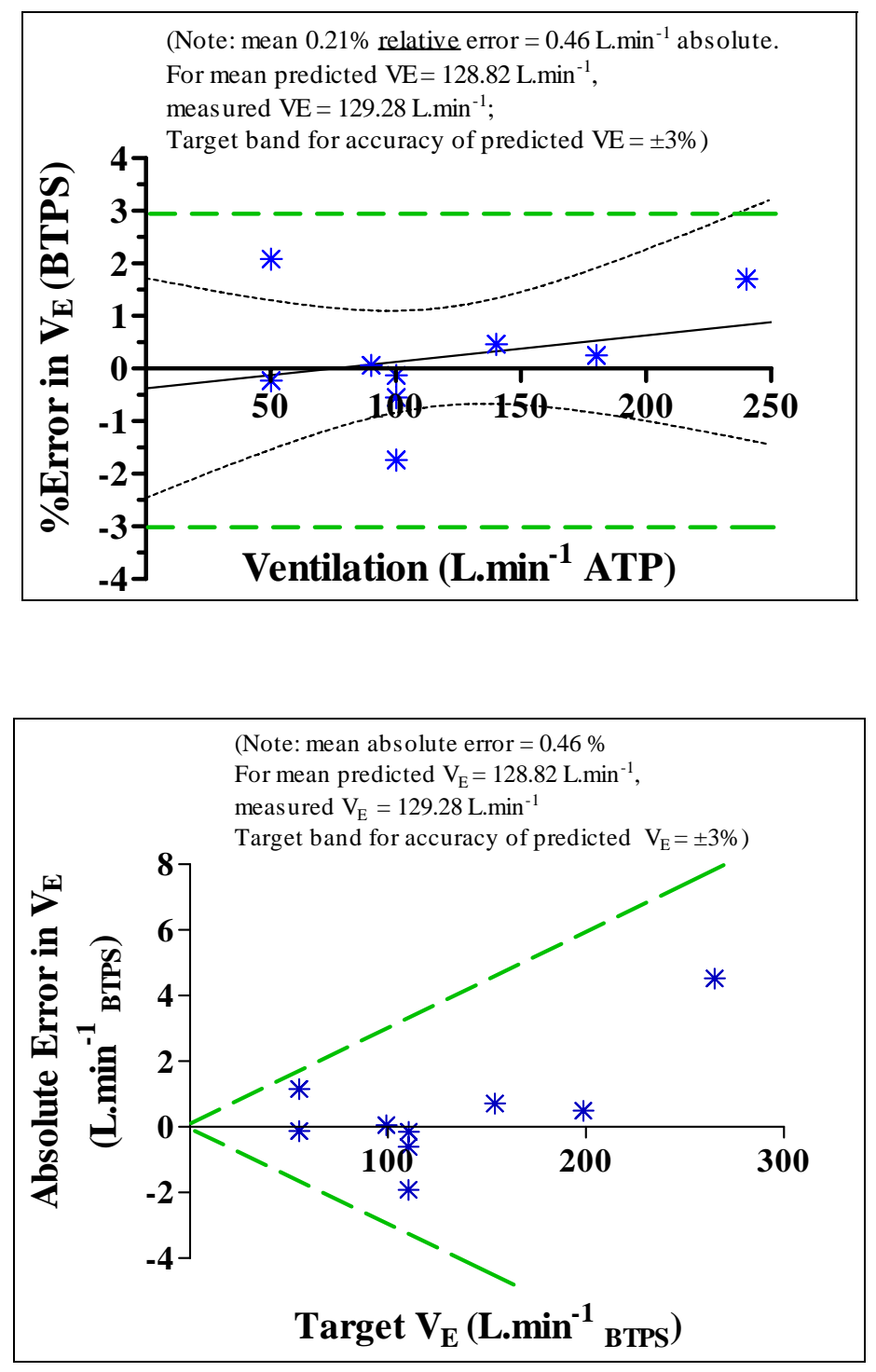
On average, the measured $\dot{\mathrm{VO}}_{2}$ for the $\mathrm{RAH} \dot{\mathrm{VO}}_{2}$ system was $0.07 \mathrm{~L} . \mathrm{min}^{-1}$ or $\sim 1.6 \%$ higher than the predicted values from MaxII. Relative errors in measured $\dot{\mathrm{VO}}_{2}$ ranged from $-0.9 \%$ to $3.3 \%$; no measurements were outside of the $\pm 5 \%$ target band. On average, the measured $\dot{\mathrm{VCO}}_{2}$ for the $\mathrm{RAH} \quad \dot{\mathrm{VO}}_{2}$ system was $0.06 \mathrm{~L} \cdot \mathrm{min}^{-1}$ or $\sim 1.3 \%$ higher than the predicted values from MaxII. Relative errors in measured $\dot{\mathrm{V} C O}{ }_{2}$ ranged from $-0.7 \%$ to $3.3 \%$; again no measurements were outside of the $\pm 5 \%$ target band.

Overall, these data suggest that the AMIS system can accurately measure $\dot{\mathrm{VO}}_{2}$ and $\dot{\mathrm{VCO}_{2}}$, since the difference between measured and predicted values is within the resolution of the calibrator.

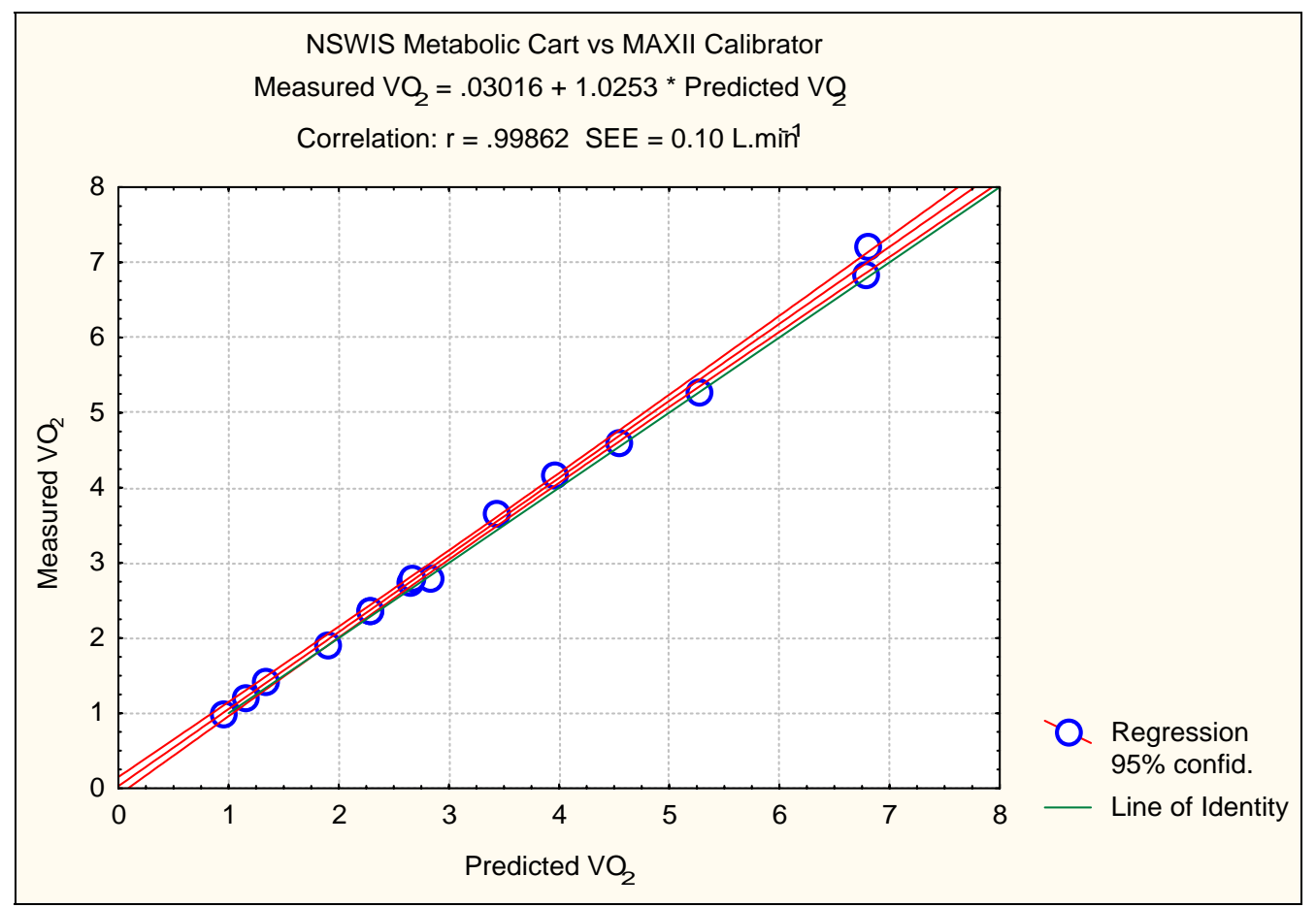




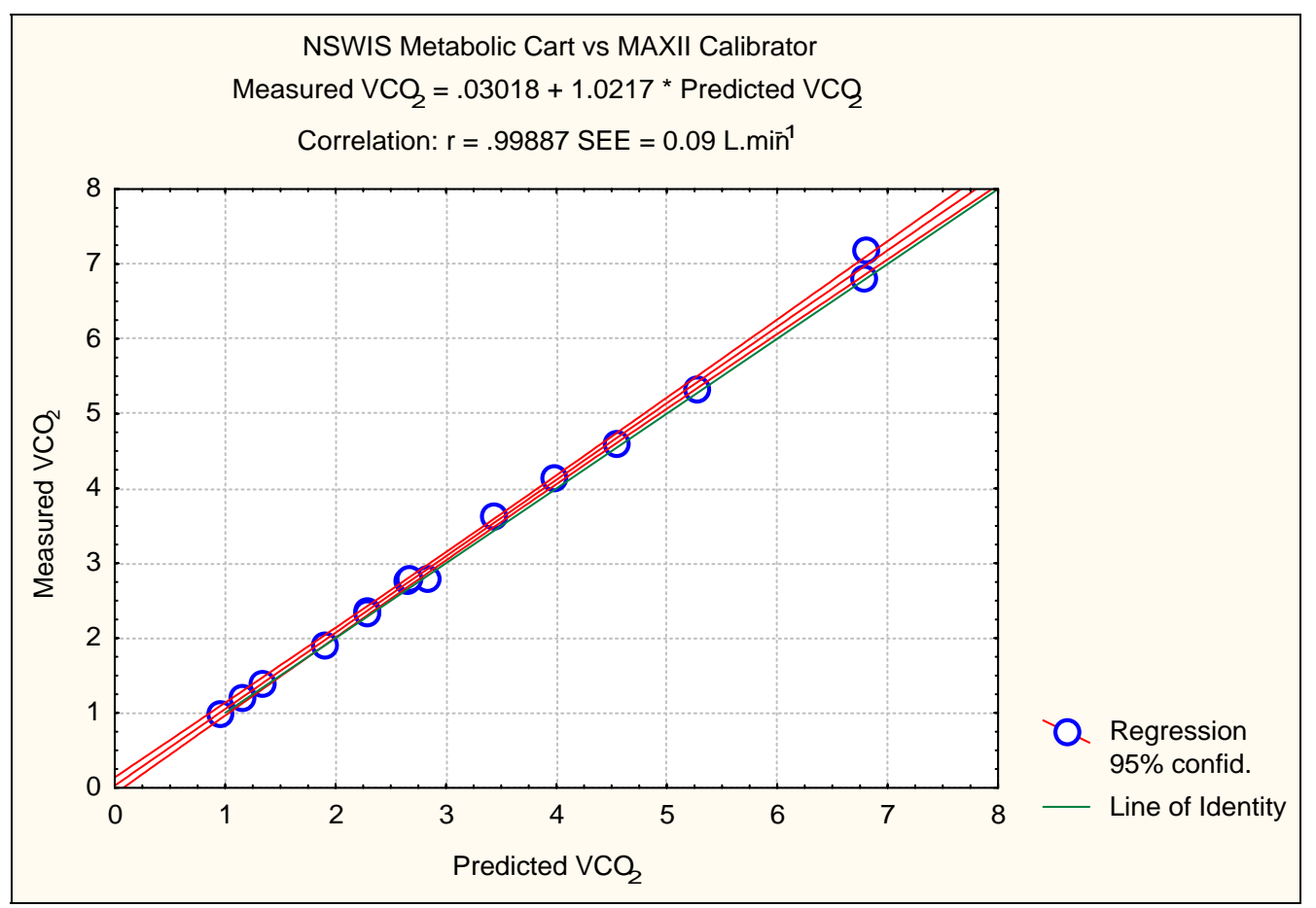

Additionally, measured $\dot{\mathrm{VO}}_{2}$ and $\dot{\mathrm{VCO}}_{2}$ from the $\mathrm{RAH} \dot{\mathrm{VO}} 2$ system were graphed as a function of the target or predicted $\dot{\mathrm{VO}}_{2}$ and $\dot{\mathrm{VCO}}_{2}\left(\mathrm{~L} \cdot \mathrm{min}^{-1}\right)$. These results demonstrate that no measurements for $\dot{\mathrm{V} O} 2$ or $\dot{\mathrm{VCO}} 2$ were outside of the $\pm 5 \%$ target band, and that generally most measurements were within $3 \%$ of the predicted values.

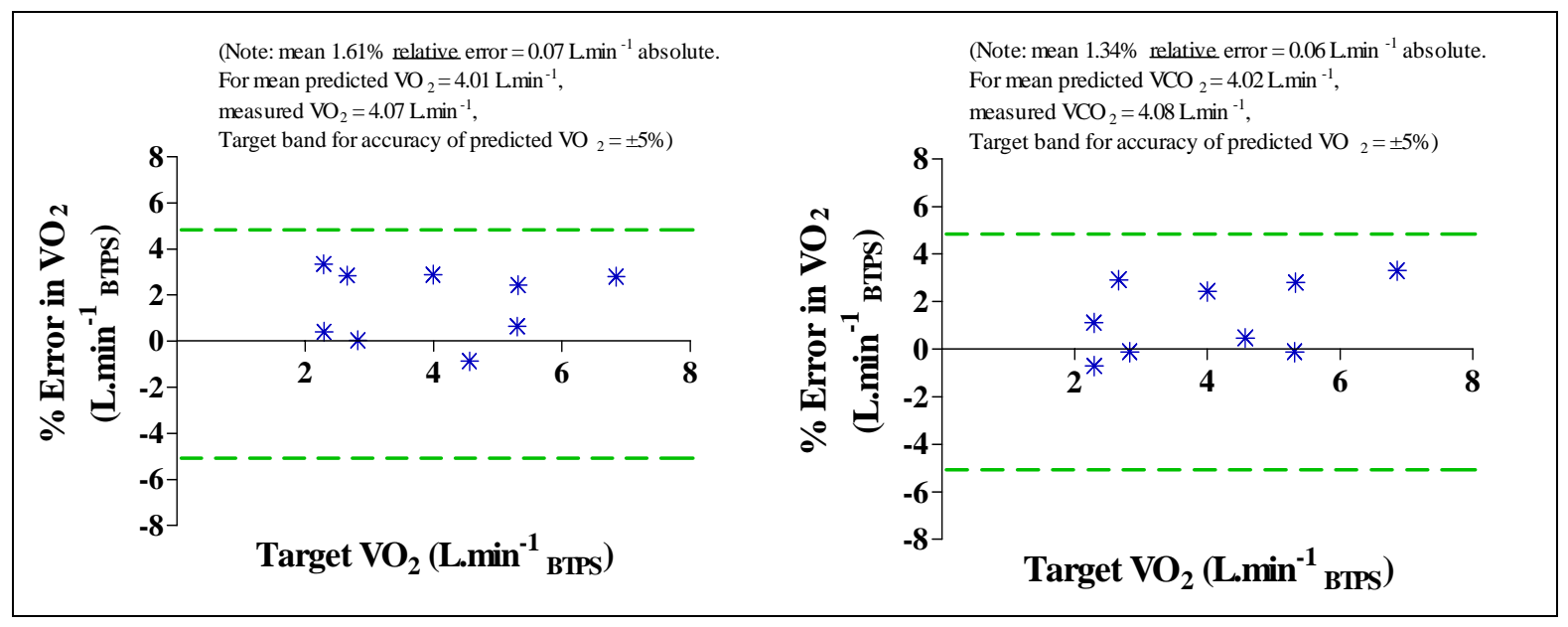




\subsubsection{Summary of Dry, no waterbath:}

Within the limitations of the MaxII calibrator, the current results indicate good accuracy of the RAH Amis $2000 \dot{\mathrm{VO}}_{2}$ system to assess physiological gas fractions and ventilation. All measurements of $\dot{\mathrm{VO}}_{2}$ and $\dot{\mathrm{VCO}}_{2}$ were within the target band of $\pm 5 \%$ of the predicted values irrespective of very high respiratory flow rates. In fact, most measurements were within $3 \%$ of the target values.

However, the most pertinent evaluation of the $\mathrm{RAH} \dot{\mathrm{VO}}_{2}$ system, requires completely saturated water vapour to match human expirate, and this is discussed in the next section (see 1.4.2) of this report.

\subsubsection{Dry versus wet waterbath:}

These data suggest that in the presence of water vapour FEO2 was slightly depressed (mean relative error $=-0.5 \%$ ) and FECO2 was somewhat elevated (mean relative error $=3.2 \%$ ).

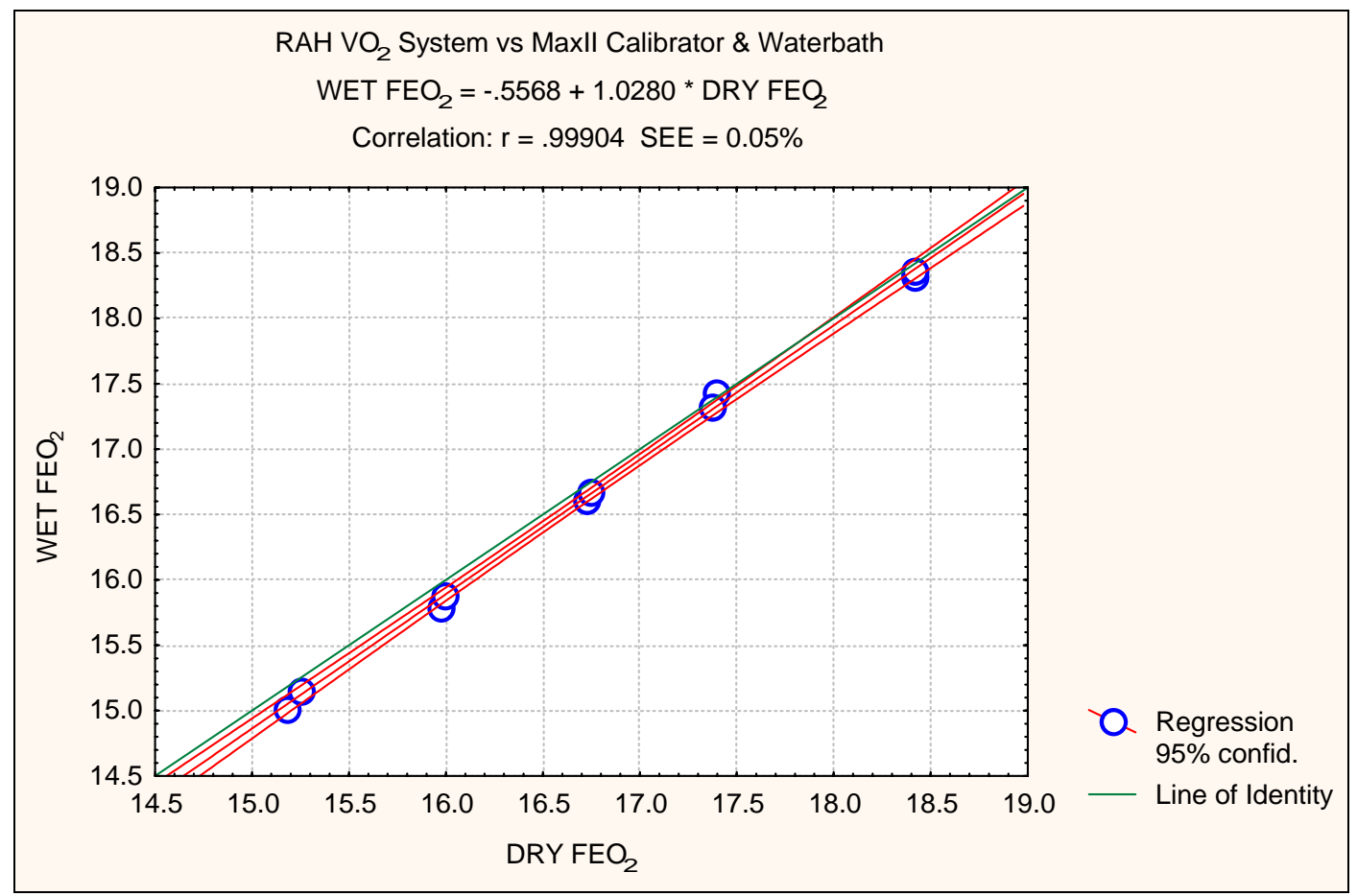




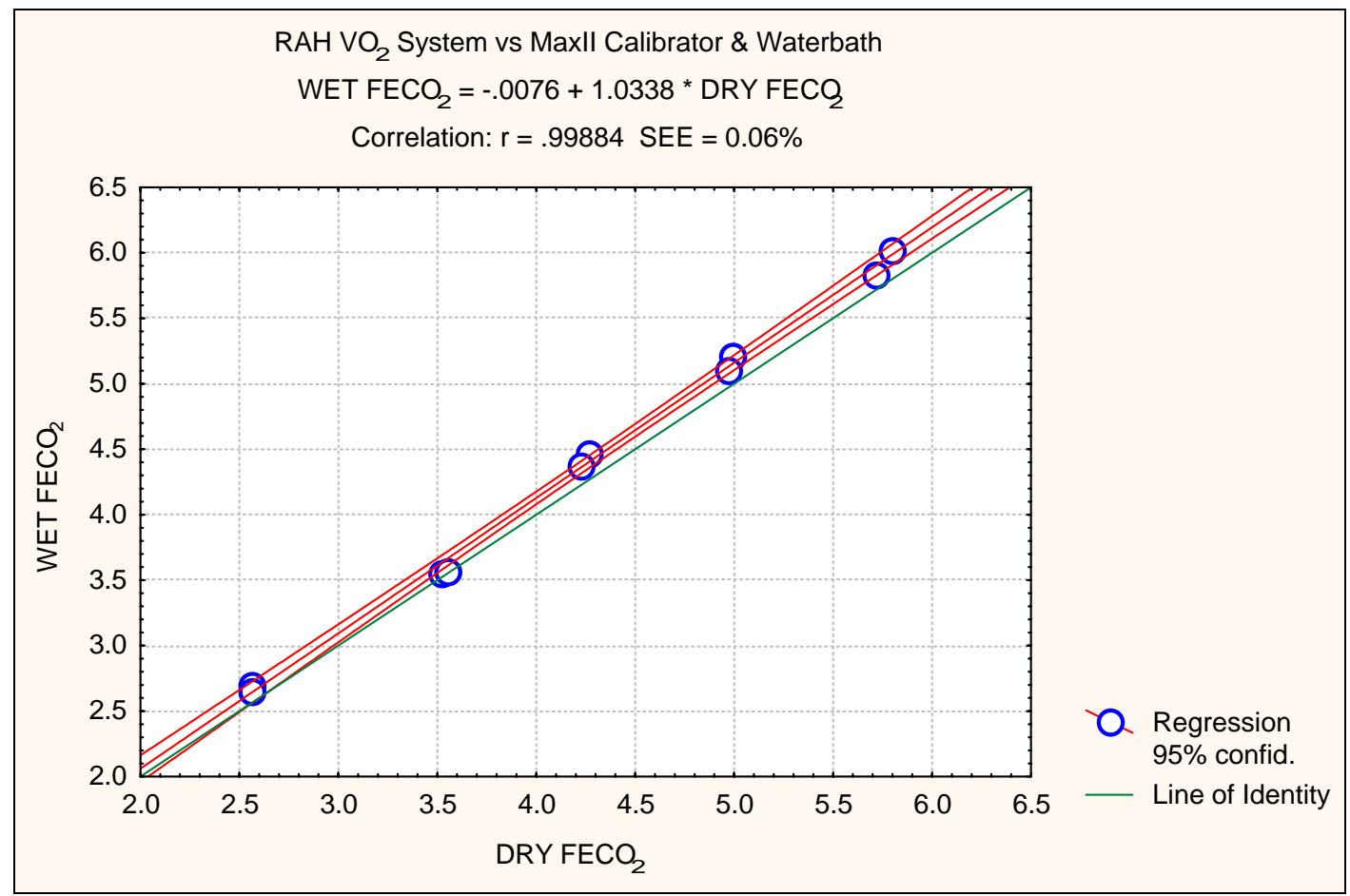

The changes in wet versus dry gas fractions values were also plotted as a function of target or predicted gas fractions (see following graph). Again it can be seen that in the presence of water vapour $\mathrm{F}_{\mathrm{E}} \mathrm{O}_{2}$ was depressed and $\mathrm{F}_{\mathrm{E}} \mathrm{CO}_{2}$ was somewhat elevated, suggesting that the 'drying system' was not totally efficient at drying gases.

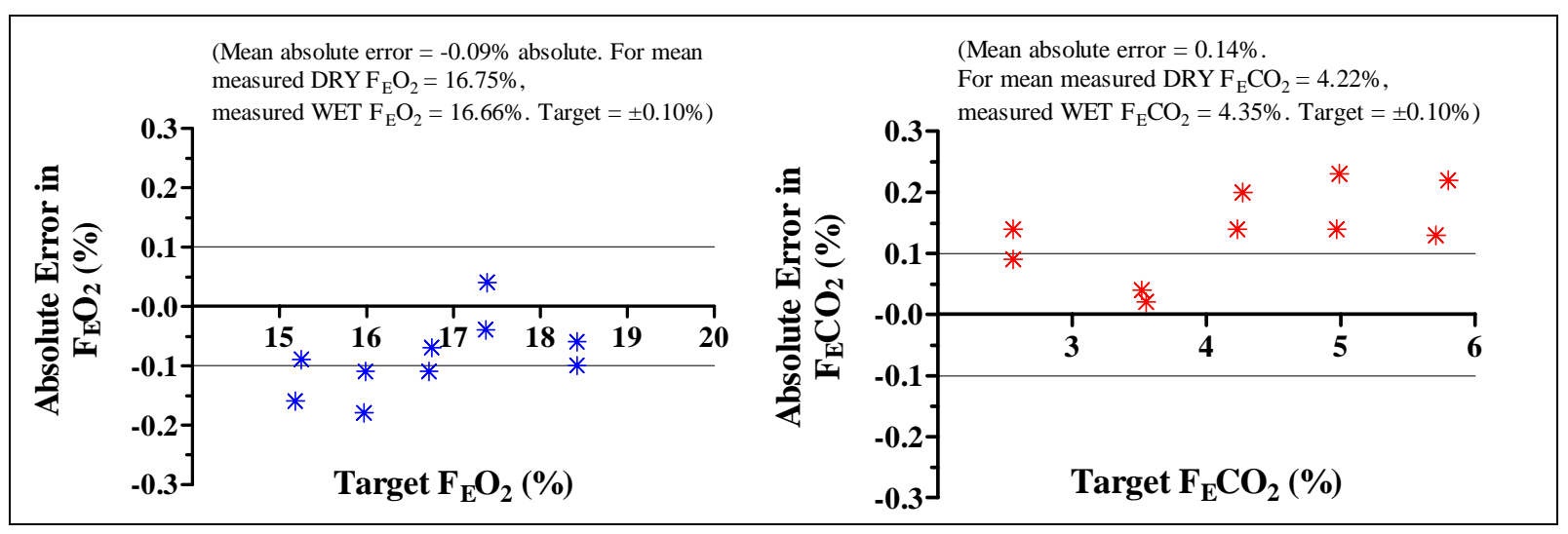

By way of comparison, the figure immediately below illustrates that on a system incorporating Ametek $\mathrm{O}_{2}$ and $\mathrm{CO}_{2}$ analysers, which dries gas fractions using $\mathrm{CaCl}_{2}$ :

a) the differences between the dry and wet gas fractions were negligible and relatively random. 
b) there was no systematic difference as a function of target gas fraction.

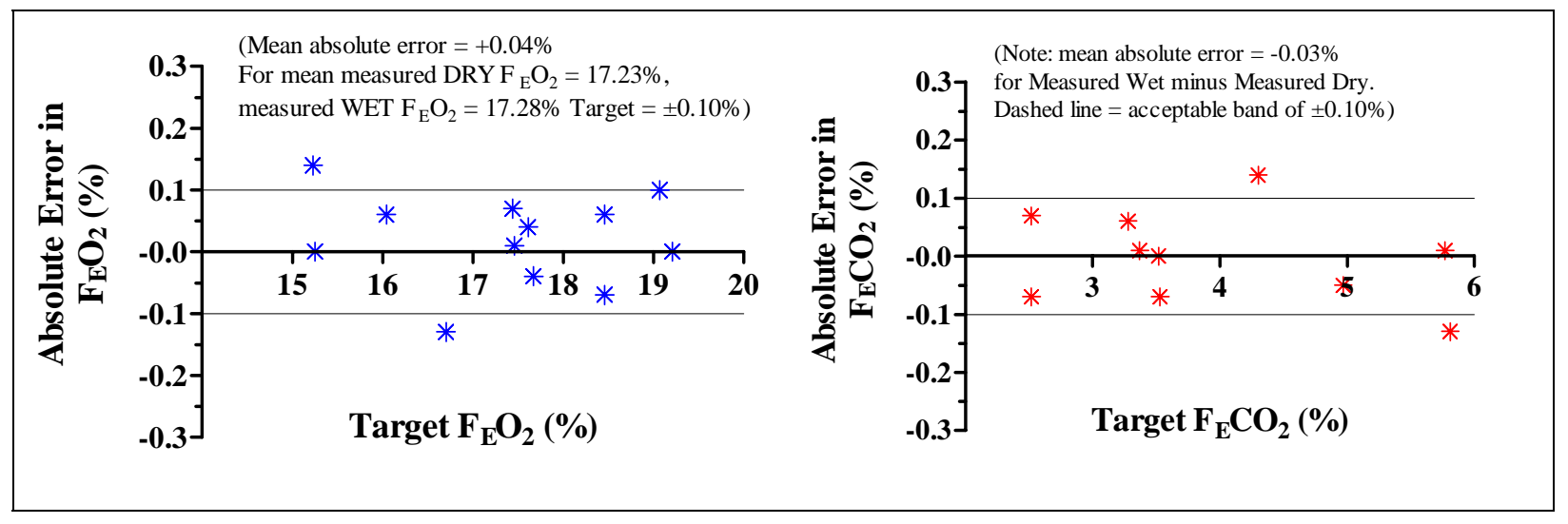

The presence of water vapour caused an imperceptible change in the accuracy of the RAH Pnuemotachograph flow sensor. When the waterbath was used under 'dry' conditions $\mathrm{VE}_{\mathrm{BTPS}}$ values tended to be $1.3 \mathrm{~L} . \mathrm{min}^{-1}$ or $1.3 \%$ higher than under 'wet' conditions. This level of accuracy is within the limitation of the MaxII calibration and thus the 'dry' and 'wet' volumes cannot be considered different.

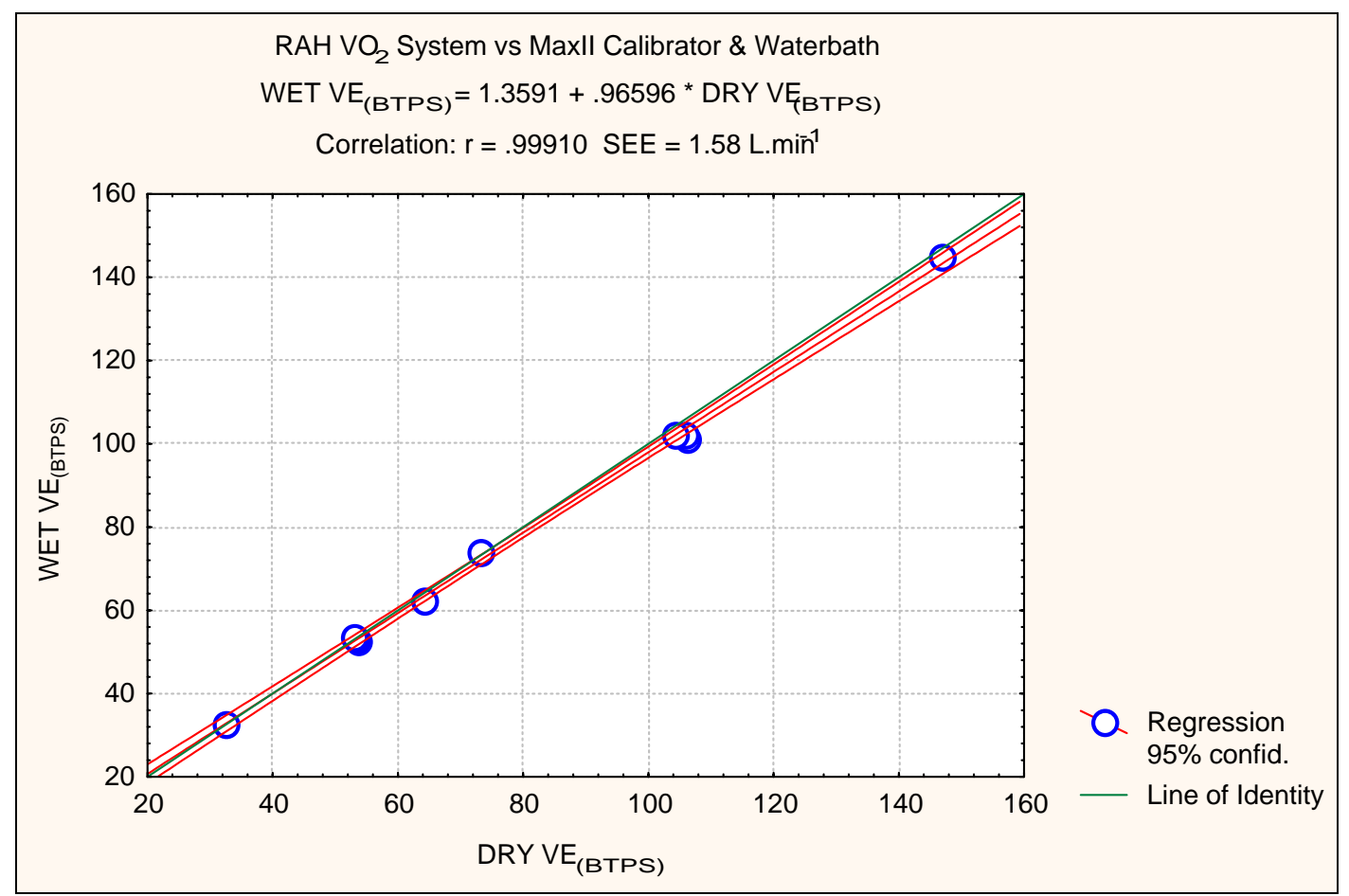


The majority of measures were within the accepted standard of $\pm 3 \%$ for volume calibration according to the American Thoracic Society.

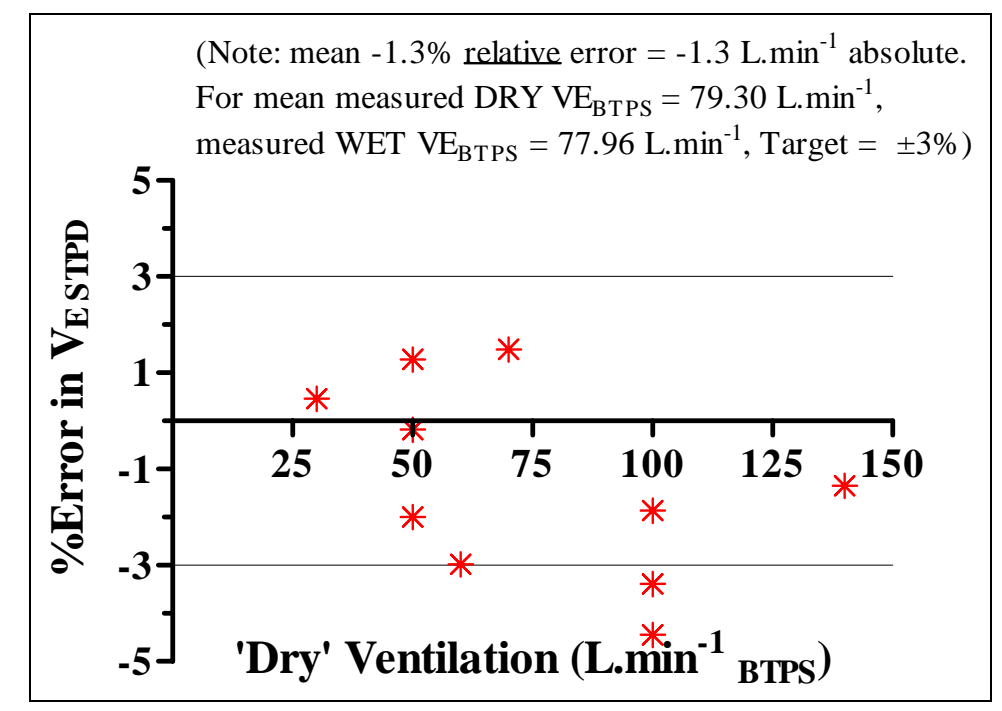

The errors if $\dot{\mathrm{VO}}_{2}\left(0.6 \%, 0.01 \mathrm{~L} \cdot \mathrm{min}^{-1}\right)$ and $\dot{\mathrm{VCO}}_{2}\left(1.95 \%, 0.04 \mathrm{~L} \cdot \mathrm{min}^{-1}\right)$ were minimal between the range of 2 and $7 \mathrm{~L} \cdot \mathrm{min}^{-1}$. The combination of a marginally too low $(\sim 1.3 \%) \dot{\mathrm{V}}_{\mathrm{E}}$ combined with a marginally too low $\mathrm{F}_{\mathrm{E}} \mathrm{O}_{2}(0.1 \%)$ are nearly equal and opposite in their effect on the calculated $\dot{\mathrm{VO}}_{2}$. The same is true for the combination of a marginally too low $(\sim 1.5 \%) \dot{\mathrm{V}}_{\mathrm{E}}$ combined with a marginally too high $\mathrm{F}_{\mathrm{E}} \mathrm{CO}_{2}(0.1 \%)$ and that they essentially counteract each other in terms of the resultant $\dot{\mathrm{VCO}_{2}}$. 

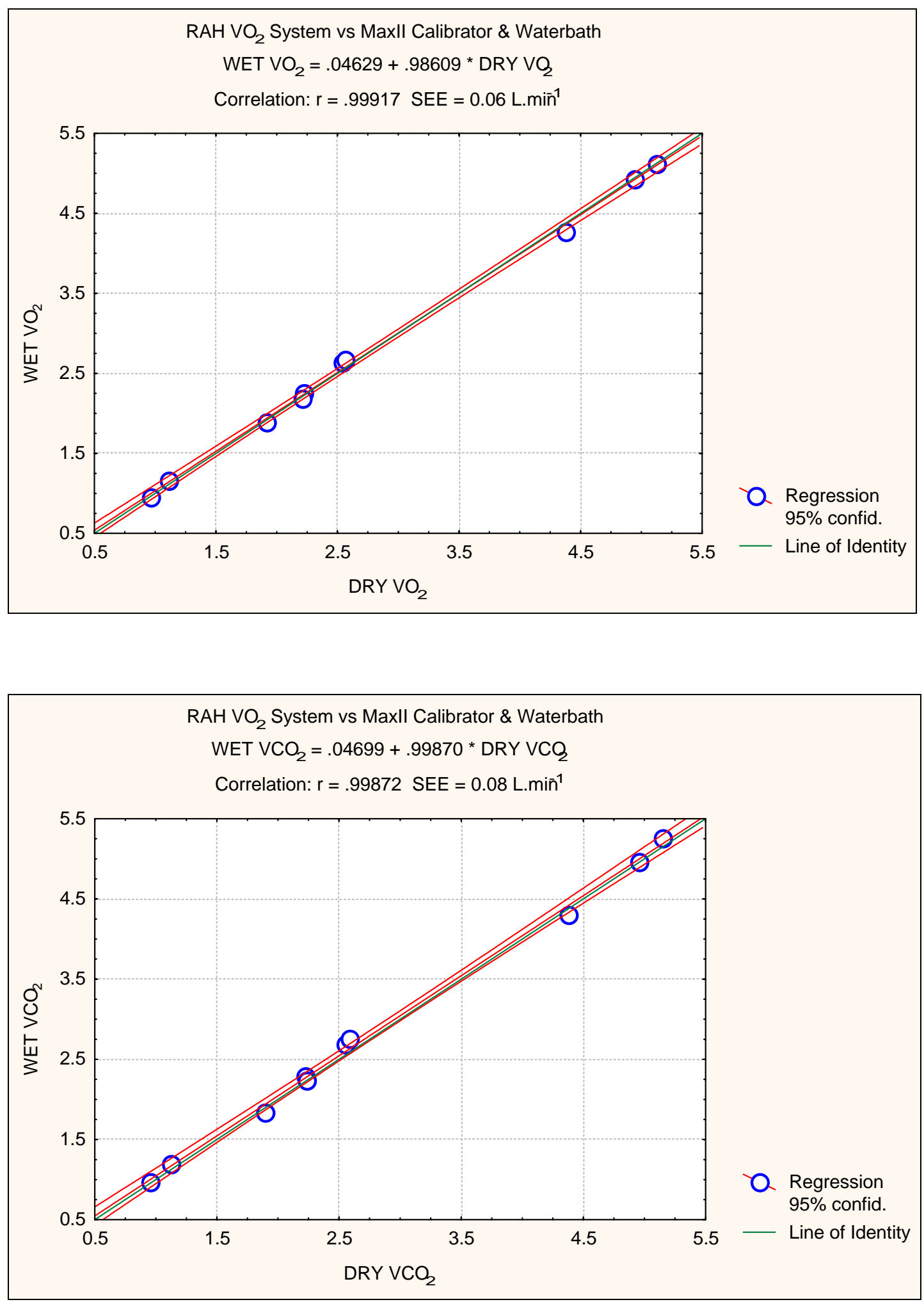
The changes in wet versus dry gas fractions values were also plotted as a function of target or predicted $\dot{\mathrm{VO}}_{2}$ and $\dot{\mathrm{VCO}}_{2}$. It can be seen from the following graph that in the presence of water vapour, errors in measured $\dot{\mathrm{VO}}_{2}$ and $\dot{\mathrm{V}}$ $\mathrm{CO}_{2}$. were relatively random.

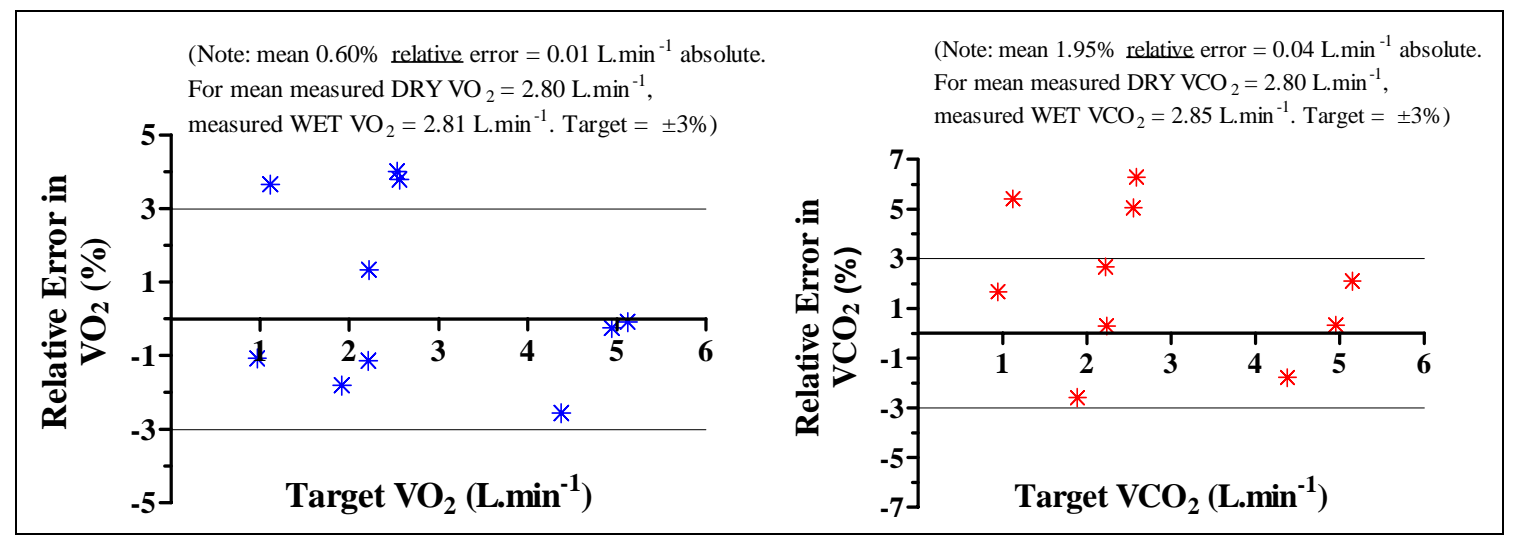

\subsubsection{Summary of Waterbath Assessment}

The small decrease (mean $=-0.09 \%$ ) in $\mathrm{F}_{\mathrm{E}} \mathrm{O}_{2}$, coupled with a corresponding increase (mean $=0.14 \%$ ) in $\mathrm{F}_{\mathrm{E}} \mathrm{CO}_{2}$ suggests that the ATPC method of ignoring water vapour is not perfect. Theoretically a depression of both $\mathrm{F}_{\mathrm{E}} \mathrm{O}_{2}$ and $\mathrm{F}_{\mathrm{E}} \mathrm{CO}_{2}$ will occur due to water vapour diluting the partial pressure of a gas ${ }^{2}$. An increase in the $\mathrm{F}_{\mathrm{E}} \mathrm{CO}_{2}$ is difficult to understand without better knowledge of the ATPC algorithm. Correspondence with technical staff at AEI (formerly Ametek) concurs that water vapour does increase the measured $\mathrm{F}_{E} \mathrm{CO}_{2}$. if using infra-red (IR) measurement. Apparently, there is enough molecular similarity that some combinations of IR sources and detectors actually measure the amount of the $\mathrm{H}_{2} \mathrm{O}$ molecules in the sample stream together with the $\mathrm{CO}_{2}$ that is present. However, extrapolating this information to a mass spectrometer is unwarranted.

Note, that the alterations in $\mathrm{F}_{\mathrm{E}} \mathrm{O}_{2}$ and $\mathrm{F}_{\mathrm{E}} \mathrm{CO}_{2}$ are right at the limits of what the MaxII calibrator can discern with confidence. Nevertheless, the observations that the change in the gas fractions was relatively consistent $( \pm 0.10 \%)$, is consistent with the presence of $\mathrm{H}_{2} \mathrm{O}$ vapour. Even if water vapour is a problem the magnitude of the associated error in $\mathrm{VO}_{2}$ and $\dot{\mathrm{VCO}}_{2}$ is on average $<3 \%$.

\subsection{Overall conclusions:}

This evaluation indicates that the RAH AMIS $2000 \dot{\mathrm{VO}}_{2}$ system is likely accurate to within $\sim \pm 3 \%$ of the predicted values for $\dot{\mathrm{VO}}_{2}$ and $\dot{\mathrm{V} C O}$ for dry and 
wet expirate. Interestingly, data from the waterbath phase of testing suggest that the 'ATPC approach' to handling water vapour is not $100 \%$ effective. However, the combination of marginally low $\dot{\mathrm{V}}_{\mathrm{E}}(\sim 1 \%)$ from the pnuemotachograph (as demonstrated in the testing with the waterbath) combined with the $0.1 \%-/+$ errors in $\mathrm{F}_{\mathrm{E}} \mathrm{O}_{2}$ and $\mathrm{F}_{\mathrm{E}} \mathrm{CO}_{2}$, respectively, (also as demonstrated in the wet waterbath testing) somewhat counteract each other on calculated $\dot{\mathrm{VO}}_{2}$ and $\dot{\mathrm{VCO}}_{2}$ when dealing with wet expirate from subjects. Consequently, total system error when testing athletes is likely of the order of 2-3\% too high for both $\dot{\mathrm{VO}}_{2}$ and $\dot{\mathrm{V}}$ $\mathrm{CO}_{2}$ compared with the true values.

Overall accuracy is as good as any system that we have currently assessed with the MaxII calibrator.

\subsection{References}

(1) Gore CJ, Catcheside PG, French SN, Bennett JM, Laforgia J. Automated $\mathrm{VO}_{2}$ max calibrator for open-circuit indirect calorimetry systems. Med Sci Sports Exerc 1997; 29(8):1095-1103.

(2) Wasserman K, Hansen H, Sue DY, Whipp BJ. Principles of Exercise Testing and Interpretation. Philadelphia: Lea and Febiger, 1987: 257-258.

(3) Hart JD, Withers RT, Tucker RC. Precision and accuracy of Morgan ventilometers at continuous and sinusoidal flows. Eur Respir J 1994; 7:813-816. 


\section{CHAPTER 8}

\section{Bibliography}

Aguilaniu, B., P. Flore, H. Perrault, J. E. Page, E. Payan and J. R. Lacour (1995). Exercise-induced hypoxaemia in master athletes: effects of a polyunsaturated fatty acid diet. Eur. J. Appl. Physiol. Occup. Physiol. 72: 44-50.

Aguilaniu, B., P. Flore, E. Page, J. Maitre, J. R. Lacour and H. Perrault (1998). Effects of indomethacin and polyunsaturated fatty acid diet on exerciseinduced hypoxaemia in master athletes. Eur. J. Appl. Physiol. Occup. Physiol. 77: 81-88.

Aguilaniu, B., P. Flore, J. Maitre, J. Ochier, J. R. Lacour and H. Perrault (2002). Early onset of pulmonary gas exchange disturbance during progressive exercise in healthy active men. J. Appl. Physiol. 92: 1879-84.

Allen, E. V. (1929). Thromboangiitis obliterans: Methods of diagnosis of chronic occlusive arterial lesions distal to the wrist with illustrative causes. Am. J. Med. Sci 178: 237.

Amann, M., M. Eldridge, A. Lovering, D. Pegelow, M. Stickland and J. 
Dempsey (2006). Arterial oxygen content influences exercise performance via effects on limb fatigue. Med. Sci. Sports Exerc. 38: 72.

American Association for Respiratory Care (AARC) Clinical Practice Guideline: Exercise Testing for the Evaluation of Hypoxemia and/or Desaturation: 2001 Revision and Update. Respir. Care 2001; 46: 514-522.

American Thoracic Society Standards for the diagnosis and care of patients with chronic obstructive pulmonary disease (COPD) and asthma. (1987) Am. Rev. Respir. Dis. 136: 225-244.

American Thoracic Society/American College of Chest Physicians. ATS/ACCP Statement on Cardiopulmonary Exercise Testing. (2003) Am. J. Respir. Crit. Care Med. 167:1451-1452

Andrews, J. L., Jr., B. E. Copeland, R. M. Salah, B. Morrissey, E. J. Enos and A. Spilios (1981). Arterial blood gas standards for healthy young nonsmoking subjects. Am. J. Clin. Pathol. 75: 773-780.

Andritsch, R. F., S. Muravchick and M. I. Gold (1981). Temperature correction of arterial blood-gas parameters: A comparative review of methodology. Anesthesiology 55: 311-316.

Anholm, J. D., E. C. Milne, P. Stark, J. C. Bourne and P. Friedman (1999). 
Radiographic evidence of interstitial pulmonary edema after exercise at altitude. J. Appl. Physiol. 86: 503-509.

Anselme, F., C. Caillaud, I. Couret, M. Rossi and C. Prefaut (1994). Histamine and exercise-induced hypoxemia in highly trained athletes. J. Appl. Physiol. 76: 127-132.

Aschoff, J. and R. Wever (1958). Kern und Schale im Warmehaushalt des Menschen. Naturwissenschaften 45: 477-485.

Ashwood, E. R., G. Kost and M. Kenny (1983). Temperature correction of blood-gas and pH measurements. Clin. Chem. 29: 1877-1885.

Asmussen, E. and M. Neilsen (1960). Alveolar-arterial gas exchange at rest and during work at different oxygen tensions. Acta Physiol. Scan. 50: 153-166.

Astrand, P. O. and K. Rodahl (1986). Textbook of Work Physiology. New York, McGraw-Hill.

Aulick, L. H., S. Robinson and S. P. Tzankoff (1981). Arm and leg intravascular temperatures of men during submaximal exercise. J. Appl. Physiol. 51: 1092-1097.

Aunola, S. and H. Rusko (1984). Reproducibility of aerobic and anaerobic 
thresholds in 20-50 year old men. Eur. J. Appl. Physiol. Occup. Physiol. 53: $260-266$.

Bachofen, H., H. J. Hobi and M. Scherrer (1973). Alveolar-arterial $\mathrm{N}_{2}$ gradients at rest and during exercise in healthy men of different ages. J. Appl. Physiol. 34: 137-142.

Bannister, E. W. and J. Griffiths (1972). Blood levels of adrenergic amines during exercise. J. Appl. Physiol. 33: 674-676.

Basset, F. A. and M. R. Boulay (2000). Specificity of treadmill and cycle ergometer tests in triathletes, runners and cyclists. Eur. J. Appl. Physiol. 81(3): 214-221.

Bazett, H. C., L. Love, M. Newton, L. Eisenberg, R. Day and R. Forster (1948). Temperature changes in blood flowing in arteries and veins in man. $J$. Appl. Physiol. 1: 3.

Beaver, W. L., K. Wasserman and B. J. Whipp (1986). Bicarbonate buffering of lactic acid generated during exercise. J. Appl. Physiol. 60: 472-478.

Beck, K. C. and I. M. Weisman (2002). Methods for cardiopulmonary exercise testing. Clinical exercise testing. I. M. Weisman and R. J. Zeballos. Basel, Switzerland, Karger: 43-59. 
Bennett, A. F. (1984). Thermal dependence of muscle function. Am. J. Physiol. 247: R217-29.

Billat, V., J. C. Renoux, J. Pinoteau, B. Petit and J. P. Koralsztein (1995). [Hypoxemia and exhaustion time to maximal aerobic speed in longdistance runners]. Can. J. Appl. Physiol. 20: 102-11.

Birks, E. K., O. Mathieu-Costello, Z. Fu, W. S. Tyler and J. B. West (1997). Very high pressures are required to cause stress failure of pulmonary capillaries in thoroughbred racehorses. J. Appl. Physiol. 82: 1584-1592.

Blomstrand, E., L. Kaijser, A. Martinsson, U. Bergh and B. Ekblom (1986). Temperature-induced changes in metabolic and hormonal responses to intensive dynamic exercise. Acta Physiol. Scand. 127: 477-484.

Boulant, J. A. and J. D. Hardy (1974). The effect of spinal and skin temperatures on the firing rate and thermosensitivity of preoptic neurones. J. Physiol. 240: 639-60.

Boulant, J. A. (2000). Role of the preoptic-anterior hypothalamus in thermoregulation and fever. Clin. Infect. Dis. 31: S157-161.

Brengelmann, G. L., J. M. Johnson and P. A. Hong (1979). Electrocardiographic 
verification of esophageal temperature probe position. J. Appl. Physiol. 47: 638-642.

Brown, D. D., R. G. Knowlton, P. B. Sanjabi and B. T. Szurgot (1993). Reexamination of the incidence of exercise-induced hypoxaemia in highly trained subjects. Br. J. Sports Med. 27: 167-170.

Buchthal, F., P. Hencke and J. Lindhard (1944). Temperature measurements in human muscles in situ at rest and during muscular work. Acta Physiol. Scand. 230-258.

Buono, M. J. and R. Maly (1996). Augmented hyperventilation via normoxic helium breathing does not prevent exercise-induced hypoxemia. Can. J. Appl. Physiol. 21: 264-270.

Bye, P. T., G. A. Farkas and C. Roussos (1983). Respiratory factors limiting exercise. Annu. Rev. Physiol. 45: 439-451.

Byrne-Quinn, E., J. V. Weil, I. E. Sodal, G. F. Filley and R. F. Grover (1971). Ventilatory control and the athlete. J. Appl. Physiol. 30: 91-98.

Cabanac, M. (1975). Temperature regulation. Ann. Rev. Physiol. 37: 415-439.

Caillaud, C., F. Anselme, J. Mercier and C. Prefaut (1993). Pulmonary gas 
exchange and breathing pattern during and after exercise in highly trained athletes. Eur. J. Appl. Physiol. 67: 431-437.

Caillaud, C., O. Serre-Cousine, F. Anselme, X. Capdevilla and C. Prefaut (1995). Computerized tomography and pulmonary diffusing capacity in highly trained athletes after performing a triathlon. J. Appl. Physiol. 79: 1226-1232.

Caillaud, C. F., F. M. Anselme and C. G. Prefaut (1996). Effects of two successive maximal exercise tests on pulmonary gas exchange in athletes. Eur. J. Appl. Physiol. Occup. Physiol. 74: 141-147.

Caputo, F. and B. S. Denadai (2006). Exercise mode affects the time to achieve $\mathrm{VO}_{2}$ max without influencing maximal exercise time at the intensity associated with $\mathrm{VO}_{2} \max$ in triathletes. Int. J. Sports. Med. 27: 798-803.

Chapman, R. F., M. Emery and J. M. Stager (1998). Extent of expiratory flow limitation influences the increase in maximal exercise ventilation in hypoxia. Respir. Physiol. 113: 65-74.

Chapman, R. F., M. Emery and J. M. Stager (1999). Degree of arterial desaturation in normoxia influences $\mathrm{VO}_{2} \max$ decline in mild hypoxia. Med. Sci. Sports Exerc. 31: 658-663. 
Chwalbinska-Moneta, J. and O. Hänninen (1989). Effect of active warming-up on thermoregulatory, circulatory, and metabolic responses to incremental exercise in endurance-trained athletes. Int. J. Sports Med. 10: 25-29.

CIBA-GEIGY (1990). Geigy Scientific Tables. Basel, CIBA-GEIGY Limited.

Coates, G., H. O'Brodovich, A. L. Jefferies and G. W. Gray (1984). Effects of exercise on lung lymph flow in sheep and goats during normoxia and hypoxia. J. Clin. Invest. 74: 133-141.

Comroe, J. H. (1944). The hyperpnea of muscular exercise. Physiol. Rev. 24: 319-339.

Connes, P., D. Bouix, F. Durand, P. Kippelen, J. Mercier, C. Prefaut, J. F. Brun and C. Caillaud (2004). Is hemoglobin desaturation related to blood viscosity in athletes during exercise? Int. J. Sports Med. 25: 569-74.

Cooper, K. E. and J. R. Kenyon (1957). A comparison of temperatures measured in the rectum, oesophagus, and on the surface of the aorta during hypothermia in man. Br. J. Surg. 44: 616-619.

Cranston, W. I., J. Gerbrandy and E. S. Snell (1954). Oral, rectal and oesophageal temperatures and some factors affecting them in man. $J$. Physiol. 126: 347-358. 
Crapo, R. O. and A. H. Morris (1981). Standardized single breath normal values for carbon monoxide diffusing capacity. Am. Rev. Respir. Dis. 123: 185189.

Crapo, R. O., A. H. Morris and R. M. Gardner (1981). Reference spirometric values using techniques and equipment that meet ATS recommendations. Am. Rev. Respir. Dis. 123: 659-664.

Crapo, R. O., R. L. Jensen, M. Hegewald and D. P. Tashkin (1999). Arterial blood gas reference values for sea level and an altitude of 1,400 meters. Am. J. Respir. Crit. Care Med. 160: 1525-1531.

Cunningham, D. J. C. and J. L. H. O'Riordan (1957). The effect of a rise in temperature of the body on the respiratory response to carbon dioxide. Quart. J. Exper. Physiol. 42: 329-345.

Dejours, P. (1963). Control of respiration by arterial chemoreceptors. Ann. N. Y. Acad. Sci. 109: 682-695.

Dejours, P. (1965). [Recall of Fundamental Concepts of Respiratory Physiology]. Rev. Prat. 15: 1433-1444.

Dempsey, J. A., D. Hanson, D. Pegelow, A. Claremont and J. Rankin (1982). 
Limitations to exercise capacity and endurance: pulmonary system. Can. J. Appl. Sport Sci. 7: 4-13.

Dempsey, J. A., P. G. Hanson and K. S. Henderson (1984). Exercise-induced arterial hypoxaemia in healthy human subjects at sea level. J. Physiol. 355: 161-175.

Dempsey, J. A. and R. F. Fregosi (1985). Adaptability of the pulmonary system to changing metabolic requirements. Am. J. Cardiol. 55: 59D-67D.

Dempsey, J. A. (1986). Is the lung built for exercise? Med. Sci. Sports Exerc. 18: 143-155.

Dempsey, J. A. and P. D. Wagner (1999). Exercise-induced arterial hypoxemia. J. Appl. Physiol. 87: 1997-2006.

Drust, B., P. Rasmussen, M. Mohr, B. Nielsen and L. Nybo (2005). Elevations in core and muscle temperature impairs repeated sprint performance. Acta Physiol. Scand. 183: 181-190.

Durand, F., P. Mucci, L. Safont and C. Prefaut (1999). Effects of nitric oxide inhalation on pulmonary gas exchange during exercise in highly trained athletes. Acta Physiol. Scand. 165: 169-176. 
Durand, F., P. Mucci and C. Prefaut (2000). Evidence for an inadequate hyperventilation inducing arterial hypoxemia at submaximal exercise in all highly trained endurance athletes. Med. Sci. Sports Exerc. 32: 926-932.

Durand, F., P. Mucci, M. Hayot, I. Couret, A. Bonnardet and C. Prefaut (2004). Attenuated ANF response to exercise in athletes with exercise-induced hypoxemia. Int. J. Sports Med. 25: 252-256.

Edwards, R. J., A. J. Belyavin and M. H. Harrison (1978). Core temperature measurement in man. Aviat. Space. Environ. Med. 49: 1289-1294.

Edwards, M. R., G. S. Hunte, A. S. Belzberg, A. W. Sheel, D. F. Worsley and D. C. McKenzie (2000). Alveolar epithelial integrity in athletes with exerciseinduced hypoxemia. J. Appl. Physiol. 89: 1537-1542.

Eichna, L. W., A. R. Berger, B. Rader and W. H. Becker (1951). Comparison of intracardiac and intravascular temperatures with rectal temperatures in man. J. Clin. Invest. 30: 353-359.

Ekblom, B., R. Huot, E. M. Stein and A. T. Thorstensson (1975). Effect of changes in arterial oxygen content on circulation and physical performance. J. Appl. Physiol. 39: 71-75.

Eldridge, F. L., D. E. Millhorn, J. P. Kiley and T. G. Waldrop (1985). 
Stimulation by central command of locomotion, respiration and circulation during exercise. Respir. Physiol. 59: 313-337.

Eldridge, M. W., A. Podolsky, R. S. Richardson, D. H. Johnson, D. R. Knight, E. C. Johnson, S. R. Hopkins, H. Michimata, B. Grassi, J. Feiner, S. S. Kurdak, P. E. Bickler, P. D. Wagner and J. W. Severinghaus (1996). Pulmonary hemodynamic response to exercise in subjects with prior highaltitude pulmonary edema. J. Appl. Physiol. 81: 911-921.

Eldridge, M. W., J. A. Dempsey, H. C. Haverkamp, H. C. Lovering and J. S. Hokason (2004). Exercise-induced intrapulmonary arteriovenous shunting in healthy humans. J. Appl. Physiol. 97: 797-805.

Febbraio, M. A., M. F. Carey, R. J. Snow, C. G. Stathis and M. Hargreaves (1996). Influence of elevated muscle temperature on metabolism during intense, dynamic exercise. Am. J. Physiol. 271: R1251-R1255.

Foster, V. L., G. J. Hume, A. L. Dickinson, S. J. Chatfield and W. C. Byrnes (1986). The reproducibility of $\mathrm{VO}_{2} \mathrm{max}$, ventilatory, and lactate thresholds in elderly women. Med. Sci. Sports. Exerc. 18: 425-430.

Fox, R. H., A. J. Solman, R. Isaacs, A. J. Fry and I. C. MacDonald (1973). A new method for monitoring deep body temperature from the skin surface. Clinical Science. 44: 81-86. 
Gale, G. E., J. R. Torre-Bueno, R. E. Moon, H. A. Saltzman and P. D. Wagner (1985). Ventilation-perfusion inequality in normal humans during exercise at sea level and simulated altitude. J. Appl. Physiol. 58: 978-988.

Galy, O., O. Hue, A. Boussana, C. Peyreigne, J. Mercier and C. Prefaut (2005). Blood rheological responses to running and cycling: a potential effect on the arterial hypoxemia of highly trained athletes? Int. J. Sports Med. 26: 915.

Galy, O., D. Le Gallais, O. Hue, A. Boussana and C. Prefaut (2005). Is exerciseinduced arterial hypoxemia in triathletes dependent on exercise modality? Int. J. Sports Med. 26: 719-726.

Gass, G. C., E. M. Camp, E. R. Nadel, T. H. Gwinn and P. Engel (1988). Rectal and rectal vs. esophageal temperatures in paraplegic men during prolonged exercise. J. Appl. Physiol. 64: 2265-2271.

Gavin, T. P., A. Derchak and J. M. Stager (1998). Ventilation's role in the decline in $\mathrm{VO}_{2}$ max and $\mathrm{SaO}_{2}$ in acute hypoxic exercise. Med. Sci. Sports Exerc. 30: 195-199.

Gavin, T. P. and J. M. Stager (1999). The effect of exercise modality on exercise-induced hypoxemia. Respir. Physiol. 115: 317-323. 
Gerbrandy, J., E. S. Snell and W. I. Cranston (1954). Oral, rectal, and oesophageal temperatures in relation to central temperature control in man. Clin. Sci. (Lond). 13: 615-624.

Gledhill, N., A. B. Froese and J. A. Dempsey (1977). Ventilation to perfusion distribution during exercise in health. Muscular exercise and the lung. J. A. Dempsey and C. E. Reed. Madison, WI, University of Wisconsin Press: $325-343$

Gonzalez-Alonso, J., C. Teller, S. L. Andersen, F. B. Jensen, T. Hyldig and B. Nielsen (1999). Influence of body temperature on the development of fatigue during prolonged exercise in the heat. J. Appl. Physiol. 86: 10321039.

Gonzalez-Alonso, J., B. Quistorff, P. Krustrup, J. Bangsbo and B. Saltin (2000). Heat production in skeletal muscle at the onset of intense dynamic exercise. J. Physiol. 524: 603-615.

Gore, C. J., A. G. Hahn, G. C. Scroop, D. B. Watson, K. I. Norton, R. J. Wood, D. P. Campbell and D. L. Emonson (1996). Increased arterial desaturation in trained cyclists during maximal exercise at $580 \mathrm{~m}$ altitude. J. Appl. Physiol. 80: 2204-2210. 
Goresky, C. A., J. W. Warnica, J. H. Burgess, R. F. P. Cronin and B. E. Nadeau (1972). Changes during exercise in man. Federation Proc. 31: 307-311.

Gothgen, I. H. (1984). Heat-induced changes in $\mathrm{PO}_{2}$ and $\mathrm{PCO}_{2}$ of blood. Acta Anaes. Scand. 28: 447-451.

Grataloup, O., F. Prieur, T. Busso, J. Castells, F. B. Favier, C. Denis and H. Benoit (2005). Effect of hyperoxia on maximal $\mathrm{O}_{2}$ uptake in exerciseinduced arterial hypoxaemic subjects. Eur. J. Appl. Physiol. 94: 641-645.

Greenhaff, P. L., M. Gleeson and R. J. Maughan (1988). Diet-induced metabolic acidosis and the performance of high intensity exercise in man. Eur. J. Appl. Physiol. Occup. Physiol. 57: 583-590.

Grodins, F. S. (1950). Analysis of factors concerned in regulation of breathing in exercise. Physiol. Rev. 30: 220-239.

Guyton, A.C. (1981) Regulation of Respiration. Textbook of Medical Physiology. Philadelphia, W.B. Saunders Company: 516-528.

Haldane, J. S. (1912). Methods of air analysis. Methods of air analysis. London, Charles Griffen and Co. Ltd: 54-58.

Hammond, M. D., G. E. Gale, K. S. Kapitan, A. Ries and P. D. Wagner (1986). 
Pulmonary gas exchange in humans during exercise at sea level. J. Appl. Physiol. 60: 1590-1598.

Hammond, M. D., G. E. Gale, K. S. Kapitan, A. Ries and P. D. Wagner (1986). Pulmonary gas exchange in humans during normobaric hypoxic exercise. J. Appl. Physiol. 61: 1749-1757.

Hanel, B., P. S. Clifford and N. H. Secher (1994). Restricted postexercise pulmonary diffusion capacity does not impair maximal transport for $\mathrm{O}_{2}$. $J$. Appl. Physiol. 77: 2408-2412.

Hanel, B., I. Teunissen, A. Rabol, J. Warberg and N. H. Secher (1997). Restricted postexercise pulmonary diffusion capacity and central blood volume depletion. J. Appl. Physiol. 83: 11-17.

Hansen, J. E. (1989). Arterial blood gases. Clin. Chest Med. 10: 227-237.

Hansen, D., R. Syben, O. Vargas, C. Spies and M. Welte (1999). The alveolararterial difference in oxygen tension increases with temperature-corrected determination during moderate hypothermia. Anesth. Analg. 88: 538-541.

Hardy, J. D. (1961). Physiology of temperature regulation. Physiol. Rev. 41: 1119-1124. 
Harms, C. A. and J. M. Stager (1995). Low chemoresponsiveness and inadequate hyperventilation contribute to exercise-induced hypoxemia. $J$. Appl. Physiol. 79: 575-580.

Harms, C. A., S. R. McClaran, G. A. Nickele, D. F. Pegelow, W. B. Nelson and J. A. Dempsey (1998). Exercise-induced arterial hypoxaemia in healthy young women. J. Physiol. (Lond.) 507: 619-628.

Harms, C. A., T. J. Wetter, S. R. McClaran, D. F. Pegelow, G. A. Nickele, W. B. Nelson, P. Hanson and J. A. Dempsey (1998). Effects of respiratory muscle work on cardiac output and its distribution during maximal exercise. J. Appl. Physiol. 85: 609-618.

Harms, C. A., S. R. McClaran, G. A. Nickele, D. F. Pegelow, W. B. Nelson and J. A. Dempsey (2000). Effect of exercise-induced arterial $\mathrm{O}_{2}$ desaturation on $\mathrm{VO}_{2}$ max in women. Med. Sci. Sports. Exerc. 32: 1101-1108.

Harrison, M. H., R. J. Edwards and D. R Leitch (1975). Effect of exercise and thermal stress on plasma volume. J. Appl. Physiol. 39: 925-931.

Helbling, D., U. Boutellier and C. M. Spengler (1997). Modulation of the ventilatory increase at the onset of exercise in humans. Respir. Physiol. 109: 219-229. 
Hensel, H. (1974). Thermoreceptors. Ann. Rev. Physiol. 36: 233.

Hesser, C. M., D. Linnarsson and L. Fagraeus (1981). Pulmonary mechanisms and work of breathing at maximal ventilation and raised air pressure. $J$. Appl. Physiol. 50: 747-753.

Hodges, A. N., B. M. Lynn, M. S. Koehle and D. C. McKenzie (2005). Effects of inhaled bronchodilators and corticosteroids on exercise induced arterial hypoxaemia in trained male athletes. Br. J. Sports Med. 39: 917-920.

Holmgren, A. and H. Linderholm (1958). Oxygen and carbon dioxide tensions of arterial blood during heavy and exhaustive exercise. Acta Physiol. Scand. 44: 203-215.

Holmgren, A. and M. B. McIlroy (1964). Effect of temperature on arterial blood gas tensions and pH during exercise. J. Appl. Physiol. 19: 243-245.

Hopkins, S. R. and D. C. McKenzie (1989). Hypoxic ventilatory response and arterial desaturation during heavy work. J. Appl. Physiol. 67: 1119-1124.

Hopkins, S. R., D. C. McKenzie, R. B. Schoene, R. W. Glenny and H. T. Robertson (1994). Pulmonary gas exchange during exercise in athletes. I. Ventilation-perfusion mismatch and diffusion limitation. J. Appl. Physiol. 77: 912-917. 
Hopkins, S. R., A. S. Belzberg, B. R. Wiggs and D. C. McKenzie (1996). Pulmonary transit time and diffusion limitation during heavy exercise in athletes. Respir. Physiol. 103: 67-73.

Hopkins, S. R., T. P. Gavin, N. M. Siafakas, L. J. Haseler, I. M. Olfert, H. Wagner and P. D. Wagner (1998). Effect of prolonged, heavy exercise on pulmonary gas exchange in athletes. J. Appl. Physiol. 85: 1523-1532.

Hopkins, S. R., R. B. Schoene, W. R. Henderson, R. G. Spragg and J. B. West (1998). Sustained submaximal exercise does not alter the integrity of the lung blood-gas barrier in elite athletes. J. Appl. Physiol. 84: 1185-1189.

Hopkins, S. R., R. C. Barker, T. D. Brutsaert, T. P. Gavin, P. Entin, I. M. Olfert, S. Veisel and P. D. Wagner (2000). Pulmonary gas exchange during exercise in women: effects of exercise type and work increment. J. Appl. Physiol. 89: 721-730.

Hopkins, S. R., E. J. Schabort and J. A. Hawley (2001). Reliability of power in physical performance tests. Sports Med. 31: 211-234.

Hopkins, S. R. and C. A. Harms (2004). Gender and pulmonary gas exchange during exercise. Exerc. Sport Sci. Rev. 32(2): 50-56. 
Hopkins, W. G. (2007). Spreadsheet for Reliability. $\underline{\text { www.sportsci.org/index.html }}$

Hultgren, H. N. (1982). Pulmonary hypertension and pulmonary edema. Oxygen Transport to Human Tissues. J. A. Riedesel. New York, Elsevier/North Holland: 243-254.

Inbar, O., P. Weiner, Y. Azgad, A. Rotstein and Y. Weinstein (2000). Specific inspiratory muscle training in well-trained athletes. Med. Sci. Sports Exerc. 32: 1233-1237.

Johnson, R. L., W. S. Spicer, J. M. Bishop and R. E. Forster (1960). Pulmonary capillary blood volume, flow and diffusing capacity during exercise. $J$. Appl. Physiol. 15: 893-902.

Johnson, B. D., K. W. Saupe and J. A. Dempsey (1992). Mechanical constraints on exercise hyperpnea in endurance athletes. J. Appl. Physiol. 73: 874-886.

Johnson, B. D., E. A. Aaron, M. A. Babcock and J. A. Dempsey (1996). Respiratory muscle fatigue during exercise: implications for performance. Med. Sci. Sports Exerc. 28: 1129-1137.

Johnston, K. N., S. C. Jenkins and S. M. Stick (2005). Repeatability of peak oxygen uptake in children who are healthy. Pediatr. Phys. Ther. 17: 11-17. 
Jones, J. H., C. R. Taylor, A. Lindholm, R. Straub, K. E. Longworth and R. H. Karas (1989). Blood gas measurements during exercise: errors due to temperature correction. J. Appl. Physiol. 67: 879-84.

Julien, M., T. S. Hakim, R. Vahi and H. K. Chang (1985). Effect of hematocrit on vascular pressure profile in dog lungs. J. Appl. Physiol. 58: 743-748.

Kampelmacher, M. J., R. G. van Kesteren and E. K. Winckers (1997). Instrumental variability of respiratory blood gases among different blood gas analysers in different laboratories. Eur. Respir. J. 10: 1341-1344.

Kanstrup, I. L. and B. Ekblom (1984). Blood volume and hemoglobin concentration as determinants of maximal aerobic power. Med. Sci. Sports Exerc. 16: 256-262.

Kao, F. F. (1963). An experimental study of the pathways involved in exercise hyperpnea employing cross circulation techniques. The regulation of human respiration. D. J. C. Cunningham and B. B. Lloyd. Blackwell, Oxford.

Kippelen, P., C. Caillaud, E. Robert, K. Masmoudi and C. Prefaut (2002). Exhaled nitric oxide level during and after heavy exercise in athletes with exercise-induced hypoxaemia. Pflugers Arch. 444: 397-404. 
Klas, J. V. and J. A. Dempsey (1989). Voluntary versus reflex regulation of maximal exercise flow: volume loops. Am. Rev. Respir. Dis. 139: 150-156.

Kohrt, W. M., D. W. Morgan, B. Bates and J. S. Skinner (1987). Physiological responses of triathletes to maximal swimming, cycling, and running. Med. Sci. Sports Exerc. 19: 51-55.

Koskolou, M. D. and D. C. McKenzie (1994). Arterial hypoxemia and performance during intense exercise. Eur. J. App.l Physiol. Occup. Physiol. 68: 80-86.

Krough, A. and J. Lindhard (1913). The regulation of respiration and circulation during the intial stages of muscular work. J. Physiol. (Lond.) 47: 112-136.

Ladegaard-Pedersen, H. J. (1978). Accuracy and reproducibility of arterial blood-gas and pH measurements. Acta Anaesthesiol. Scand. Suppl. 67: 6365.

Landgraf, H. and A. M. Ehrly (1980). [Oxygen tension in the arterial blood and in muscle tissue in healthy persons of different age (author's translation)]. Aktuelle Gerontol. 10: 511-514.

Laursen, P. B., G. C. Tsang, G. J. Smith, M. V. van Velzen, B. B. Ignatova, E. 
B. Sprules, K. S. Chu, K. D. Coutts and D. C. McKenzie (2002). Incidence of exercise-induced arterial hypoxemia in prepubescent females. Pediatr. Pulmonol. 34: 37-41.

Laursen, P. B., E. C. Rhodes, R. H. Langill, J. E. Taunton and D. C. McKenzie (2005). Exercise-induced arterial hypoxemia is not different during cycling and running in triathletes. Scand. J. Med. Sci. Sports 15: 113-117.

Lawler, J., S. K. Powers and D. Thompson (1988). Linear relationship between $\mathrm{VO}_{2} \max$ and $\mathrm{VO}_{2}$ max decrement during exposure to acute hypoxia. $J$. Appl. Physiol. 64: 1486-1492.

Lee, S. M., W. J. Williams and S. M. Fortney Schneider (2000). Core temperature measurement during supine exercise: esophageal, rectal, and intestinal temperatures. Aviat. Space Environ. Med. 71: 939-945.

Legrand, R., S. Ahmaidi, W. Moalla, D. Chocquet, A. Marles, F. Prieur and P. Mucci (2005). $\mathrm{O}_{2}$ arterial desaturation in endurance athletes increases muscle deoxygenation. Med. Sci. Sports Exerc. 37: 782-8.

Lillienthal, J. L., R. L. Riley, D. D. Proemmel and R. E. Franke (1946). An experimental analysis in man of the oxygen pressure gradient from alveolar air to arterial blood during rest and exercise at sea level and at altitude.: 199-216. 
Lindstedt, S. L., D. J. Wells, J. H. Jones, H. Hoppeler and H. A. Thronson, Jr. (1988). Limitations to aerobic performance in mammals: interaction of structure and demand. Int. J. Sports. Med. 9: 210-217.

MacIntyre, N., R.O. Crapo, G. Viegi, D.C. Johnson, C.P.M. van der Grinten, V. Brusasco, F. Burgos, R. Casaburi, A. Coates, P. Enright, P. Gustafsson, J. Hankinson, R. Jensen, R. McKay, M.R. Miller, D. Navajas, O.F. Pedersen, R. Pellegrino, J. Wanger (2005). Standardisation of the single-breath determination of carbon monoxide uptake in the lung. Eur. Resp. J. 26: 720-735.

Mairiaux, P., J. C. Sagot and V. Candas (1983). Oral temperature as an index of core temperature during heat transients. Eur. J. Appl. Physiol. 50: 331-341.

Mancini, D. M., N. Ferrerro, D. Nazzaro, B. Chance and J. R. Wilson (1991). Respiratory muscle deoxygenation during exercise in patients with heart failure demonstrated with near-infrared spectroscopy. J. Am. Coll. Cardiol. 18: $492-498$.

Manier, G., J. Moinard, P. Techoueyres, N. Varene and H. Guenard (1991). Pulmonary diffusion limitation after prolonged strenuous exercise. Respir. Physiol. 83: 143-154. 
Manohar, M., T. E. Goetz, A. S. Hassan, T. Depuy and S. Humphrey (2002). Anti-inflammatory agent, dexamethasone, does not affect exercise-induced arterial hypoxemia in Thoroughbreds. J. Appl. Physiol. 93: 99-106.

Marshall, B. E., L. R. Soma and G. R. Neufeld (1975). Lung water volume at rest and exercise in dogs. J. Appl. Physiol. 39: 7-8.

Martin, D. and J. O'Kroy (1993). Effects of acute hypoxia on the $\mathrm{VO}_{2}$ max of trained and untrained subjects. J. Sports Sci. 11: 37-42.

Masse-Biron, J., J. Mercier, J. P. Cano, C. Caillaud, F. Anselme and C. Préfaut (1990). Hemoglobin desaturation during exhaustive exercise in master athletes. Science and Sports 4: 191-196.

Mateika, J. H. and J. Duffin (1995). A review of the control of breathing during exercise. Eur. J. Appl. Physiol. 71: 1-27.

Matthay, M. A. and K. Chatterjee (1988). Bedside catheterization of the pulmonary artery: Risks compared with benefits. Ann. Int. Med. 109: 826834.

McGovern, J. P., S. A. Sasse, D. W. Stansbury, L. A. Causing and R. W. Light (1996). Comparison of oxygen saturation by pulse oximetry and cooximetry during exercise testing in patients with COPD. Chest 109: 1151- 
McKenzie, D. C., I. L. Lama, J. E. Potts, A. W. Sheel and K. D. Coutts (1999). The effect of repeat exercise on pulmonary diffusing capacity and EIH in trained athletes. Med. Sci. Sports Exerc. 31: 99-104.

McLellan, T. M. and I. Jacobs (1993). Reliability, reproducibility and validity of the individual anaerobic threshold. Eur. J. Appl. Physiol. Occup. Physiol. 67: $125-131$

Mead, J. and J. L. Whittenberger (1953). Physical properties of human lungs measured during spontaneous respiration. J. Appl. Physiol. 5: 779-796.

Mead, J. (1960). Control of respiratory frequency. J. Appl. Physiol. 15: 336.

Medelli, J., Y. Maingourd, B. Bouferrache, V. Bach, M. Freville and J. P. Libert (1993). Maximal oxygen uptake and aerobic-anaerobic transition on treadmill and bicycle in triathletes. Jpn. J. Physiol. 43: 347-360.

Meyer, T., O. Faude, J. Scharhag, A. Urhausen and W. Kindermann (2004). Is lactic acidosis a cause of exercise induced hyperventilation at the respiratory compensation point? Br. J. Sports Med. 38: 622-625.

Miles, D. S., C. E. Doerr, S. A. Schonfeld, D. E. Sinks and R. W. Gotshall 
(1983). Changes in pulmonary diffusing capacity and closing volume after running a marathon. Respir. Physiol. 52: 349-359.

Miles, D. S., A. D. Enoch and S. C. Grevey (1986). Interpretation of changes in DLCO and pulmonary function after running five miles. Respir. Physiol. 66: $135-145$

Mitchell, J. H., W. C. Reardon, D. I. McCloskey and K. Wildenthal (1977). Possible role of muscle receptors in the cardiovascular response to exercise. Ann. N. Y. Acad. Sci. 301: 232-42.

Mitchell, G. S. (1990). Ventilatory control during exercise with increased respiratory dead space in goats. J. Appl. Physiol. 69: 718-727.

Miyachi, M. and H. Shibayama (1992). Ventilatory capacity and exerciseinduced arterial desaturation of highly trained endurance athletes. Ann. Physiol. Anthrop. 11: 263-267.

Miyachi, M. and I. Tabata (1992). Relationship between arterial oxygen desaturation and ventilation during maximal exercise. J. Appl. Physiol. 73(6): 2588-2591.

Molnar, G. W. and R. C. Read (1974). Studies during open-heart surgery on the special characteristics of rectal temperature. J. Appl. Physiol. 36: 333-336. 
Morris, J. G., M. E. Nevill, L. H. Boobis, I. A. Macdonald and C. Williams (2005). Muscle metabolism, temperature, and function during prolonged, intermittent, high-intensity running in air temperatures of 33 degrees and 17 degrees C. Int. J. Sports Med. 26: 805-814.

Mota, S., P. Casan, F. Drobnic, J. Giner, O. Ruiz, J. Sanchis and J. Milic-Emili (1999). Expiratory flow limitation during exercise in competition cyclists. J. Appl. Physiol. 86: 611-616.

Mucci, P., J. Prioux, M. Hayot, M. Ramonatxo and C. Prefaut (1998). Ventilation response to $\mathrm{CO}_{2}$ and exercise-induced hypoxaemia in master athletes. Eur J Appl Physiol Occup Physiol 77: 343-351.

Mucci, P., F. Anselme-Poujol, C. Caillaud, I. Couret, M. Rossi and C. Prefaut (1999). Basophil releasability in young highly trained and older athletes. Med. Sci. Sports Exerc. 31: 507-513.

Mucci, P., F. Durand, B. Lebel, J. Bousquet and C. Prefaut (2001). Basophils and exercise-induced hypoxemia in extreme athletes. J. Appl. Physiol. 90: 989-996.

Mucci, P., N. Blondel, C. Fabre, C. Nourry and S. Berthoin (2004). Evidence of exercise-induced $\mathrm{O}_{2}$ arterial desaturation in non-elite sportsmen and 
sportswomen following high-intensity interval-training. Int. J. Sports Med. 25: 6-13.

Newstead, C. G., G. C. Donaldson and J. R. Sneyd (1990). Potassium as a respiratory signal in humans. J. Appl. Physiol. 69: 1799-1803.

Nielsen, B. and M. Nielsen (1962). Body temperature during work. Acta Physiol. Scan. 56: 120-129.

Nielsen, H. B., P. Madsen, L. B. Svendsen, R. C. Roach and N. H. Secher (1998). The influence of $\mathrm{PaO} 2, \mathrm{pH}$ and $\mathrm{SaO} 2$ on maximal oxygen uptake. Acta Physiol. Scand. 164: 89-97.

Nielsen, H. B., M. Bousen and N. H. Secher (2001). Near-infrared spectroscopy determined brain and muscle oxygenation during exercise and resistive breathing. Acta Physiol.Scan. 171: 63-70.

Nielsen, H. B., L. Hein, L. B. Svendsen, N. H. Secher and B. Quistorff (2002). Bicarbonate attenuates intracellular acidosis. Acta Anaesthesiol. Scand. 46: $579-584$

Nielsen, H. B. (2003). Arterial desaturation during exercise in man: implication for $\mathrm{O}_{2}$ uptake and work capacity. Scand. J. Med. Sci. Sports 13: 339-358. 
Nihill, M. R., D. G. McNamara and R. L. Vick (1976). The effects of increased blood viscosity on pulmonary vascular resistance. Am. Heart J. 92: 65-72.

Norton, K. I., B. Squires, L. H. Norton, N. P. Craig, P. McGrath and T. S. Olds (1995). Exercise stimulus increases ventilation from maximal to supramaximal exercise. Eur. J. Appl. Physiol. 70: 115-125.

Nourry, C., C. Fabre, F. Bart, J. M. Grosbois, S. Berthoin and P. Mucci (2004). Evidence of exercise-induced arterial hypoxemia in prepubescent trained children. Pediatr. Res. 55: 674-681.

O'Kroy, J. and D. Martin (1989). Effect of acute hypoxia and hyperoxia on maximal oxygen uptake of trained and untrained subjects. Med. Sci. Sports Exerc. 21(Abstracts): S21.

O'Neill, M., K. L. Dorrington and D. J. Paterson (1993). Cardiac sympathetic nerve stimulation enhances cardiovascular performance during hyperkalaemia in the anaesthetized pig. Exp. Physiol. 78: 549-552.

Olfert, I. M., J. Balouch, A. Kleinsasser, A. Knapp, H. Wagner, P. D. Wagner and S. R. Hopkins (2004). Does gender affect human pulmonary gas exchange during exercise? J. Physiol. 557: 529-541.

Pan, L. G., H. V. Forster, P. Martino, P. J. Strecker, J. Beales, A. Serra, T. F. 
Lowry, M. M. Forster and A. L. Forster (1998). Important role of carotid afferents in control of breathing. J. Appl. Physiol. 85: 1299-1306.

Pannier, J. L., J. Vrijens and C. Van Cauter (1980). Cardiorespiratory response to treadmill and bicycle exercise in runners. Eur. J. Appl. Physiol. 43: 243251.

Parkin, J. M., M. F. Carey, S. Zhao and M. A. Febbraio (1999). Effect of ambient temperature on human skeletal muscle metabolism during fatiguing submaximal exercise. J. Appl. Physiol. 86: 902-908.

Paterson, D. J. (1992). Potassium and ventilation in exercise. J. Appl. Physiol. 72: 811-820.

Paterson, D. J., J. Rogers, T. Powell and H. F. Brown (1993). Effect of catecholamines on the ventricular myocyte action potential in raised extracellular potassium. Acta Physiol. Scand. 148: 177-186.

Paterson, D. J. (1997). Potassium and breathing in exercise. Sports Med. 23: 149-163.

Pedersen, P. K., H. Mandoe, K. Jensen, C. Andersen and K. Madsen (1996). Reduced arterial $\mathrm{O}_{2}$ saturation during supine exercise in highly trained cyclists. Acta Physiol. Scand. 158: 325-331. 
Peltonen, J. E., J. Rantamaki, S. P. Niittymaki, K. Sweins, J. T. Viitasalo and H. K. Rusko (1995). Effects of oxygen fraction in inspired air on rowing performance. Med. Sci. Sports Exerc. 27: 573-579.

Piiper, J. and P. Scheid (1980). Blood-gas equilibration in lungs. Pulmonary Gas Exchange. J. B. West. New York, Academic: 132-173.

Podolsky, A., M. W. Eldridge, R. S. Richardson, D. R. Knight, E. C. Johnson, S. R. Hopkins, D. H. Johnson, H. Michimata, B. Grassi, J. Feiner, S. S. Kurdak, P. E. Bickler, J. W. Severinghaus and P. D. Wagner (1996). Exercise-induced $\mathrm{V}_{\mathrm{A}} / \mathrm{Q}$ inequality in subjects with prior high-altitude pulmonary edema. J. Appl. Physiol. 81: 922-932.

Poppius, H. and A. A. Viljanen (1977). A new ear oximeter for assessment of exercise-induced arterial desaturation in patients with pulmonary diseases. Scand. J. Respir. Dis. 58: 279-283.

Powers, S. K., S. Dodd, J. Woodyard, R. E. Beadle and G. Church (1984). Haemoglobin saturation during incremental arm and leg exercise. Br. J. Sports Med. 18: 212-216.

Powers, S. K. and J. Williams (1987). Exercise-induced hypoxaemia in highly trained athletes. Sports Med 4: 46-53. 
Powers, S. K., S. Dodd, J. Lawler, G. Landry, M. Kirtley, T. McKnight and S. Grinton (1988). Incidence of exercise induced hypoxemia in elite endurance athletes at sea level. Eur. J. Appl. Physiol. Occup. Physiol. 58: 298-302.

Powers, S. K., S. Dodd, J. Freeman, G. D. Ayers, H. Samson and T. McKnight (1989). Accuracy of pulse oximetry to estimate $\mathrm{HbO}_{2}$ fraction of total $\mathrm{Hb}$ during exercise. J. Appl. Physiol. 67: 300-304.

Powers, S. K., J. Lawler, J. A. Dempsey, S. Dodd and G. Landry (1989). Effects of incomplete pulmonary gas exchange on $\mathrm{VO}_{2}$ max. J. Appl. Physiol. 66: 2491-2495.

Powers, S. K., S. Dodd, D. Criswell, J. Lawler, D. Martin and S. Grinton (1991). Evidence for an alveolar-arterial $\mathrm{PO}_{2}$ gradient threshold during incremental exercise. Int. J. Sports Med. 12: 313-318.

Powers, S. K., D. Martin, M. Cicale, N. Collop, D. Huang and D. Criswell (1992). Exercise-induced hypoxemia in athletes: role of inadequate hyperventilation. Eur. J. Appl. Physiol. Occup. Physiol. 65: 37-42.

Powers, S. K., D. Martin and S. Dodd (1993). Exercise-induced hypoxaemia in elite endurance athletes. Incidence, causes and impact on $\mathrm{VO}_{2} \max$. Sports 
Med. 16: 14-22.

Prefaut, C., F. Anselme, C. Caillaud and J. Masse-Biron (1994). Exerciseinduced hypoxemia in older athletes. J. Appl. Physiol. 76: 120-126.

Prefaut, C., F. Anselme-Poujol and C. Caillaud (1997). Inhibition of histamine release by nedocromil sodium reduces exercise-induced hypoxemia in master athletes. Med. Sci. Sports Exerc. 29: 10-16.

Préfaut, C., F. Durand, P. Mucci and C. Caillaud (2000). Exercise-induced arterial hypoxemia in athletes: a review. Sports Med. 30: 47-61.

Rasmussen, B. S., B. Hanel, K. Jensen, B. Serup and N. H. Secher (1986). Decrease in pulmonary diffusion capacity after maximal exercise. J. Sports Sci. 4: 185-188.

Rasmussen, B. S., P. Elkjaer and B. Juhl (1988). Impaired pulmonary and cardiac function after maximal exercise. J. Sports Sci. 6: 219-228.

Rasmussen, J., B. Hanel, B. Diamant and N. H. Secher (1991). Muscle mass effect on arterial desaturation after maximal exercise. Med. Sci. Sports Exerc. 23: 1349-1352.

Rice, A. J., G. C. Scroop, C. J. Gore, A. T. Thornton, M. A. Chapman, H. W. 
Greville, M. D. Holmes and R. Scicchitano (1999). Exercise-induced hypoxaemia in highly trained cyclists at $40 \%$ peak oxygen uptake. Eur. $J$. Appl. Physiol. Occup. Physiol. 79: 353-359.

Rice, A. J., A. T. Thornton, C. J. Gore, G. C. Scroop, H. W. Greville, H. Wagner, P. D. Wagner and S. R. Hopkins (1999). Pulmonary gas exchange during exercise in highly trained cyclists with arterial hypoxemia. J. Appl. Physiol. 87: 1802-1812.

Rice, A. J., G. C. Scroop, A. T. Thornton, N. S. McNaughton, K. J. Rogers, M. J. Chapman, H. W. Greville, R. Scicchitano and C. J. Gore (2000). Arterial hypoxaemia in endurance athletes is greater during running than cycling. Respir. Physiol. 123: 235-246.

Ries, A. L., J. T. Farrow and J. L. Clausen (1985). Accuracy of two ear oximeters at rest and during exercise in pulmonary patients. Am. Rev. Respir. Dis. 132: 685-689.

Robinson, J. L., R. F. Seal, D. W. Spady and M. R. Joffres (1998). Comparison of esophageal, rectal, axillary, bladder, tympanic, and pulmonary artery temperature in children. J. Pediatr. 133: 553-556.

Roughton, F. J. W. (1945). The average time spent by the blood in the human lung capillary and its relation to the rates of CO uptake and elimination in 
man. Am. J. Physiol. 143: 621-633.

Rowell, L. B., H. L. Taylor, Y. Wang and W. S. Carlson (1964). Saturation of arterial blood with oxygen during maximal exercise. J. Appl. Physiol. 19: 284-286.

Saltin, B. and L. Hermansen (1966). Esophageal, rectal, and muscle temperature during exercise. J. Appl. Physiol. 21: 1757-1762.

Saltin, B., A. P. Gagge and J. A. Stolwijk (1968). Muscle temperature during submaximal exercise in man. J. Appl. Physiol. 25: 679-688.

Schaffartzik, W., D. C. Poole, T. Derion, K. Tsukimoto, M. C. Hogan, J. P. Arcos, D. E. Bebout and W. P.D. (1992). $\mathrm{V}_{\mathrm{A}} / \mathrm{Q}$ distribution during heavy exercise and recovery in humans: implications for pulmonary edema. $J$. Appl. Physiol. 72: 1657-1667.

Schmidt-Nielsen, K. (1963). Heat conservation in Counter-current Systems. Temperature: Its measurement and control in science and industry. J. D. Hardy. New York, Reinhold Book Corporation. 3: 143.

Schneider, D. A. and J. Pollack (1991). Ventilatory threshold and maximal oxygen uptake during cycling and running in female triathletes. Int. J. Sports. Med. 12: 379-383. 
Schwartz, J. D., S. A. Katz, R. W. Fegley and M. S. Tockman (1988). Sex and race differences in the development of lung function. Am. Rev. Respir. Dis. 138: $1415-1421$.

Scrimgeour, A. G., T. D. Noakes, B. Adams and K. Myburgh (1986). The influence of weekly training distance on fractional utilization of maximum aerobic capacity in marathon and ultramarathon runners. Eur. J. Appl. Physiol. Occup. Physiol. 55: 202-209.

Seeherman, H. J. and E. A. Morris (1990). Methodology and repeatability of a standardised treadmill exercise test for clinical evaluation of fitness in horses. Equine Vet. J. Suppl. 9: 20-25.

Severinghaus, J. W., M. Stupfel and A. F. Bradley (1956). Accuracy of blood pH and $\mathrm{PCO}_{2}$ determinations. J. Physiol. 9: 189 - 196.

Severinghaus, J. W. (1959). Respiration and hypothermia. Ann. N. Y. Acad. Sci. 80: 384-394.

Severinghaus, J. W. (1966). Blood gas calculator. J. Appl. Physiol. 21: 11081116.

Severinghaus, J. W. (1968). Measurements of blood gases: $\mathrm{PO}_{2}$ and $\mathrm{PCO}_{2}$. Ann. 
N. Y. Acad. Sci. 148: 115-132.

Severinghaus, J. W. (1979). Simple, accurate equations for human blood $\mathrm{O}_{2}$ dissociation computations. J. Appl. Physiol. 46: 599-602.

Shapiro, B. A. (1995). Temperature correction of blood gas values. Respir. Care Clin. N. Am. 1: 69-76.

Sheel, A. W., M. R. Edwards and D. C. McKenzie (2000). Relationship between decreased oxyhaemoglobin saturation and exhaled nitric oxide during exercise. Acta Physiol. Scand. 169: 149-156.

Shiraki, K., N. Konda and S. Sagawa (1986). Esophageal and tympanic temperature responses to core blood temperature changes during hyperthermia. J. Appl. Physiol. 61: 98-102.

Siggaard-Andersen, O., P. D. Wimberley, I. Gothgen and M. Siggaard-Andersen (1984). A mathematical model of the hemoglobin-oxygen dissociation curve of human blood and of the oxygen partial pressure as a function of temperature. Clin. Chem. 30: 1646-1651.

Sjodin, B. and J. Svedenhag (1985). Applied physiology of marathon running. Sports Med. 2: 83-99. 
Smyth, R. J., A. D. D'Urzo, A. S. Slutsky, B. M. Galko and A. S. Rebuck (1986). Ear oximetry during combined hypoxia and exercise. J. Appl. Physiol. 60: 716-719.

Sosa Leon, L., D. R. Hodgson, D. L. Evans, S. P. Ray, G. P. Carlson and R. J. Rose (2002). Hyperhydration prior to moderate-intensity exercise causes arterial hypoxaemia. Equine Vet. J. Suppl. 34: 425-9.

Spengler, C. M. and U. Boutellier (2000). Breathless Legs? Consider Training Your Respiration. News Physiol. Sci. 15: 101-105.

St Croix, C. M., C. A. Harms, S. R. McClaran, G. A. Nickele, D. F. Pegelow, W. B. Nelson and J. A. Dempsey (1998). Effects of prior exercise on exerciseinduced arterial hypoxemia in young women. J. Appl. Physiol. 85: 15561563.

Staub, N. C., J. M. Bishop and R. E. Forster (1962). Importance of diffusion and chemical reactionrates in $\mathrm{O}_{2}$ uptake in the lung. J. Appl. Physiol. 17: 2127.

Stuessi, C., C. M. Spengler, C. Knopfli-Lenzin, G. Markov and U. Boutellier (2001). Respiratory muscle endurance training in humans increases cycling endurance without affecting blood gas concentrations. Eur. J. Appl. Physiol. 84: 582-586. 
Taylor, L. E., D. S. Kronfeld, P. L. Ferrante, J. A. Wilson and W. Tiegs (1998). Blood-gas measurements adjusted for temperature at three sites during incremental exercise in the horse. J. Appl. Physiol. 85: 1030-1036.

Teeter, J. G. and E. R. Bleecker (1996). Mechanisms of asthma. Curr. Opin. Pulm. Med. 2: 23-28.

Thurlbeck, W. M. (1982). Postnatal human lung growth. Thorax 37: 564-571.

Thys, H., E. Dreezen and A. Vanderstappen (1979). [Effect of the modality of exercise on the $\mathrm{VO}_{2}$ max]. Arch. Int. Physiol. Biochim. 87: 565-573.

Todaro, A., L. M. Leonardi, M. Besi, P. Faccini, F. Sardella, C. Menchinelli and C. Gallozzi (1995). Pulmonary gas exchange in athletes with exerciseinduced hypoxaemia. J. Sports Med. Phys. Fitness 35: 114-123.

Torre-Bueno, J. R., P. D. Wagner, H. A. Saltzman, G. E. Gale and R. E. Moon (1985). Diffusion limitation in normal humans during exercise at sea level and simulated altitude. J. Appl. Physiol. 58: 989-995.

Tortora, G.J. and N.P. Anagnostakos (1987). The Respiratory System. Principles of Anatomy and Physiology (Fifth Edition). Harper and Row, Publishers, Inc. 554-588 
Turcotte, R., L. Kiteala, J. E. Marcotte and H. Perrault (1997). Exercise-induced oxyhemoglobin desaturation and pulmonary diffusing capacity during high-intensity exercise. Eur. J. Appl. Physiol. 75: 425-430.

Verges, S., P. Flore, A. Favre-Juvin, P. Levy and B. Wuyam (2005). Exhaled nitric oxide during normoxic and hypoxic exercise in endurance athletes. Acta Physiol. Scand. 185: 123-131.

Volianitis, S., A. K. McConnell, Y. Koutedakis, L. McNaughton, K. Backx and D. A. Jones (2001). Inspiratory muscle training improves rowing performance. Med. Sci. Sports Exerc. 33: 803-809.

Von Euler, U. S. (1938). Reflectorische und zentrale Wirkung von Kaliumionen auf Blutdruck und Atmung. Skand. Arch. Physiol. 80: 94-123.

Wagner, P. D., P. F. Naumann and R. B. Laravuso (1974). Simultaneous measurement of eight foreign gases in blood by gas chromatography. $J$. Appl. Physiol. 36: 600-605.

Wagner, P. D., H. A. Saltzman and J. B. West (1974). Measurement of continuous distributions of ventilation-perfusion ratios: theory. J. Appl. Physiol. 36: 588-599.

Wagner, P. D. (1977). Recent advances in pulmonary gas exchange. Int. 
Anesthesiol. Clin. 15: 81-111.

Wagner, P. D. (1982). Influence of mixed venous $\mathrm{PO}_{2}$ on diffusion of $\mathrm{O}_{2}$ across the pulmonary blood:gas barrier. Clin. Physiol. 2: 105-115.

Wagner, P. D., G. E. Gale, R. E. Moon, J. R. Torre-Bueno, B. W. Stolp and H. A. Saltzman (1986). Pulmonary gas exchange in humans exercising at sea level and simulated altitude. J. Appl. Physiol. 61: 260-270.

Wagner, P. D., J. R. Sutton, J. T. Reeves, A. Cymerman, B. M. Groves and M. K. Malconian (1987). Operation Everest II: pulmonary gas exchange during a simulated ascent of Mt. Everest. J. Appl. Physiol. 63: 2348-2359.

Wagner, P. D., J. R. Gillespie, G. L. Landgren, M. R. Fedde, B. W. Jones, R. M. DeBowes, R. L. Pieschl and H. H. Erickson (1989). Mechanism of exercise-induced hypoxemia in horses. J. Appl. Physiol. 66: 1227-1233.

Wagner, P. D. (1992). Ventilation-perfusion matching during exercise. Chest. 101: 192S-198S.

Wagner, P. D. (1992). Gas exchange and peripheral diffusion limitation. Med. Sci. Sports Exerc. 24: 54-58.

Wagner, P. D. (2002). Exercise, extravascular lung water, and gas exchange. $J$. 
Appl. Physiol. 92: 2224; author reply 2224-2225.

Warren, G. L., K. J. Cureton, W. F. Middendorf, C. A. Ray and J. A. Warren (1991). Red blood cell pulmonary capillary transit time during exercise in athletes. Med. Sci. Sports Exerc. 23: 1353-1361.

Wasserman, K., A. L. Van Kessel and G. G. Burton (1967). Interaction of physiological mechanisms during exercise. J. Appl. Physiol. 22: 71-85.

Wasserman, K. (1978). Breathing during exercise. New Eng. J. Med. 298: 780785.

Wasserman, K., B. J. Whipp, R. Casaburi, M. Golden and W. L. Beaver (1979). Ventilatory control during exercise in man. Bull. Eur. Physiopathol. Respir. 15: 27-47.

Wasserman, K., J. E. Hansen, D. Y. Sue, B. J. Whipp and R. Casaburi (1994). Principles of Exercise Testing and Interpretation. Philadelphia, PA, Lea \& Febiger.

Watt, K. K., W. G. Hopkins and R. J. Snow (2002). Reliability of performance in repeated sprint cycling tests. J. Sci. Med. Sport. 5: 354-361.

West, J. B., K. Tsukimoto, O. Mathieu-Costello and R. Prediletto (1991). Stress 
failure in pulmonary capillaries. J. Appl. Physiol. 70: 1731-1742.

West, J. B. and O. Mathieu-Costello (1992). Strength of the pulmonary bloodgas barrier. Respir. Physiol. 88: 141-148.

West, J. B. and O. Mathieu-Costello (1992). High altitude pulmonary edema is caused by stress failure of pulmonary capillaries. Int. J. Sports Med. 13 Suppl 1: S54-S58.

West, J. B., G. L. Colice, Y. J. Lee, Y. Namba, S. S. Kurdak, Z. Fu, L. C. Ou and O. Mathieu-Costello (1995). Pathogenesis of high-altitude pulmonary oedema: direct evidence of stress failure of pulmonary capillaries [see comments]. Eur. Respir. J. 8: 523-529.

West, J. B. and O. Mathieu-Costello (1995). Stress failure of pulmonary capillaries as a limiting factor for maximal exercise. Eur. J. Appl. Physiol. 70: 99-108.

Wetter, T. J., C. M. St Croix, D. F. Pegelow, D. A. Sonetti and J. A. Dempsey (2001). Effects of exhaustive endurance exercise on pulmonary gas exchange and airway function in women. J. Appl. Physiol. 91: 847-858.

Wetter, T. J., Z. Xiang, D. A. Sonetti, H. C. Haverkamp, A. J. Rice, A. A. Abbasi, K. C. Meyer and J. A. Dempsey (2002). Role of lung 
inflammatory mediators as a cause of exercise-induced arterial hypoxemia in young athletes. J. Appl. Physiol. 93: 116-126.

Whipp, B. J. and K. Wasserman (1970). Effect of body temperature on the ventilatory response to exercise. Respir. Physiol. 8: 354-360.

Whipp, B. J. and J. A. Davis (1979). Peripheral chemoreceptors and exercise hyperpnea. Med. Sci. Sports. 11: 204-212.

Whipp, B. J. (1994). Peripheral chemoreceptor control of exercise hyperpnea in humans. Med. Sci. Sports Exerc. 26: 337-347.

Whitby, J. D. and L. J. Dunkin (1968). Temperature differences in the oesophagus. Br. J. Anaesth. 40: 991-995.

Williams, J. H., S. K. Powers and M. Kelly Stuart (1986). Hemoglobin desaturation in highly trained athletes during heavy exercise. Med. Sci. Sports Exerc. 18: 168-173.

Wolfel, E. E., M. A. Selland, A. Cymerman, G. A. Brooks, G. E. Butterfield, R. S. Mazzeo, R. F. Grover and J. T. Reeves (1998). O ${ }_{2}$ extraction maintains $\mathrm{O}_{2}$ uptake during submaximal exercise with beta- adrenergic blockade at 4,300 m [In Process Citation]. J. Appl. Physiol. 85: 1092-1102. 
Wood, R. J., C. J. Gore, A. G. Hahn, K. I. Norton, G. C. Scroop, D. P. Campbell, D. B. Watson and D. L. Emonson (1997). Accuracy of two pulse oximeters during maximal cycling exercise. Aust. J. Sci. Med. Sport. 29: 47-50.

Wood, H. E., M. Fatemian and P. A. Robbins (2003). A learned component of the ventilatory response to exercise in man. J. Physiol. 553: 967-74.

Yamamoto, Y., Y. Mutoh, H. Kobayashi and M. Miyashita (1987). Effects of reduced frequency breathing on arterial hypoxemia during exercise. Eur. J. Appl. Physiol. 56: 522-527.

Yoshida, T., M. Udo, M. Chida, M. Ichioka and K. Makiguchi (1989). Effect of hypoxia on arterial and venous blood levels of oxygen, carbon dioxide, hydrogen ions and lactate during incremental forearm exercise. Eur. J. Appl. Physiol. 58: 772-777.

Yoshida, T., M. Udo, M. Chida, K. Makiguchi, M. Ichioka and I. Muraoka (1989). Arterial blood gases, acid-base balance, and lactate and gas exchange variables during hypoxic exercise. Int. J. Sports Med. 10: 279285.

Younes, M., Z. Bshouty and J. Ali (1987). Longitudinal distribution of pulmonary vascular resistance with very high pulmonary blood flow. $J$. 
Appl. Physiol. 62: 344-358.

Zavorsky, G. S., K. R. Walley, G. S. Hunte, D. C. McKenzie, G. P. Sexsmith and J. A. Russell (2002). Acute hypervolemia lengthens red cell pulmonary transit time during exercise in endurance athletes. Respir. Physiol. Neurobiol. 131: 255-68. 